\title{
Cochrane
}

Library

Cochrane Database of Systematic Reviews

\section{Ezetimibe for the prevention of cardiovascular disease and all-cause mortality events (Review)}

Zhan S, Tang M, Liu F, Xia P, Shu M, Wu X

Zhan S, Tang M, Liu F, Xia P, Shu M, Wu X.

Ezetimibe for the prevention of cardiovascular disease and all-cause mortality events.

Cochrane Database of Systematic Reviews 2018, Issue 11. Art. No.: CD012502.

DOI: 10.1002/14651858.CD012502.pub2.

www.cochranelibrary.com 
TABLE OF CONTENTS

HEADER

ABSTRACT

PLAIN LANGUAGE SUMMARY

SUMMARY OF FINDINGS

BACKGROUND

OBJECTIVES

METHODS

RESULTS

Figure 1.

Figure 2.

Figure 3.

Figure 4.

Figure 5.

Figure 6.

Figure 7.

Figure 8.

Figure 9.

DISCUSSION

AUTHORS' CONCLUSIONS

ACKNOWLEDGEMENTS

REFERENCES

CHARACTERISTICS OF STUDIES

DATA AND ANALYSES

Analysis 1.1. Comparison 1 Ezetimibe plus other lipid-modifying drugs vs other lipid-modifying drugs alone or plus placebo, Outcome 1 MACE (subgroup analysis: duration of follow up).

Analysis 1.2. Comparison 1 Ezetimibe plus other lipid-modifying drugs vs other lipid-modifying drugs alone or plus placebo, Outcome 2 MACE (subgroup analysis: participates with/without ASCVD).

Analysis 1.3. Comparison 1 Ezetimibe plus other lipid-modifying drugs vs other lipid-modifying drugs alone or plus placebo, Outcome 3 MACE (sensitivity analysis: only including low risk of bias studies).

Analysis 1.4. Comparison 1 Ezetimibe plus other lipid-modifying drugs vs other lipid-modifying drugs alone or plus placebo, Outcome 4 MACE (sensitivity analysis: random-effects models).

Analysis 1.5. Comparison 1 Ezetimibe plus other lipid-modifying drugs vs other lipid-modifying drugs alone or plus placebo, Outcome 5 MACE (sensitivity analysis: excluding the studies compared ezetimibe plus statins versus double-dose statins alone).

Analysis 1.6. Comparison 1 Ezetimibe plus other lipid-modifying drugs vs other lipid-modifying drugs alone or plus placebo, Outcome 6 All-cause mortality (subgroup analysis: duration of follow up).

Analysis 1.7. Comparison 1 Ezetimibe plus other lipid-modifying drugs vs other lipid-modifying drugs alone or plus placebo, Outcome 7 All-cause mortality (subgroup analysis: participates with/without ASCVD).

Analysis 1.8. Comparison 1 Ezetimibe plus other lipid-modifying drugs vs other lipid-modifying drugs alone or plus placebo, Outcome 8 All-cause mortality (sensitivity analysis: only including low risk of bias studies).

Analysis 1.9. Comparison 1 Ezetimibe plus other lipid-modifying drugs vs other lipid-modifying drugs alone or plus placebo, Outcome 9 All-cause mortality (sensitivity analysis: random-effects models).

Analysis 1.10. Comparison 1 Ezetimibe plus other lipid-modifying drugs vs other lipid-modifying drugs alone or plus placebo, Outcome 10 All-cause mortality (sensitivity analysis: excluding the studies compared ezetimibe plus statins versus double-dose statins alone).

Analysis 1.11. Comparison 1 Ezetimibe plus other lipid-modifying drugs vs other lipid-modifying drugs alone or plus placebo, Outcome 11 Myocardial infarction (non-fatal).

Analysis 1.12. Comparison 1 Ezetimibe plus other lipid-modifying drugs vs other lipid-modifying drugs alone or plus placebo, Outcome 12 Myocardial infarction (sensitivity analysis: only including low risk of bias studies).

Analysis 1.13. Comparison 1 Ezetimibe plus other lipid-modifying drugs vs other lipid-modifying drugs alone or plus placebo, Outcome 13 Myocardial infarction (sensitivity analysis: excluding the studies compared ezetimibe plus statins versus doubledose statins alone).

Analysis 1.14. Comparison 1 Ezetimibe plus other lipid-modifying drugs vs other lipid-modifying drugs alone or plus placebo, Outcome 14 Ischaemic stroke (non-fatal). 
Analysis 1.15. Comparison 1 Ezetimibe plus other lipid-modifying drugs vs other lipid-modifying drugs alone or plus placebo, Outcome 15 Ischaemic stroke (sensitivity analysis: only including low risk of bias studies).

Analysis 1.16. Comparison 1 Ezetimibe plus other lipid-modifying drugs vs other lipid-modifying drugs alone or plus placebo, Outcome 16 Ischaemic stroke (sensitivity analysis: excluding the studies compared ezetimibe plus statins versus double-dose statins alone).

Analysis 1.17. Comparison 1 Ezetimibe plus other lipid-modifying drugs vs other lipid-modifying drugs alone or plus placebo, Outcome 17 Cardiovascular mortality.

Analysis 1.18. Comparison 1 Ezetimibe plus other lipid-modifying drugs vs other lipid-modifying drugs alone or plus placebo, Outcome 18 Cardiovascular mortality (sensitivity analysis: only including low risk of bias studies).

Analysis 1.19. Comparison 1 Ezetimibe plus other lipid-modifying drugs vs other lipid-modifying drugs alone or plus placebo, Outcome 19 Cardiovascular mortality (sensitivity analysis: excluding the studies compared ezetimibe plus statins versus double-dose statins alone).

Analysis 1.20. Comparison 1 Ezetimibe plus other lipid-modifying drugs vs other lipid-modifying drugs alone or plus placebo, Outcome 20 Coronary revascularization.

Analysis 1.21. Comparison 1 Ezetimibe plus other lipid-modifying drugs vs other lipid-modifying drugs alone or plus placebo, Outcome 21 Coronary revascularization (sensitivity analysis: only including low risk of bias studies).

Analysis 1.22. Comparison 1 Ezetimibe plus other lipid-modifying drugs vs other lipid-modifying drugs alone or plus placebo, Outcome 22 Coronary revascularization (sensitivity analysis: excluding the studies compared ezetimibe plus statins versus double-dose statins alone).

Analysis 1.23. Comparison 1 Ezetimibe plus other lipid-modifying drugs vs other lipid-modifying drugs alone or plus placebo, Outcome 23 Adverse events - hepatopathy.

Analysis 1.24. Comparison 1 Ezetimibe plus other lipid-modifying drugs vs other lipid-modifying drugs alone or plus placebo, Outcome 24 Adverse events - hepatopathy (sensitivity analysis: only including low risk of bias studies).

Analysis 1.25. Comparison 1 Ezetimibe plus other lipid-modifying drugs vs other lipid-modifying drugs alone or plus placebo, Outcome 25 Adverse events - myopathy.

Analysis 1.26. Comparison 1 Ezetimibe plus other lipid-modifying drugs vs other lipid-modifying drugs alone or plus placebo, Outcome 26 Adverse events - myopathy (sensitivity analysis: only including low risk of bias studies).

Analysis 1.27. Comparison 1 Ezetimibe plus other lipid-modifying drugs vs other lipid-modifying drugs alone or plus placebo, Outcome 27 Adverse events - rhabdomyolysis.

Analysis 1.28. Comparison 1 Ezetimibe plus other lipid-modifying drugs vs other lipid-modifying drugs alone or plus placebo, Outcome 28 Adverse events - rhabdomyolysis (sensitivity analysis: only including low risk of bias studies).

Analysis 1.29. Comparison 1 Ezetimibe plus other lipid-modifying drugs vs other lipid-modifying drugs alone or plus placebo, Outcome 29 Adverse events - cancer.

Analysis 1.30. Comparison 1 Ezetimibe plus other lipid-modifying drugs vs other lipid-modifying drugs alone or plus placebo, Outcome 30 Adverse events - cancer (sensitivity analysis: only including low risk of bias studies).

Analysis 1.31. Comparison 1 Ezetimibe plus other lipid-modifying drugs vs other lipid-modifying drugs alone or plus placebo, Outcome 31 Adverse events - cancer (sensitivity analysis: excluding the studies compared ezetimibe plus statins versus doubledose statins alone).

Analysis 1.32. Comparison 1 Ezetimibe plus other lipid-modifying drugs vs other lipid-modifying drugs alone or plus placebo, Outcome 32 Adverse events - gallbladder-related AE.

Analysis 1.33. Comparison 1 Ezetimibe plus other lipid-modifying drugs vs other lipid-modifying drugs alone or plus placebo, Outcome 33 Adverse events - gallbladder-related AE (sensitivity analysis: only including low risk of bias studies).

Analysis 1.34. Comparison 1 Ezetimibe plus other lipid-modifying drugs vs other lipid-modifying drugs alone or plus placebo, Outcome 34 Discontinuation due to adverse event.

Analysis 1.35. Comparison 1 Ezetimibe plus other lipid-modifying drugs vs other lipid-modifying drugs alone or plus placebo, Outcome 35 Discontinuation due to adverse event (sensitivity analysis: only including low risk of bias studies).

Analysis 1.36. Comparison 1 Ezetimibe plus other lipid-modifying drugs vs other lipid-modifying drugs alone or plus placebo, Outcome 36 Discontinuation due to adverse event (sensitivity analysis: excluding the studies compared ezetimibe plus statins versus double-dose statins alone).

Analysis 1.37. Comparison 1 Ezetimibe plus other lipid-modifying drugs vs other lipid-modifying drugs alone or plus placebo, Outcome $37 \mathrm{LDL}-\mathrm{C}$ (end of follow up).

Analysis 1.38. Comparison 1 Ezetimibe plus other lipid-modifying drugs vs other lipid-modifying drugs alone or plus placebo, Outcome 38 LDL-C (end of follow up) (sensitivity analysis: excluding the studies compared ezetimibe plus statins versus doubledose statins alone).

Analysis 1.39. Comparison 1 Ezetimibe plus other lipid-modifying drugs vs other lipid-modifying drugs alone or plus placebo, Outcome 39 LDL-C (end of follow up) (sensitivity analysis: excluding studies with serious missing data).

109

110 
Analysis 1.40. Comparison 1 Ezetimibe plus other lipid-modifying drugs vs other lipid-modifying drugs alone or plus placebo, Outcome 40 TC (end of follow up).

Analysis 1.41. Comparison 1 Ezetimibe plus other lipid-modifying drugs vs other lipid-modifying drugs alone or plus placebo, Outcome 41 TC (end of follow up) (sensitivity analysis: excluding the studies compared ezetimibe plus statins versus doubledose statins alone).

Analysis 1.42. Comparison 1 Ezetimibe plus other lipid-modifying drugs vs other lipid-modifying drugs alone or plus placebo, Outcome 42 TC (end of follow up) (sensitivity analysis: excluding studies with serious missing data).

Analysis 1.43. Comparison 1 Ezetimibe plus other lipid-modifying drugs vs other lipid-modifying drugs alone or plus placebo, Outcome $43 \mathrm{HDL}-\mathrm{C}$ (end of follow up).

Analysis 1.44. Comparison 1 Ezetimibe plus other lipid-modifying drugs vs other lipid-modifying drugs alone or plus placebo, Outcome $44 \mathrm{HDL}-\mathrm{C}$ (end of follow up) (sensitivity analysis: excluding the studies compared ezetimibe plus statins versus doubledose statins alone).

Analysis 1.45. Comparison 1 Ezetimibe plus other lipid-modifying drugs vs other lipid-modifying drugs alone or plus placebo, Outcome $45 \mathrm{HDL}-\mathrm{C}$ (end of follow up) (sensitivity analysis: excluding studies with serious missing data).

Analysis 1.46. Comparison 1 Ezetimibe plus other lipid-modifying drugs vs other lipid-modifying drugs alone or plus placebo, Outcome 46 TG (end of follow up).

Analysis 1.47. Comparison 1 Ezetimibe plus other lipid-modifying drugs vs other lipid-modifying drugs alone or plus placebo, Outcome 47 TG (end of follow up) (sensitivity analysis: excluding the studies compared ezetimibe plus statins versus doubledose statins alone).

Analysis 1.48. Comparison 1 Ezetimibe plus other lipid-modifying drugs vs other lipid-modifying drugs alone or plus placebo, Outcome 48 TG (end of follow up) (sensitivity analysis: excluding studies with serious missing data).

ADDITIONAL TABLES

APPENDICES

CONTRIBUTIONS OF AUTHORS 
[Intervention Review]

\section{Ezetimibe for the prevention of cardiovascular disease and all-cause mortality events}

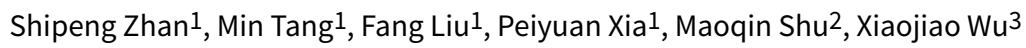

1Pharmacy Department, First Affiliated Hospital of Third Military Medical University (Army Medical University), Chongqing, China. ${ }^{2}$ Cardiovascular Department, First Affiliated Hospital of Third Military Medical University (Army Medical University), Chongqing, China. ${ }^{3}$ Department of Health Statistics, College of Preventive Medicine, Third Military Medical University (Army Medical University), Chongqing, China

Contact address: Peiyuan Xia, Pharmacy Department, First Affiliated Hospital of Third Military Medical University (Army Medical University), 30 Gaotanyan Street, Shapingba District, Chongqing, 400038, China. peiyuan_xia@163.com.

Editorial group: Cochrane Heart Group.

Publication status and date: New, published in Issue 11, 2018.

Citation: Zhan S, Tang M, Liu F, Xia P, Shu M, Wu X. Ezetimibe for the prevention of cardiovascular disease and all-cause mortality events. Cochrane Database of Systematic Reviews 2018, Issue 11. Art. No.: CD012502. DOI: 10.1002/14651858.CD012502.pub2.

Copyright $(2018$ The Cochrane Collaboration. Published by John Wiley \& Sons, Ltd.

\section{A B S T R A C T}

\section{Background}

Cardiovascular disease (CVD) remains an important cause of mortality and morbidity, and high levels of blood cholesterol are thought to be the major modifiable risk factors for CVD. The use of statins is the preferred treatment strategy for the prevention of CVD, but some people at high-risk for CVD are intolerant to statin therapy or unable to achieve their treatment goals with the maximal recommended doses of statin. Ezetimibe is a selective cholesterol absorption inhibitor, whether it has a positive effect on CVD events remains uncertain. Results from clinical studies are inconsistent and a thorough evaluation of its efficacy and safety for the prevention of CVD and mortality is necessary.

\section{Objectives}

To assess the efficacy and safety of ezetimibe for the prevention of CVD and all-cause mortality.

\section{Search methods}

We searched the CENTRAL, MEDLINE, Embase and Web of Science on 27 June 2018, and two clinical trial registry platforms on 11 July 2018. We checked reference lists from primary studies and review articles for additional studies. No language restrictions were applied.

\section{Selection criteria}

We included randomised controlled trials (RCTs) that compared ezetimibe versus placebo or ezetimibe plus other lipid-modifying drugs versus other lipid-modifying drugs alone in adults, with or without CVD, and which had a follow-up of at least 12 months.

\section{Data collection and analysis}

Two review authors independently selected studies for inclusion, extracted data, assessed risk of bias and contacted trialists to obtain missing data. We performed statistical analyses according to the Cochrane Handbook for Systematic Reviews of Interventions and used the GRADE to assess the quality of evidence.

\section{Main results}

We included 26 RCTs randomising 23,499 participants. All included studies assessed effects of ezetimibe plus other lipid-modifying drugs compared with other lipid-modifying drugs alone or plus placebo. Our findings were driven by the largest study (IMPROVE-IT), which had weights ranging from $41.5 \%$ to $98.4 \%$ in the different meta-analyses. 
Ezetimibe with statins probably reduces the risk of major adverse cardiovascular events compared with statins alone (risk ratio (RR) 0.94, $95 \%$ confidence interval (CI) 0.90 to 0.98 ; a decrease from $284 / 1000$ to $267 / 1000,95 \%$ Cl 256 to $278 ; 21,727$ participants; 10 studies; moderate-quality evidence). Trials reporting all-cause mortality used ezetimibe with statin or fenofibrate and found they have little or no effect on this outcome (RR $0.98,95 \% \mathrm{Cl} 0.91$ to $1.05 ; 21,222$ participants; 8 studies; high-quality evidence). Adding ezetimibe to statins probably reduces the risk of non-fatal myocardial infarction (MI) (RR 0.88, 95\% Cl 0.81 to 0.95; a decrease from 105/1000 to 92/1000, 95\% CI 85 to $100 ; 21,145$ participants; 6 studies; moderate-quality evidence) and non-fatal stroke (RR $0.83,95 \% \mathrm{Cl} 0.71$ to 0.97 ; a decrease $32 / 1000$ to $27 / 1000,95 \% \mathrm{Cl} 23$ to $31 ; 21,205$ participants; 6 studies; moderate-quality evidence). Trials reporting cardiovascular mortality added ezetimibe to statin or fenofibrate, probably having little or no effect on this outcome (RR 1.00, $95 \% \mathrm{Cl} 0.89$ to $1.12 ; 19457$ participants; 6 studies; moderate-quality evidence). The need for coronary revascularisation might be reduced by adding ezetimibe to statin (RR $0.94,95 \%$ $\mathrm{Cl} 0.89$ to 0.99 ; a decrease from 196/1000 to 184/1000, 95\% 175 to 194; 21,323 participants; 7 studies); however, no difference in coronary revascularisation rate was observed when a sensitivity analysis was limited to studies with a low risk of bias.

In terms of safety, adding ezetimibe to statins may make little or no difference in the risk of hepatopathy (RR $1.14,95 \% \mathrm{Cl} 0.96$ to 1.35 ; 20,687 participants; 4 studies; low-quality evidence). It is uncertain whether ezetimibe increase or decrease the risk of myopathy (RR 1.31, $95 \% \mathrm{Cl} 0.72$ to $2.38 ; 20,581$ participants; 3 studies; very low-quality evidence) and rhabdomyolysis, given the wide Cls and low event rate. Little or no difference in the risk of cancer, gallbladder-related disease and discontinuation due to adverse events were observed between treatment groups. For serum lipids, adding ezetimibe to statin or fenofibrate might further reduce the low-density lipoprotein cholesterol (LDL-C), total cholesterol and triglyceride levels and likely increase the high-density lipoprotein cholesterol levels; however, substantial heterogeneity was detected in most analyses.

None of the included studies reported on health-related quality of life.

\section{Authors' conclusions}

Moderate- to high-quality evidence suggests that ezetimibe has modest beneficial effects on the risk of CVD endpoints, primarily driven by a reduction in non-fatal MI and non-fatal stroke, but it has little or no effect on clinical fatal endpoints. The cardiovascular benefit of ezetimibe might involve the reduction of LDL-C, total cholesterol and triglycerides. There is insufficient evidence to determine whether ezetimibe increases the risk of adverse events due to the low and very low quality of the evidence. The evidence for beneficial effects was mainly obtained from individuals with established atherosclerotic cardiovascular disease (ASCVD, predominantly with acute coronary syndrome) administered ezetimibe plus statins. However, there is limited evidence regarding the role of ezetimibe in primary prevention and the effects of ezetimibe monotherapy in the prevention of CVD, and these topics thus requires further investigation.

\section{PLAIN LANGUAGE SUMMARY}

\section{Ezetimibe for the prevention of heart disease and death}

\section{Review question}

Is taking ezetimibe safe and does it prevent heart disease and death?

\section{Background}

Heart disease remains the leading cause of death worldwide, and controlling lipid levels is one of the most effective strategies for preventing heart disease. The use of statins is the preferred treatment strategy for the prevention of heart disease, but some people at high risk of heart disease are intolerant to statins or with a poor response to statin therapy. Ezetimibe is a non-statin drug that can reduce the blood lipids levels by inhibiting cholesterol absorption, but whether it has beneficial effects on heart disease and death remains uncertain.

\section{Study characteristics}

This evidence is current up to July 2018. We included 26 studies involving 23,499 participants. These studies assessed the effects of ezetimibe plus other lipid-lowering drugs versus lipid-lowering drugs alone for heart disease. The participants were adults, and most of them had been diagnosed with coronary heart disease.

\section{Key results}

Ezetimibe with statins probably reduces the risk for combined outcome of death due to heart disease, heart attack or stroke, but the benefit is moderate. However, adding ezetimibe to statin or fenofibrate have little or no effect on death from any cause. Treatment with ezetimibe and statin probably reduces the risk for non-fatal heart attacks and non-fatal stroke. Adding ezetimibe to statin or fenofibrate probably have little or no effect on heart-related death. Ezetimibe with statins might reduce the need for coronary revascularisation (the restoration of an adequate blood supply to the heart) by means of surgery.

In terms of safety, we do not have enough evidence to know whether ezetimibe increases or decreases side-effects (e.g. liver injury, muscle pain, cancer, gallbladder-related disease and discontinuation). The analysis of blood lipids revealed that the addition of ezetimibe statin or fenofibrate therapy might further reduce the levels of blood lipids, including low-density lipoprotein cholesterol ('bad' cholesterol), total cholesterol and triglycerides, and likely increased the level of high-density lipoprotein cholesterol ('good' cholesterol). None of the 
included studies reported on health-related quality of life. There is a lack of evidence supporting the use of ezetimibe monotherapy for the prevention of heart disease, and this topic requires further investigation.

\section{Quality of evidence}

The quality of evidence ranged from high to very low across the outcomes. 


\section{SUMMARY OF FINDINGS}

\section{Summary of findings for the main comparison. Ezetimibe for the prevention of cardiovascular disease and all-cause mortality events}

Ezetimibe plus other lipid-modifying drugs compared to other lipid-modifying drugs alone or plus placebo for the prevention of cardiovascular disease and allcause mortality events

Patient or population: people with cardiovascular disease or at high risk of cardiovascular disease

Setting: inpatients or outpatient

Intervention: ezetimibe plus other lipid-modifying drugs (statin or fenofibrate)

Comparison: other lipid-modifying drugs (statin or fenofibrate) alone or plus placebo

\begin{tabular}{|c|c|c|c|c|c|c|}
\hline \multirow[t]{2}{*}{ Outcomes } & \multicolumn{2}{|c|}{$\begin{array}{l}\text { Anticipated absolute effects }{ }^{*} \\
(95 \% \mathrm{Cl})\end{array}$} & \multirow[t]{2}{*}{$\begin{array}{l}\text { Relative effect } \\
(95 \% \mathrm{Cl})\end{array}$} & \multirow{2}{*}{$\begin{array}{l}\text { № of partici- } \\
\text { pants } \\
\text { (studies) }\end{array}$} & \multirow{2}{*}{$\begin{array}{l}\text { Certainty of } \\
\text { the evidence } \\
\text { (GRADE) }\end{array}$} & \multirow[t]{2}{*}{ Comments } \\
\hline & $\begin{array}{l}\text { Risk with oth- } \\
\text { er lipid-mod- } \\
\text { ifying drugs } \\
\text { alone or plus } \\
\text { placebo }\end{array}$ & $\begin{array}{l}\text { Risk with Eze- } \\
\text { timibe plus } \\
\text { other lipid- } \\
\text { modifying } \\
\text { drugs }\end{array}$ & & & & \\
\hline $\begin{array}{l}\text { Major adverse } \\
\text { cardiovascular } \\
\text { events (MACE) } \\
\text { follow-up: range } \\
1 \text { years to } 6 \text { years }\end{array}$ & 284 per 1,000 & $\begin{array}{l}267 \text { per } 1,000 \\
\text { ( } 256 \text { to } 278)\end{array}$ & $\begin{array}{l}\text { RR } 0.94 \\
(0.90 \text { to } 0.98)\end{array}$ & $\begin{array}{l}21,727 \\
(10 \mathrm{RCTs})\end{array}$ & $\begin{array}{l}\oplus \oplus \oplus \ominus \\
\text { MODERATE } 1\end{array}$ & $\begin{array}{l}\text { The data were obtained from studies comparing eze- } \\
\text { timibe plus statin versus statin alone. } \\
\text { The IMPROVE-IT study carried } 88.8 \% \text { of the weight. }\end{array}$ \\
\hline \multirow{2}{*}{$\begin{array}{l}\text { All-cause mortal- } \\
\text { ity } \\
\text { follow-up: range } \\
1 \text { years to } 6 \text { years }\end{array}$} & \multicolumn{2}{|c|}{ Study population } & \multirow{2}{*}{$\begin{array}{l}\text { RR } 0.98 \\
\text { (0.91 to } 1.05)\end{array}$} & \multirow{2}{*}{$\begin{array}{l}21,222 \\
\text { (8 RCTs) }\end{array}$} & \multirow{2}{*}{$\begin{array}{l}\oplus \oplus \oplus \oplus \\
\mathrm{HIGH}\end{array}$} & The IMPROVE-IT study carried $94.6 \%$ of the weight. \\
\hline & 123 per 1,000 & $\begin{array}{l}120 \text { per } 1,000 \\
(112 \text { to } 129)\end{array}$ & & & & $\begin{array}{l}\text { Two additional studies reported that no deaths oc- } \\
\text { curred, and one study reported the total deaths but } \\
\text { did not provide data by treatment arm. }\end{array}$ \\
\hline \multirow{3}{*}{$\begin{array}{l}\text { Myocardial in- } \\
\text { farction (non-fa- } \\
\text { tal) } \\
\text { follow-up: range } \\
1 \text { years to } 6 \text { years }\end{array}$} & \multicolumn{2}{|c|}{ Study population } & \multirow{3}{*}{$\begin{array}{l}\text { RR } 0.88 \\
\text { (0.81 to } 0.95)\end{array}$} & \multirow{3}{*}{$\begin{array}{l}21,145 \\
(6 \mathrm{RCTs})\end{array}$} & \multirow{3}{*}{$\begin{array}{l}\oplus \oplus \oplus \ominus \\
\text { MODERATE } 1\end{array}$} & \multirow{3}{*}{$\begin{array}{l}\text { The data were obtained from studies comparing eze- } \\
\text { timibe plus statin versus statin alone. } \\
\text { The IMPROVE-IT study carried } 97.8 \% \text { of the weight, } \\
\text { and also provided data on any MI (HR } 0.87,95 \% \mathrm{Cl} 0.80 \\
\text { to } 0.95 \text { ) and fatal MI (HR } 0.84,95 \% \mathrm{Cl} 0.55 \text { to } 0.1 .27 \text { ). } \\
\text { Two additional studies reported that no MI events oc- } \\
\text { curred. }\end{array}$} \\
\hline & 105 per 1,000 & $\begin{array}{l}92 \text { per } 1,000 \\
(85 \text { to } 100)\end{array}$ & & & & \\
\hline & & & & & & \\
\hline Stroke (non-fatal) & \multicolumn{2}{|c|}{ Study population } & $\begin{array}{l}\text { RR } 0.83 \\
\text { (0.71 to } 0.97)\end{array}$ & $\begin{array}{l}21,205 \\
(6 \text { RCTs) }\end{array}$ & $\begin{array}{l}\oplus \oplus \oplus \ominus \\
\text { MODERATE } 1\end{array}$ & $\begin{array}{l}\text { The data were obtained from studies comparing eze- } \\
\text { timibe plus statin versus statin alone. }\end{array}$ \\
\hline
\end{tabular}




\section{2 per $1,000 \quad 27$ per 1,000}

(23 to 31 )

The IMPROVE-IT study carried $89.4 \%$ of the weight, and also provided data on any stroke (HR $0.86,95 \% \mathrm{C}$ 0.73 to 1.00 ), ischaemic stroke (HR $0.79,95 \% \mathrm{Cl} 0.67$ to 0.94 ), haemorrhagic stroke (HR $1.38,95 \% \mathrm{Cl} 0.93$ to 2.04 ) and fatal stroke (HR $1.22,95 \% \mathrm{Cl} 0.81$ to 1.82 ).

One additional study reported that no stroke events occurred.

\begin{tabular}{|c|c|c|c|c|c|c|}
\hline \multirow{2}{*}{$\begin{array}{l}\text { Cardiovascular } \\
\text { mortality } \\
\text { follow-up: range } \\
1 \text { years to } 6 \text { years }\end{array}$} & \multicolumn{2}{|c|}{ Study population } & \multirow{2}{*}{$\begin{array}{l}\text { RR } 1.00 \\
\text { (0.89 to } 1.12)\end{array}$} & \multirow{2}{*}{$\begin{array}{l}19,457 \\
\text { (6 RCTs) }\end{array}$} & \multirow{2}{*}{$\begin{array}{l}\oplus \oplus \oplus \ominus \\
\text { MODERATE } 2\end{array}$} & \multirow{2}{*}{$\begin{array}{l}\text { The IMPROVE-IT study carried } 98.4 \% \text { of the weight. } \\
\text { Four additional studies reported that no cardiovascu- } \\
\text { lar death occurred and one study reported total car- } \\
\text { diac deaths but did not provide data by treatment } \\
\text { arm. }\end{array}$} \\
\hline & 56 per 1,000 & $\begin{array}{l}56 \text { per } 1,000 \\
(50 \text { to } 63 \text { ) }\end{array}$ & & & & \\
\hline \multirow{3}{*}{$\begin{array}{l}\text { Adverse events - } \\
\text { hepatopathy } \\
\text { follow-up: range } \\
1 \text { to } 6 \text { years }\end{array}$} & \multicolumn{2}{|c|}{ Study population } & \multirow{3}{*}{$\begin{array}{l}\text { RR } 1.14 \\
\text { (0.96 to } 1.35 \text { ) }\end{array}$} & \multirow{3}{*}{$\begin{array}{l}20,687 \\
\text { (4 RCTs) }\end{array}$} & \multirow{3}{*}{$\begin{array}{l}\oplus \oplus \ominus \ominus \\
\text { LOW } 13\end{array}$} & \multirow{3}{*}{$\begin{array}{l}\text { The data were obtained from studies comparing eze- } \\
\text { timibe plus statin versus statin alone. } \\
\text { The IMPROVE-IT study carried } 89.6 \% \text { of the weight. } \\
\text { Ten additional studies reported no occurrence in the } \\
\text { levels of ALT and/or AST being more than or equal } 3 \times \\
\text { ULN. }\end{array}$} \\
\hline & 22 per 1,000 & $\begin{array}{l}26 \text { per } 1,000 \\
(22 \text { to } 30)\end{array}$ & & & & \\
\hline & & & & & & \\
\hline \multirow{2}{*}{$\begin{array}{l}\text { Adverse events - } \\
\text { myopathy } \\
\text { follow-up: range } \\
1 \text { years to } 6 \text { years }\end{array}$} & \multicolumn{2}{|c|}{ Study population } & \multirow{2}{*}{$\begin{array}{l}\text { RR } 1.31 \\
(0.72 \text { to } 2.38)\end{array}$} & \multirow{2}{*}{$\begin{array}{l}20,581 \\
\text { (3 RCTs) }\end{array}$} & \multirow{2}{*}{$\begin{array}{l}\oplus \ominus \ominus \ominus \\
\text { VERY LOW } 14\end{array}$} & \multirow{2}{*}{$\begin{array}{l}\text { The data were obtained from studies comparing eze- } \\
\text { timibe plus statin versus statin alone. } \\
\text { The IMPROVE-IT study carried } 52.5 \% \text { of the weight. } \\
\text { Thirteen additional studies reported that none of the } \\
\text { participants in either group developed a CK level more } \\
\text { than or equal } 10 \times \text { ULN. }\end{array}$} \\
\hline & 2 per 1,000 & $\begin{array}{l}2 \text { per } 1,000 \\
(1 \text { to } 4)\end{array}$ & & & & \\
\hline
\end{tabular}

*The risk in the intervention group (and its $95 \%$ confidence interval) is based on the assumed risk in the comparison group and the relative effect of the intervention (and its $95 \% \mathrm{Cl})$.

Cl: Confidence interval; HR: hazard ratio; RR: Risk ratio

\section{GRADE Working Group grades of evidence}

High certainty: We are very confident that the true effect lies close to that of the estimate of the effect

Moderate certainty: We are moderately confident in the effect estimate. The true effect is likely to be close to the estimate of the effect, but there is a possibility that it is substantially different

Low certainty: Our confidence in the effect estimate is limited. The true effect may be substantially different from the estimate of the effect

Very low certainty: We have very little confidence in the effect estimate. The true effect is likely to be substantially different from the estimate of effect 
Downgraded by one level due to risk of bias.

2 Downgraded by one level due to imprecision (the $95 \% \mathrm{Cl}$ exclude serious harm, but included the null).

3 Downgraded by one level due to imprecision (the $95 \% \mathrm{Cl}$ of the overall effect included both no effect and important harm).

4 Downgraded by two levels due to imprecision (few events and wide $\mathrm{Cl}$ ). 


\section{B A C K G R O U N D}

\section{Description of the condition}

Cardiovascular disease (CVD) is a group of disorders of the heart and blood vessels, including coronary heart disease (heart attacks), cerebrovascular disease (stroke), hypertensive heart disease, heart failure, peripheral artery disease, rheumatic heart disease, congenital heart disease and other conditions (WHO 2016). CVD remains the leading cause of death worldwide, is an increasing cause of morbidity and a major cause of disability and illhealth (Mozaffarian 2016; Nichols 2014; Roth 2015a; WHO 2015). An estimated 17.5 million people died from CVDs in 2012, accounting for $31 \%$ of deaths globally from all causes (WHO 2015). Of these deaths, an estimated 7.4 million and 6.7 million were due to coronary heart disease and stroke, respectively. The burden of the disease is particularly high in low- and middle-income countries, where over 75\% of CVD deaths occur (GBD 2016; Roth 2015b). The health burden of CVD is also accompanied by a significant harmful economic impact at both national and household levels. The global cost of CVD in 2010 was estimated at USD 863 billion (an average per capita cost of USD 125), and that figure is projected to rise to at least USD 1044 billion in 2030, an increase of 22\% (Bloom 2011). CVD produces immense health and economic burdens globally, therefore preventing deaths and diseases due to CVD is a priority for global public health.

CVD is multi-factorial in its causation. One of the major modifiable risk factors for CVD is thought to be high levels of blood cholesterol (hypercholesterolaemia), therefore lowering cholesterol, in particular low-density lipoprotein cholesterol (LDLC), is considered an important target of therapy in the primary and secondary prevention of CVD (Grundy 2004; PSC 2007; Stone 2014).

\section{Description of the intervention}

Ezetimibe is a non-statin lipid-modifying drug, which is the first and only selective inhibitor of intestinal cholesterol absorption. It is an effective LDL-C lowering agent, which is safe and well-tolerated. A standard dose of $10 \mathrm{mg}$ a day of ezetimibe lowers LDL-C by $13 \%$ to $20 \%$, non-high density lipoprotein cholesterol (non-HDL-C) by $14 \%$ to $19 \%$, and triglyceride (TG) by $5 \%$ to $11 \%$, and increases $\mathrm{HDL}$ C by $3 \%$ to $5 \%$ (Jacobson 2015). Ezetimibe in combination with other lipid-modifying agents can lead to superior lipid outcomes and does not increase the rate of adverse reactions (Gudzune 2014; Phan 2012). Furthermore, it does not affect the activity of CYP450, a major drug metabolising enzyme, so avoiding any potential pharmacokinetic interactions with most medications (Kosoglou 2005). Ezetimibe is indicated for the treatment of primary hyperlipidaemia, either alone or in combination with statins; mixed hyperlipidaemia in combination with fenofibrate, simvastatin or atorvastatin; homozygous familial hypercholesterolaemia in combination with atorvastatin or simvastatin; and homozygous sitosterolaemia.

\section{How the intervention might work}

Ezetimibe is a selective cholesterol absorption inhibitor that blocks the intestinal absorption of dietary and biliary cholesterol, as well as related plant sterols, without affecting the uptake of fat-soluble vitamins, triglycerides or bile acids (Sudhop 2009). It localises to the brush border of the small intestine and reduces the enterocyte uptake and absorption of cholesterol and plant sterols by binding to the Niemann-Pick C1 Like 1 (NPC1L1) protein (Altmann 2004;
Jia 2011). It can therefore decrease the delivery of intestinal cholesterol to the liver, leading to a reduction of hepatic cholesterol stores and an increase in clearance of cholesterol from the blood (Altmann 2004; Kosoglou 2005; Sudhop 2002). A study confirmed that ezetimibe could reduce intestinal cholesterol absorption by $54 \%$ (Sudhop 2002). As the effect of ezetimibe is mainly in the enterohepatic circulation, thereby limiting systemic exposure, it is less likely to cause adverse drug interactions (Van Heek 2000). In addition, ezetimibe was shown to have some pleiotropic effects, including the improvement of inflammation, insulin resistance, fatty liver and so on, although the potential mechanisms for these benefits have not been fully elucidated and have not been related to improved clinical outcomes (Lioudaki 2011).

\section{Why it is important to do this review}

Control of lipid levels is one of the most effective strategies for CVD prevention. Statin therapy is currently the cornerstone of treatment for lowering LDL-C in the vast majority of individuals with increased risk for CVD (Perk 2012; Stone 2014). More intensive LDL-C lowering (compared with less intensive LDL-C lowering) based on statin monotherapy steadily reduced clinical outcomes in people with cardiovascular risk (CTT 2010; CTT 2012). However, some people have contraindications or intolerance to statin therapy, particularly people at high cardiovascular risk (Reiner 2014). Adverse effects are more common with higher-intensity statin regimens. Therefore, the combination of non-statin lipid-modifying drugs with the lowest statin dose tolerated or, as an alternative, a combination of nonstatin lipid-modifying drugs, represent possible approaches for people intolerant to statins. Due to the lack of convincing clinical evidence, however, the optimal treatment strategy for people who cannot tolerate statin therapy or those who need additional lipidmodifying therapy is unclear.

The American College of Cardiology/American Heart Association (ACC/AHA) guidelines state that there is no evidence supporting the routine use of non-statin drugs with statin therapy for incremental atherosclerotic cardiovascular disease (ASCVD) risk reduction (Stone 2014). The guideline recommends that clinicians consider the addition of a non-statin cholesterol-lowering drug for people at high-risk of ASCVD with insufficient response to statin therapy, or for people who are intolerant to the recommended statin intensity. Similarly, the National Lipid Association (NLA) recommendations for people who cannot tolerate a statin say that a non-statin drug alone or in combination with another cholesterol-lowering agent may be considered (Jacobson 2015). According to the guidelines above and other current guidelines on the management of dyslipidaemia or the prevention of CVD (EDP 2014; Rabar 2014), non-statin treatments are not routinely used as monotherapy to decrease LDL-C concentrations, unless people with CVD are intolerant to statins and they are recommended as combination therapy with statins in high-risk patients when their treatment goals are not reached with the maximal tolerated dose of a statin. Ezetimibe, which is a non-statin drug and acts via a novel mechanism, can be combined with a statin to provide complementary cholesterol reduction. The combination therapy enables a more efficient reduction of LDL-C levels beyond that which can be achieved by statin monotherapy. In addition, clinical trials have reported that ezetimibe demonstrates a favourable safety profile without severe adverse events. However, whether ezetimibe can reduce the rate of cardiovascular events is uncertain. Also, it is unclear whether its combination with other lipid- 
modifying agents can reduce the rate of cardiovascular events further compared with other lipid-modifying agents monotherapy. A number of clinical studies evaluating the use of ezetimibe therapy have resulted in inconsistent data regarding its safety and efficacy (Baigent 2011; Cannon 2015; Kastelein 2008; Rossebo 2008), so it is necessary to evaluate published evidence on efficacy and safety of ezetimibe for the prevention of CVD events and mortality.

\section{OB JECTIVES}

To assess the efficacy and safety of ezetimibe versus placebo or ezetimibe plus other lipid-modifying drugs versus other lipidmodifying drugs alone for the prevention of cardiovascular disease (CVD) events and all-cause mortality events.

\section{METHODS}

\section{Criteria for considering studies for this review Types of studies}

We included randomised controlled trials (RCTs) with a follow-up of at least 12 months. We included studies reported as full text, those published as abstract only, and unpublished data. ClusterRCTs, cross-over trials and non-randomised studies were ineligible for this review, and we excluded them during title and abstract screening.

We restricted the follow-up time of at least 12 months because only long-term clinical trials may provide sufficient and reliable intervention effects on mortality and cardiovascular morbidity. Guidance on clinical investigation of medicinal products in the treatment of lipid disorders that published by EMA (European Medicines Agency) recommend that a sufficient cohort of patients should be continuously exposed to the drug for at least one year to obtain long-term effects and safety data (EMA 2004).

\section{Types of participants}

We included adults aged at least 18 years, with or without established CVD.

Where studies only included a subset of participants eligible for our review, we contacted the study authors for details on only those participants which met our inclusion criteria. If this was not possible, we planned only to include the trial if it presented the outcomes for eligible participants in a separate subgroup.

\section{Types of interventions}

Ezetimibe can be administered as monotherapy or as combination therapy with other lipid-modifying drug(s) with no restriction on dosage and frequency. We included the following comparisons.

1. Ezetimibe versus placebo

2. Ezetimibe plus other lipid-modifying drug(s) versus other lipidmodifying drug(s) alone or plus placebo

\section{Types of outcome measures}

\section{Primary outcomes}

1. Major adverse cardiovascular events (MACE), defined as a composite outcome of cardiovascular death, non-fatal myocardial infarction (MI), non-fatal stroke, hospitalisation for unstable angina, or coronary revascularisation procedures.

\section{All-cause mortality}

\section{Secondary outcomes}

1. Myocardial infarction (MI) (fatal and non-fatal)

2. Ischaemic stroke (fatal and non-fatal)

3. Cardiovascular mortality

4. Coronary revascularisation

5. Adverse events (AEs) including hepatopathy, myopathy, rhabdomyolysis, cancer, gallbladder-related disease and discontinuation due to AEs

6. Lipid parameters (total cholesterol, LDL-C, HDL-C, triglycerides): mean difference (MD) at the end of follow-up or the change from baseline

7. Health-related quality of life (using any well-validated scale)

\section{Search methods for identification of studies}

\section{Electronic searches}

We identified trials through systematic searches of the following bibliographic databases on 27 June 2018.

1. Cochrane Central Register of Controlled Trials (CENTRAL) (Issue 6 of 12,2018 ) in the Cochrane Library

2. Epub Ahead of Print, In-Process \& Other Non-Indexed Citations, MEDLINE Daily and MEDLINE (Ovid, 1946 to 27 June 2018)

3. Embase (Ovid, 1980 to 2018 week 26)

4. Web of Science Core Collection (Thomson Reuters, 1900 to 27 June 2018)

We adapted the preliminary search strategy for MEDLINE (Ovid) (Appendix 1) for use in the other databases and we applied the Cochrane sensitivity-maximising RCT filter (Lefebvre 2011) to MEDLINE (Ovid) and adaptations of it to the other databases, except CENTRAL.

We also conducted a search of ClinicalTrials.gov and the WHO International Clinical Trials Registry Platform (ICTRP) Search Portal (apps.who.int/trialsearch/) for relevant RCTs on 11 July 2018.

We searched all databases from their inception to the present, and we imposed no restriction on language of publication.

We did not perform a separate search for adverse effects of interventions used for the treatment of ezetimibe. We considered adverse effects described in included studies only.

\section{Searching other resources}

We checked reference lists of all primary studies and review articles for additional references. We contacted study authors to clarify details or obtain additional data not included in the publish reports.

We also examined any relevant retraction statements and errata for included studies.

In addition, we retrieved publicly-available application materials of the IMPROVE-IT study that were published on Food and Drug Administration (FDA) website. 


\section{Data collection and analysis}

\section{Selection of studies}

Two review authors (SZ, MT) independently screened titles and abstracts for inclusion of all the potential studies we identified as a result of the search and coded them as 'retrieve' (eligible or potentially eligible/unclear) or 'do not retrieve'. If there were any disagreements, a third review author was asked to arbitrate (PX). We retrieved the full-text study reports/publication and two review authors (SZ, MT) independently screened the full-text and identified studies for inclusion, and identified and recorded reasons for exclusion of the ineligible studies. We resolved any disagreement through discussion or, if required, consulted a third person (PX). We identified and excluded duplicates and collate multiple reports of the same study so that each study rather than each report was the unit of interest in the review. We recorded the selection process in sufficient detail to complete a PRISMA flow diagram (Liberati 2009) and 'Characteristics of excluded studies' table.

\section{Data extraction and management}

We used a data collection form for study characteristics and outcome data that has been piloted on at least one study in the review. Two review authors (SZ, MT) extracted study characteristics from included studies. We extracted the following study characteristics.

1. Methods: study design, total duration of study, details of any 'run-in' period, number of study centres and location, study setting, withdrawals, and date of study.

2. Participants: N, mean age, age range, gender, severity of condition, diagnostic criteria, body mass index (BMI), smoking history, inclusion criteria, and exclusion criteria.

3. Interventions: intervention, comparison, concomitant medications, and excluded medications.

4. Outcomes: primary and secondary outcomes specified and collected, and time points reported.

5. Notes: funding for trial, and notable conflicts of interest of trial authors.

Two review authors (SZ, MT) independently extracted outcome data from included studies. We resolved disagreements by consensus or by involving a third person (PX). One review author (FL) transferred data into the Review Manager 5 (RevMan 5) (RevMan 2014) file. We double-checked that data were entered correctly by comparing the data presented in the systematic review with the study reports. A second review author (PX) spot-checked study characteristics for accuracy against the study report.

\section{Assessment of risk of bias in included studies}

Two review authors (SZ, FL) independently assessed the risk of bias for each included study using the criteria outlined in the Cochrane Handbook for Systematic Reviews of Interventions (Higgins 2011). We resolved any disagreements by discussion or by involving another review author (PX). We assessed the risk of bias according to the following domains.

1. Random sequence generation

2. Allocation concealment

3. Blinding of participants and personnel
4. Blinding of outcome assessment

5. Incomplete outcome data

6. Selective outcome reporting

7. Other bias. (e.g. industry funding)

We graded each potential source of bias as 'high', 'low' or 'unclear' and provided a quote from the study report together with a justification for our judgment in the 'Risk of bias' section of the Characteristics of included studies table. We summarised the 'Risk of bias' judgements across different studies for each of the domains listed. Where information on risk of bias related to unpublished data or correspondence with a trialist, we noted this in the 'Risk of bias' section of the Characteristics of included studies table.

When considering treatment effects, we took into account the risk of bias for the studies that contributed to that outcome.

\section{Assessment of bias in conducting the systematic review}

We conducted the review according to this published protocol (Zhan 2017) and reported any deviations from it in the 'Differences between protocol and review' section of the systematic review.

\section{Measures of treatment effect}

We analysed dichotomous data as risk ratios (RRs) with 95\% confidence intervals (Cls). One of the included studies (IMPROVEIT 2015) reported hazard ratios (HRs) for subgroup analyses stratified by age, gender, statin experience and diabetes at baseline, and these HR are reported narratively in the text. We analysed continuous data as mean difference (MD) because all studies used the same scales. We entered the data presented as a scale with a consistent direction of effect. We described skewed data reported as medians and interquartile ranges (IQRs) in narrative form.

\section{Unit of analysis issues}

We included RCTs with parallel design. Three studies (EFECTL 2017; VYCTOR 2009; Zinellu 2012) had three intervention arms. However, we only included data from two intervention arms related to this review.

\section{Dealing with missing data}

We contacted investigators or study sponsors in order to verify key study characteristics and obtain missing numerical outcome data where possible. Where this were not possible, and the missing data were thought to introduce serious bias, we explored the impact of including such studies in the overall assessment of results by a sensitivity analysis.

\section{Assessment of heterogeneity}

We first assessed methodological and clinical heterogeneity with respect to the type of participants, interventions and outcomes in the included studies. We evaluated statistical heterogeneity using the $\mathrm{Chi}^{2}$ test with a $\mathrm{P}$ value less than 0.1 indicating significant heterogeneity, and we used the $I^{2}$ statistic (Higgins 2003) to quantify statistical heterogeneity. In cases of no heterogeneity, we performed a fixed-effect meta-analysis, whereas if we identified substantial heterogeneity $\left(\mathrm{I}^{2}\right.$ greater than $\left.50 \%\right)$, we reported this finding and explored possible causes through a prespecified subgroup analysis. If the source of heterogeneity could not be explained, we considered the following options: we used a random- 
effects model with appropriate cautious interpretation or provided a narrative overview and did not aggregate the studies.

\section{Assessment of reporting biases}

We explored any possible reporting bias by assessing asymmetry in funnel plots to determine whether the studies were selectively reported (Sterne 2011). We constructed a funnel plot if at least 10 studies could be included.

\section{Data synthesis}

We undertook meta-analyses only if the analysis was meaningful, that is, if the treatments, participants and underlying clinical question were similar enough for pooling to make sense. We used RevMan 5 (RevMan 2014) to combine the outcomes from individual trials if these were consistent on clinical grounds and if outcome data were available. In the absence of substantial heterogeneity $\left(I^{2}\right.$ $<50 \%$ ) and if there were sufficient trials, we combined the results using a fixed-effect model. If the heterogeneity was substantial, we performed a random-effects meta-analysis with appropriate cautious interpretation or provided a narrative overview and did not aggregate the studies (Deeks 2011; Huedo-Medina 2006). For dichotomous outcomes, we used Mantel-Haenszel methods to calculate the pooled RRs. We analysed continuous outcomes using an inverse variance method for pooling MDs, and had the studies used different scales, we would have used standardised mean differences (SMDs) (Deeks 2011). All the data are accompanied by the $95 \% \mathrm{Cls}$.

\section{'Summary of findings' table}

We created a 'Summary of findings' table using the following outcomes.

1. Major adverse cardiovascular events (MACE)

2. All-cause mortality

3. Myocardial infarction (MI) (fatal and non-fatal)

4. Ischaemic stroke (fatal and non-fatal)

5. Cardiovascular mortality

6. AEs (hepatopathy)

7. AEs (myopathy)

Two review authors (SZ, FL) independently graded the body of evidence using adapted decision rules. We used the five GRADE considerations (study limitations, consistency of effect, imprecision, indirectness and publication bias) to assess the quality of a body of evidence as it relates to the studies that contributed data to the meta-analyses for the prespecified outcomes. We used the methods and recommendations described in Section 8.5 (Higgins 2011) and Chapter 12 (Schünemann 2011) of the Cochrane Handbook for Systematic Reviews of Interventions using GRADEpro GDT software. The overall quality of the evidence was assessed as either high, moderate, low or very low. We justified all decisions to down- or up-grade the quality of the studies using footnotes, and provided comments to aid the readers' understanding of the review where necessary.

\section{Subgroup analysis and investigation of heterogeneity}

We planned to perform the following subgroup analyses.

1. Age ( $\geq 65$ years versus $<65$ years)

2. Sex
3. Statin treatment prior to trial participation versus no statin treatment prior to trial participation

4. Diabetes at baseline

5. Duration of follow-up $\leq 2$ years and $>2$ years

6. Participants with or without existing atherosclerotic cardiovascular disease (ASCVD)

We used the following outcomes in the subgroup analyses:

1. Major adverse cardiovascular events (MACEs)

2. All-cause mortality

We used the formal test for subgroup interactions in RevMan 5 (RevMan 2014).

However, we were only able to perform subgroup analyses based on duration of follow-up and participants with or without existing ASCVD because data for the prespecified subgroups were unavailable. IMPROVE-IT 2015 reported the subgroup analysis of primary composite endpoints (MACE) by age, gender, statin experience and diabetes at baseline, so we reported these results in the text.

\section{Sensitivity analysis}

We performed the following sensitivity analyses.

1. A sensitivity analysis that included only studies with a low risk of bias was performed. We regarded studies as at low risk of bias if no domain was at high risk of bias and at least five domains (randomisation, allocation concealment, performance and detection biases, attrition bias) for bias assessment were judged to be low risk.

2. The consistency in primary outcomes between different statistical models (fixed-effect models and random-effects models) was checked.

3. A sensitivity analysis that excluded studies compared ezetimibe plus statins versus double-dose statins alone.

\section{Reaching conclusions}

We based our conclusions only on findings from the quantitative or narrative synthesis of included studies for this review. We avoided making recommendations for practice and in the Implications for research' section, we suggest priorities for future research and outline what the remaining uncertainties are in the area.

\section{RE S U L T S}

\section{Description of studies}

\section{Results of the search}

The search of databases retrieved 7180 records and the clinical trial registries retrieved 515 records. Two reference was identified through reference checking. After the removal of duplicates, we screened the titles and abstracts of 3823 records. Among them, 3625 records did not meet the inclusion criteria and were therefore excluded. The remaining 198 records were assessed for eligibility through a review of full text, and 63 studies ( 83 records) were excluded. Finally, 26 studies (108 records) were found to be eligible for inclusion. We identified three ongoing studies and four studies awaiting classification. This process is illustrated with a PRISMA flow chart (Figure 1). 
Figure 1. Study flow diagram.

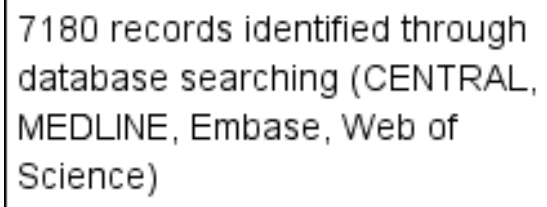
database searching (CENTRAL, MEDLINE, Embase, Web of Science)

515 additional records identified through clinical trials registries (ClinicalTrials gov and WHO ICTRP)

2 additional record identified through reference searching
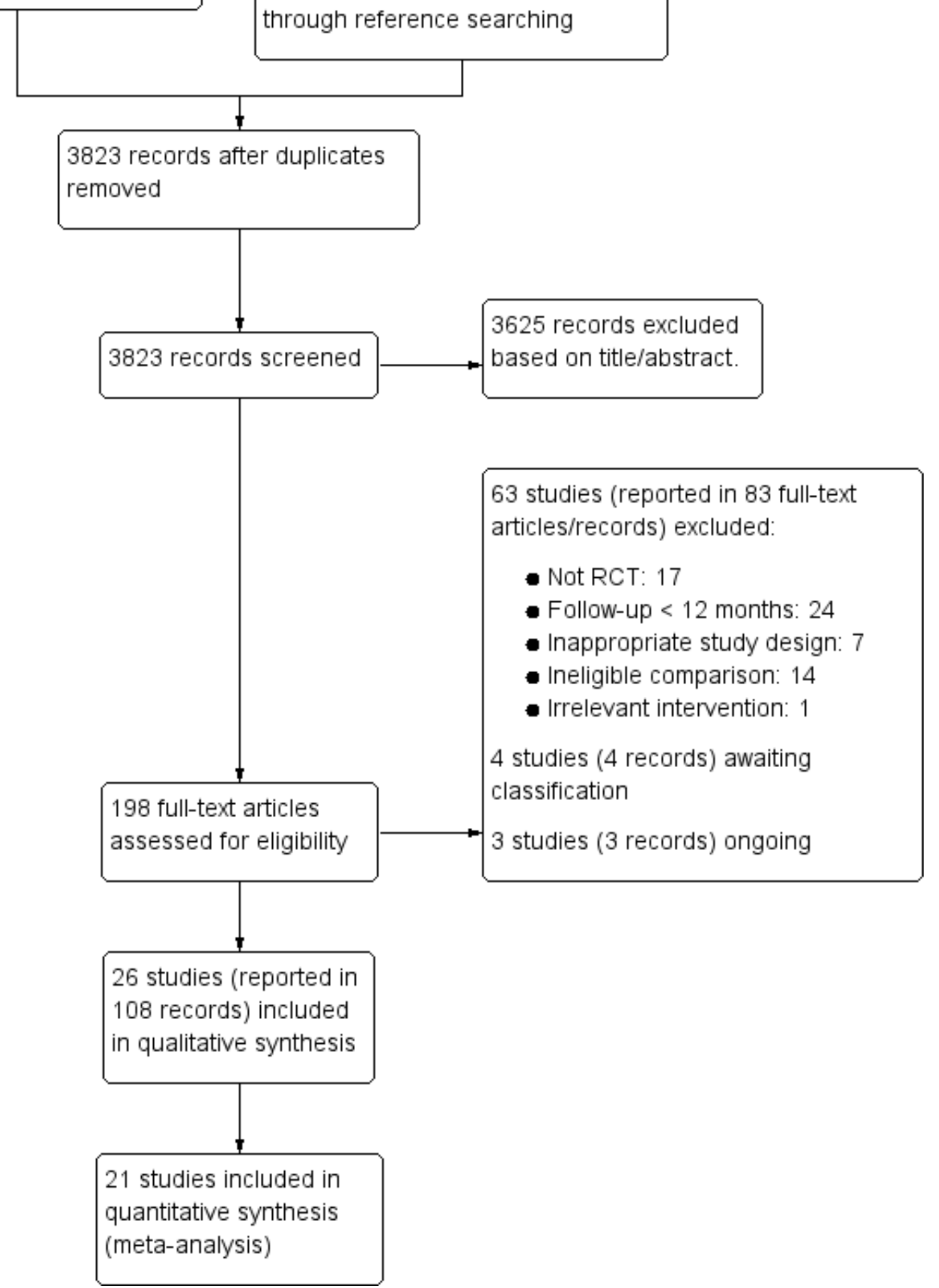


\section{Included studies}

Details of the methods, participants, intervention, comparison and outcome measures for each of the studies are shown in the Characteristics of included studies table and Table 1.

This review includes 26 studies (108 records) involving 23,499 randomised participants that were published from 2004 to 2018. Three of them were international and multi-centre studies (Ballantyne 2004; ENHANCE 2008; IMPROVE-IT 2015). Seven were multi-centre studies conducted in Japan (EFECTL 2017; Hibi 2018; HIJ-PROPER 2017; Okada 2012; PRECISE-IVUS 2015; RESEARCH 2017; Suzuki 2013). Sixteen studies were single-centre studies, and of these, seven were conducted in China (Liu 2017; Luo 2014; Luo 2016; Ren 2017; Wang 2016; Wang 2017; Zou 2016), three were performed in Japan (Katoh 2017; Kinouchi 2013; Sawayama 2011), two were conducted in the USA (Kodali 2011; West 2011), one was conducted in Greece (Kouvelos 2013), one was conducted in Denmark (OCTIVUS 2017), one was performed in Italy (Zinellu 2012), and one was conducted in Mexico (VYCTOR 2009).

The numbers of participants randomised in each study ranged from 18 (Kodali 2011) to 18,144 (IMPROVE-IT 2015).

The duration of follow-up of the included studies ranged from one to six years. Although most studies had a follow-up of one to two years (Ballantyne 2004; EFECTL 2017; ENHANCE 2008; Hibi 2018; Kinouchi 2013; Kodali 2011; Kouvelos 2013; Liu 2017; Luo 2014; Luo 2016; OCTIVUS 2017; Okada 2012; PRECISE-IVUS 2015; Ren 2017; RESEARCH 2017; Sawayama 2011; Suzuki 2013; VYCTOR 2009; Wang 2016; Wang 2017; West 2011; Zinellu 2012; Zou 2016), three studies had a follow-up of more than three years (HIJ-PROPER 2017; IMPROVE-IT 2015; Katoh 2017). The IMPROVE-IT 2015 study, which included 18,144 participants and a median follow-up period of six years, was the largest scale study, and the HIJ-PROPER 2017 study was the second largest scale study, with 1734 cases and a median follow-up period of 3.86 years. The remaining studies were small to moderate (3720 cases, 18 to 720 ) and had a follow-up period of one to two years.

Although most of the included studies had two parallel treatment arms, three studies (EFECTL 2017; VYCTOR 2009; Zinellu 2012) had three intervention arms, but we only included data from two of the three intervention arms related to this review.

\section{Participants}

The studies varied in the types of participants recruited and their levels of cardiovascular disease (CVD) risk. Fourteen studies recruited participants with existing atherosclerotic cardiovascular disease (ASCVD). Specifically, four studies (Hibi 2018; HIJ-PROPER 2017; IMPROVE-IT 2015; Liu 2017) recruited participants with acute coronary syndrome (ACS); six studies (Luo 2016; Okada 2012; PRECISE-IVUS 2015; Wang 2016; Wang 2017; Zou 2016) recruited participants with coronary heart disease; OCTIVUS 2017 recruited participants with ST-segment elevation myocardial infarction (MI); Ren 2017 recruited participants with acute Ml; Katoh 2017 recruited participants with stable angina pectoris; and West 2011 recruited participants with peripheral arterial atherosclerosis (PAD).

Seven studies (Ballantyne 2004; ENHANCE 2008; EFECTL 2017; Kinouchi 2013; Luo 2014; RESEARCH 2017; Sawayama 2011) recruited participants with hypercholesterolaemia; two studies (Suzuki 2013; Zinellu 2012) recruited participants with chronic kidney disease (CKD); Kouvelos 2013 recruited participants undergoing vascular surgery; VYCTOR 2009 recruited participants at high risk of coronary artery disease; and Kodali 2011 recruited participants with maximum carotid stenosis $>50 \%$.

The participants' mean age ranged from 46 years (ENHANCE 2008) to 84 years (Liu 2017). Fifteen studies recruited participants with a mean age in the range of 50 to 65 years (Ballantyne 2004; EFECTL 2017; Hibi 2018; IMPROVE-IT 2015; Kinouchi 2013; Luo 2016; OCTIVUS 2017; Ren 2017; RESEARCH 2017; Suzuki 2013; VYCTOR 2009; Wang 2016; Wang 2017; West 2011; Zinellu 2012), seven studies recruited older participants (mean age of at least 65 years, HIJ-PROPER 2017; Kouvelos 2013; Liu 2017; Luo 2014; Okada 2012; PRECISE-IVUS 2015; Zou 2016), one study recruited younger participants (mean age under 50 years, ENHANCE 2008), and three studies did not specify the age of the participants (Katoh 2017; Kodali 2011; Sawayama 2011).

The participants in 10 studies were mostly male (at least $70 \%$ ) (Hibi 2018; HIJ-PROPER 2017; IMPROVE-IT 2015; Kouvelos 2013; OCTIVUS 2017; Okada 2012; PRECISE-IVUS 2015; Ren 2017; Wang 2016; Zou 2016). Thirteen of the included studies recruited equal numbers of men and women, whereas the other three studies did not state the gender of the participants (Katoh 2017; Kodali 2011; Sawayama 2011).

Two studies only included participants with type 2 diabetes (RESEARCH 2017; Wang 2017), one study excluded participants with diabetes (Zou 2016), four studies did not report data on participants with diabetes (Katoh 2017; Kodali 2011; Sawayama 2011; Zinellu 2012), and the remaining 19 studies included participants with diabetes, and the proportion of these participants ranged from $1.8 \%$ (ENHANCE 2008) to 51.3\% (Okada 2012) of the entire cohort.

A summary of the characteristics of the participants in the included studies is shown in Table 2.

\section{Interventions and comparators}

No study compared ezetimibe alone versus placebo. All the included studies compared ezetimibe plus other lipid-modifying drugs versus other lipid-modifying drugs alone or plus placebo. Only one study (EFECTL 2017) compared ezetimibe plus fenofibrate versus fenofibrate alone. The remaining 25 studies compared ezetimibe plus statins versus statins alone or plus placebo. The dose of ezetimibe in all studies was $10 \mathrm{mg} /$ day.

Eighteen studies used the same initial dose of statin in the intervention group and control group. Among these studies, five compared ezetimibe plus simvastatin versus simvastatin alone (Kodali 2011; West 2011; Zinellu 2012) or simvastatin plus placebo (ENHANCE 2008; IMPROVE-IT 2015); seven compared ezetimibe plus atorvastatin versus atorvastatin alone (PRECISE-IVUS 2015; Luo 2014; Luo 2016; Wang 2017; Zou 2016) or atorvastatin plus placebo (Ballantyne 2004; OCTIVUS 2017); three compared ezetimibe plus rosuvastatin versus rosuvastatin alone (Kouvelos 2013; Ren 2017; Wang 2016); two compared ezetimibe plus pitavastatin versus pitavastatin alone (Hibi 2018; HIJ-PROPER 2017); and one compared ezetimibe plus fluvastatin versus fluvastatin alone (Kinouchi 2013).

Seven studies used the usual dose of statin plus ezetimibe compared with a double-dose of statin. Liu 2017 compared ezetimibe plus atorvastatin versus double-dose atorvastatin; 
VYCTOR 2009 compared ezetimibe plus simvastatin versus doubledose simvastatin; Sawayama 2011 compared ezetimibe plus pitavastatin versus double-dose pitavastatin; and Okada 2012 compared ezetimibe plus atorvastatin or rosuvastatin versus double-dose atorvastatin or rosuvastatin. In addition, RESEARCH 2017 compared ezetimibe plus atorvastatin or pitavastatin versus double-dose atorvastatin or pitavastatin; Suzuki 2013 compared ezetimibe plus statin versus double-dose statin, the choice of statins was at the discretion of the physician; and Katoh 2017 compared ezetimibe plus statin versus incremental dose of statin, but did not report which statin was used.

\section{Outcome}

Five studies specified the composite of cardiovascular events as the primary outcome (HIJ-PROPER 2017; IMPROVE-IT 2015; Kouvelos 2013; Liu 2017; Wang 2016), whereas five studies specified serum lipid parameters as the primary outcome (EFECTL 2017; Okada 2012; Ren 2017; RESEARCH 2017; Zinellu 2012), and three studies specified changes in coronary intravascular ultrasonography outcome as the primary outcome (Hibi 2018; OCTIVUS 2017; PRECISE-IVUS 2015). ENHANCE 2008 and VYCTOR 2009 specified changes in carotid intima-media thickness (cIMT) as the primary outcome and West 2011 specified changes in the superficial femoral artery plaque volume as the primary outcome. Ballantyne 2004 and Suzuki 2013 specified the incidence of adverse events (AEs) as the primary outcome, and Kinouchi 2013 specified changes in kidney function (estimated glomerular filtration rate (eGFR)) as the primary outcome. Four studies (Luo 2014; Luo 2016; Wang 2017; Zou 2016) did not specify the primary outcomes but evaluated the lipid levels, cIMT and adverse reactions. In addition, Luo 2014 and Luo 2016 also reported cardiovascular events.

Three studies (Katoh 2017; Kodali 2011; Sawayama 2011) were only published as conference abstracts. Katoh 2017 reported the coronary plaque volume, serum lipids and cardiovascular events; Sawayama 2011 reported the cIMT and serum lipids; and Kodali 2011 did not report any outcome data of relevance for this review. We attempted to contact the authors for more information regarding study design and outcomes, but no contact could be established.

For the studies that did not report outcomes of interest, we emailed the trialists to establish whether these outcomes were measured but not reported, but only Dr. Mikkel provided additional data (OCTIVUS 2017). No response was received from the other studies (Ballantyne 2004; HIJ-PROPER 2017; Katoh 2017; Kinouchi 2013; Kouvelos 2013; Liu 2017; Luo 2014; Okada 2012; Ren 2017; RESEARCH 2017; Sawayama 2011; Suzuki 2013; VYCTOR 2009; Wang 2017; Zinellu 2012).
Among all the included studies, 10 studies specified Major adverse cardiovascular events (MACE) as an outcome (ENHANCE 2008; Hibi 2018; HIJ-PROPER 2017; IMPROVE-IT 2015; Kouvelos 2013; Liu 2017; Luo 2016; PRECISE-IVUS 2015; Wang 2016; West 2011), but the definition of MACE was not consistent across these studies. In addition, three studies specified all-cause mortality as an outcome (HIJ-PROPER 2017; IMPROVE-IT 2015; PRECISE-IVUS 2015).

\section{Sources of funding}

Five studies were funded by the pharmaceutical industry (Ballantyne 2004; ENHANCE 2008; IMPROVE-IT 2015; Okada 2012; VYCTOR 2009); nine studies were funded by not-for-profit organisations (EFECTL 2017; Hibi 2018; HIJ-PROPER 2017; OCTIVUS 2017; PRECISE-IVUS 2015; RESEARCH 2017; Wang 2016; West 2011; Zinellu 2012); four studies did not receive any funding (Kouvelos 2013; Liu 2017; Suzuki 2013; Wang 2017); and eight studies did not report their funding sources (Katoh 2017; Kinouchi 2013; Kodali 2011; Luo 2014; Luo 2016; Ren 2017; Sawayama 2011; Zou 2016).

\section{Excluded studies}

We excluded 63 studies (83 references) after full-text assessment, and detailed reasons for exclusion are provided in the Characteristics of excluded studies table. The reasons for exclusion included non-randomised controlled trial (non-RCT), follow-up period shorter than 12 months, ineligible comparison, inappropriate study design and irrelevant intervention.

\section{Studies awaiting classification}

We identified four studies that await classification (JPRN-UMIN000002964; JPRN-UMIN000011745; NCT01086020; NCT02588235). Details of these studies are shown in the Characteristics of studies awaiting classification. These studies with an unknown recruitment status are listed on the clinical trial registries, and their completion date was more than two years ago. We contacted the authors of these for more information but did not receive a reply.

\section{Ongoing studies}

We identified three ongoing studies that likely fit our inclusion criteria (NCT03044665; NCT03169985; NCT03543774), and the details of these studies are shown in the table titled "Characteristics of ongoing studies".

\section{Risk of bias in included studies}

The risk of bias of the included studies are detailed in the table titled "Characteristics of included studies".

An overview of the review authors' judgements about each risk of bias item for each individual study and across all studies is provided in Figure 2 and Figure 3. 
Figure 2. 'Risk of bias' graph: review authors' judgements about each risk of bias item presented as percentages across all included studies.

Random sequence generation (selection bias)

Allocation concealment (selection bias)

Blinding of participants and personnel (performance bias)

Blinding of outcome assessment (detection bias)

Incomplete outcome data (attrition bias)

Selective reporting (reporting bias)

Other bias

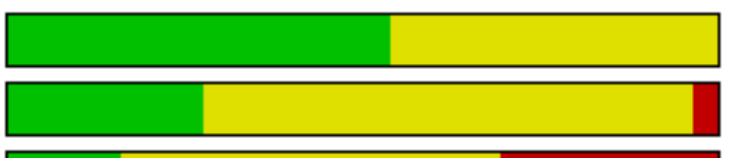

L

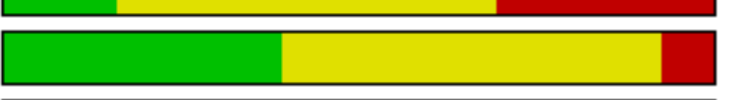

L
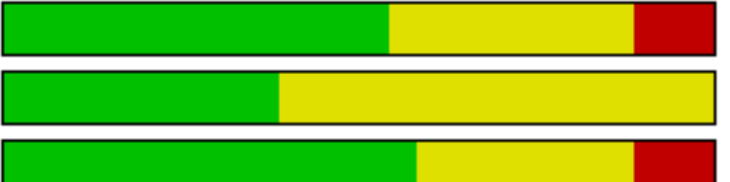

\begin{tabular}{|lllll}
\hline $0 \%$ & & 1 & & 1 \\
& $25 \%$ & $50 \%$ & $75 \%$ & $100 \%$
\end{tabular}

Low risk of bias

Unclear risk of bias

High risk of bias 
Figure 3. 'Risk of bias' summary: review authors' judgements about each risk of bias item for each included study.

\begin{tabular}{|c|c|c|c|c|c|c|c|}
\hline & 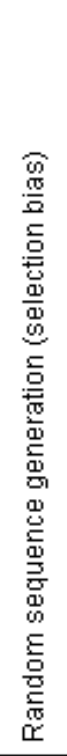 & 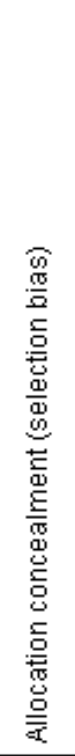 & 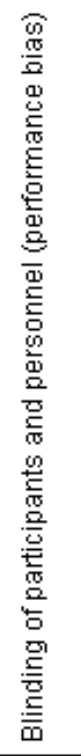 & 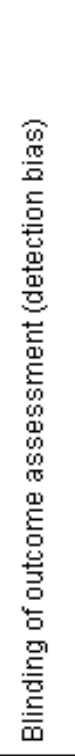 & 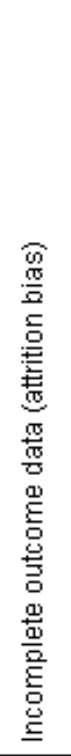 & 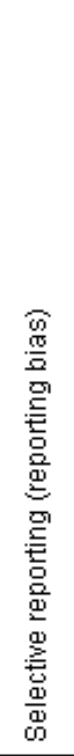 & 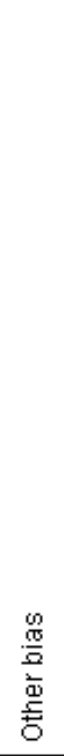 \\
\hline Ballantyne 2004 & $?$ & $?$ & $\odot$ & + & $\odot$ & $?$ & $?$ \\
\hline EFECTL 2017 & $\odot$ & 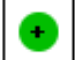 & $\Theta$ & $\odot$ & $?$ & $\odot$ & + \\
\hline ENHANCE 2008 & + & + & $\odot$ & $\odot$ & + & $\odot$ & + \\
\hline Hibi 2018 & $\odot$ & $\odot$ & $\odot$ & + & $\odot$ & $?$ & + \\
\hline HIJ-PROPER 2017 & + & $?$ & $\Theta$ & + & + & $\odot$ & + \\
\hline IMPROVE-IT 2015 & $\odot$ & + & 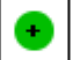 & + & + & $\odot$ & $?$ \\
\hline Katoh 2017 & $?$ & $?$ & $?$ & $?$ & $?$ & $?$ & 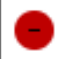 \\
\hline Kinouchi 2013 & $?$ & $\odot$ & $\odot$ & $\odot$ & $\oplus$ & $?$ & $?$ \\
\hline Kodali 2011 & $?$ & $?$ & $?$ & $?$ & $?$ & $?$ & - \\
\hline Kouvelos 2013 & + & $?$ & $\odot$ & $?$ & + & $?$ & + \\
\hline Liu 2017 & $\odot$ & $?$ & $?$ & $?$ & + & $?$ & + \\
\hline Luo 2014 & $?$ & $?$ & $?$ & $?$ & $?$ & $?$ & $?$ \\
\hline Luo 2016 & + & $?$ & $?$ & $?$ & $\odot$ & $?$ & $?$ \\
\hline octIVUS 2017 & + & $\odot$ & 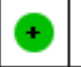 & + & $?$ & $\odot$ & + \\
\hline Okada 2012 & $?$ & $?$ & $?$ & $?$ & $\Theta$ & $?$ & $?$ \\
\hline PRECISE-IVUS 2015 & + & + & 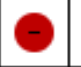 & + & + & + & + \\
\hline Ren 2017 & + & $?$ & $?$ & $?$ & + & $?$ & $?$ \\
\hline RESEARCH 2017 & + & $?$ & $?$ & $?$ & $\odot$ & 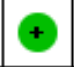 & + \\
\hline Sawayama 2011 & $?$ & $?$ & $?$ & $?$ & $?$ & $?$ & \\
\hline Suzuki 2013 & + & $?$ & $\odot$ & $\odot$ & $?$ & + & + \\
\hline
\end{tabular}


Figure 3. (Continued)

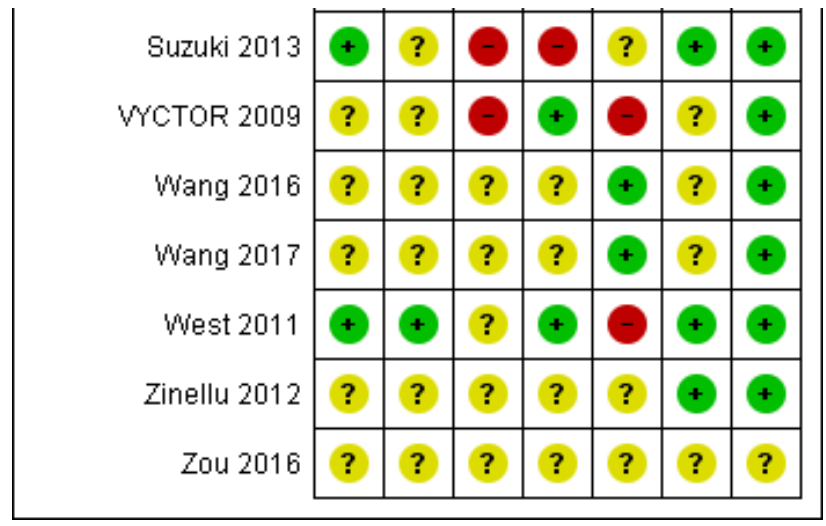

\section{Allocation}

Fourteen studies reported random sequence methods and were rated as low risk of bias (EFECTL 2017; ENHANCE 2008; Hibi 2018; HIJ-PROPER 2017; IMPROVE-IT 2015; Kouvelos 2013; Liu 2017; Luo 2016; OCTIVUS 2017; PRECISE-IVUS 2015; Ren 2017; RESEARCH 2017; Suzuki 2013; West 2011). We assessed 12 studies at unclear risk of bias for this domain because no information was provided in the study reports.

Seven studies used a method for allocation concealment that was judged to be of low risk of bias (EFECTL 2017; ENHANCE 2008; Hibi 2018; IMPROVE-IT 2015; OCTIVUS 2017; PRECISE-IVUS 2015; West 2011). We judge Kinouchi 2013 to be at high risk of bias for this domain because the study reported that allocation concealment was not implemented. We assessed 18 studies to be at unclear risk of bias for this domain because no information was provided in study reports.

\section{Blinding}

We assessed four studies as low risk of bias regarding blinding of participants and personnel (Ballantyne 2004; ENHANCE 2008; IMPROVE-IT 2015; OCTIVUS 2017). Eight studies were based on an open-label designs and were therefore judged to be at high risk of performance bias (EFECTL 2017; Hibi 2018; HIJ-PROPER 2017; Kinouchi 2013; Kouvelos 2013; PRECISE-IVUS 2015; Suzuki 2013; VYCTOR 2009). Two studies (Luo 2016; West 2011) reported double-blind designs but did not use a matching placebo; thus we judged these studies to be at unclear risk of performance bias. The remaining 12 studies were assessed to be at unclear risk of bias because no information was provided.

Detection bias was judged to be at low risk in ten studies (Ballantyne 2004; EFECTL 2017; ENHANCE 2008; Hibi 2018; HIJPROPER 2017; IMPROVE-IT 2015; OCTIVUS 2017; PRECISE-IVUS 2015; VYCTOR 2009; West 2011). Two studies (Kinouchi 2013; Suzuki 2013) were open-label designs and did not describe the blinding of assessors; therefore we judged these to be at high risk of detection bias. The remaining 14 studies did not provide information and were judged to be at unclear risk of detection bias.

\section{Incomplete outcome data}

Attrition bias was judged to be at low risk in 14 studies (Ballantyne 2004; ENHANCE 2008; Hibi 2018; HIJ-PROPER 2017; IMPROVE-IT 2015; Kinouchi 2013; Kouvelos 2013; Liu 2017; Luo 2016; PRECISE-
IVUS 2015; Ren 2017; RESEARCH 2017; Wang 2016; Wang 2017) because the dropout rate was $<20 \%$ and balanced between the trial arms, number of participants that discontinued were reported and reasons were stated, and all outcomes analyses were performed by using a intention-to-treat principle. Three studies were judged to be at high risk of bias for this domain because the dropout rate was over $20 \%$ and did not use appropriate methods to address the missing data (Okada 2012; VYCTOR 2009; West 2011). The remaining nine studies were assessed as unclear risk of bias for attrition bias because no information was provided for judgement.

\section{Selective reporting}

We assessed 10 studies to be at low risk of reporting bias (EFECTL 2017; ENHANCE 2008; HIJ-PROPER 2017; IMPROVE-IT 2015; OCTIVUS 2017; PRECISE-IVUS 2015; RESEARCH 2017; Suzuki 2013; West 2011; Zinellu 2012) because they reported all prespecified outcomes in either published protocols or clinical trial registers before enrolment. We were unable to assess the reporting bias in 16 studies because the information was not available in the form of protocols or clinical trial registry entries.

\section{Other potential sources of bias}

Fifteen studies were judged to be at low risk of other biases (mainly based on providing funding details and declaring any conflict of interest by the authors) (EFECTL 2017; ENHANCE 2008; Hibi 2018; HIJ-PROPER 2017; Kouvelos 2013; Liu 2017; OCTIVUS 2017; PRECISE-IVUS 2015; RESEARCH 2017; Suzuki 2013; VYCTOR 2009; Wang 2016; Wang 2017; West 2011; Zinellu 2012).

We judged three studies (Katoh 2017; Kodali 2011; Sawayama 2011) to be at high risk of other bias because they were only published as conference abstracts, and not publishing complete results might lead to a bias. The remaining eight studies were judged to be at an unclear risk of bias because there was insufficient information to make a judgement.

\section{Effects of interventions}

See: Summary of findings for the main comparison Ezetimibe for the prevention of cardiovascular disease and all-cause mortality events

We included 26 studies that involved a total of 23,499 participants and assessed ezetimibe combined with other lipid-modifying drugs versus other lipid-modifying drugs alone or plus placebo. The 
main outcomes for this comparison are presented in Summary of findings for the main comparison. The findings from this comparison were driven by IMPROVE-IT 2015. Three studies (Kodali 2011; Sawayama 2011; Zinellu 2012) did not contribute any outcome data of interest for this review.

\section{Primary outcome}

\section{Major adverse cardiovascular events (MACEs)}

Twelve studies provided data on MACE (ENHANCE 2008; Hibi 2018; HIJ-PROPER 2017; IMPROVE-IT 2015; Katoh 2017; Kouvelos 2013; Liu 2017; Luo 2016; PRECISE-IVUS 2015; Suzuki 2013; Wang 2016; West 2011), but the definitions of MACE in some studies were not completely consistent with this review. Of these studies, Suzuki 2013 reported that no serious cardiovascular event occurred, and Katoh 2017 reported that three cardiovascular events occurred in the ezetimibe group and seven cardiovascular events occurred in the control group. However, because their definition of cardiovascular events was unclear and we were unable to contact the researchers for further information, we did not include these two studies in the meta-analysis.

We included data from 10 studies in the meta-analysis (ENHANCE 2008; Hibi 2018; HIJ-PROPER 2017; IMPROVE-IT 2015; Kouvelos 2013; Liu 2017; Luo 2016; PRECISE-IVUS 2015; Wang 2016; West 2011). The analysis performed with a fixed-effect model revealed that the ezetimibe group had a lower risk of MACE than the control group (risk ratio (RR) $0.94,95 \%$ confidence interval $(\mathrm{Cl}) 0.90$ to $0.98 ; I^{2}=0 \%$; a decrease from $284 / 1000$ to $267 / 1000,95 \% 256$ to 278; participants $=21,727$; studies $=10$; moderate-quality evidence; Analysis 1.1). It should be noted that the pooled MACE result in our review was likely influenced by IMPROVE-IT 2015 results, which were driven by differences in non-fatal MI, non-fatal stroke and urgent coronary revascularisations.

The funnel plot (Figure 4) did not indicate a strong possibility of publication bias.

Figure 4. Funnel plot of comparison: 1 Ezetimibe plus other lipid-modifying drugs vs other lipid-modifying drugs alone or plus placebo, outcome: 1.1 MACE (subgroup analysis: duration of follow-up).

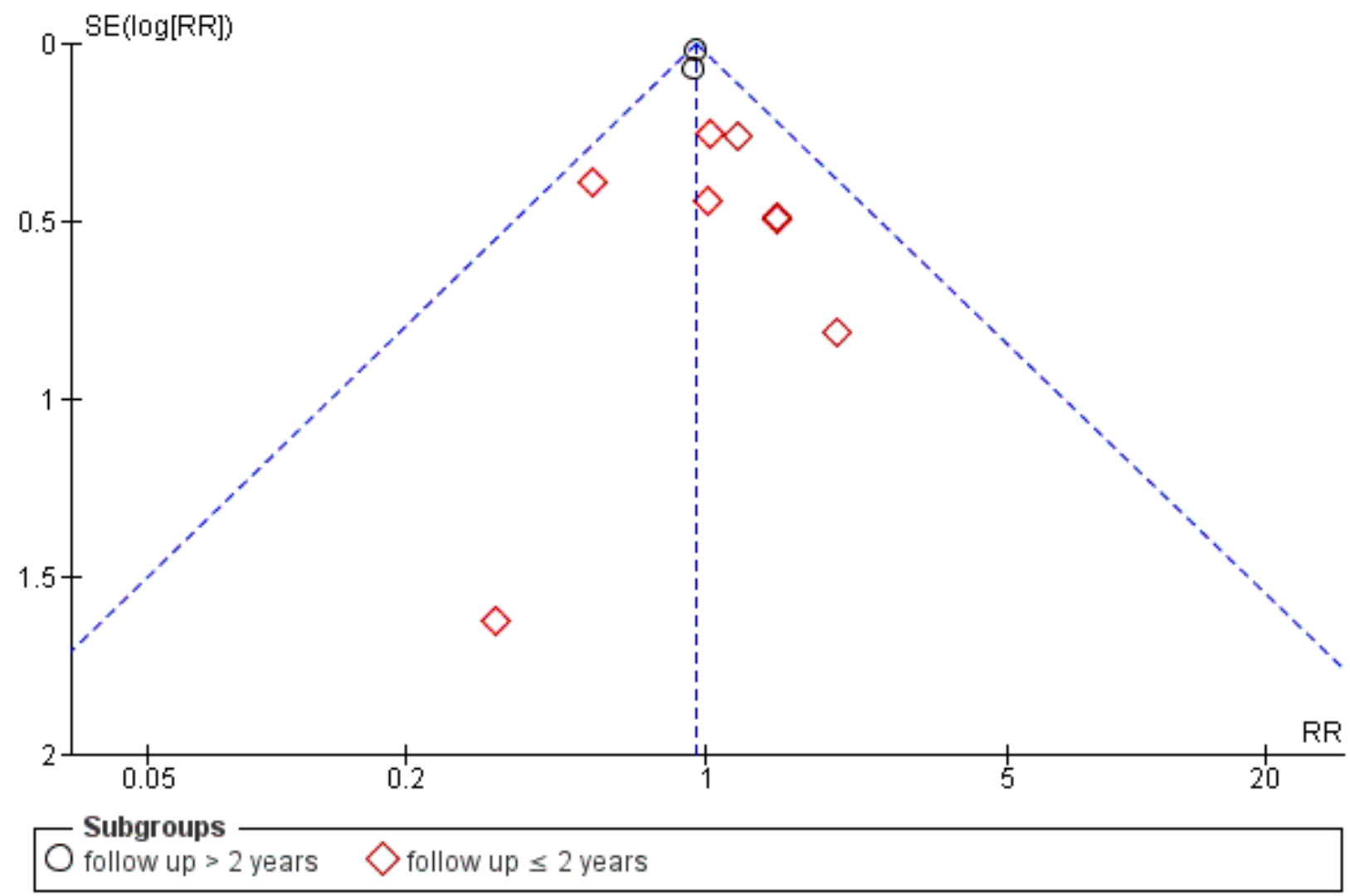

\section{All-cause mortality}

Eleven studies provided data on death from any cause (Ballantyne 2004; EFECTL 2017; ENHANCE 2008; Hibi 2018; HIJ-PROPER 2017; IMPROVE-IT 2015; Kouvelos 2013; Liu 2017; OCTIVUS 2017 ; PRECISE-IVUS 2015; West 2011). Of these, two studies reported that no deaths occurred (Ballantyne 2004; PRECISE-IVUS 2015), and one study (Kouvelos 2013) reported the total deaths but did not provide data by treatment arm.
We included data from eight studies in the meta-analysis (EFECTL 2017; ENHANCE 2008; Hibi 2018; HIJ-PROPER 2017; IMPROVE-IT 2015; Liu 2017; OCTIVUS 2017 West 2011). When the data were pooled with a fixed-effect model, there was little or no difference in the reduction of all-cause mortality between the groups (RR 0.98 , $95 \% \mathrm{Cl} 0.91$ to $1.05 ; \mathrm{I}^{2}=0 \%$; participants $=21,222$; studies $=8$; highquality evidence; Analysis 1.6). 


\section{Secondary outcomes}

\section{Myocardial infarction (MI) (fatal and non-fatal)}

Data on MI were provided in nine studies (ENHANCE 2008; HIJPROPER 2017; IMPROVE-IT 2015; Kouvelos 2013; Liu 2017; Luo 2014; Luo 2016; PRECISE-IVUS 2015; Wang 2016), and two of these reported that no MI events occurred (Luo 2014; Luo 2016). Kouvelos 2013 only provided data on MI that occurred during the follow-up period of 1 to 12 months (no events occurred in the intervention group, three fatal $\mathrm{MI}$ and one nonfatal $\mathrm{MI}$ occurred in the control group) but did not provide data on MI that occurred within 30 days of follow-up.

We included data from six studies that reported non-fatal $\mathrm{MI}$ in the meta-analysis (ENHANCE 2008; HIJ-PROPER 2017; IMPROVEIT 2015; Liu 2017; PRECISE-IVUS 2015; Wang 2016). The analysis performed using a fixed-effect model showed that the ezetimibe group had a lower risk of non-fatal MI than the control group (RR $0.88,95 \% \mathrm{Cl} 0.81$ to $0.95 ; \mathrm{I}^{2}=0 \%$; a decrease from $105 / 1000$ to $92 / 1000,95 \% \mathrm{Cl} 85$ to 100 ; participants $=21,145$; studies $=6$; moderate-quality evidence; Analysis 1.11). PRECISE-IVUS 2015 and Wang 2016 reported that fatal MI events did not occur.

In addition, IMPROVE-IT 2015 with 18,044 participants also provided hazard ratios (HR) on any MI (HR $0.87,95 \% \mathrm{Cl} 0.80$ to 0.95 ) and fatal MI (HR $0.84,95 \% \mathrm{Cl} 0.55$ to 0.1 .27 ).

\section{Stroke (fatal and non-fatal)}

Eight studies provided data on stroke (ENHANCE 2008; HIJPROPER 2017; IMPROVE-IT 2015; Kouvelos 2013; Liu 2017; Luo 2016; PRECISE-IVUS 2015; Wang 2016). Among these, Wang 2016 reported that no events of stroke occurred. Kouvelos 2013 only provided data on ischaemic stroke that occurred during the follow-up period of one to 12 months (one event in each group), but did not provide data on stroke events that occurred within 30 days of follow-up.

We included data from six studies that reported non-fatal stroke in the meta-analysis (ENHANCE 2008; HIJ-PROPER 2017; IMPROVEIT 2015; Liu 2017; Luo 2016; PRECISE-IVUS 2015). When the data were pooled with a fixed-effect model, the ezetimibe group had a lower risk of non-fatal stroke than the control group (RR 0.83, 95\% $\mathrm{Cl} 0.71$ to $0.97 ; \mathrm{I}^{2}=0 \%$; a decrease $32 / 1000$ to $27 / 1000,95 \% \mathrm{Cl} 23$ to 31 ; participants $=21,205$; studies $=6$; moderate-quality evidence; Analysis 1.14). Luo 2016 and PRECISE-IVUS 2015 reported that fatal stroke events did not occur.

In addition, IMPROVE-IT 2015 with 18,044 participants also provided hazard ratios on any stroke (HR $0.86,95 \% \mathrm{Cl} 0.73$ to 1.00$)$, ischaemic stroke (HR $0.79,95 \% \mathrm{Cl} 0.67$ to 0.94 ), hemorrhagic stroke (HR 1.38, 95\% Cl 0.93 to 2.04), and fatal stroke (HR 1.22, 95\% Cl 0.81 to 1.82 ).

\section{Cardiovascular mortality}

Data on death from cardiovascular causes were available in 11 studies (EFECTL 2017; ENHANCE 2008; Hibi 2018; IMPROVE-IT 2015; Kouvelos 2013; Liu 2017; Luo 2014; Luo 2016; OCTIVUS 2017; PRECISE-IVUS 2015; Wang 2016). Four of these reported that no cardiovascular deaths occurred (Luo 2014; Luo 2016; PRECISE-IVUS 2015; Wang 2016), and one study reported total cardiac deaths but did not provide data by treatment arm (Kouvelos 2013).
We included data from six studies in the meta-analysis (EFECTL 2017; ENHANCE 2008; Hibi 2018; IMPROVE-IT 2015; Liu 2017; OCTIVUS 2017). The analysis using a fixed-effect model found little or no difference in the reduction of cardiovascular mortality between the groups (RR $1.00,95 \% \mathrm{Cl} 0.89$ to $1.12 ; \mathrm{I}^{2}=0 \%$; participants $=19,457 ;$ studies $=6 ;$ moderate-quality evidence; Analysis 1.17).

\section{Coronary revascularisation}

Seven studies provided data on coronary revascularisation (ENHANCE 2008; Hibi 2018; HIJ-PROPER 2017; IMPROVE-IT 2015; Liu 2017; Luo 2016; PRECISE-IVUS 2015). When the data were pooled with a fixed-effect model, the rate of coronary revascularisation was slightly lower in the ezetimibe group compared with the control group (RR $0.94,95 \% \mathrm{Cl} 0.89$ to $0.99 ; 1^{2}=0 \%$; a decrease from $196 / 1000$ to $184 / 1000,95 \%$ Cl 175 to 194 ; participants = 21,323; studies $=7$; Analysis 1.20).

However, a sensitivity analysis that included only studies at low overall risk of bias revealed little or no difference in coronary revascularisation rate between the groups ( $\mathrm{RR} 0.94,95 \% \mathrm{Cl} 0.89$ to $1.00 ; I^{2}=0 \%$; participants $=18,864$; studies $=2$; Analysis 1.21 ).

\section{Adverse events (AEs)}

All the included studies except six provided data on AEs. Pooling the total number of AEs in all the studies was not feasible due to heterogeneity of the definition of AEs and because not all of the studies reported the total number of AEs. The individual studies included in this review showed no difference in AEs between the ezetimibe group and the control group. The following specific AEs, including hepatopathy, myopathy, rhabdomyolysis, cancer, gallbladder-related disease and discontinuation due to AEs were analysed:

\section{Hepatopathy (liver injury)}

In this review, hepatopathy was defined as the hepatic transaminase (alanine aminotransferase (ALT) or aspartate aminotransferase (AST), or both) levels exceeded three times the upper limit of normal rang ( $\geq 3 \times$ ULN (upper limit of normal)) in this review.

Sixteen of the included studies evaluated the hepatic enzyme levels during the study periods (Ballantyne 2004; EFECTL 2017; ENHANCE 2008; HIJ-PROPER 2017; IMPROVE-IT 2015; Kinouchi 2013; Kouvelos 2013; Liu 2017; Luo 2014; Luo 2016; PRECISE-IVUS 2015; RESEARCH 2017; Suzuki 2013; Wang 2016; Wang 2017; Zou 2016). Among these, 10 studies reported no occurrence in the levels of ALT or AST, or both values being more than or equal 3 x ULN (Ballantyne 2004; EFECTL 2017; Kinouchi 2013; Kouvelos 2013; Liu 2017; Luo 2014; Luo 2016; RESEARCH 2017; Wang 2017; Zou 2016). Suzuki 2013 reported data on ALT or AST greater than $2 \times$ ULN. PRECISE-IVUS 2015 reported data on abnormal ALT/AST levels, but did not specify the definition of liver enzyme abnormalities.

We included data from four studies in the meta-analysis (ENHANCE 2008; IMPROVE-IT 2015; HIJ-PROPER 2017 Wang 2016). The analysis of pooled data with a fixed-effect model revealed no evidence for a difference in the risk of hepatopathy between the groups (RR 1.14, $95 \% \mathrm{Cl} 0.96$ to $1.35 ; I^{2}=0 \%$; participants $=20,687$; studies $=4$; lowquality evidence; Analysis 1.23). 


\section{Myopathy}

Myopathy was defined as a creatine kinase (CK) level $\geq 10 \times$ ULN with associated muscle symptoms.

Sixteen studies evaluated myopathy and the CK level during the study period (Ballantyne 2004; EFECTL 2017; ENHANCE 2008; HIJPROPER 2017; IMPROVE-IT 2015; Kinouchi 2013; Kouvelos 2013; Liu 2017; Luo 2014; Luo 2016; PRECISE-IVUS 2015; RESEARCH 2017; Suzuki 2013; Wang 2016; Wang 2017; Zou 2016), and 13 of these studies reported that none of the participants in either group developed a CK level $\geq 10$ x ULN (Ballantyne 2004; EFECTL 2017; Kinouchi 2013; Kouvelos 2013; Liu 2017; Luo 2014; Luo 2016; PRECISE-IVUS 2015; RESEARCH 2017; Suzuki 2013; Wang 2016; Wang 2017; Zou 2016).

We included data from three studies in the meta-analysis (ENHANCE 2008; IMPROVE-IT 2015; HIJ-PROPER 2017). When the data were pooled with a fixed-effect model, no evidence of a difference in the risk of myopathy was found between the groups (RR $1.31,95 \% \mathrm{Cl} 0.72$ to $2.38 ; \mathrm{I}^{2}=0 \%$; participants $=20,581$; studies = 3; very low-quality evidence; Analysis 1.25).

\section{Rhabdomyolysis}

Four studies reported data on rhabdomyolysis (Ballantyne 2004; HIJ-PROPER 2017; IMPROVE-IT 2015; Wang 2016), and two of these studies reported no occurrence of rhabdomyolysis events (Ballantyne 2004; Wang 2016). We included data from two studies in the meta-analysis (IMPROVE-IT 2015; HIJ-PROPER 2017), and the analysis of pooled data with a fixed-effect model revealed no evidence for a difference in risk of rhabdomyolysis between the groups (RR $0.79,95 \% \mathrm{Cl} 0.40$ to $1.55 ; \mathrm{I}^{2}=0 \%$; participants = 19,865 ; studies $=2$; Analysis 1.27).

\section{Cancer}

In this review, the term cancer includes any new, relapsing, or progressing cancer. Six of the included studies reported data on cancer rates (HIJ-PROPER 2017; IMPROVE-IT 2015; Kouvelos 2013; Liu 2017; OCTIVUS 2017; RESEARCH 2017), and one of the studies reported three cases of cancer, but did not provide data by treatment arm (OCTIVUS 2017). We included data from five studies in the meta-analysis (HIJ-PROPER 2017; IMPROVE-IT 2015; Kouvelos 2013; Liu 2017; RESEARCH 2017), and when the data were pooled with a fixed-effect model, little or no difference in cancer rates was detected between the groups (RR 1.01, 95\% Cl 0.92 to $1.11 ;\left.\right|^{2}=0 \%$; participants $=20,455$; studies $=5$; Analysis 1.29 ).

\section{Gallbladder-related disease}

Three studies reported data on gallbladder-related disease (IMPROVE-IT 2015; EFECTL 2017; HIJ-PROPER 2017). The analysis performed with a fixed-effect model showed that there seemed to be some weak evidence of a small reduction in gallbladder-related disease between groups (RR $0.88,95 \% \mathrm{Cl} 0.75$ to $1.03 ; \mathrm{I}^{2}=0 \%$; participants $=20,024$; studies $=3$; Analysis 1.32 ).

\section{Discontinuation due to adverse events}

Twelve studies reported data on discontinuation due to AEs (Ballantyne 2004; ENHANCE 2008; HIJ-PROPER 2017; IMPROVE-IT 2015; Kinouchi 2013; Kouvelos 2013; OCTIVUS 2017; PRECISE-IVUS 2015; VYCTOR 2009; Wang 2016; West 2011; Wang 2017), and two of these studies reported no discontinuation due to AEs (Kinouchi 2013; Wang 2017).

We included data from 10 studies in the meta-analysis (Ballantyne 2004; ENHANCE 2008; HIJ-PROPER 2017; IMPROVE-IT 2015; Kouvelos 2013; OCTIVUS 2017; Okada 2012; PRECISE-IVUS 2015; VYCTOR 2009; Wang 2016; West 2011). When the data were pooled with a fixed-effect model, no evidence for a difference in the risk of discontinuation due to AEs between the groups was found (RR $0.91,95 \% \mathrm{Cl} 0.75$ to $1.09 ;\left.\right|^{2}=0 \%$; participants $=21,746$; studies $=10$; Analysis 1.34).

The funnel plot (Figure 5) did not indicate a strong possibility of publication bias. 
Figure 5. Funnel plot of comparison: 1 Ezetimibe plus other lipid-modifying drugs vs other lipid-modifying drugs alone or plus placebo, outcome: 1.34 Discontinuation due to adverse event.

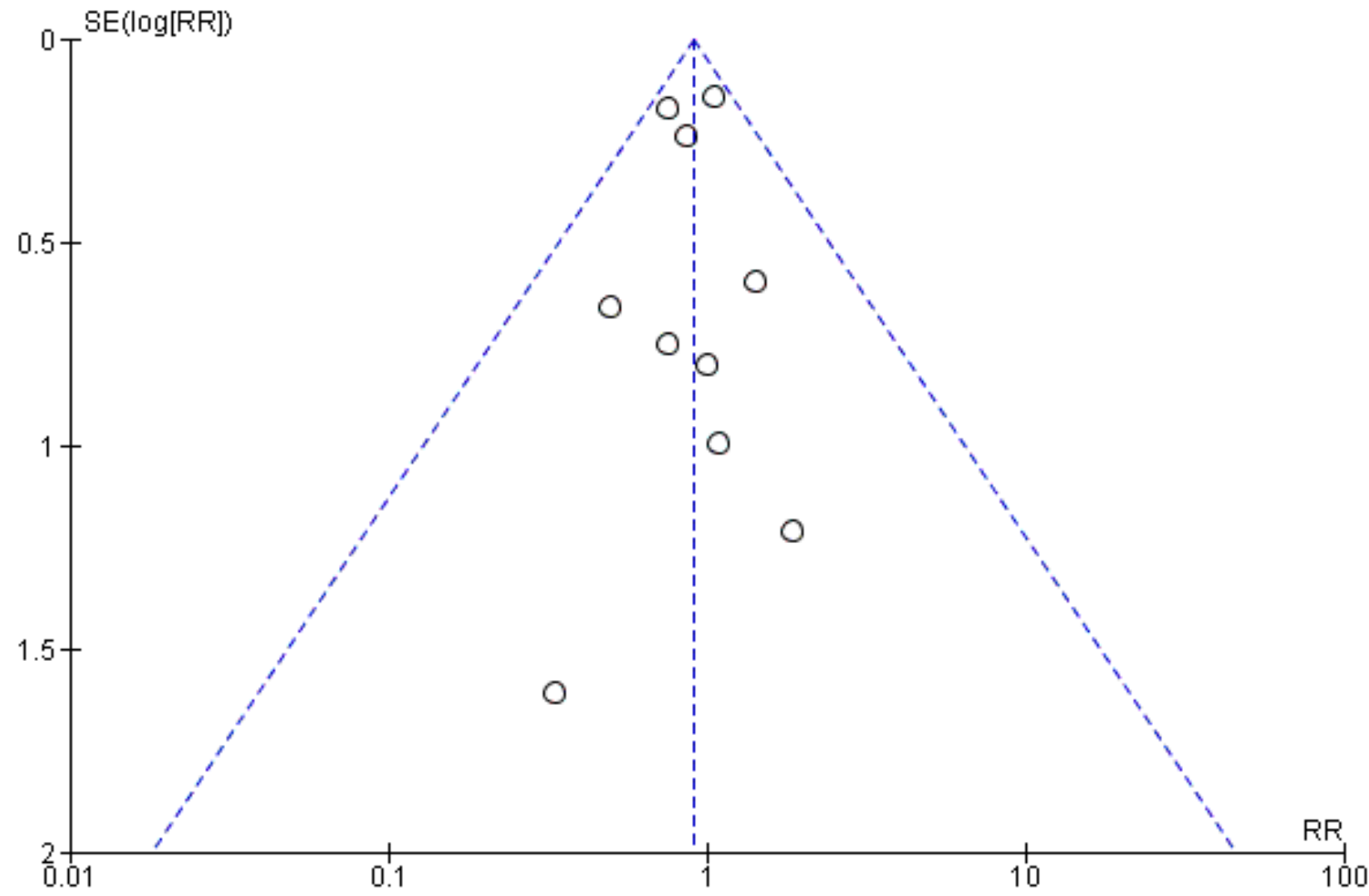

\section{Lipid parameters}

The lipid-related data provided in the included studies are presented in a separate table (Table 3 ).

All the studies except Kodali 2011 measured lipids, and three studies measured lipids but did not provide any useable data that could be included in our meta-analyses (Sawayama 2011; Suzuki 2013; Zinellu 2012). Two studies only provided data on LDL-C (HIJPROPER 2017; Katoh 2017). One study (Ballantyne 2004) provided lipid data; only mean values without standard deviations (SDs) were provided; thus this study could not be included in the metaanalysis. IMPROVE-IT 2015 performed a follow-up for six years, but lipid data were only obtained at baseline and at the one-year follow-up time point, and these data were reported as the means, medians and interquartile ranges (IQRs). Because the median and mean values of the cholesterol were quite close, indicating the data were only slightly skewed, we calculated SDs from IQRs for the meta-analyses.

\section{Low-density lipoprotein cholesterol (LDL-C)}

Twenty-one studies provided data on LDL-C at baseline and during follow-up. Meta-analysis using final follow-up data suggested that the addition of ezetimibe reduced LDL-C level, but the data were heterogeneous (MD - $16.79 \mathrm{mg} / \mathrm{dL}, 95 \% \mathrm{Cl}-17.36$ to -16.23 ; $\mathrm{I}^{2}=84 \%$; participants $=17,854$; studies $=21$; Analysis 1.37$)$. This substantial heterogeneity might be due to differences in the lipid levels at baseline, type of disease, lengths of follow-up, and risk of bias among the various studies. The funnel plot (Figure 6) did not indicate a strong possibility of publication bias. 
Figure 6. Funnel plot of comparison: 1 Ezetimibe plus other lipid-modifying drugs vs other lipid-modifying drugs alone or plus placebo, outcome: 1.37 LDL-C (end of follow up).

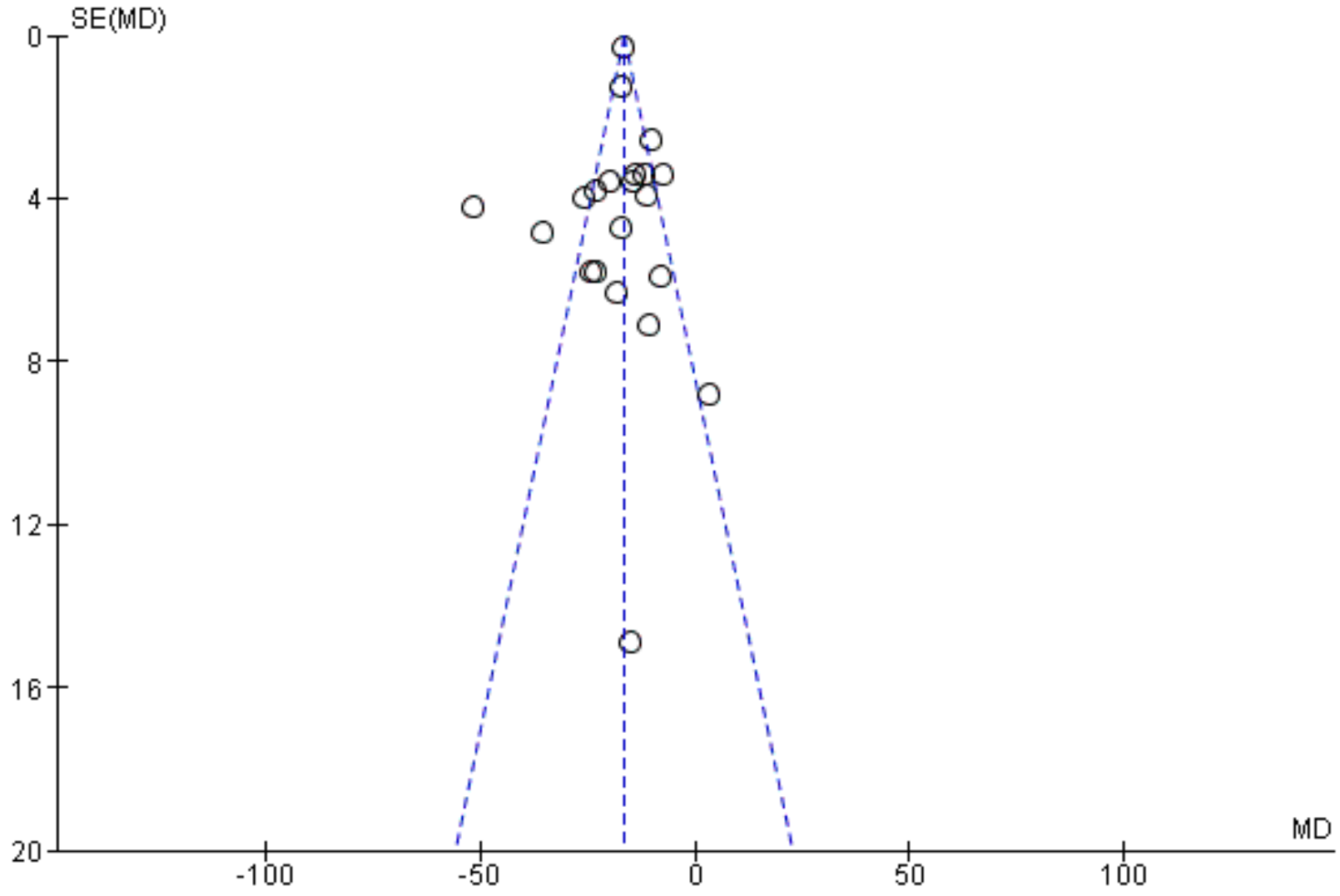

One study (Sawayama 2011) provided LDL-C data without variance information (conference abstracts) and could thus not be included in the meta-analysis. This study also reported that the low-dose pravastatin plus ezetimibe group had significantly decreased LDLC levels compared with the standard-dose pravastatin group.

\section{Total cholesterol (TC)}

Eighteen studies provided data on TC at baseline and followup. A meta-analysis using final follow-up data suggested that the addition of ezetimibe reduced the TC level, but the data were heterogeneous (MD - $19.70 \mathrm{mg} / \mathrm{dL}, 95 \% \mathrm{Cl}-20.48$ to $-18.92 ; \mathrm{I}^{2}=89 \%$; participants $=16,330 ;$ studies $=18$; Analysis 1.40$)$. This substantial heterogeneity might be due to differences in the lipid levels at baseline, type of disease, lengths of follow-up, and risk of bias among the various studies. The funnel plot (Figure 7) did not indicate a strong possibility of publication bias. 
Figure 7. Funnel plot of comparison: 1 Ezetimibe plus other lipid-modifying drugs vs other lipid-modifying drugs alone or plus placebo, outcome: 1.40 TC (end of follow up).

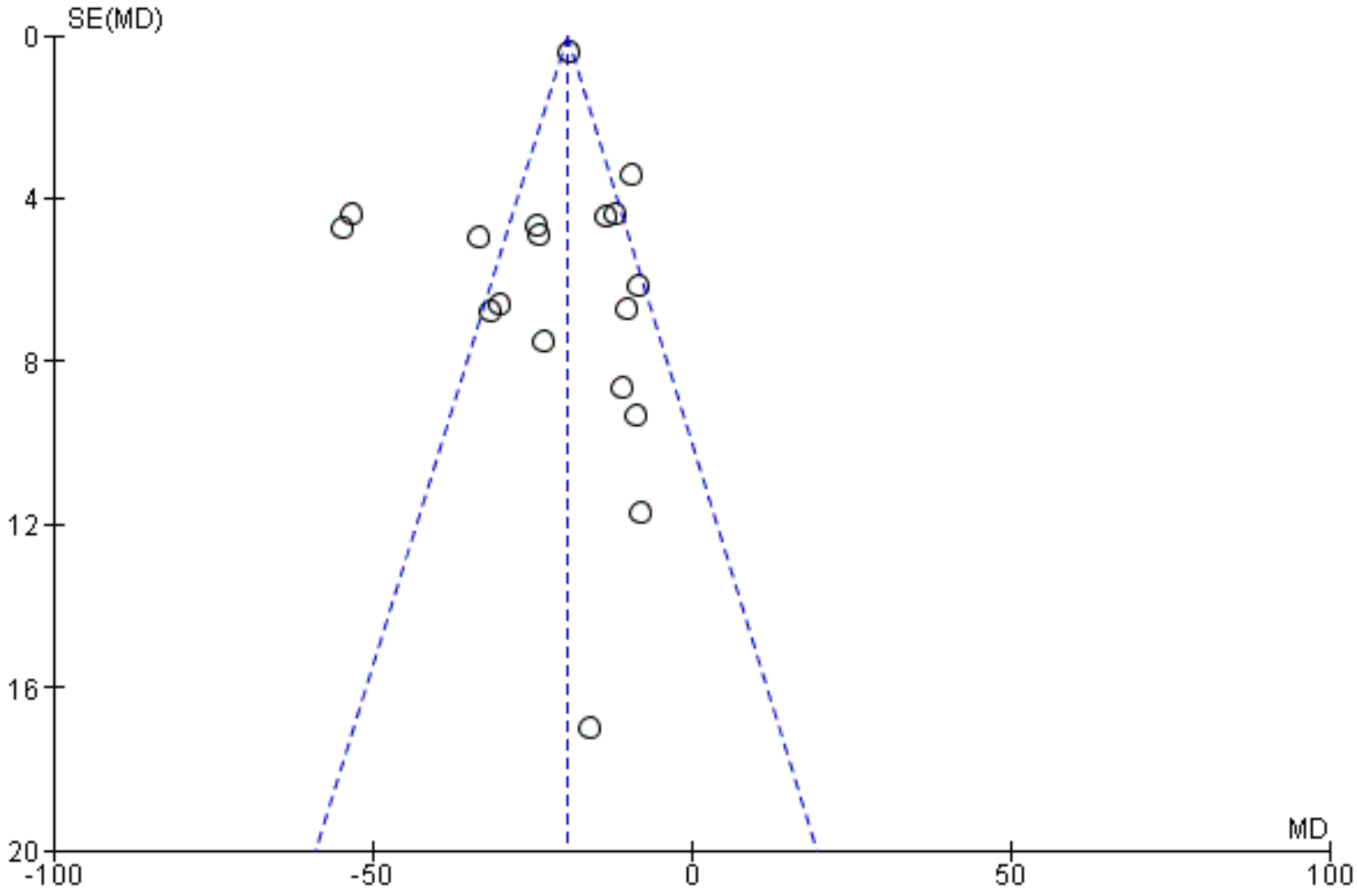

\section{High-density cholesterol (HDL-C)}

Eighteen studies provided data on HDL-C at baseline and followup. A meta-analysis using final follow-up data suggested that the addition of ezetimibe increased the HDL-C level (MD $0.66 \mathrm{mg} / \mathrm{dL}$, $95 \% \mathrm{Cl} 0.30$ to $1.03 ; \mathrm{I}^{2}=0 \%$; participants $=16,434$; studies $=18$; Analysis 1.43). The funnel plot (Figure 8 ) did not indicate a strong possibility of publication bias. 
Figure 8. Funnel plot of comparison: 1 Ezetimibe plus other lipid-modifying drugs vs other lipid-modifying drugs alone or plus placebo, outcome: 1.43 HDL-C (end of follow up).

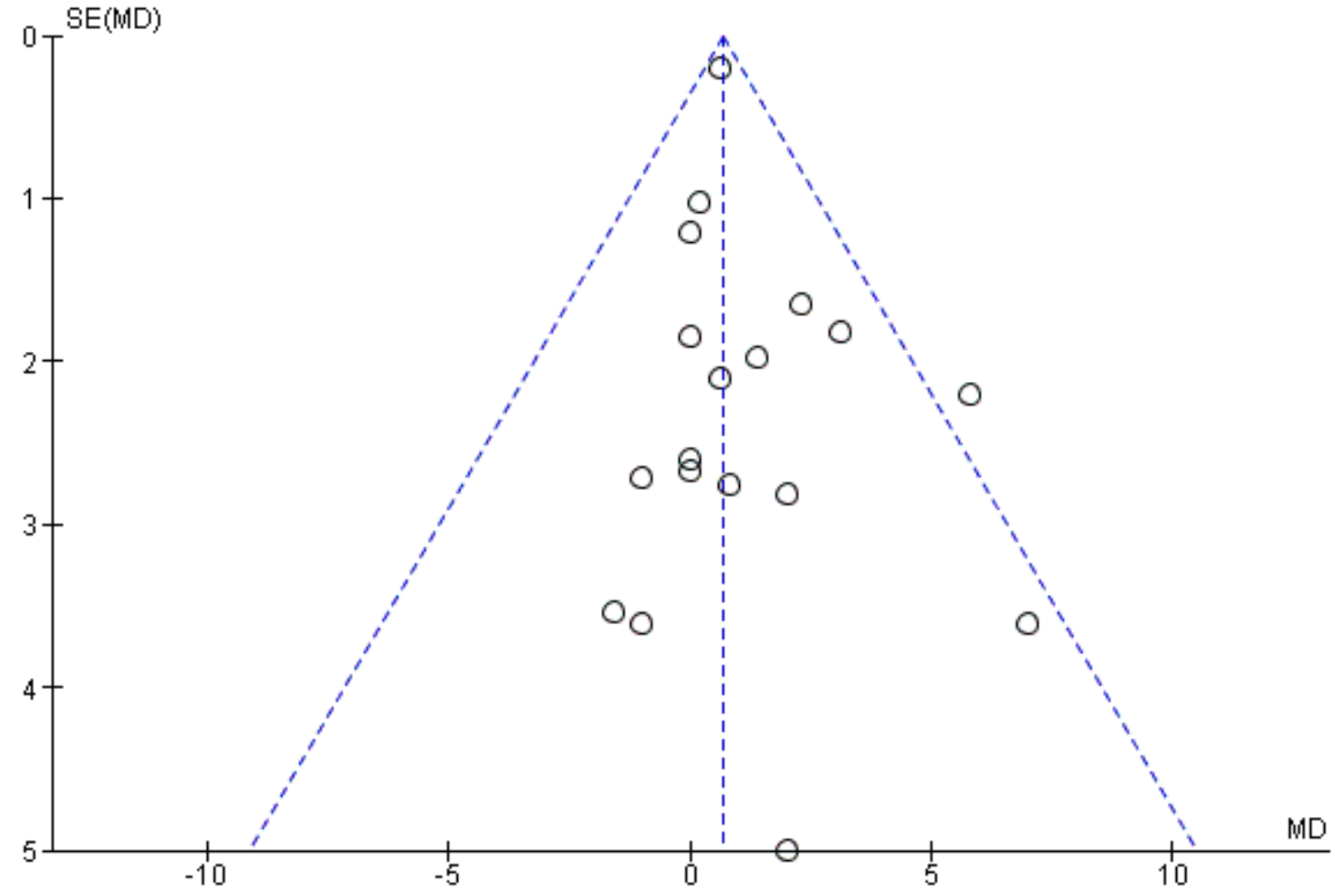

\section{Triglycerides (TG)}

Twelve studies provided data on TG at baseline and followup. A meta-analysis using final follow-up data suggested that supplementation with ezetimibe resulted in a reduced TG level, but the data were heterogeneous (MD $-27.58,95 \% \mathrm{Cl}-33.67$ to -21.49 ;
$1^{2}=74 \% ;$ participants = 1253; studies = 12; Analysis 1.46). This substantial heterogeneity might be due to differences in the lipid levels at baseline, type of disease, lengths of follow-up, and risk of bias among the various studies.The funnel plot (Figure 9) did not indicate a strong possibility of publication bias. 
Figure 9. Funnel plot of comparison: 1 Ezetimibe plus other lipid-modifying drugs vs other lipid-modifying drugs alone or plus placebo, outcome: 1.46 TG (end of follow up).

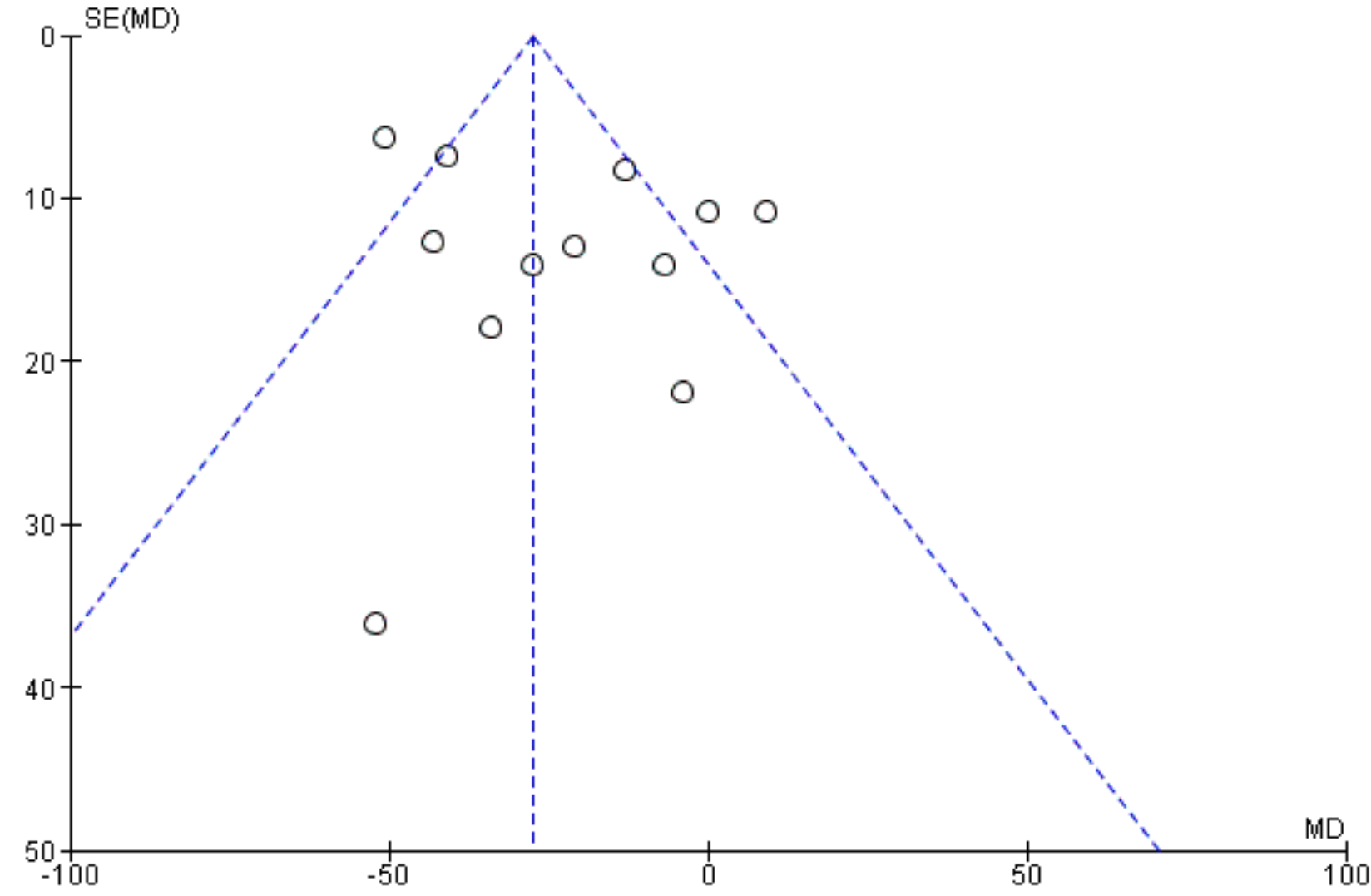

Two studies (Ballantyne 2004; Kouvelos 2013) provided only mean values without SDs. Five studies (ENHANCE 2008; Kinouchi 2013; IMPROVE-IT 2015; Okada 2012; PRECISE-IVUS 2015) provided the results as medians and IQRs, and among these, IMPROVE-IT 2015 provided mean and median values, but the data were strongly skewed $($ mean $=137.6$, median $=120.0)$. The other four studies did not provide the mean values, and a result, it is not possible to compare these data with the medians. Therefore, we removed these studies from the meta-analyses, and present them in Table 3.

\section{Health-related quality of life}

None of the included studies reported information about quality of life.

\section{Subgroup analysis}

We were unable to perform a subgroup analysis by age, sex, statin experience and diabetes at baseline for primary outcomes due to data being unavailable and differences in outcome reporting. However, IMPROVE-IT 2015 performed subgroup analysis of primary composite endpoints (cardiovascular death, nonfatal $\mathrm{MI}$, documented unstable angina requiring admission to the hospital, coronary revascularisation with percutaneous coronary intervention $(\mathrm{PCl})$ or : coronary artery bypass grafting (CABG) at least 30 days after randomisation, and non-fatal stroke) by age, sex, statin experience and diabetes at baseline, and these results are reported in a narrative form.

\section{Age}

The subgroup analysis performed in the IMPROVE-IT 2015 study stratified by different ages showed that older patients tended to have better outcomes ( $<65$ versus $\geq 65$ years). Patients who were $\geq 65$ years had a hazard ratio $(\mathrm{HR})=0.89(95 \% \mathrm{Cl} 0.82$ to 0.96$)$, whereas patients $<65$ years had an $\mathrm{HR}=0.98$ ( $95 \% \mathrm{Cl} 0.90$ to 1.05$)$ (interaction $\mathrm{P}=0.098$ ). An analysis of other age groups (age $<75$ years versus $\geq 75$ years) showed that patients who were $\geq 75$ years had a lower HR estimate for the primary composite endpoint $(0.80$ $(95 \% \mathrm{Cl} 0.70$ to 0.90$))$ than patients who were $<75$ years of age $(0.97$ (95\% $\mathrm{Cl} 0.92$ to 1.03 ), interaction $\mathrm{P}=0.005$ ).

\section{Sex}

The IMPROVE-IT 2015 subgroup analyses of different sexes found no sex-related difference in the HR ratio for the primary composite endpoint. The HR for men was 0.95 (95\% $\mathrm{Cl} 0.90$ to 1.01$)$, and that for women was 0.89 ( $95 \% \mathrm{Cl} 0.79$ to 0.99$)$. No evidence of an interaction between sex and outcome was found $(P=0.267)$.

\section{Statin treatment versus no statin treatment prior to trial participation}

The subgroup analyses performed in the IMPROVE-IT 2015 study to investigate statin treatment prior to trial participation found no difference in the HR for the primary composite endpoint based on statin experience. People who had previously received statin treatment had an $\mathrm{HR}$ of 0.91 ( $95 \% \mathrm{Cl} 0.84$ to 0.99$)$, and those who had not been previously administered a statin treatment had an HR 
of 0.95 ( $95 \% \mathrm{Cl} 0.89$ to 1.02$)$. The findings revealed no evidence of an interaction between administration of a previous statin treatment and outcome $(P=0.414)$.

\section{Diabetes at baseline}

In the IMPROVE-IT 2015 subgroup analyses of diabetes at baseline, patients with diabetes had an $\mathrm{HR}=0.86(95 \% \mathrm{Cl} 0.78$ to 0.94$)$ with an interaction $\mathrm{P}=0.023$. Among the $73 \%$ of trial participants who were non-diabetic at baseline, the HR was $0.98(95 \% \mathrm{Cl} 0.92$ to 1.04$)$.

\section{Duration of follow-up}

We performed a subgroup analysis of the follow-up duration to assess the short-term ( $\leq 2$ years) and long-term ( $>2$ years) effects on primary outcomes.

The subgroup analyses showed no difference in MACE between the long-term studies (> 2 years: RR $0.94,95 \% \mathrm{Cl} 0.90$ to $0.98, \mathrm{I}^{2}=0 \%$; participants $=19,865$; studies $=2$ ) and short-term studies $(\leq 2$ years: RR $1.03,95 \% \mathrm{Cl} 0.79$ to $1.35, \mathrm{I}^{2}=0 \%$; participants $=1862$; studies $=$ 8) (test for subgroup differences $(P=0.50)$, Analysis 1.1 ).

The subgroup analyses also revealed no difference in all-cause mortality between the long-term studies ( $>2$ years: RR 0.97, 95\% $\mathrm{Cl} 0.91$ to $1.05, \mathrm{I}^{2}=68 \%$; participants $=19,865$; studies $\left.=2\right)$ and short-term studies ( $\leq 2$ years: RR $1.35,95 \% \mathrm{Cl} 0.61$ to $3.00, \mathrm{I}^{2}=0 \%$; participants $=1357$; studies $=6)$ (test for subgroup differences $(P=$ 0.43), Analysis 1.6).

\section{Participants with versus without existing atherosclerotic cardiovascular disease (ASCVD)}

Of the studies included in the primary outcome analysis, eight included participants with ASCVD (Hibi 2018; HIJ-PROPER 2017; IMPROVE-IT 2015; Liu 2017; Luo 2016; PRECISE-IVUS 2015; Wang 2016; West 2011), and two studies (EFECTL 2017; ENHANCE 2008) included participants with combined hyperlipidaemia and familial hyperlipidaemia, respectively, who had a lower proportion of cardiovascular disease $(5.03 \%$ and $5.6 \%$, respectively). The latter two studies were thus classified as studies that included participants without ASCVD. In another study (Kouvelos 2013), $49.2 \%$ of the participants had coronary heart disease; therefore, this study could not be classified as either a study with ASCVD or a study with participants without ASCVD and was excluded from this subgroup analysis.

The subgroup analysis revealed no evidence of a difference in MACE between the participants with ASCVD (RR $0.94,95 \% \mathrm{Cl} 0.90$ to $0.98 ; I^{2}=0 \%$; participants $=20,745$; studies $=8$ ) and participants without ASCVD (RR 1.45, 95\% Cl 0.56 to 3.77; participants = 720; studies $=1$ ) (test for subgroup differences $(P=0.37)$, Analysis 1.2). The confidence interval was very wide, and a comparatively fewer number of individuals were included in the subgroup of participants without ASCVD.

The subgroup analysis showed no evidence of a different in allcause mortality between the participants with ASCVD (RR 0.98, 95\% Cl 0.91 to $1.05 ; I^{2}=6 \%$; participants = 20,343; studies = 6) and participants without ASCVD (RR 0.78, 95\% Cl 0.16 to $3.89 ; 1^{2}=35 \%$; participants $=879$; studies $=2)$ (test for subgroup difference $(P=$ 0.78 ) Analysis 1.7). The confidence interval was very wide, and a comparatively fewer people in the subgroup of participants without ASCVD.

\section{Sensitivity analysis \\ Inclusion of only studies at a low risk of bias}

We performed a sensitivity analysis by only including studies assessed at low risk of bias. None of the estimates for most outcomes were significantly changed, except for coronary revascularisation, for which no difference between the groups was observed (Analysis 1.3; Analysis 1.8; Analysis 1.12; Analysis 1.15; Analysis 1.18; Analysis 1.21; Analysis 1.24; Analysis 1.26; Analysis 1.28; Analysis 1.30; Analysis 1.33; Analysis 1.35).

\section{Use of different statistical models (fixed-effect models and random-effects models)}

Another meta-analyses using a random-effects model showed that the results of the primary outcomes were consistent with the results obtained using a fixed-effect model (Analysis 1.4; Analysis 1.9).

\section{Excluding studies with serious missing data}

We explored the impact of including studies with missing data in the overall assessment of results through a sensitivity analysis. Five studies (EFECTL 2017; HIJ-PROPER 2017; Okada 2012; VYCTOR 2009; West 2011) had a proportion of missing data more than $20 \%$ for lipid outcomes and did not use appropriate methods to address the missing data, which were considered to introduce serious bias. The sensitivity analysis performed without these studies suggested little change in the overall results (Analysis 1.39; Analysis 1.42; Analysis 1.45; Analysis 1.48).

\section{Excluding studies compared ezetimibe plus statins versus double-dose statins alone}

We performed a sensitivity analysis by excluding studies that compared ezetimibe plus statins versus double-dose statins alone (Katoh 2017; Liu 2017; Okada 2012; RESEARCH 2017; Sawayama 2011; Suzuki 2013; VYCTOR 2009). The sensitivity analysis performed without these studies suggested little change in the overall results (Analysis 1.5; Analysis 1.10; Analysis 1.13; Analysis 1.16; Analysis 1.19; Analysis 1.22; Analysis 1.31; Analysis 1.36; Analysis 1.38; Analysis 1.41; Analysis 1.44; Analysis 1.47).

\section{DISCUSSION}

\section{Summary of main results}

This review included 26 RCTs with 23,499 randomised participants. We identified three ongoing trials with treatment arms that included the interventions assessed in this review. A further four studies await assessment.

All the included studies assessed the effects of ezetimibe plus other lipid-modifying drugs compared with other lipid-modifying drugs alone or plus placebo. Among the included studies, 25 compared ezetimibe plus statin versus statin alone or plus placebo, and the other compared ezetimibe plus fenofibrate versus fenofibrate alone. Our findings from this comparison were driven by the largest study (IMPROVE-IT 2015), whose weights ranged from $41.5 \%$ to $98.4 \%$ in the different meta-analyses performed in this review.

We found that the addition of ezetimibe to statin therapy probably reduces the risk of major adverse cardiovascular events (MACE) compared with statins alone. Studies reporting all-cause mortality used ezetimibe with statin or fenofibrate and found they have little or no effect on this outcome. Adding ezetimibe to statins 
probably reduces the risk of non-fatal myocardial infarction (MI) and non-fatal stroke. Studies reporting cardiovascular mortality added ezetimibe to statin or fenofibrate, probably having little or no effect on this outcome. The need for coronary revascularisation might be reduced by adding ezetimibe to statin; however, no difference in coronary revascularisation rate was observed when a sensitivity analysis was limited to studies with a low risk of bias.

In terms of safety, adding ezetimibe to statins may have little or no difference in the risk of hepatopathy. It is uncertain whether ezetimibe increases or decreases the risk of myopathy and rhabdomyolysis, given the wide confidence intervals and low event rate. Little or no difference in the risk of cancer, gallbladderrelated disease and discontinuation due to adverse events (AEs) were observed between treatment groups. However, the quality of the evidence for hepatopathy and myopathy was low and very low, respectively, due to imprecision and risk of bias. The analysis of serum lipids revealed that the addition of ezetimibe to statin or fenofibrate might further reduce: low-density lipoprotein cholesterol (LDL-C), total cholesterol (TC) and triglyceride (TG) levels and likely increase high-density lipoprotein cholesterol (HDL-C) levels; however, most analyses included substantial heterogeneity.

None of the included studies reported on health-related quality of life.

\section{Overall completeness and applicability of evidence}

This review provides a comprehensive appraisal of the evidence, but the applicability of the results has some limitations. First, the data in this review were obtained from studies of ezetimibe combined with statins or fenofibrate. The effects of ezetimibe monotherapy in preventing cardiovascular disease (CVD) and allcause mortality remain uncertain.

Second, most participants in the included studies were diagnosed with atherosclerotic cardiovascular disease (ASCVD), predominantly with acute coronary syndrome (ACS) (more than $90 \%$ ). Although a subgroup analysis showed that no difference in primary outcomes between individuals with and individuals without established ASCVD, the confidence interval was very wide and comparatively fewer individuals were included in the subgroup without ASCVD. Therefore, caution should be taken when extrapolating the results of this review to individuals without ASCVD, and the evidence regarding the use of ezetimibe for primary prevention remains uncertain.

Third, it should be noted that in patients with ACS, the efficacy of lipid-lowering drugs on CVD outcomes might be lower and confounded by underlying shifts in lipid levels due to the resolution of acute-phase changes at least in the initial three to six months. A persistent finding of statin meta-analyses (CTT 2012) is that secondary prevention populations tend to show a slower time from drug administration to benefit (curve separation) than primary prevention populations, indicating that it takes three years for the full effects to be revealed. In this review, only three included studies were followed up for more than three years, and the remaining studies included a follow-up duration of only one or two years. The follow-up duration might be insufficient for the observation of the full effects of the treatment. The IMPROVE-IT results showed that the benefit with ezetimibe began to emerge after one year of treatment, and continued over the ensuing years of the trial.
This information suggests that its benefits are not associated with events immediately surrounding the acute ACS event, but rather its benefits are associated with reducing the atherosclerotic burden and the risk of events over the chronic phase of ischaemic heart disease. Thus the results have relevance when considering treatment for chronic coronary heart disease.

Finally, our results for cardiovascular outcomes originated from the studies of ezetimibe in combination with statins; thus the cardiovascular benefit might not be applied to ezetimibe combined with fenofibrate due to a lack of evidence.

\section{Quality of the evidence}

We used GRADE to assess the quality of the evidence for the outcomes of MACE, all-cause mortality, MI, stroke, cardiovascular mortality, hepatopathy and myopathy. See Summary of findings for the main comparison.

The quality of the evidence for all-cause mortality was judged to be high, and that for cardiovascular mortality was judged to be moderate due to imprecision (the $95 \% \mathrm{Cl}$ includes both plausible harm and benefit). We judged the quality of the evidence for MACE, MI and stroke as moderate, mainly due to potential bias (as discussed in detail below). For AEs (hepatopathy and myopathy), we rated the quality of evidence as low for hepatopathy and very low for myopathy when considering the risk of bias together with imprecision (95\% $\mathrm{Cl}$ includes plausible harm and benefit).

Our evidence was mainly driven by one large study (IMPROVE-IT) that had weighs of more than $88 \%$ in the different meta-analyses for clinical outcomes. This international, multi-centre study was rated as low risk of bias. Although we included some studies that were judged to have unclear risk of bias or high risk of performance bias, they were unlikely to affect the results because the sample size of these studies was generally small. Moreover, the results were robust, as demonstrated in a sensitivity analysis that included only those studies with low risk of bias.

However, we should carefully consider several caveats. First, after a median of six years, $42 \%$ of the IMPROVE-IT study participants prematurely stopped taking their study medications, but all the participants, including those who discontinued from treatment, were monitored for suspected clinical endpoint events and AEs until the termination of the trial. At the end of the study, the vital status was obtained in $96 \%$ of all randomised participants, whereas approximately $11 \%$ of participants discontinued their follow-up for the primary cardiovascular endpoint (MACE) prior to the closeout period. Therefore, we did not downgrade mortality outcomes due to risk of bias, but we cannot ignore the potential impact of medication compliance or missing data on other outcomes.

Second, it should be noted that the MACE outcome is a composite cardiovascular endpoint that contains five components in our review. Some studies that were included in the meta-analysis have different definitions of MACE, which mainly did not include hospitalisation for unstable angina or coronary revascularisation (and did not provide data on these components). However, three studies, including the IMPROVE-IT study, provided data for all components of MACE that were defined in this review and played a dominant role in the pooled results.

Third, we also noted that coronary revascularisation contributed to a large proportion of MACE. This endpoint was investigator- 
determined and based on many factors including LDL cholesterol levels, which could be biased and unblinded. From another perspective, the meta-analysis for coronary revascularisation showed that ezetimibe had a marginal effect compared with the control treatment, whereas a sensitivity analysis that only included studies with a low risk of bias showed no difference between treatment groups. Therefore, we are not sure whether the pooled result for MACE was influenced by the differences in coronary revascularisation between the two groups. However, the significance of the pooled MACE result was likely influenced by the IMPROVE-IT results, which were driven by differences in non-fatal $\mathrm{MI}$, non-fatal stroke and urgent coronary revascularisations.

Based on the above discussion, we downgraded the quality of the evidence for all the cardiovascular endpoints and AEs due to these potential biases.

We judged imprecision by whether the $95 \% \mathrm{Cl}$ included the null, and whether it included important benefits and harms. Where the confidence interval of the overall effect included both no effect and potential benefit, we downgraded the evidence. Thus, we downgraded the evidence for cardiovascular mortality, hepatopathy and myopathy due to imprecision.

We did not downgrade the quality of the evidence for any outcome due to inconsistency or indirectness. Although all the studies mainly included men (the IMPROVE-IT study carried much of the weight in the meta-analysis and did not have any interaction between gender and primary outcome), we did not downgrade the outcomes for indirectness.

We judged publication bias according to whether there was any suggestion of publication or small-study bias in the funnel plot. The funnel plots did not indicate any strong possibilities of publication bias (Figure 4 - Figure 9).

\section{Potential biases in the review process}

We performed a comprehensive search of major databases and clinical trial registry platforms. We also checked the reference lists of all primary studies and review articles for additional references. In addition, we used unpublished data of IMPROVE-IT study from licensing applications that were submitted to the Food and Drug Administration (FDA). However, we might have missed clinical trials that have not been reported or are unregistered.

When information on relevant outcomes was not reported, we attempted to contact the authors of the study, but only a limited number of responses was received.

We only included studies with the follow-up period of at least 12 months because long-term trials might yield sufficient and reliable results of long-term effects on mortality and cardiovascular morbidity. However, we excluded most studies due to their shortterm interventions, which limited the number of studies eligible for inclusion.

\section{Agreements and disagreements with other studies or reviews}

We identified five published reviews relevant to our review. Two reviews (Battaggia 2015; Savarese 2015) both compared ezetimibe plus other lipid-modifying drugs versus placebo or the same other lipid-modifying drugs alone. One review (Thomopoulos
2015) compared ezetimibe/simvastatin with placebo or simvastatin alone. These three reviews all included the comparison of ezetimibe plus statins versus placebo alone, but we did not include this comparison because it only assessed the effect of the combination rather the ezetimibe. Thus, extrapolating the efficacy of ezetimibe from this comparison is questionable.

Two other reviews (Fei 2018; Nusßaumer 2016) compared ezetimibe-statin combination therapy with statin monotherapy. However, our review assessed the a combination therapy of ezetimibe with other lipid-lowering drugs (not limited to statins), but we only identified studies that investigated ezetimibe in combination with statins or fenofibrate.

All these reviews included studies with a follow-up period of more than six months, whereas our review included studies with a follow-up period of at least 12 months. We considered studies with long follow-up periods may provide sufficient and reliable intervention effects on mortality and cardiovascular morbidity. Although longer follow-up periods are needed, most of the studies included in the above-mentioned reviews were included in our review. Furthermore, our review included more recent clinical trials.

The results of Battagia's review suggested that ezetimibe does not offer benefit for all all-cause mortality, cardiovascular mortality, $\mathrm{MI}$ and stroke. However, this review was published earlier and did not include the IMPROVE-IT study. The other four reviews and our review included the IMPROVE-IT study, and our results were largely consistent with these reviews, showing that ezetimibe moderately reduced the risk of $\mathrm{MI}$ and stroke.

To date, the IMPROVE trial is the largest clinical trial of ezetimibe, and thus, this study plays a leading role in our results. Although our review included more recent studies than the previous reviews, these additional studies were small and did not significantly change the overall effect estimates.

Overall, our review was more comprehensive than previous reviews because we included more studies, assessed more outcomes, used unpublished data that were submitted to regulatory bodies (FDA), and performed subgroup analyses and sensitivity analyses.

\section{AUTHORS' CONCLUSIONS}

\section{Implications for practice}

Moderate- to high-quality evidence suggests that ezetimibe has modest beneficial effects on the risk of cardiovascular disease (CVD) endpoints, primarily driven by a reduction in non-fatal myocardial infarction (MI) and non-fatal stroke, but it has little or no effect on clinical fatal endpoints (all-cause mortality and cardiovascular mortality). The cardiovascular benefit of ezetimibe might involve reductions in low-density lipoprotein cholesterol (LDL-C), total cholesterol (TC) and triglyceride (TG). There is insufficient evidence to determine whether ezetimibe increases the risk of adverse events (AEs), including incidence of hepatopathy, myopathy, rhabdomyolysis, cancer, gallbladderrelated disease and discontinuation due to AEs, due to the low and very low quality of the evidence. The evidence for beneficial effects was mainly derived from individuals with established atherosclerotic cardiovascular disease (ASCVD) (predominantly with acute coronary syndrome (ACS)) who were administered 
ezetimibe plus statins, but there is limited evidence for the role of ezetimibe in primary prevention. Therefore, the addition of ezetimibe to statin therapy might be an alternative treatment for patients at high risk of ASCVD who are unable to tolerate the recommended statin intensities or fail to achieve their treatment goals.

\section{Implications for research}

First, the effects of ezetimibe monotherapy for the prevention of CVD are currently unknown and need to be further investigated.

Second, subgroup analysis performed in IMPROVE-IT study suggests a more favourable treatment effect on diabetic and elderly (aged at least 75 years) individuals. However, the evidence originated from a single study, and thus, more studies are required to further confirm this finding.

Third, the IMPROVE-IT study generally used a moderate-intensity statin (40 mg/day simvastatin), but high-intensity statin therapy is currently recommended for the treatment of patients with ACS. There remains a lack of evidence to assess the effects of ezetimibe in combination with moderate- or high-intensity statin versus highintensity statin alone on cardiovascular endpoints.

Fourth, similar findings can be observed in the meta-analysis recently published by Cochrane regarding the clinical efficacy of PCSK9 antibodies (Schmidt 2017), which revealed that the effect on major adverse cardiovascular events (MACE) was less efficient than expected and likewise the fatal endpoint was not affected. However, the Cholesterol Treatment Trialists (CTT) metaanalysis (CTT 2012) of statin trials showed a significant reduction in risk for MACE and all-cause death with every $\mathrm{mmol} / \mathrm{L}$ of LDL-C level reduction $(R R=0.79, P<0.0001$ and $R R=0.91$ $P<0.0001$, respectively). These observations should encourage medical research toward a more in-depth study of the relationship between the decrease in LDL-C and the clinical endpoint (also in view of the cost of new classes of lipid-lowering drugs).

Finally, results from our study, alongside with the results of the PCSK9 antibodies review, suggest that a) other ways of lowering LDL-C, or b) targeting novel targets in the lipid metabolism, c) inflammatory pathways, or d) other processes leading to atherosclerotic plaque formation should be pursued in the future for a more pronounced reduction in fatal cardiovascular endpoints in this group of patients.

\section{ACKNOWLEDGEMENTS}

We wish to thank Nicole Martin and Andrea Takeda for providing assistance with this review. We also wish to thank Charlene Bridges (Information Specialist, Cochrane Heart Group) for help in defining the search strategy and running searches. 


\section{R E F E R E N C E S}

\section{References to studies included in this review}

Ballantyne 2004 \{published data only\}

Ballantyne CM, Lipka LJ, Sager PT, Strony J, Alizadeh J, Suresh R, et al. Long-term safety and tolerability profile of ezetimibe and atorvastatin coadministration therapy in patients with primary hypercholesterolaemia. International Journal of Clinical Practice 2004;58(7):653-8.

\section{EFECTL 2017 \{published data only\}}

* Oikawa S, Yamashita S, Nakaya N, Sasaki J, Kono S for the Effect of Fenofibrate and Ezetimibe Combination Treatment on Lipid (EFECTL) Study Investigators. Efficacy and safety of longterm coadministration of fenofibrate and ezetimibe in patients with combined hyperlipidemia: results of the EFECTL study. Journal of Atherosclerosis \& Thrombosis 2017;24(1):77-94.

Oikawa S, Yamashita S, Nakaya N, Sasaki J, Kono S, Investigators G Efectl Study. Efficacy and safety of long-term coadministration of fenofibrate and ezetimibe in patients with combined hyperlipidemia: results of the EFECTL study. Atherosclerosis 2016;252:E230.

UMIN000001224. Effect of fenofibrate and ezetimibe combination treatment on lipid. http://apps.who.int/ trialsearch/Trial2.aspx?TrialID=JPRN-UMIN000001224.

\section{ENHANCE 2008 \{published data only\}}

Kastelein J, Sager P, De Groot E, Veltri E. The ENHANCE trial: Ezetimibe and simvastatin in hypercholesterolemia enhances atherosclerosis regression. Atherosclerosis Supplements 2003;4(2):341.

* Kastelein JJ, Akdim F, Stroes ES, Zwinderman AH, Bots ML, Stalenhoef AF, et al. Simvastatin with or without ezetimibe in familial hypercholesterolemia. New England Journal of Medicine 2008;358(14):1431-43

Kastelein JJ, Akdim F, Stroes ES, Zwinderman AH, Bots ML, Stalenhoef AF, et al. Simvastatin with or without ezetimibe in familial hypercholesterolemia.[Erratum]. New England Journal of Medicine 2008;358(18):1977.

Kastelein JJ, Sager PT, de Groot E, Veltri E. Comparison of ezetimibe plus simvastatin versus simvastatin monotherapy on atherosclerosis progression in familial hypercholesterolemia. Design and rationale of the Ezetimibe and Simvastatin in Hypercholesterolemia Enhances Atherosclerosis Regression (ENHANCE) trial. American Heart Journal 2005;149(2):234-9.

Kastelein JJ, Strony J, Sager PT, de Groot E, Veltri EP. The ENHANCE Trial: ezetimibe and simvastatin in hypercholesterolemia enhances atherosclerosis regression. Stroke 2004;35(6):E258.

NCT00552097. Effect of ezetimibe plus simvastatin versus simvastatin alone on atherosclerosis in the carotid artery (ENHANCE). https://clinicaltrials.gov/ct2/show/NCT00552097.
Hibi 2018 \{published data only\}

Hibi K, Kimura K, Sonoda S, Otsuji Y, Murohara T, Ishii H, et al. Effects of statin plus ezetimibe versus statin alone on coronary atherosclerosis in acute coronary syndrome. Circulation 2015;132(SUPPL 3):14134.

* Hibi K, Sonoda S, Kawasaki M, Otsuji Y, Murohara T, Ishii H, et al. Effects of ezetimibe-statin combination therapy on coronary atherosclerosis in acute coronary syndrome. Circulation Journal 2018;82(3):757-66.

\section{HIJ-PROPER 2017 \{published data only\}}

* Hagiwara N, Kawada-Watanabe E, Koyanagi R, Arashi H, Yamaguchi J, Nakao K, et al. Low-density lipoprotein cholesterol targeting with pitavastatin + ezetimibe for patients with acute coronary syndrome and dyslipidaemia: the HIJ-PROPER study, a prospective, open-label, randomized trial. European Heart Journal 2017;38(29):2264-79.

Kanbayashi K, Yamaguchi J, Fujii S, Kawada-Watanabe E, Arashi $\mathrm{H}$, Sekiguchi $\mathrm{H}$, et al. The impact of serum sitosterol level on clinical outcomes in acute coronary syndrome patients with dyslipidemia: a subanalysis of HIJ PROPER. European Heart Journal 2017; Vol. 38, issue Supplement 1:237.

Kawada-Watanabe E, Ogawa H, Koyanagi R, Arashi H, Yamaguchi J, Matsui K, et al. Rationale, design features, and baseline characteristics: the Heart Institute of Japan-PRoper level of lipid IOwering with Pitavastatin and Ezetimibe in acute coRonary syndrome (HIJ-PROPER). Journal of Cardiology 2017;69(3):536-41.

Sekiguchi H, Kawada-Watanabe E, Arashi H, Yamaguchi J, Ogawa $\mathrm{H}$, Hagiwara N. Impact of type 2 diabetes on optimal target LDLC level for secondary prevention of cardiovascular disease in patients with acute coronary syndrome: A subanalysis of HIJPROPER. Circulation 2017;136(Supplement 1):A18891.

UMIN000002742. Proper Level of lipid lowering with pitavastatin and ezetimibe in acute coronary syndrome. http://apps.who.int/trialsearch/Trial2.aspx?TriallD=JPRNUMIN000002742.

Watanabe E, Ogawa R, Yamaguchi J, Sekiguchi H, Ogiso M, Arashi $\mathrm{H}$, et al. Impact of high sensitivity $\mathrm{C}$ reactive protein levelon clinical outcomes of acute coronary syndrome patients with dyslipidemia undergoing contemporary lipid lowering therapy. Journal of the American College of Cardiology 2018;71(Supplement 1):A53.

Yamaguchi J, Kawada-Watanabe E, Koyanagi R, Arashi H, Sekiguchi H, Nakao K, et al. Baseline serum sitosterol level as predictor of adverse clinical events in acute coronary syndrome patients with dyslipidaemia: A sub-analysis of HIJ-PROPER. Atherosclerosis 2018;274:139-45.

\section{IMPROVE-IT 2015 \{published data only\}}

Ambrosy AP, Cerbin LP, Clare R, Lokhnygina Y, Tershakovec A, Roe Mt, et al. The natural history of patients post-acute coronary syndrome based on heart failure status-an analysis 
of the improve-it trial. Circulation 2017; Vol. 136, issue Supplement 1:A17275.

Bach RG, Cannon C, Giugliano R, White J, Lokhnygina Y, Tershakovec A, et al. Increasing age and the benefit from higher-intensity lipid lowering with ezetimibe/simvastatin vs. simvastatin alone: Results from the IMPROVE-IT trial. Circulation 2015;132(SUPPL 3):A16708.

Blazing MA, Giugliano RP, Cannon CP, Musliner TA, Tershakovec AM, White JA, et al. Evaluating cardiovascular event reduction with ezetimibe as an adjunct to simvastatin in 18,144 patients after acute coronary syndromes: final baseline characteristics of the IMPROVE-IT study population. American Heart Journal 2014;168(2):205-12.e1.

Blazing MA, Giugliano RP, DeLemos J, Cannon CP, Musliner T, Tershakovec AM, et al. On-Treatment Analysis of the IMProved Reduction of Outcomes: Vytorin Efficacy International Trial (IMPROVE-IT). Circulation 2014;130(23):2112.

Blazing MA, Giugliano RP, Wiviott SD, White JA, Delemos JA, McGuire DK, et al. Muscle related complaints, serious adverse events vents and drug discontinuations in 17,706 subjects randomized to simvastatin or ezetimibe/simvastatin in the IMPROVE-IT study. European Heart Journal 2015;36(SUPPL $1): 1151$

Blazing MA, Giugliano RP, de Lemos JA, Cannon CP, Tonkin A, Ballantyne $\mathrm{CM}$, et al. On-treatment analysis of the Improved Reduction of Outcomes: Vytorin Efficacy International Trial (IMPROVE-IT). American Heart Journal 2016;182:89-96.

Bohula EA, Giugliano RP, Cannon CP, Zhou J, Murphy SA, White JA, et al. Achievement of dual low-density lipoprotein cholesterol and high-sensitivity C-reactive protein targets more frequent with the addition of ezetimibe to simvastatin and associated with better outcomes in IMPROVE-IT. Circulation 2015;132(13):1224-33

Bohula EA, Morrow DA, Giugliano RP, Blazing MA, He P, Park JG, et al. Atherothrombotic risk stratification and ezetimibe for secondary prevention. Journal of the American College of Cardiology 2017;69(8):911-21.

Bohula EA, Wiviott SD, Giugliano RP, Blazing MA, Park JG, Murphy SA, et al. Prevention of stroke with the addition of ezetimibe to statin therapy in patients with acute coronary syndrome in IMPROVE-IT (Improved Reduction of Outcomes: Vytorin Efficacy International Trial). Circulation 2017; Vol. 136, issue $25: 2440-50$.

Bohula May EA, Giugliano RP, Cannon CP, Murphy SA, Zhou J, Blazing MA, et al. Achievement of dual LDL-C ( $<70 \mathrm{mg} / \mathrm{dL})$ and hs-CRP ( $<2 \mathrm{mg} / \mathrm{L}$ ) goals more frequent with addition of ezetimibe and associated with better outcomes in IMPROVE-IT. European Heart Journal 2015;36(SUPPL 1):1060.

Bohula May EA, White JA, Blazing M, Giugliano R, Musliner T, Tershakovec A, et al. Risk stratification for cardiovascular events in the improve-it trial. Journal of the American College of Cardiology 2015;65(10 SUPPL 1):A3.
Califf RM, Lokhnygina Y, Cannon CP, Stepanavage ME, McCabe $\mathrm{CH}$, Musliner TA, et al. An update on the IMProved reduction of outcomes: Vytorin Efficacy International Trial (IMPROVE-IT) design. American Heart Journal 2010;159(5):705-9.

* Cannon CP, Blazing MA, Giugliano RP, McCagg A, White JA, Theroux $P$, et al. Ezetimibe added to statin therapy after acute coronary syndromes. New England Journal of Medicine 2015;372(25):2387-97.

Cannon CP, Giugliano RP, Blazing MA, Harrington RA, Peterson JL, Sisk CM, et al. Rationale and design of IMPROVEIT (IMProved Reduction of Outcomes: Vytorin Efficacy International Trial): comparison of ezetimbe/simvastatin versus simvastatin monotherapy on cardiovascular outcomes in patients with acute coronary syndromes. American Heart Journal 2008;156(5):826-32.

Cannon CP, Investigators Improve It. IMPROVE-IT Trial: A comparison of ezetimibe/simvastatin versus simvastatin monotherapy on cardiovascular outcomes after acute coronary syndromes. Circulation 2014;130(23):2109.

Fanaroff AC, Navar AM, Clare R, Lokhnygina Y, Roe M, Giugliano R, et al. Association of type of presentation, STEMI vs NSTEMI/UA, with the relative long-term incidence of cardiovascular and non-cardiovascular mortality. Circulation 2016;134(Supplement 1):A18895.

Fanaroff AC, Roe MT, Clare RM, Lokhnygina Y, Navar AM, Giugliano RP, et al. Competing risks of cardiovascular versus noncardiovascular death during long-term follow-up after acute coronary syndromes. Journal of the American Heart Association 2017;6(9):e005840.

Giugliano RP, Cannon CP, Blazing MA, Nicolau JC, Corbalan R, Spinar J, et al. Benefit of adding ezetimibe to statin therapy on cardiovascular outcomes and safety in patients with versus without diabetes mellitus: results from IMPROVE-IT (Improved Reduction of Outcomes: Vytorin Efficacy International Trial). Circulation 2018;137:1571-82.

Giugliano RP, Cannon CP, Blazing MA, White J, Murphy S, Tershakovec A, et al. Baseline LDL-C and clinical outcomes with addition of ezetimibe to statin in 18,144 patients post ACS. Journal of the American College of Cardiology 2015;65(10):A4.

Giugliano RP, Wiviott SD, Blazing MA, De Ferrari GM, Park JeongGun, Murphy SA, et al. Long-term safety and efficacy of achieving very low levels of low-density lipoprotein cholesterol: A prespecified analysis of the IMPROVE-IT Trial. JAMA Crdiology 2017;2(5):547-55.

Giugliano RP, Wiviott SD, Fuchs CS, Wagner AJ, Goessling W, White JA, et al. Prospectivev evaluation of cancer in 18,144 patients randomized to ezetimibe vs placebo: A prespecified analysis from the IMPROVE IT trial. European Heart Journal 2015;36:181.

Kato ET, Cannon CP, Blazing MA, Bohula E, Guneri S, White JA, et al. Efficacy and safety of adding ezetimibe to statin therapy among women and men: insight from IMPROVE-IT (Improved Reduction of Outcomes: Vytorin Efficacy International Trial). 
Journal of the American Heart Association 2017; Vol. 6, issue 11:e006901.

Kato ET, Giugliano RP, Blazing MA, May EB, Guneri S, White JA, et al. Benefit and safety of adding ezetimibe to statin therapy on cardiovascular outcomes in 4416 women in the IMPROVE-IT trial. Circulation 2015;132(SUPPL 3):A17862.

Magnuson EA, Chinnakondepalli K, Vilain K, Mark DB, Davies G, Giugliano RP, et al. Impact of ezetimibe on hospitalizationrelated costs among patients with a recent acute coronary syndrome: Results from the improve-it trial. Circulation 2015;132(SUPPL 3):A13035.

Murphy SA, Cannon CP, Blazing MA, Giugliano RP, White JA, Lokhnygina $Y$, et al. Reduction in total cardiovascular events with ezetimibe/simvastatin post-acute coronary syndrome: the IMPROVE-IT Trial. Journal of the American College of Cardiology 2016;67(4):353-61.

NCT00202878. IMPROVE-IT: Examining outcomes in subjects with acute coronary syndrome: Vytorin (ezetimibe/ simvastatin) vs simvastatin. https://clinicaltrials.gov/ct2/show/ NCT00202878.

Pokharel Y, Chinnakondepalli K, Vilain K, Wang K, Mark DB, Davies G, et al. Impact of ezetimibe on the rate of cardiovascular-related hospitalizations and associated costs among patients with a recent acute coronary syndrome: Results from the IMPROVE-IT Trial (Improved Reduction of Outcomes: Vytorin Efficacy International Trial). Circulation: Cardiovascular Quality and Outcomes 2017;10(5):e003201.

Qamar A, Giugliano RP, Blazing MA, Park JG, Murphy SA, Cannon CP, et al. Biomarkers, cardiovascular outcomes and effect of ezetimibe after acute coronary syndrome in the IMPROVE-IT trial. Circulation 2017; Vol. 136, issue Supplement 1.

Silverman MG, Cannon C, Blazing M, Mach F, Zhou J, Tershakovec A, et al. Long term significance of heart failure complicating acute myocardial infarction in 11,185 patients from the improved reduction of outcomes: Vytorin efficacy international trial (IMPROVE-IT). Journal of the American College of Cardiology 2016;67(13 SUPPL 1):484.

Stanifer JW, Charytan DM, White J, Lokhnygina Y, Cannon C, Blazing MA. Comparative efficacy of ezetimibe plus simvastatin combined therapy vs. simvastatin monotherapy for individuals with reduced estimated glomerular filtration rate. European Heart Journal 2016;37(Supplement 1):1205.

Stanifer JW, Charytan DM, White J, Lokhnygina Y, Cannon CP, Roe MT, et al. Benefit of ezetimibe added to simvastatin in reduced kidney function. Journal of the American Society of Nephrology 2017;28(10):3034-43.

U.S. Food, Drug Administration. 2015 Meeting materials, Endocrinologic and Metabolic Drugs Advisory Committee. December 14, 2015 Meeting of the Endocrinologic and Metabolic Drugs Advisory Committee. https://www.fda.gov/ AdvisoryCommittees/CommitteesMeetingMaterials/Drugs/ EndocrinologicandMetabolicDrugsAdvisoryCommittee/ ucm426278.htm (accessed 9 October 2017).
Wiviott SD, Giugliano RP, Blazing MA, Cannon CP, Zhou J, Murphy SA, et al. Reduction in non-hemorrhagic stroke with ezetimibe/simvastatin compared with simvastatin alone in the IMPROVE-IT trial. Circulation 2015;132(SUPPL 3):A19694.

\section{Katoh 2017 \{published data only\}}

Katoh A, Hattori Y, Yoshikwa N, Niiyama H, Harada H, Kai H, et al. The effects of ezetimibe on coronary plaque volume in patients with stable angina pectoris previously treated with statins. European Heart Journal 2017; Vol. 38, issue Supplement 1:188.

\section{Kinouchi 2013 \{published data only\}}

* Kinouchi K, Ichihara A, Bokuda K, Morimoto S, Itoh H. Effects of adding ezetimibe to fluvastatin on kidney function in patients with hypercholesterolemia: a randomized control trial. Journal of Atherosclerosis \& Thrombosis 2013;20(3):245-56.

Kinouchi K, Ichihara A, Bokuda K, Morimoto S, Itoh H. Ezetimibe preserves renal function in hypercholesterolemic patients treated with fluvastatin. Journal of Hypertension 2012;30(SUPPL 1):e214.

\section{Kodali 2011 \{published data only\}}

Kodali S, Doyle M, Grant S, Neff D, Williams RB, Yamrozik J, et al. Paradoxical changes in lumen size during progression and regression of carotid atherosclerosis. Journal of Cardiovascular Magnetic Resonance 2012;14(SUPPL 1):043.

* Kodali S, Doyle M, Grant SB, Neff DR, Williams RB, Yamrozik JA, et al. A reversal of Glagov's hypothesis; A preliminary demonstration by cardiac magnetic resonance. Journal of Cardiovascular Magnetic Resonance. Conference 2011;13(SUPPL 1):P178.

\section{Kouvelos 2013 \{published data only\}}

Kouvelos G, Milionis H, Arnaoutoglou E, Kostara C, Papa N, Koulouras V, et al. The effect of intensified lipid lowering therapy on one-year prognosis in patients undergoing vascular surgery. Interactive Cardiovascular and Thoracic Surgery 2011;12(SUPPL 1):S61-2.

* Kouvelos GN, Arnaoutoglou EM, Matsagkas MI, Kostara C, Gartzonika C, Bairaktari ET, et al. Effects of rosuvastatin with or without ezetimibe on clinical outcomes in patients undergoing elective vascular surgery: results of a pilot study. Journal of Cardiovascular Pharmacology \& Therapeutics 2013;18(1):5-12.

Kouvelos GN, Arnaoutoglou EM, Milionis HJ, Raikou VD, Papa N, Matsagkas MI. The effect of adding ezetimibe to rosuvastatin on renal function in patients undergoing elective vascular surgery. Angiology 2015;66(2):128-35.

\section{Liu 2017 \{published data only\}}

Liu Z, Hao H, Yin C, Chu Y, Li J, Xu D. Therapeutic effects of atorvastatin and ezetimibe compared with double-dose atorvastatin in very elderly patients with acute coronary syndrome. Oncotarget 2017;8(25):41582-9.

\section{Luo 2014 \{published data only\}}

Luo P, Li L, Wang LX, Zhu HH, Du S, Wu SL, et al. Effects of atorvastatin in combination with ezetimibe on carotid 
atherosclerosis in elderly patients with hypercholesterolemia. Genetics \& Molecular Research 2014;13(2):2377-84.

\section{Luo 2016 \{published data only\}}

Luo P, Wang L, Zhu H, Du S, Wang G, Ding S. Impact of atorvastatin combined with ezetimibe for the treatment of carotid atherosclerosis in patients with coronary heart disease. Acta Cardiologica Sinica 2016;32(5):578-85.

\section{OCTIVUS 2017 \{published data only\}}

Hougaard M, Hansen HS, Junker A, Thayssen P, Antonsen L, Maehara A, et al. Effect of ezetimibe in addition to statin therapy in statin naive STEMI patients assessed by optical coherence tomography and intravascular ultrasound with iMap (the OCTIVUS trial). Journal of the American College of Cardiology 2014;64(11 Suppl 1):B112.

* Hougaard M, Hansen HS, Thayssen P, Antonsen L, Junker A, Veien $\mathrm{K}$, et al. Influence of ezetimibe in addition to high-dose atorvastatin therapy on plaque composition in patients with ST-segment elevation myocardial infarction assessed by serial: Intravascular ultrasound with iMap: the OCTIVUS trial. Cardiovascular Revascularization Medicine 2017;18(2):110-7.

NCT01385631. Ezetimibe in addition to atorvastatin therapy on the plaque composition in patients with acute myocardial infarction (OCTIVUS). clinicaltrials.gov/ct2/show/NCT01385631 (first posted 30 June 2011).

\section{Okada 2012 \{published data only\}}

Okada K, Fukui K, Himeno H, Endo T, Shimizu M, Kobayashi S, et al. Long-term effect of ezetimibe-statin combination therapy on low-density lipoprotein cholesterol lowering in patients with coronary artery disease; focus on cholesterol absorption and synthesis. Journal of the American College of Cardiology 2011;57(14 SUPPL 1):E524.

Okada K, Iwahashi N, Endo T, Himeno H, Fukui K, Kobayashi S, et al. Long-term effects of ezetimibe plus statin combination vs double-dose statin therapy on low-density lipoprotein cholesterol lowering in coronary artery disease patients pretreated with statins; focus on proprotein convertase subtilisin/ kexin type 9. Circulation 2012;126(21 SUPPL 1):A10846.

* Okada K, Iwahashi N, Endo T, Himeno H, Fukui K, Kobayashi S, et al. Long-term effects of ezetimibe-plus-statin therapy on lowdensity lipoprotein cholesterol levels as compared with doubledose statin therapy in patients with coronary artery disease. Atherosclerosis 2012;224(2):454-6.

Okada K, Kimura K, Iwahashi N, Endo T, Hideo H, Shimizu M, et al. The mechanism of long-term low-density lipoprotein cholesterol lowering effect of ezetimibe-plus-statin combination therapy in coronary artery disease patients; compared with double-dose statin therapy. Journal of the American College of Cardiology 2012;59(13 SUPPL 1):E1541.

Okada K, Kimura K, Iwahashi N, Endo T, Himeno H, Fukui K, et al. Long-term effect of ezetimibe-plus-statin vs doubledose statin on low-density lipoprotein cholesterol lowering in coronary artery disease patients pre-treated with a statin focus on cholesterol absorption and synthesis. Circulation 2011;124(21 SUPPL 1):A12204.

\section{PRECISE-IVUS 2015 \{published data only\}}

Fujisue K, Nagamatsu S, Shimomura H, Yamashita T, Nakao K, Nakamura $S$, et al. Impact of statin-ezetimibe combination on coronary atheroma plaque in patients with and without chronic kidney disease - Sub-analysis of PRECISE-IVUS trial. International Journal of Cardiology 2018;268:23-6.

Fujisue K, Nagamatsu S, Sugiyama S, Sumida H, Shimomura H, Yamashita T, et al. The different effects of statin and ezetimibe combination on coronary atheroma plaque in patients with and without diabetes mellitus: Sub-analysis of precise-IVUS trial. Journal of the American College of Cardiology 2018;71(11 SUPPL 1):A1781.

NCT01043380. Plaque REgression With Cholesterol Absorption Inhibitor or Synthesis Inhibitor Evaluated by IntraVascular UltraSound (PRECISE-IVUS). https://clinicaltrials.gov/ct2/show/ NCT01043380.

Nagamatsu S, Tsujita K, Yamanaga K, Sugiyama S, Shimomura H, Yamashita T, et al. Impact of statin-ezetimibe combination on coronary atheroma progression/regression in patients with and without chronic kidney disease-subanalysis of precise-IVUS trial. Circulation 2016; Vol. 134, issue SUPPL 1:A14740.

* Tsujita K, Sugiyama S, Sumida H, Shimomura H, Yamashita T, Yamanaga K, et al. Impact of dual lipid-lowering strategy with ezetimibe and atorvastatin on coronary plaque regression in patients with percutaneous coronary intervention: the multicenter randomized controlled PRECISE-IVUS trial. Journal of the American College of Cardiology 2015;66(5):495-507.

Tsujita K, Sugiyama S, Sumida H, Shimomura H, Yamashita T, Yamanaga $\mathrm{K}$, et al. Plaque REgression with Cholesterol absorption Inhibitor or Synthesis inhibitor Evaluated by IntraVascular UltraSound (PRECISE-IVUS Trial): Study protocol for a randomized controlled trial. Journal of Cardiology 2015;66(4):353-8.

Tsujita K, Yamanaga K, Komura N, Sakamoto K, Sugiyama S, Sumida $\mathrm{H}$, et al. Lipid profile associated with coronary plaque regression in patients with acute coronary syndrome: subanalysis of PRECISE-IVUS trial. Atherosclerosis 2016; Vol. 251:367-72.

Tsujita K, Yamanaga K, Komura N, Sakamoto K, Sugiyama S, Sumida $\mathrm{H}$, et al. Synergistic effect of ezetimibe addition on coronary atheroma regression in patients with prior statin therapy: subanalysis of PRECISE-IVUS trial. European Journal of Preventive Cardiology 2016; Vol. 23, issue 14:1524-8.

Tsujita K, Yamanaga K, Komura N, Shimomura H, Ishihara M, Kaikita K, et al. Dual lipid-lowering with ezetimibe/statin as a promising anti-atherosclerotic strategy. Journal of the American College of Cardiology 2016;67(13):2132.

Tsujita K, Yamanaga K, Sugiyama S, Shimomura H, Yamashita T, Sakamoto K, et al. Impact of statin-ezetimibe combination on coronary atheroma progression/regression in patients with and without prior statin therapy-subanalysis of precise-IVUS trial. Circulation 2015;132(SUPPL 3):A13849. 
Yamanaga K, Tsujita K, Sugiyama S, Sumida H, Shimomura H, Yamashita T, et al. The impact of statin-ezetimibe combination therapy in patients with decreased cholesterol absorption ability. Circulation 2015; Vol. 132, issue SUPPL 3.

\section{Ren 2017 \{published data only\}}

Ren Y, Zhu H, Fan Z, Gao Y, Tian N. Comparison of the effect of rosuvastatin versus rosuvastatin/ezetimibe on markers of inflammation in patients with acute myocardial infarction. Experimental and Therapeutic Medicine 2017; Vol. 14, issue 5:4942-50.

\section{RESEARCH 2017 \{published data only\}}

Inazawa T, Sakamoto K, Kohro T, lijima R, Kitazawa T, Hirano T, et al. RESEARCH (Recognized effect of Statin and ezetimibe therapy for achieving LDL-C Goal), a randomized, doctororiented, multicenter trial to compare the effects of higherdose statin versus ezetimibe-plus-statin on the serum LDL-C concentration of Japanese type-2 diabetes patients design and rationale. Lipids in Health and Disease 2013;12:142.

Kawamura M, Watanabe T, Sakamoto K, Ashidate K, Kohro T, Tanaka A, et al. RESEARCH: Superior effect of ezetimibe was sustained on LDL-C level and the rate of achievement of target value in a 52-week analysis. Diabetologia 2015;58(SUPPL 1):S82.

* Sakamoto K, Kawamura M, Watanabe T, Ashidate K, Kohro T, Tanaka A, et al. Effect of ezetimibe add-on therapy over 52 weeks extension analysis of prospective randomized trial (RESEARCH study) in type 2 diabetes subjects. Lipids in Health and Disease 2017;16(1):122.

UMIN000002593. Recognized effect of statin and ezetimibe therapy for achievement LDL-C goal. apps.who.int/trialsearch/ Trial2.aspx?TrialID=JPRN-UMIN000002593 (date of registration 7 October 2009).

\section{Sawayama 2011 \{published data only\}}

Sawayama Y. Low-dose pravastatin plus ezetimibe verus standard-dose pravastatin: the effect on the carotid atherosclerosis of patients with hypercholesterolemia. Atherosclerosis Supplements 2011;12 (1):180.

\section{Suzuki 2013 \{published data only\}}

Suzuki H, Watanabe $\mathrm{Y}$, Kumagai H, Shuto H. Comparative efficacy and adverse effects of the addition of ezetimibe to statin versus statin titration in chronic kidney disease patients. Therapeutic Advances in Cardiovascular Disease 2013;7(6):306-15.

UMIN000002935. A community-based surveillance of ezetimibe added to statin therapy for chronic kidney disease patients. apps.who.int/trialsearch/Trial2.aspx?TrialID=JPRNUMIN000002935 (date of registration 1 January 2010).

\section{VYCTOR 2009 \{published data only\}}

Meaney A, Ceballos G, Asbun J, Solache G, Mendoza E, Vela A, et al. The VYtorin on Carotid intima-media thickness and overall arterial rigidity (VYCTOR) study. Journal of Clinical Pharmacology 2009;49(7):838-47.
Wang 2016 \{published data only\}

Wang X, Zhao X, Li L, Yao H, Jiang Y, Zhang J. Effects of combination of ezetimibe and rosuvastatin on coronary artery plaque in patients with coronary heart disease. Heart, Lung and Circulation 2016;25(5):459-65.

\section{Wang 2017 \{published data only\}}

Wang J, Ai XB, Wang F, Zou YW, Li L, Yi XL. Efficacy of ezetimibe combined with atorvastatin in the treatment of carotid artery plaque in patients with type 2 diabetes mellitus complicated with coronary heart disease. International Angiology 2017; Vol. 36 , issue $5: 467-73$.

\section{West 2011 \{published data only\}}

NCT00587678. Comprehensive magnetic resonance of peripheral arterial disease. https://clinicaltrials.gov/ct2/show/ NCT00587678.

West AM, Anderson JD, Epstein FH, Meyer CH, Wang $\mathrm{H}$, Hagspiel KD, et al. Low-density lipoprotein lowering does not improve calf muscle perfusion, energetics, or exercise performance in peripheral arterial disease. Journal of the American College of Cardiology 2011;58(10):1068-76.

West AM, Anderson JD, Meyer CH, Epstein FH, Hagspiel KD, Berr SS, et al. Type of lipid lowering therapy impacts atherosclerosis progression in peripheral arterial disease as assessed by CMR. Journal of Cardiovascular Magnetic Resonance 2010;12(SUPPL 1):192.

* West AM, Anderson JD, Meyer CH, Epstein FH, Wang H, Hagspiel KD, et al. The effect of ezetimibe on peripheral arterial atherosclerosis depends upon statin use at baseline. Atherosclerosis 2011;218(1):156-62.

West AM, Pesch AJ, Mehta N, Anderson JD, Epstein FH, Meyer $\mathrm{CH}$, et al. Changes in atherosclerotic plaque composition assessed by MRI in the superficial femoral artery with two years of lipid lowering therapy. Journal of Cardiovascular Magnetic Resonance 2011;13(SUPPL1):P382.

\section{Zinellu 2012 \{published data only\}}

Carru C, Loriga G, Farre G, Zinellu A, Sotgia S, Scanu B, et al. An improvement of endothelial dysfunction markers in chronic kidney disease simvastatin/ezetimibe combined therapy. Atherosclerosis Supplements 2010;11(2):192-3.

NCT00861731. Ezetimibe/simvastatin combination in proteinuric nephropathy (VICTORY). clinicaltrials.gov/ct2/show/ NCT00861731 (first posted 13 March 2009).

Pisanu E, Sanna M, Scanu B, Satta AE, Deiana L, Zinellu A. Lipid lowering therapy decreases LDL-S-homocysteinilation levels in chronic kidney desease patients. FEBS Journal 2012;279(SUPPL 1):104.

Sanna M, Pisanu E, Cambedda D, Ena S, Loriga G, Carru C. Effect of combined simvastatin/ezetimibe administration on taurine levels and oxidative status in patients CDK. FEBS Journal 2012;279(SUPPL 1):218.

* Zinellu A, Sotgia S, Loriga G, Deiana L, Satta AE, Carru C. Oxidative stress improvement is associated with increased 
levels of taurine in CKD patients undergoing lipid-lowering therapy. Amino Acids 2012;43(4):1499-507.

Zinellu A, Sotgia S, Mangoni AA, Sanna M, Satta AE, Carru C. Impact of cholesterol lowering treatment on plasma kynurenine and tryptophan concentrations in chronic kidney disease: relationship with oxidative stress improvement. Nutrition Metabolism and Cardiovascular Diseases 2015;25(2):153-9.

Zinellu A, Sotgia S, Mangoni AA, Sotgiu E, Ena S, Satta AE, et al. Effect of cholesterol lowering treatment on plasma markers of endothelial dysfunction in chronic kidney disease. Journal of Pharmaceutical \& Biomedical Analysis 2016;129:383-8.

Zinellu A, Sotgia S, Pisanu E, Loriga G, Deiana L, Satta AE, et al. LDL S-homocysteinylation decrease in chronic kidney disease patients undergone lipid lowering therapy. European Journal of Pharmaceutical Sciences 2012;47(1):117-23.

Zinellu A, Sotgia S, Sotgiu E, Assaretti S, Baralla A, Mangoni AA, et al. Cholesterol lowering treatment restores blood global DNA methylation in chronic kidney disease (CKD) patients. Nutrition, Metabolism and Cardiovascular Diseases 2017; Vol. 27, issue 9:822-9.

\section{Zou 2016 \{published data only\}}

Zou YC, Lu Y, Bai J, Gao Y, Li Y. Effect of ezetimibe combined with low-dose atorvastain calcium on carotid atherosclerosis in elderly patients with coronary heart disease. Journal of the American Geriatrics Society 2016;64:S328.

\section{References to studies excluded from this review}

\section{ARBITER 6-HALTS \{published data only\}}

Devine PJ, Turco MA, Taylor AJ. Design and rationale of the ARBITER 6 trial (Arterial Biology for the Investigation of the Treatment Effects of Reducing Cholesterol)-6-HDL and LDL Treatment Strategies in Atherosclerosis (HALTS). Cardiovascular Drugs and Therapy 2007;21(3):221-5.

Taylor AJ, Villines TC, Stanek EJ. Paradoxical progression of atherosclerosis related to low-density lipoprotein reduction and exposure to ezetimibe. European Heart Journal 2012;33(23):2939-45.

* Taylor AJ, Villines TC, Stanek EJ, Devine PJ, Griffen L, Miller M, et al. Extended-release niacin or ezetimibe and carotid intima-media thickness. New England Journal of Medicine 2009;361(22):2113-22.

Villines TC, Stanek EJ, Devine PJ, Turco M, Miller M, Weissman NJ, et al. The ARBITER 6-HALTS Trial (Arterial Biology for the Investigation of the Treatment Effects of Reducing Cholesterol 6-HDL and LDL Treatment Strategies in Atherosclerosis): final results and the impact of medication adherence, dose, and treatment duration. Journal of the American College of Cardiology 2010;55(24):2721-6.

\section{Arimura 2012 \{published data only\}}

Arimura T, Miura S, Ike A, Sugihara M, Iwata A, Nishikawa H, et al. Comparison of the efficacy and safety of statin and statin/ ezetimibe therapy after coronary stent implantation in patients with stable angina. Journal of Cardiology 2012;60(2):111-8.

\section{Auscher 2015 \{published data only\}}

Auscher S, Heinsen L, Nieman K, Vinther KH, Logstrup B, Moller JE, et al. Effects of intensive lipid-lowering therapy on coronary plaques composition in patients with acute myocardial infarction: Assessment with serial coronary CT angiography. Atherosclerosis 2015;241(2):579-87.

Bays 2008 \{published data only\}

Bays H, Sapre A, Taggart W, Liu J, Capece R, Tershakovec A. Long-term (48-week) safety of ezetimibe $10 \mathrm{mg} /$ day coadministered with simvastatin compared to simvastatin alone in patients with primary hypercholesterolemia. Current Medical Research and Opinion 2008;24(10):2953-66.

\section{Crespo-Leiro 2008 \{published data only\}}

Crespo-Leiro MG, Paniagua MJ, Marzoa R, Grille Z, Naya C, Flores $X$, et al. The efficacy and safety of ezetimibe for treatment of dyslipidemia after heart transplantation. Transplantation Proceedings 2008;40(9):3060-2.

\section{Dagli 2007 \{published data only\}}

Dagli N, Yavuzkir M, Karaca I. The effects of high dose pravastatin and low dose pravastatin and ezetimibe combination therapy on lipid, glucose metabolism and inflammation. Inflammation 2007;30(6):230-5.

\section{DESCARTES 2014 \{published data only\}}

Blom DJ, Hala T, Bolognese M, Lillestol MJ, Toth PD, Burgess L, et al. A 52-week placebo-controlled trial of evolocumab in hyperlipidemia. New England Journal of Medicine 2014;370(19):1809-19.

\section{Dujovne 2008 \{published data only\}}

Dujovne CA, Suresh R, McCrary Sisk C, Maccubbin D, Strony J, Veltri E. Safety and efficacy of ezetimibe monotherapy in 1624 primary hypercholesterolaemic patients for up to 2 years. International Journal of Clinical Practice 2008;62(9):1332-6.

\section{EASEGO 2008 \{published data only\}}

Roeters van Lennep HW, Liem AH, Dunselman PH, DallingaThie GM, Zwinderman AH, Jukema JW. The efficacy of statin monotherapy uptitration versus switching to ezetimibe/ simvastatin: results of the EASEGO study. Current Medical Research and Opinion 2008;24(3):685-94.

\section{ELIMIT 2013 \{published data only\}}

Brunner G, Yang EY, Kumar A, Sun W, Virani SS, Negi SI, et al. The Effect of Lipid Modification on Peripheral Artery Disease after Endovascular Intervention Trial (ELIMIT). Atherosclerosis 2013;231(2):371-7.

\section{Enajat 2009 \{published data only\}}

Enajat M, Teerenstra S, van Kuilenburg JT, van SorgeGreve AH, Albers-Akkers MT, Verheugt FW, et al. Safety of the combination of intensive cholesterol-lowering therapy with oral anticoagulation medication in elderly patients with atrial fibrillation: a randomized, double-blind, placebo-controlled study. Drugs and Aging 2009;26(7):585-93. 


\section{Ferrieres 2016 \{published data only\}}

Ferrieres J, Dallongeville J, Rossignol M, Benichou J, Caro JJ, Getsios D, et al. Model-observational bridging study on the effectiveness of ezetimibe on cardiovascular morbidity and mortality in France: A population-based study. Journal of Clinical Lipidology 2016;10(6):1379-88.

\section{Foody 2013 \{published data only\}}

Foody JM, Toth PP, Tomassini JE, Sajjan S, Ramey DR, Neff D, et al. Changes in LDL-C levels and goal attainment associated with addition of ezetimibe to simvastatin, atorvastatin, or rosuvastatin compared with titrating statin monotherapy. Vascular Health and Risk Management 2013;9:719-27.

Habara 2014 \{published data only\}

Habara M, Nasu K, Terashima M, Ko E, Yokota D, Ito T, et al. Impact on optical coherence tomographic coronary findings of fluvastatin alone versus fluvastatin + ezetimibe. American Journal of Cardiology 2014;113(4):580-7.

\section{Hayek 2013 \{published data only\}}

Hayek S, Canepa Escaro F, Sattar A, Gamalski S, Wells KE, Divine $\mathrm{G}$, et al. Effect of ezetimibe on major atherosclerotic disease events and all-cause mortality. American Journal of Cardiology 2013;111(4):532-9.

\section{HEAVEN 2012 \{published data only\}}

Kovarnik T. Changes of plaque volume and plaque composition during dual lipid-lowering therapy (atorvastatin+ezetimibe) compared to standard therapy. Study with intravascular ultrasound and virtual histology. Eurolntervention 2013;9 EuroPCR Abstracts 2013:no pagination.

Kovarnik T, Horak J, Sonka M, Uhrova J, Skalicka H, Simek S, et al. Virtual histology evaluation of atherosclerosis regression during atorvastatin and ezetimibe administration - HEAVEN study (ongoing). American Journal of Cardiology 2009;104(6 SUPPL 1):60D-61D.

* Kovarnik T, Mintz GS, Skalicka H, Kral A, Horak J, Skulec R, et al. Virtual histology evaluation of atherosclerosis regression during atorvastatin and ezetimibeadministration: HEAVEN study. Circulation Journal 2012;76(1):176-83.

\section{Hiro 2014 \{published data only\}}

Hiro T, Hirayama A, Ueda Y, Komatsu S, Matsuoka H, Takayama $\mathrm{T}$, et al. Rationale and design of a randomized clinical study to investigate the effect of ezetimibe, a cholesterol absorption inhibitor, on the regression of intracoronary plaque evaluated by non-obstructive angioscopy and ultrasound: The ZIPANGU study. Journal of Cardiology 2014;64(6):501-7.

\section{Jackowska 2016 \{published data only\}}

Jackowska P, Pytel E, Koter-Michalak M, OlszewskaBanaszczyk M, Legeza A, Broncel M. The effect of combined ezetimibe/atorvastatin therapy vs. atorvastatin monotherapy on the erythrocyte membrane structure in patients with coronary artery disease: A pilot study. Advances in Clinical \& Experimental Medicine 2016;25(3):433-9.

\section{Japaridze 2017 \{published data only\}}

* Japaridze L, Sadunishvili M. The short-term effect of atorvastatin plus ezetimibe therapy versus atorvastatin monotherapy on clinical outcome in acute coronary syndrome patients by gender. Kardiologia Polska 2017;75(8):770-8.

Japaridze L, Sadunishvili M, Megreladze I. Combination therapy effectiveness of ezetimibe and atorvastatin in patients with acute coronary syndrome. Georgian Medical News 2016;252:15-22.

\section{Koren 2014 \{published data only\}}

Koren MJ, Lundqvist P, Bolognese M, Neutel JM, Monsalvo ML, Yang J, et al. Anti-PCSK9 monotherapy for hypercholesterolemia: the MENDEL-2 randomized, controlled phase III clinical trial of evolocumab. Journal of the American College of Cardiology 2014;63(23):2531-40.

Kral 2011 \{published data only\}

Kral A, Kovarnik T, Kralik L, Skalicka H, Horak J, Mintz GS, et al. Genetic variants in haem oxygenase-1 and endothelial nitric oxide synthase influence the extent and evolution of coronary artery atherosclerosis. Folia Biologica (Czech Republic) 2011;57(5):182-90.

\section{Le 2015 \{published data only\}}

Le NA, Tomassini JE, Tershakovec AM, Neff DR, Wilson PW. Effect of switching from statin monotherapy to ezetimibe/simvastatin combination therapy compared with other intensified lipidlowering strategies on lipoprotein subclasses in diabetic patients with symptomatic cardiovascular disease. Journal of the American Heart Association 2015;4(10):e001675.

\section{Lopez 2008 \{published data only\}}

Lopez V, Gutierrez C, Gutierrez E, Sola E, Cabello M, Burgos D, et al. Treatment with ezetimibe in kidney transplant recipients with uncontrolled dyslipidemia. Transplantation Proceedings 2008;40(9):2925-6.

\section{Masana 2005 \{published data only\}}

Masana L, Mata P, Gagne C, Sirah W, Cho M, JohnsonLevonas AO, et al. Long-term safety and, tolerability profiles and lipid-modifying efficacy of ezetimibe coadministered with ongoing simvastatin treatment: a multicenter, randomized, double-blind, placebo-controlled, 48-week extension study. Clinical Therapeutics 2005;27(2):174-84.

\section{Masia 2009 \{published data only\}}

Masia M, Bernal E, Padilla S, Garcia N, Escribano JC, Martanez E, et al. A pilot randomized trial comparing an intensive versus a standard intervention in stable HIV-infected patients with moderate - High cardiovascular risk. Journal of Antimicrobial Chemotherapy 2009;64(3):589-98.

\section{Masuda 2015 \{published data only\}}

Masuda J, Tanigawa T, Yamada T, Nishimura Y, Sasou T, Nakata T, et al. Effect of combination therapy of ezetimibe and rosuvastatin on regression of coronary atherosclerosis in patients with coronary artery disease. International Heart Journal 2015;56(3):278-85. 
McKenney 2006 \{published data only\}

McKenney JM, Farnier M, Lo KW, Bays HE, Perevozkaya I, Carlson G, et al. Safety and efficacy of long-term coadministration of fenofibrate and ezetimibe in patients with mixed hyperlipidemia. Journal of the American College of Cardiology 2006;47(8):1584-7.

\section{Nicholls 2016 \{published data only\}}

Nicholls S, Ray K, Ballantyne C, Beacham L, Miller D, Ruotolo G, et al. Workshop 3.1: Novel Therapies. Comparative effects of cholesteryl ester transfer protein inhibiton, statin and ezetimibe therapy on atherogenic and protective lipid factors: The ACCENTUATE Trial. Atherosclerosis 2016;252:E237-8.

\section{ODYSSEY COMBO II \{published data only\}}

Cannon CP, Cariou B, Blom D, McKenney JM, Lorenzato C, Pordy R, et al. Efficacy and safety of alirocumab in high cardiovascular risk patients with inadequately controlled hypercholesterolaemia on maximally tolerated doses of statins: the ODYSSEY COMBO II randomized controlled trial. European Heart Journal 2015;36(19):1186-94.

\section{Okada 2010 \{published data only\}}

Okada K, Fukuoka T, Saitoh T, Endo T, Uchino K, Fukui K, et al. Measuring the baseline cholesterol absorption and synthesis marker can predict the LDL-C lowering response to ezetimibestatin combination therapy in patients with coronary artery disease: A multi-center prospective randomized trial. Circulation 2010;122(21):2.

\section{Okuyama 2012 \{published data only\}}

Okuyama Y, Kuramoto Y, Kawasaki M, Iwasaki Y, Tanaka K, Furukawa Y, et al. Assessment of atrial late potentials in patients with hypercholesteremia, to investigate the preventive effect of pitavastatin on atrial fibrillation (Alpina study). Journal of the American College of Cardiology 2012;59(13 SUPPL 1):E687.

\section{Palacio 2016 \{published data only\}}

Palacio E, Viadero-Cervera R, Revilla M, Larrosa-Campo D, Acha-Salazar O, Novo-Robledo F, et al. Utility of treatment with atorvastatin $40 \mathrm{mg}$ plus ezetimibe $10 \mathrm{mg}$ versus atorvastatin $80 \mathrm{mg}$ in reducing the levels of LDL cholesterol in patients with ischaemic stroke or transient ischaemic attack. Revista De Neurologia 2016;62(5):203-10.

\section{Pandey 2008 \{published data only\}}

Pandey AS, Bissonnette S, Boukas S, Sampalis JS. Effectiveness and tolerability of ezetimibe $10 \mathrm{mg} / \mathrm{d}$ coadministered with statins vs statin dose-doubling in patients at high coronary artery disease risk who are not at target LDL-C on statin monotherapy: The EZE (STAT)(2) trial. Arteriosclerosis Thrombosis and Vascular Biology 2008;28(6):E132.

\section{Patel 2013 \{published data only\}}

Patel AY, Pillarisetti J, Marr J, Vacek JL. Ezetimibe in combination with a statin does not reduce all-cause mortality. Journal of Clinical Medicine Research 2013;5(4):275-80.

\section{Pauriah 2014 \{published data only\}}

Pauriah M, Elder DH, Ogston S, Noman AY, Majeed A, Wyatt JC, et al. High-potency statin and ezetimibe use and mortality in survivors of an acute myocardial infarction: a population-based study. Heart 2014;100(11):867-72.

Pesaro 2010 \{published data only\}

Pesaro AE, Serrano CV, Fernandes JL, Cavalcanti AB, Campos AH, Martins HS, et al. A randomized trial comparing the pleotropic effects of ezetimibe plus moderate dose statin versus high dose statin monotherapy. Circulation 2010;122(21):2.

Pop-Purceleanu 2009 \{published data only\}

Pop-Purceleanu M, Wezenberg E, Enajat M, Zwiers M, Urner M, De Leeuw FE, et al. Cholesterol lowering treatment in atrial fibrillation (AF) reduces MTL atrophy. Biological Psychiatry 2009;65(8 SUPPL 1):152S.

\section{Pytel 2017 \{published data only\}}

Pytel E, Bukowska B, Koter-Michalak M, OlszewskaBanaszczyk M, Gorzelak-Pabi P, Broncel M. Effect of intensive lipid-lowering therapies on cholinesterase activity in patients with coronary artery disease. Pharmacological Reports 2017; Vol. 69, issue 1:150-5.

\section{Ran 2017 \{published data only\}}

Ran D, Nie HJ, Gao YL, Deng SB, Du JL, Liu YJ, et al. A randomized, controlled comparison of different intensive lipid-lowering therapies in Chinese patients with non-STelevation acute coronary syndrome (NSTE-ACS): Ezetimibe and rosuvastatin versus high-dose rosuvastatin. International Journal of Cardiology 2017;235:49-55.

\section{REMEDY 2016 \{published data only\}}

* Briguori C, Madonna R, Zimarino M, Calabro P, Quintavalle C, Salomone M, et al. Rosuvastatin for reduction of myocardial damage during coronary angioplasty - the REMEDY trial. Cardiovascular Drugs and Therapy 2016;30(5):465-72.

Briguori C, Quintavalle C, D'Alessio F, Donahue M, Roscigno G, Micco F, et al. Impact of statin therapy intensity on endothelial progenitor cells after percutaneous coronary intervention in diabetic patients. The REMEDY-EPC late study. International Journal of Cardiology 2017; Vol. 244:112-8.

Madonna R, Renna FV, Lanuti P, Pertetti M, Marchisio M, Briguori C, et al. The acute impact of high-dose lipid-lowering treatment on endothelial progenitor cells in patients with coronary artery disease-The REMEDY-EPC early substudy. PLOS One 2017;12(4):e0172800.

\section{SANDS 2008 \{published data only\}}

Fleg J, Meta M, Howard B, Roman M, Howard W. The SANDS trial: the effect of statins with versus without ezetimibe on carotid atherosclerosis in type 2 diabetes. Atherosclerosis Supplements 2009;10(2):e165.

* Fleg JL, Mete M, Howard BV, Umans JG, Roman MJ, Ratner RE, et al. Effect of statins alone versus statins plus ezetimibe on carotid atherosclerosis in type 2 diabetes: the SANDS (Stop Atherosclerosis in Native Diabetics Study) trial. Journal of the American College of Cardiology 2008;52(25):2198-205.

Howard BV, Roman MJ, Devereux RB, Fleg JL, Galloway JM, Henderson JA, et al. Effect of lower targets for blood pressure 
and LDL cholesterol on atherosclerosis in diabetes: the SANDS randomized trial. JAMA: Journal of the American Medical Association 2008;299(14):1678-89.

Mete M, Wilson C, Lee ET, Silverman A, Russell M, Stylianou M, et al. Relationship of glycemia control to lipid and blood pressure lowering and atherosclerosis: The SANDS experience. Journal of Diabetes and its Complications 2011;25(6):362-7.

Russell M, Silverman A, Fleg JL, Lee ET, Mete M, Weir M, et al. Achieving lipid targets in adults with type 2 diabetes: the Stop Atherosclerosis in Native Diabetics Study. Journal of Clinical Lipidology 2010;4(5):435-43.

\section{Santos 2014 \{published data only\}}

Santos PC, Morgan AC, Jannes CE, Krieger JE, Santos RD, Pereira AC. The MYLIP p.N342S polymorphism is associated with response to lipid-lowering therapy in Brazilian patients with familial hypercholesterolemia. Pharmacogenetics and Genomics 2014;24(11):548-55.

\section{SEAS 2008 \{published data only\}}

Rossebo AB, Pedersen TR, Allen C, Boman K, Chambers J, Egstrup $K$, et al. Design and baseline characteristics of the simvastatin and ezetimibe in aortic stenosis (SEAS) study. American Journal of Cardiology 2007;99(7):970-3.

* Rossebo AB, Pedersen TR, Boman K, Brudi P, Chambers JB, Egstrup K, et al. Intensive lipid lowering with simvastatin and ezetimibe in aortic stenosis. New England Journal of Medicine 2008;359(13):1343-56.

\section{Sertbas 2010 \{published data only\}}

Sertbas Y, Ersoy U, Ayter M, Gultekin Tirtil F, Kucukkaya B. Ezetimibe effect on bone mineral density and markers of bone formation and resorption. Journal of Investigative Medicine 2010;58(2):295-7.

\section{SHARP 2011 \{published data only\}}

Baigent C, Landray M, Reith C, Dasgupta T, Emberson J, Herrington W, et al. Study of Heart and Renal Protection (SHARP): Randomized trial to assess the effects of lowering low-density lipoprotein cholesterol among 9,438 patients with chronic kidney disease. American Heart Journal 2010;160(5):785-U28.

* Baigent C, Landray MJ, Reith C, Emberson J, Wheeler DC, Tomson C, et al. The effects of lowering LDL cholesterol with simvastatin plus ezetimibe in patients with chronic kidney disease (Study of Heart and Renal Protection): a randomised placebo-controlled trial. Lancet 2011;377(9784):2181-92.

Baigent C, Landry M. Study of Heart and Renal Protection (SHARP). Kidney International, Supplement 2003;63(84):S207-10.

\section{Steg 2008 \{published data only\}}

* Steg PG, Verdier JC, Carre F, Darne B, Ducardonnet A, Jullien $G$, et al. A randomised trial of three counselling strategies for lifestyle changes in patients with hypercholesterolemia treated with ezetimibe on top of statin therapy (TWICE). Archives of Cardiovascular Diseases 2008;101(11-12):723-35.
Steg PG, Verdier JC, Carre F, Ducardonnet A, Farnier M, Giral P, et al. Does patient counseling enhance the lipid-lowering efficacy of ezetimibe in hypercholesterolemic patients uncontrolled with a statin? The TWICE randomized trial. European Heart Journal 2007;28:589-90.

\section{Stein 2008 \{published data only\}}

Stein EA, Ballantyne CM, Engelhardt M, Gimpelewicz CR, Ghani S, Lescol XL: Myalgia Study Grp. Treating patients with a prior history of statin related muscle side effects to LDL-C goals using fluvastatin $\mathrm{XL}$ alone, or in combination with ezetimibe: $\mathrm{A}$ randomized, double blind multicentre study. European Heart Journal 2007;28:209.

Stein EA, Ballantyne CM, Gimplewicz C, Seper C, Ghani S. A randomized, double-blind, double-dummy, comparison of efficacy and tolerability of fluvastatin XL alone, ezetimibe alone and the combination, in patients with a history of muscle related side effects with other statins. Circulation 2006;114(18):905.

* Stein EA, Ballantyne CM, Windler E, Sirnes PA, Sussekov A, Yigit Z, et al. Efficacy and tolerability of fluvastatin XL $80 \mathrm{mg}$ alone, ezetimibe alone, and the combination of fluvastatin $\mathrm{XL} 80 \mathrm{mg}$ with ezetimibe in patients with a history of musclerelated side effects with other statins. American Journal of Cardiology 2008;101(4):490-6.

\section{Strony 2008 \{published data only\}}

Strony J, Yang B, Hanson ME, Veltri EP. Long-term safety and tolerability of ezetimibe coadministered with simvastatin in hypercholesterolemic patients: a randomized, 12-month double-blind extension study. Current Medical Research and Opinion 2008;24(11):3149-57.

\section{Strony 2008a \{published data only\}}

Strony J, Hoffman R, Hanson M, Veltri E. Tolerability and effects on lipids of ezetimibe coadministered with pravastatin or simvastatin for twelve months: results from two open-label extension studies in hypercholesterolemic patients. Clinical Therapeutics 2008;30(12):2280-97.

\section{Suzuki 2010 \{published data only\}}

Suzuki H, Inoue T, Watanabe Y, Kikuta T, Sato T, Tsuda M. Efficacy and safety of ezetimibe and low-dose simvastatin as primary treatment for dyslipidemia in peritoneal dialysis patients. Advances in Peritoneal Dialysis 2010;26:53-7.

\section{Takase 2017 \{published data only\}}

Takase S, Matoba T, Nakashiro S, Mukai Y, Inoue S, Oi K, et al. Ezetimibe in combination with statins ameliorates endothelial dysfunction in coronary arteries after stenting: The CuVIC Trial (Effect of Cholesterol Absorption Inhibitor Usage on Target Vessel Dysfunction After Coronary Stenting), a multicenter randomized controlled trial. Arteriosclerosis, Thrombosis and Vascular Biology 2017;37(2):350-8.

\section{Tendolkar 2012 \{published data only\}}

Tendolkar I, Enajat M, Zwiers MP, van Wingen G, de Leeuw FE, van Kuilenburg J, et al. One-year cholesterol lowering treatment reduces medial temporal lobe atrophy and memory decline in stroke-free elderly with atrial fibrillation: evidence from 
a parallel group randomized trial. International Journal of Geriatric Psychiatry 2012;27(1):49-58.

\section{Teramoto 2013 \{published data only\}}

Teramoto T, Abe K, Taneyama T. Safety and efficacy of longterm combination therapy with bezafibrate and ezetimibe in patients with dyslipidemia in the prospective, observational JCOMPATIBLE study. Cardiovascular Diabetology 2013;12:163.

\section{Thongtang 2012 \{published data only\}}

Thongtang N, Lin J, Schaefer EJ, Lowe RS, Tomassini JE, Shah AK, et al. Effects of ezetimibe added to statin therapy on markers of cholesterol absorption and synthesis and LDL-C lowering in hyperlipidemic patients. Atherosclerosis 2012;225(2):388-96.

\section{Troxel 2016 \{published data only\}}

Troxel AB, Asch DA, Mehta SJ, Norton L, Taylor D, Calderon TA, et al. Rationale and design of a randomized trial of automated hovering for post-myocardial infarction patients: The HeartStrong program. American Heart Journal 2016;179:166-74.

\section{Turk 2008 \{published data only\}}

Turk TR, Voropaeva E, Kohnle M, Nurnberger J, Philipp T, Kribben A, et al. Ezetimibe treatment in hypercholesterolemic kidney transplant patients is safe and effective and reduces the decline of renal allograft function: a pilot study. Nephrology Dialysis Transplantation 2008;23(1):369-73.

\section{UK-HARP- || 2006 \{published data only\}}

Landray M, Baigent C, Leaper C. Biochemical safety and efficacy of co-administration of Ezetimibe and Simvastatin among patients with chronic kidney disease: the second UK-heart and renal protection (UK-HARP-II) study. Oxford University Research Archive 2003; Vol. 18, issue Suppl 4:119-20.

* Landray M, Baigent C, Leaper C, Adu D, Altmann P, Armitage J, et al. The second United Kingdom Heart and Renal Protection (UK-HARP-II) Study: a randomized controlled study of the biochemical safety and efficacy of adding ezetimibe to simvastatin as initial therapy among patients with CKD. American Journal of Kidney Diseases 2006;47(3):385-95.

\section{van der Graaf 2008 \{published data only\}}

van der Graaf A, Cuffie-Jackson C, Vissers MN, Trip MD, Gagne C, Shi $G$, et al. Efficacy and safety of coadministration of ezetimibe and simvastatin in adolescents with heterozygous familial hypercholesterolemia. Journal of the American College of Cardiology 2008;52(17):1421-9.

\section{van Kuilenburg 2011 \{published data only\}}

van Kuilenburg J, Lappegard KT, Sexton J, Plesiewicz I, Lap P, Bouwels $L$, et al. Persisting thrombin activity in elderly patients with atrial fibrillation on oral anticoagulation is decreased by anti-inflammatory therapy with intensive cholesterol-lowering treatment. Journal of Clinical Lipidology 2011;5(4):273-80.

\section{Vera-Lastra 2016 \{published data only\}}

Vera-Lastra O, Mendez-Flores S, Cruz-Dominguez MP, Medina G, Calderon-Aranda E, Jara LJ. Effect of ezetimibe plus pravastatin on endothelial dysfunction in patients with systemic lupus erythematosus. Lupus 2016;25(7):741-8.

Wierzbicki 2005 \{published data only\}

Wierzbicki AS, Doherty E, Lumb PJ, Chik G, Crook MA. Efficacy of ezetimibe in patients with statin-resistant and statin-intolerant familial hyperlipidaemias. Current Medical Research and Opinion 2005;21(3):333-8.

\section{Zhao 2014 \{published data only\}}

Zhao XQ, Davis J, Isquith D, Dowdy A, Boltz S, Neradilek M, et al. Mortality reduction in patients treated with long-term intensive lipid therapy: 20-year follow-up of the familiar atherosclerosis treatment study-observational study. Journal of the American College of Cardiology 2014;63(12 SUPPL 1):A1287.

ZIPANGU 2017 \{published data only\}

Hiro T, Hirayama A, Ueda Y, Komatsu S, Matsuoka H, Takayama T, et al. Rationale and design of a randomized clinical study to investigate the effect of ezetimibe, a cholesterol absorption inhibitor, on the regression of intracoronary plaque evaluated by non-obstructive angioscopy and ultrasound: The ZIPANGU study. Journal of Cardiology 2014;64(6):501-7.

* Ueda Y, Hiro T, Hirayama A, Komatsu S, Matsuoka H, Takayama T, et al. Effect of ezetimibe on stabilization and regression of intracoronary plaque: the ZIPANGU study. Circulation Journal 2017; Vol. 81, issue 11:1611-9.

\section{References to studies awaiting assessment}

JPRN-UMIN000002964 \{published data only\}

JPRN-UMIN000002964. Prospective, randomized, openlabel, clinical trial comparing fibrate monotherapy and fibrate-ezetimibe combination therapy on progression of atherosclerotic plaques, endothelial function, and markers for anti-inflammatory properties/obesity/antioxidative properties. apps.who.int/trialsearch/Trial2.aspx?TrialID=JPRNUMIN000002964 (date of registration 3 January 2010).

\section{JPRN-UMIN000011745 \{published data only\}}

JPRN-UMIN000011745. Prospective, randomized, openlabel, clinical trial comparing rosuvastatin monotherapy and combination therapy with ezetimibe on progression of atherosclerotic plaques and endothelial function. apps.who.int/ trialsearch/Trial2.aspx?TrialID=JPRN-UMIN000011745 (date of registration 14 September 2013).

NCT01086020 \{published data only\}

NCT01086020. Atorvastatin plus Ezetimibe on coronary Plaque Progression (AEPP). clinicaltrials.gov/ct2/show/NCT01086020 (first posted 12 March 2010).

\section{NCT02588235 \{published data only\}}

NCT02588235. Ezetimibe and atorvastatin Therapy on TCFA. clinicaltrials.gov/ct2/show/NCT02588235 (first posted 27 October 2015). 


\section{References to ongoing studies}

\section{NCT03044665 \{published data only\}}

NCT03044665. RAndomized Comparison of efficacy and safety of lipid-lowerING with statin monotherapy versus statin/ezetimibe combination for high-risk cardiovascular diseases (RACING Trial). https://clinicaltrials.gov/ct2/show/ NCT03044665.

\section{NCT03169985 \{published data only\}}

NCT03169985. Usual dose Rosuvastatin plus EZetimibe versus high-dose rosuvastatin on coronary atherosclerotic plaque (Rosuzet-IVUS). clinicaltrials.gov/ct2/show/nct03169985 (first posted 30 May 2017).

\section{NCT03543774 \{published data only\}}

NCT03543774. Lipid-lowering therapies in Vietnamese Chronic Kidney Disease population (VietCKD). clinicaltrials.gov/ct2/ show/NCT03543774 (first posted 1 June 2018).

\section{Additional references}

\section{Altmann 2004}

Altmann SW, Davis HR Jr, Zhu LJ, Yao X, Hoos LM, Tetzloff G, et al. Niemann-Pick C1 Like 1 protein is critical for intestinal cholesterol absorption. Science 2004;303(5661):1201-4.

\section{Baigent 2011}

Baigent C, Landray MJ, Reith C, Emberson J, Wheeler DC, Tomson C, et al. The effects of lowering LDL cholesterol with simvastatin plus ezetimibe in patients with chronic kidney disease (Study of Heart and Renal Protection): a randomised placebo-controlled trial. Lancet 2011;377(9784):2181-92.

\section{Battaggia 2015}

Battaggia A, Donzelli A, Font M, Molteni D, Galvano A. Clinical efficacy and safety of Ezetimibe on major cardiovascular endpoints: systematic review and meta-analysis of randomized controlled trials. PLoS One [Electronic Resource] 2015;10(4):e0124587.

\section{Bloom 2011}

Bloom DE, Cafiero ET, Jané-Llopis E, Abrahams-Gessel S, Bloom LR, Fathima S, et al. The Global Economic Burden of Non-communicable Diseases. Geneva: World Economic Forum 2011.

\section{Cannon 2015}

Cannon CP, Blazing MA, Giugliano RP, McCagg A, White JA, Theroux $\mathrm{P}$, et al. Ezetimibe added to statin therapy after acute coronary syndromes. New England Journal of Medicine 2015;372(25):2387-97.

\section{CTT 2010}

Cholesterol Treatment Trialists Collaboration, Baigent C, Blackwell L, Emberson J, Holland LE, Reith C, Bhala N, et al. Efficacy and safety of more intensive lowering of LDL cholesterol: a meta-analysis of data from 170,000 participants in 26 randomised trials. Lancet 2010;376(9753):1670-81.

\section{CTT 2012}

Cholesterol Treatment Trialists Collaboration, Mihaylova B, Emberson J, Blackwell L, Keech A, Simes J, Barnes EH, et al. The effects of lowering LDL cholesterol with statin therapy in people at low risk of vascular disease: meta-analysis of individual data from 27 randomised trials. Lancet 2012;380(9841):581-90.

\section{Deeks 2011}

Deeks JJ, Higgins JPT, Altman DG (editors). Chapter 9: Analysing data and undertaking meta-analyses. In: Higgins JPT, Green $\mathrm{S}$ (editors). Cochrane Handbook for Systematic Reviews of Interventions Version 5.1.0 (updated March 2011). The Cochrane Collaboration, 2011. Available from handbook.cochrane.org.

\section{EDP 2014}

Expert Dyslipidemia Panel of the International Atherosclerosis Society Panel members. An International Atherosclerosis Society Position Paper: global recommendations for the management of dyslipidemia--full report. Journal of Clinical Lipidology 2014;8(1):29-60.

\section{EMA 2004}

European Medicines Agency (EMA). Committee for Medicinal Products For Human Use. Note for guidance on clinical investigation of medicinal products in the treatment of lipid disorders. www.ema.europa.eu/docs/en_GB/document_ library/Scientific_guideline/2009/09/WC500003235.pdf (accessed 1 December 2016).

\section{Fei 2018}

Fei Y, Guyatt GH, Alexander PE, El Dib R, Siemieniuk RAC, Vandvik PO, et al. Addition of ezetimibe to statins for patients at high cardiovascular risk: Systematic review of patientimportant outcomes. Journal of Evaluation in Clinical Practice 2018;24(1):222-31

\section{GBD 2016}

Global Burden of Disease (GBD) 2015 Mortality and Causes of Death Collaborators. Global, regional, and national life expectancy, all-cause mortality, and cause-specific mortality for 249 causes of death, 1980-2015: a systematic analysis for the Global Burden of Disease Study 2015. Lancet 2016;388(10053):1459-544.

\section{Grundy 2004}

Grundy SM, Cleeman JI, Merz CN, Brewer HB Jr, Clark LT, Hunninghake DB, et al. Implications of recent clinical trials for the National Cholesterol Education Program Adult Treatment Panel III guidelines. Circulation 2004;110(2):227-39.

\section{Gudzune 2014}

Gudzune KA, Monroe AK, Sharma R, Ranasinghe PD, Chelladurai Y, Robinson KA. Effectiveness of combination therapy with statin and another lipid-modifying agent compared with intensified statin monotherapy: a systematic review. Annals of Internal Medicine 2014;160(7):468-76.

\section{Higgins 2003}

Higgins JPT, Thompson SG, Deeks JJ, Altman DG. Measuring inconsistency in meta-analyses. BMJ 2003;327:557-60. 


\section{Higgins 2011}

Higgins JPT, Altman DG, Sterne JAC (editors). Chapter 8: Assessing risk of bias in included studies. In: Higgins JPT, Green $S$ (editors). Cochrane Handbook for Systematic Reviews of Interventions Version 5.1.0 (updated March 2011). The Cochrane Collaboration, 2011. Available from handbook.cochrane.org.

\section{Huedo-Medina 2006}

Huedo-Medina TB, Sanchez-Meca J, Marin-Martinez F, Botella J. Assessing heterogeneity in meta-analysis: Q statistic or 12 index?. Psychological Methods 2006;11(2):193-206.

\section{Jacobson 2015}

Jacobson TA, Ito MK, Maki KC, Orringer CE, Bays HE, Jones PH, et al. National lipid association recommendations for patientcentered management of dyslipidemia: part 1- full report. Journal of Clinical Lipidology 2015;9(2):129-69.

\section{Jia 2011}

Jia L, Betters JL, Yu L. Niemann-pick C1-like 1 (NPC1L1) protein in intestinal and hepatic cholesterol transport. Annual Review of Physiology 2011;73:239-59.

\section{Kastelein 2008}

Kastelein JJ, Akdim F, Stroes ES, Zwinderman AH, Bots ML, Stalenhoef AF, et al. Simvastatin with or without ezetimibe in familial hypercholesterolemia. New England Journal of Medicine 2008;358(14):1431-43.

\section{Kosoglou 2005}

Kosoglou T, Statkevich P, Johnson-Levonas AO, Paolini JF, Bergman AJ, Alton KB. Ezetimibe: a review of its metabolism, pharmacokinetics and drug interactions. Clinical Pharmacokinetics 2005;44(5):467-94.

\section{Lefebvre 2011}

Lefebvre C, Manheimer E, Glanville J. Chapter 6: Searching for studies. In: Higgins JPT, Green S (editors). Cochrane Handbook for Systematic Reviews of Interventions Version 5.1.0 (updated March 2011). The Cochrane Collaboration, 2011. Available from handbook.cochrane.org.

\section{Liberati 2009}

Liberati A, Altman DG, Tetzlaff J, Mulrow C, Gotzsche PC, Ioannidis JP, et al. The PRISMA statement for reporting systematic reviews and meta-analyses of studies that evaluate health care interventions: explanation and elaboration. PLOS Medicine 2009;6:e1000100.

\section{Lioudaki 2011}

Lioudaki E, Ganotakis ES, Mikhailidis DP. Ezetimibe; more than a low density lipoprotein cholesterol lowering drug? An update after 4 years. Current Vascular Pharmacology 2011;9(1):62-86.

\section{Mozaffarian 2016}

Mozaffarian D, Benjamin EJ, Go AS, Arnett DK, Blaha MJ, Cushman M, et al. Heart disease and stroke statistics - 2016 update: a report from the American Heart Association. Circulation 2016;133(4):e38-e360.

\section{Nichols 2014}

Nichols M, Townsend N, Scarborough P, Rayner M. Cardiovascular disease in Europe 2014: epidemiological update. European Heart Journal 2014;35(42):2950-9.

\section{Nusßaumer 2016}

Nusßaumer B, Glechner A, Kaminski-Hartenthaler A, Mahlknecht P, Gartlehner G. Ezetimibe-statin combination therapy. Deutsches Arzteblatt International 2016;113(26):445-53.

\section{Perk 2012}

Perk J, De Backer G, Gohlke H, Graham I, Reiner Z, Verschuren $\mathrm{M}$, et al. European guidelines on cardiovascular disease prevention in clinical practice (version 2012). The fifth Joint Task Force of the European Society of Cardiology and other societies on cardiovascular disease prevention in clinical practice (constituted by representatives of nine societies and by invited experts). European Heart Journal 2012;33(13):1635-701.

\section{Phan 2012}

Phan BA, Dayspring TD, Toth PP. Ezetimibe therapy: mechanism of action and clinical update. Vascular Health and Risk Management 2012;8:415-27.

\section{PSC 2007}

Prospective Studies Collaboration, Lewington S, Whitlock G, Clarke R, Sherliker P, Emberson J, et al. Blood cholesterol and vascular mortality by age, sex, and blood pressure: a metaanalysis of individual data from 61 prospective studies with 55,000 vascular deaths. Lancet 2007;370(9602):1829-39.

\section{Rabar 2014}

Rabar S, Harker M, O'Flynn N, Wierzbicki AS, Guideline Development Group. Lipid modification and cardiovascular risk assessment for the primary and secondary prevention of cardiovascular disease: summary of updated NICE guidance. BMJ 2014;349:g4356.

\section{Reiner 2014}

Reiner Z. Resistance and intolerance to statins. Nutrition, Metabolism and Cardiovascular Diseases 2014;24(10):1057-66.

\section{RevMan 2014 [Computer program]}

Nordic Cochrane Centre; The Cochrane Collaboration. Review Manager 5 (RevMan 5). Version 5.3. Copenhagen: Nordic Cochrane Centre; The Cochrane Collaboration, 2014.

\section{Rossebo 2008}

Rossebo AB, Pedersen TR, Boman K, Brudi P, Chambers JB, Egstrup K, et al. Intensive lipid lowering with simvastatin and ezetimibe in aortic stenosis. New England Journal of Medicine 2008;359(13):1343-56.

\section{Roth 2015a}

Roth GA, Forouzanfar MH, Moran AE, Barber R, Nguyen G, Feigin VL, et al. Demographic and epidemiologic drivers of global cardiovascular mortality. New England Journal of Medicine 2015;372(14):1333-41. 


\section{Roth 2015b}

Roth GA, Huffman MD, Moran AE, Feigin V, Mensah GA, Naghavi M, et al. Global and regional patterns in cardiovascular mortality from 1990 to 2013. Circulation 2015;132(17):1667-78.

\section{Savarese 2015}

Savarese G, De Ferrari GM, Rosano GM, Perrone-Filardi P. Safety and efficacy of ezetimibe: A meta-analysis. International Journal of Cardiology 2015;201:247-52.

\section{Schmidt 2017}

Schmidt AF, Pearce LS, Wilkins JT, Overington JP, Hingorani AD, Casas JP. PCSK9 monoclonal antibodies for the primary and secondary prevention of cardiovascular disease. Cochrane Database of Systematic Reviews 2017, Issue 4. [DOI: 10.1002/14651858.CD011748.pub2]

\section{Schünemann 2011}

Schünemann HJ, Oxman AD, Vist GE, Higgins JP, Deeks JJ, Glasziou P, et al. Chapter 12: Interpreting results and drawing conclusions. In: Higgins JPT, Green S (editors), Cochrane Handbook for Systematic Reviews of Interventions Version 5.1.0 (updated March 2011). The Cochrane Collaboration, 2011. Available from handbook.cochrane.org.

\section{Sterne 2011}

Sterne JAC, Egger M, Moher D (editors). Chapter 10: Addressing reporting biases. In: Higgins JPT, Green S (editors). Cochrane Handbook for Systematic Reviews of Intervention. Version 5.1.0 (updated March 2011). The Cochrane Collaboration, 2011. Available from handbook.cochrane.org.

\section{Stone 2014}

Stone NJ, Robinson JG, Lichtenstein AH, Bairey Merz CN, Blum CB, Eckel RH, et al. 2013 ACC/AHA guideline on the treatment of blood cholesterol to reduce atherosclerotic cardiovascular risk in adults: a report of the American College of Cardiology/American Heart Association Task Force on Practice Guidelines. Circulation 2014;129(25 Suppl 2):S1-45.

\section{Sudhop 2002}

Sudhop T, Lutjohann D, Kodal A, Igel M, Tribble DL, Shah S, et al. Inhibition of intestinal cholesterol absorption by ezetimibe in humans. Circulation 2002;106(15):1943-8.

\section{CHARACTERISTICS OF STUDIES}

Characteristics of included studies [ordered by study ID]

\section{Sudhop 2009}

Sudhop T, Reber M, Tribble D, Sapre A, Taggart W, Gibbons P, et al. Changes in cholesterol absorption and cholesterol synthesis caused by ezetimibe and/or simvastatin in men. Journal of Lipid Research 2009;50(10):2117-23.

\section{Thomopoulos 2015}

Thomopoulos C, Skalis G, Michalopoulou H, Tsioufis C, Makris T. Effect of low-density lipoprotein cholesterol lowering by ezetimibe/simvastatin on outcome incidence: overview, metaanalyses, and meta-regression analyses of randomized trials. Clinical Cardiology 2015;38(12):763-9.

\section{Van Heek 2000}

Van Heek M, Farley C, Compton DS, Hoos L, Alton KB, Sybertz EJ, et al. Comparison of the activity and disposition of the novel cholesterol absorption inhibitor, SCH58235, and its glucuronide, $\mathrm{SCH} 60663$. British Journal of Pharmacology 2000;129(8):1748-54.

\section{WHO 2015}

World Health Organization. Cardiovascular diseases (CVDs) [Fact sheet number 317, Updated January 2015]. www.who.int/ mediacentre/factsheets/fs317/en/ (accessed 15 March 2016).

\section{WHO 2016}

World Health Organization. Cardiovascular diseases. www.who.int/topics/cardiovascular_diseases/en/ (accessed 15 March 2016).

\section{References to other published versions of this review}

\section{Zhan 2017}

Zhan S, Xia P, Tang M, Liu F, Shu M, Wu X. Ezetimibe for the prevention of cardiovascular disease and all-cause mortality events. Cochrane Database of Systematic Reviews 2017, Issue 1. [DOI: 10.1002/14651858.CD012502]

* Indicates the major publication for the study

Ballantyne 2004

Methods Design: multinational, randomised, placebo-controlled, extension study

Number of study centres: multinational (conducted in 16 countries, but did not report the number of study centres)

Setting: outpatient

Patient recruitment: not reported

Duration of study: 12 months 
Randomised (N): intervention: 201; control:45

Withdrawn (N): not reported

Lost to follow-up (N): not reported

Completed the study (N): intervention: 167; control: 39

Analysed (N): intervention: 201; control:45

Age (years) (mean, range): intervention: 57.6 (26-86); control: 58.5 (34-76)

Sex (male, N, \%): intervention: 78 (39\%); control: 23 (51\%)

Smoking history (N, \%): intervention: 26 (13\% ); control: 4 (9\%)

BMI $\left(\mathbf{k g} / \mathbf{m}^{2}\right)$ : not reported

Diabetes (N, \%): intervention: 14 (7\%) ; control: $1(2 \%)$

Hypertension (N, \%): intervention: 68 (34\%); control: 19 (42\%)

History of CHD (N, \%): intervention:23(11\%) ; control:6(13\%)

Statin pretreatment (N, \%): not reported

Inclusion criteria: this was an extension study of a 12-week RCT comparing ezetimibe $10 \mathrm{mg}$; atorvastatin $10 \mathrm{mg}, 20 \mathrm{mg}, 40 \mathrm{mg}$ or $80 \mathrm{mg}$; ezetimibe + atorvastatin $10 \mathrm{mg}, 20 \mathrm{mg}, 40 \mathrm{mg}$ or $80 \mathrm{mg}$ or placebo. Patients who successfully completed the base study were offered enrolment in the 12-month extension study. The inclusion criteria of the parent study: men and women $>=18$ years of age were screened for primary hypercholesterolaemia, defined as calculated LDL-C 7 of 145 to $250 \mathrm{mg} / \mathrm{dL}$, inclusive, and triglyceride levels $<=350 \mathrm{mg} / \mathrm{dL}$.

Exclusion criteria: the exclusion criteria of the parent study included congestive heart failure (defined as New York Heart Association class III or IV heart failure 8); uncontrolled cardiac arrhythmias; MI, coronary bypass surgery, or angioplasty within 6 months of study entry; history of unstable or severe peripheral artery disease within 3 months of study entry; unstable angina pectoris; uncontrolled or newly diagnosed (within 1 month of study entry) diabetes mellitus; unstable endocrine or metabolic diseases known to influence serum lipids and lipoproteins; known impairment of renal function; active or chronic hepatic or hepatobiliary disease; and known coagulopathy.

Interventions Intervention: ezetimibe + atorvastatin $10 \mathrm{mg}$

Comparison: placebo + atorvastatin $10 \mathrm{mg}$

Quote: "Following intervals of 6 weeks, patients who were not at their National Cholesterol Education Program Adult Treatment Panel II (NCEP ATP II) LDL-C goals were titrated to the next higher dose of atorvastatin, up to a maximum dose of atorvastatin $(80 \mathrm{mg}) . "$

Details of any 'run-in' period: not reported

Concomitant medications: not reported

Excluded medications: not reported

1. treatment-emergent adverse events;

2. percent change from baseline to endpoint in LDL-C, total cholesterol (TC), HDL-C and triglyceride and proportion of patients attaining the NCEP ATP II LDL-C goal 
Ballantyne 2004 (Continued)

Notes
Funding: Study was funded by Schering-Plough Research Institute and Merck/Schering-Plough Pharmaceuticals.

Emailed trialists to ask for details number of discontinuations due to patient request, non-compliance with protocol and lost to follow-up. No response.

\section{Risk of bias}

\begin{tabular}{|c|c|c|}
\hline Bias & Authors' judgement & Support for judgement \\
\hline $\begin{array}{l}\text { Random sequence genera- } \\
\text { tion (selection bias) }\end{array}$ & Unclear risk & $\begin{array}{l}\text { The author reported that they randomly assigned patients but the details were } \\
\text { not available. }\end{array}$ \\
\hline $\begin{array}{l}\text { Allocation concealment } \\
\text { (selection bias) }\end{array}$ & Unclear risk & Insufficient information to permit judgement. \\
\hline $\begin{array}{l}\text { Blinding of participants } \\
\text { and personnel (perfor- } \\
\text { mance bias) } \\
\text { All outcomes }\end{array}$ & Low risk & Double-blind, using matching placebo. \\
\hline $\begin{array}{l}\text { Blinding of outcome as- } \\
\text { sessment (detection bias) } \\
\text { All outcomes }\end{array}$ & Low risk & $\begin{array}{l}\text { A central laboratory performed all clinical laboratory analyses (lipids, liver en- } \\
\text { zymes, creatine kinases, etc.). }\end{array}$ \\
\hline $\begin{array}{l}\text { Incomplete outcome data } \\
\text { (attrition bias) } \\
\text { All outcomes }\end{array}$ & Low risk & $\begin{array}{l}\text { Quote: "Discontinuations due to patient request, non-compliance with proto- } \\
\text { col and lost to follow-up were not different between treatment groups". } \\
\text { The efficacy and safety analyses were performed in the intention-to-treat pop- } \\
\text { ulation. }\end{array}$ \\
\hline $\begin{array}{l}\text { Selective reporting (re- } \\
\text { porting bias) }\end{array}$ & Unclear risk & No protocol published, or trials registry record found. \\
\hline Other bias & Unclear risk & $\begin{array}{l}\text { Insufficient information to permit judgement. } \\
\text { Study was funded by Schering-Plough Research Institute and Merck/Scher- } \\
\text { ing-Plough Pharmaceuticals. }\end{array}$ \\
\hline
\end{tabular}

\section{EFECTL 2017}

$\begin{array}{ll}\text { Methods } & \text { Design: three-arm parallel-group, open-label randomised trial } \\ \text { Number of study centres: } 50 \text { study centres in Japan } \\ \text { Setting: outpatient clinics } \\ \text { Patient recruitment: March } 2009 \text { to December } 2012 \\ \text { Duration of study: } 52 \text { weeks } \\ \text { Clinical setting: combined hyperlipidaemia } \\ \text { Enrolment (N): } 236 \text { in total, of interest are combination group with ezetimibe plus fenofibrate (N = 118) } \\ \text { and fenofibrate group (N = 59) } \\ \text { Randomised (N): combination group: 118; fenofibrate group 59; ezetimibe group: } 59 \\ \text { Pithdrawn (N): combination group: } 30 ; \text { fenofibrate group: 18; ezetimibe group: } 15\end{array}$


Lost to follow-up (N): combination group: ; fenofibrate group:

Completed the study (N): combination group: 88; fenofibrate group: 41; ezetimibe group: 44

Analysed (N): combination group: 107; fenofibrate group: 51; ezetimibe group: 52

Age (years) (mean \pm SD): combination group: $55.8 \pm 12.6$; fenofibrate group: $58.3 \pm 10.4$

Sex (male, N, \%): combination group: 63 (58.9\%); fenofibrate group: 31 (59.6\%)

Smoking history ( $\mathrm{N}, \%)$ : not reported

BMI (kg/m $\mathbf{2}$, mean \pm SD):): combination group: $27.0 \pm 4.4$; fenofibrate group: $25.2 \pm 2.9$

Diabetes (N, \%): combination group: 22 (20.6\%); fenofibrate group: 10 (19.2\%)

Hypertension (N, \%): combination group: 45 (42.1\%); fenofibrate group: 24 (46.2\%)

Existing CHD: combination group:4 (\%), fenofibrate group: 4 (\%)

History of MI (N, \%): combination group: 1 (0.9\%); fenofibrate group: 1 (1.9\%)

Statin pretreatment (N, \%): not reported

Inclusion criteria: Quote: "Eligible patients were men and women aged between 20 and 75 years at the time of obtaining informed consent. Patients were required to have a TG concentration of $200-400 \mathrm{mg} /$ $\mathrm{dL}$ and LDL-C concentration of $\geq 140 \mathrm{mg} / \mathrm{dL}$ as calculated by the Friedewald formula at screening."

Exclusion criteria: Quote: "1) use of probucol within the previous year; 2) familial hypercholesterolemia; 3) drug-induced hyperlipidemia from steroids or other drugs; 4) history or complication of malignant tumor, pancreatitis, gallstones, gallbladder disease, drug abuse, alcoholism, recent MI or cerebrovascular disorder (within 3 months before the study), cardiac arrhythmia requiring drug treatment, uncontrolled diabetes mellitus, or serious liver or renal disorder; 5) drug hypersensitivity including history of hypersensitivity to fenofibrate or ezetimibe; 6) problems related to discontinuing prohibited drugs; 7) patients who were pregnant, lactating, possibly pregnant, or planning to become pregnant; 8) participation in other clinical research such as clinical trials; 9) condition successfully controlled by current anti-hyperlipidemic drug; 10) participation otherwise judged inappropriate by the study physicians; 11 ) the screening tests resulted in a hemoglobin $\mathrm{Alc}$ ( $\mathrm{HbA1c}$ ) of $\geq 8 \%$, aspartate amino-transferase (AST) or alanine aminotransferase (ALT) concentrations twice the upper limits of the institutional reference range or $\geq 80 \mathrm{lU} / \mathrm{L}$, or serum creatinine level of $\geq 1.5 \mathrm{mg} / \mathrm{dL}$."

Interventions

\section{Intervention:}

Arm 1 (combination group): fenofibrate (either 2 capsules of Lipidil $100 \mathrm{mg} /$ capsule or 2 tablets of Lipidil $80 \mathrm{mg} /$ tablet) plus ezetimibe (10 $\mathrm{mg} /$ day).

Arm 2 (fenofibrate group): fenofibrate (either 2 capsules of Lipidil $100 \mathrm{mg} /$ capsule or 2 tablets of Lipidil $80 \mathrm{mg} /$ tablet).

Arm 3 (ezetimibe group): ezetimibe (10 mg/day)

We only included Arm 1 and Arm 2.

Details of any 'run-in' period: Quote: "If patients were under medication for dyslipidaemia, the study began with a 4-week washout period, which was followed by a 4-week observation period and 52-week treatment period. Treatment-naïve patients did not go through the washout period. During the observation period, patients who had been screened for eligibility were enrolled and randomly assigned."

Concomitant medications: not reported

Excluded medications: not reported

\section{Outcomes}

\section{Primary:}

1. per cent changes in LDL-C and TG concentrations. 
EFECTL 2017 (Continued)

\section{Secondary:}

1. the incidence of adverse events, including the incidence of gallstones detected by abdominal ultrasound; the incidence of abnormal findings for safety variables, including laboratory tests and physical examination; and the per cent change in HDL-C.

\section{Others:}

1. per cent change in other lipid variables (high-sensitivity assays for lipoprotein lipase (LPL), remnant lipoprotein cholesterol (RemL-C), LDL particle size, HDL particle size, apolipoprotein (apo) A-I, A-II, B, B-48, C-II, C-III, E, and phospholipid hydroperoxide);

2. non-lipid variables (high-sensitivity assay for C-reactive protein (hsCRP), adiponectin);

3. per cent change in lipid variables in patients with familial combined hyperlipidaemia;

4. trends in concentrations of serum lipid subclasses.

In the results section of the article, the study reported one case of fatal arrhythmia occurred during the study. However, the investigator concluded that there was no causal relationship between arrhythmia and experimental drugs.

Notes

Funding: Quote: "the study were provided to the Comprehensive Support Project for Clinical Research of Lifestyle-Related Disease of the Public Health Research Foundation, the Secretariat of the study, by Aska Pharmaceutical Co., Ltd., the manufacturer of fenofibrate.". "Neither the funder nor the sponsor had any role in study design, collection, analysis, or interpretation of data, writing the report, or the decision to submit the report for publication."

UMIN000001224

\section{Risk of bias}

\begin{tabular}{lll}
\hline Bias & Authors' judgement & Support for judgement \\
\hline $\begin{array}{l}\text { Random sequence genera- } \\
\text { tion (selection bias) }\end{array}$ & Low risk & $\begin{array}{l}\text { Quote: "The allocation schedule was created by a data center. Random num- } \\
\text { bers were generated with the SAS for Windows release 9.1.3 statistical soft- } \\
\text { ware program. " }\end{array}$ \\
\hline $\begin{array}{l}\text { Allocation concealment } \\
\text { (selection bias) }\end{array}$ & Low risk & $\begin{array}{l}\text { Quote: "The allocation schedule was created by a data center"; "A central reg- } \\
\text { istration system at the data center was used to ensure that allocation was con- } \\
\text { cealed from other researchers". }\end{array}$ \\
\hline
\end{tabular}

Blinding of participants High risk Open-label study, no blinding of participants and personnel.

and personnel (perfor-

mance bias)

All outcomes

\begin{tabular}{lll}
\hline $\begin{array}{l}\text { Blinding of outcome as- } \\
\text { sessment (detection bias) } \\
\text { All outcomes }\end{array}$ & Low risk & $\begin{array}{l}\text { Quote: "Samples for the analysis of endpoints were tested at a central labora- } \\
\text { tory"; low risk of bias for mortality. }\end{array}$ \\
\hline $\begin{array}{l}\text { Incomplete outcome data } \\
\text { (attrition bias) }\end{array}$ & Unclear risk & $\begin{array}{l}\text { Quote: "9 patients in the combination group and } 6 \text { patients in the fenofibrate } \\
\text { group were never treated with the study drug or drugs. Moreover, } 2 \text { patients } \\
\text { in the combination group, } 1 \text { in the fenofibrate group were removed for proto- } \\
\text { col violations because of administration of the wrong study drug for their as- } \\
\text { signed group". Of the patients who completed the } 52 \text {-week treatments, } 12 \text { pa- } \\
\text { tients were found to have been ineligible (9 in the combination group, } 1 \text { in the } \\
\text { fenofibrate group, and } 2 \text { in the ezetimibe group). These patients were included } \\
\text { in the analysis." }\end{array}$ \\
\hline
\end{tabular}

$\begin{array}{ll}\begin{array}{l}\text { Selective reporting (re- } \\ \text { porting bias) }\end{array} & \text { Low risk } \\ & \text { Nound (UMIN000001224). }\end{array}$


EFECTL 2017 (Continued)

All prespecified outcomes were reported.

Other bias Low risk

The study was industry funded, but neither the funder nor the sponsor had any role in study design, collection, analysis, or interpretation of data, writing the report, or the decision to submit the report for publication.

Number of study centres: 18 ambulatory care centres in the USA, Canada, South Africa, Spain, Denmark, Norway, Sweden, and the Netherlands

Setting: ambulatory care

Patient recruitment: August 2002 to April 2004

Duration of study: 24 months

Clinical setting: familial hypercholesterolaemia

Randomised (N): intervention: 357; control: 363

Withdrawn (N): intervention: 41; control: 64

Lost to follow-up (N): intervention: 2; control: 2

Completed the study (N): intervention: 316; control: 299

Analysed (N): intervention: 357; control: 363

Age (years) (mean \pm SD): intervention: $46.1 \pm 9.0$; control: $45.7 \pm 10.0$

Sex (male, N, \%): intervention: 191 (53.5\%); control: 179 (49.3\%)

Smoking history (N, \%): intervention: 104 (28.7\%); control: 102 (28.6\%)

BMI (kg/m², mean \pm SD):): intervention: $27.4 \pm 4.6$; control: $26.7 \pm 4.4$

Diabetes (N, \%): intervention: 8 (2.2\%); control: 5 (1.4\%)

Hypertension (N, \%): intervention: 67 (18.8\%); control: 51 (14.0\%)

History of MI (N, \%): intervention: 26 (7.2\%); control: 14 (3.9\%)

Statin pretreatment (N, \%): intervention: 286 (80.1\%); control: $297(81.8 \%)$

\section{Inclusion criteria:}

1. men and women between the ages of 30 and 75 years were eligible to participate in the study if familial hypercholesterolaemia had been diagnosed either by genotyping or by their having met the diagnostic criteria outlined by the World Health Organization;

2. untreated levels of LDL cholesterol had to be $210 \mathrm{mg} / \mathrm{dL}$ or more.

3. patients who were receiving lipid-lowering therapy and who had an LDL cholesterol level of less than $210 \mathrm{mg} / \mathrm{dL}$ at the time of screening were permitted to undergo randomisation if their LDL cholesterol level was $210 \mathrm{mg} / \mathrm{dL}$ or more after the placebo run-in period.

Exclusion criteria: high-grade stenosis or occlusion of the carotid artery, a history of carotid endarterectomy or carotid stenting, homozygous familial hypercholesterolaemia, New York Heart Associ- 
ENHANCE 2008 (Continued)

ation class III or IV congestive heart failure, cardiac arrhythmia, angina pectoris, or recent cardiovascu-

lar events.

\begin{tabular}{|c|c|}
\hline Interventions & $\begin{array}{l}\text { Intervention: simvastatin } 80 \mathrm{mg} / \text { day + ezetimibe } 10 \mathrm{mg} / \mathrm{day} \\
\text { Comparison: simvastatin } 80 \mathrm{mg} / \text { day + ezetimibe placebo } \\
\text { Details of any 'run-in' period: a single-blind 6-week placebo run-in period } \\
\text { Concomitant medications: not reported } \\
\text { Excluded medications: not reported }\end{array}$ \\
\hline Outcomes & $\begin{array}{l}\text { Primary: } \\
\text { 1. the change from baseline in ultrasonographic measurement of the mean carotid-artery intima-media } \\
\text { thickness. } \\
\text { Secondary: } \\
\text { 1. the proportion of patients with regression in the mean carotid-artery intima-media thickness from } \\
\text { baseline; } \\
\text { 2. the proportion of patients with new carotid-artery plaques of more than } 1.3 \mathrm{~mm} \text {; } \\
\text { 3. the change from baseline in the mean maximal carotid-artery intima-media thickness; } \\
\text { 4. the change from baseline in the average mean intima-media thickness of the carotid and common } \\
\text { femoral arteries; } \\
\text { 5. the change from baseline in the mean IMT, separately for the three carotid artery segments (common } \\
\text { carotid, carotid bulb, and the internal carotid artery) and the } \\
\text { 6. femoral artery; } \\
\text { 7. the per cent change from baseline in lipid parameters (LDL-C, HDL-C, total cholesterol, apoB, and } \\
\text { triglycerides); } \\
\text { 8. the per cent change from baseline in lipid indices: total cholesterol, calculated LDL-C, HDL-C, triglyc- } \\
\text { erides, apolipoprotein B, apolipoprotein Al, and CRP. }\end{array}$ \\
\hline
\end{tabular}

Other: adverse event; major adverse cardiovascular events, including death, MI, stroke, resuscitated cardiac arrest, and coronary revascularisation.

Notes

Funding: Supported by Merck and Schering-Plough.

NCT00552097

\section{Risk of bias}

\begin{tabular}{lll}
\hline Bias & Authors' judgement & Support for judgement \\
\hline $\begin{array}{l}\text { Random sequence genera- } \\
\text { tion (selection bias) }\end{array}$ & Low risk & $\begin{array}{l}\text { Quote "Randomization which was based on computer-generated codes pro- } \\
\text { vided to the clinical centers by a central randomization service, was stratified } \\
\text { according to clinical center." }\end{array}$ \\
\hline $\begin{array}{l}\text { Allocation concealment } \\
\text { (selection bias) }\end{array}$ & Low risk & Central randomisation \\
\hline
\end{tabular}

Blinding of participants $\quad$ Low risk
and personnel (perfor-
mance bias)
All outcomes

Blinding of outcome as- Low risk Quote "Sonographers are also blinded to treatment assignment"
sessment (detection bias)
All outcomes


ENHANCE 2008 (Continued)

Incomplete outcome data Low risk (attrition bias)

All outcomes
Quote: "All analyses were performed on an intention-to-treat basis. We used the last-observation-carried-forward method for patients who did not complete the study."

Number of participants that discontinued were reported and reasons were stated.

\begin{tabular}{lll}
\hline $\begin{array}{l}\text { Selective reporting (re- } \\
\text { porting bias) }\end{array}$ & Low risk & $\begin{array}{l}\text { The study protocol was pre-published and all of the study's prespecified out- } \\
\text { comes have been reported. }\end{array}$ \\
\hline Other bias & Low risk & $\begin{array}{l}\text { Although the study was supported by pharmaceutical companies, the primary } \\
\text { outcome were negative. }\end{array}$ \\
\hline
\end{tabular}

Hibi 2018

Design: randomised open-label parallel group study
Number of study centres: 10 centres in Japan
Setting: inpatient and outpatient
Patient recruitment: October 2010 and September 2012
Duration of study (Follow-up): 8-12 months
Clinical setting: acute coronary syndrome (ACS)

Participants

Enrolment (N): 128

Randomised (N): intervention: 65 ; control: 63

Withdrawn (N): intervention: 2; control: 4

Lost to follow-up (N): intervention: 9; control: 6

Completed the study (N): intervention: 50; control: 53

Analysed (N): intervention: 50 ; control: 53

Safety analysed: intervention: 65 , control: 63

Age (years) (mean \pm SD): intervention: $63 \pm 10$; control: $63 \pm 12$

Sex (male, N, \%): intervention: 41 (82\%); control: 41 (77\%)

Smoking history (N, \%): intervention: 22 (44\%) ; control: 20 (38\%)

BMI $\left(\mathbf{k g} / \mathbf{m}^{2}\right.$, mean \pm SD):): not reported

Diabetes (N, \%): intervention: 10 (20) ; control: $11(21)$

Hypertension (N, \%): intervention: 23 (46\%) ; control: 34 (64\%)

STMI (N, \%): intervention: 38 (76\%) ; control: $(68 \%)$

Statin pretreatment (N, \%): intervention: 0; control:0

Inclusion criteria: statin-naïve patients with ACS. All participants were diagnosed with ACS and underwent successful percutaneous coronary intervention (PCI) for the culprit lesion under intravascular ultrasound (IVUS) guidance. 
Hibi 2018 (Continued)

Exclusion criteria: patients with severely calcified lesions, coronary bypass graft lesion, restenotic lesion, treatment with lipid-lowering agents (statin, niacin, probucol, fibrate, and anion exchange resin), homozygous familial hypercholesterolaemia, haemodynamic instability, cardiogenic shock, planned revascularisation of the target plaque, history of revascularisation of the target plaque, active liver disease (ALT $\geq 100 \mathrm{IU} / \mathrm{L}$ ), or severe renal insufficiency (serum creatinine $\geq 2.0 \mathrm{mg} / \mathrm{dL}$ ).

Interventions

Intervention: pitavastatin ( $2 \mathrm{mg} /$ day) plus ezetimibe $(10 \mathrm{mg} /$ day $)$

Comparison: pitavastatin monotherapy (2 mg/day)

Details of any 'run-in' period: not reported

Concomitant medications: not reported

Excluded medications: not reported

Outcomes Primary: the percentage change in non-culprit coronary plaque volume (PV) and lipid PV on integrated
backscatter IVUS.

Secondary: absolute change in \%PV and in normalized PV (NPV).

Other: Major Adverse Cardiac Events (MACE), which defined as a composite of cardiac death, MI, or any repeat revascularisation during the study period.

Notes

Funding: supported by a grant from Japan Heart Foundation.

NCT00549926

\section{Risk of bias}

\begin{tabular}{lll}
\hline Bias & Authors' judgement & Support for judgement \\
\hline $\begin{array}{l}\text { Random sequence genera- } \\
\text { tion (selection bias) }\end{array}$ & Low risk & $\begin{array}{l}\text { Quote "Patients were centrally randomized using an internet-based program, } \\
\text { and stratified according to hyperlipidemia and diabetes using the minimiza- } \\
\text { tion method." }\end{array}$
\end{tabular}

\begin{tabular}{|c|c|c|}
\hline $\begin{array}{l}\text { Allocation concealment } \\
\text { (selection bias) }\end{array}$ & Low risk & $\begin{array}{l}\text { Quote: "Patients were centrally randomized using an internet-based program, } \\
\text { and stratified according to hyperlipidemia and diabetes using the minimiza- } \\
\text { tion method." }\end{array}$ \\
\hline
\end{tabular}

Blinding of participants High risk Open-label parallel group study
and personnel (perfor-
mance bias)

\begin{tabular}{|c|c|c|}
\hline $\begin{array}{l}\text { Blinding of outcome as- } \\
\text { sessment (detection bias) } \\
\text { All outcomes }\end{array}$ & Low risk & $\begin{array}{l}\text { Quote: "Two independent experienced investigators blinded to the clinical da- } \\
\text { ta analyzed the IVUS quantitatively in the independent core laboratory" }\end{array}$ \\
\hline $\begin{array}{l}\text { Incomplete outcome data } \\
\text { (attrition bias) } \\
\text { All outcomes }\end{array}$ & Low risk & $\begin{array}{l}\text { Quote: "The treated group consisted of all patients who received any dose of } \\
\text { study medication ( } 128 \text { randomized patients) and was considered for analysis } \\
\text { of safety and adverse events." }\end{array}$ \\
\hline \multirow[t]{2}{*}{$\begin{array}{l}\text { Selective reporting (re- } \\
\text { porting bias) }\end{array}$} & Unclear risk & $\begin{array}{l}\text { No protocol published, but a pre-registration in a clinical trial registry was } \\
\text { found (NCT00549926). }\end{array}$ \\
\hline & & $\begin{array}{l}\text { The registration information was inconsistent with published article, but out- } \\
\text { comes published match trials register. }\end{array}$ \\
\hline Other bias & Low risk & $\begin{array}{l}\text { Quote: "This work was supported in part by a grant from Japan Heart Founda- } \\
\text { tion" }\end{array}$ \\
\hline
\end{tabular}


Hibi 2018 (Continued)

Quote: "The funding agency had no role in the design or conduct of the study, in the collection, analysis, or interpretation of the data, or in the preparation, review, or approval of the manuscript."

\section{HIJ-PROPER 2017}

Methods

Design: multi-centre, prospective, randomised, open-label, blinded-endpoint trial with an active-control design

Number of study centres: 19 hospitals in Japan

Setting: inpatient

Patient recruitment: January 2010 and April 2013

Duration of study: 3.86 years

Clinical setting: acute coronary syndrome (ACS) and dyslipidaemia

Participants

Enrolment (N): 1734

Randomised (N): intervention: 869; control: 865

Withdrawn (N): not reported

Lost to follow-up (N): intervention: 5; control: 8

Completed the study (N): intervention: 864; control: 857

Analysed (N): intervention: 864; control: 857

Age (years) (mean \pm SD): intervention: $65.7 \pm 11.7$; control: $65.5 \pm 11.9$

Sex (male, N, \%): intervention: 639 (74.0\%); control: 661 (77.1\%)

Smoking history (N, \%):

1. current: intervention: 294 (34.0\%); control: 300 (35.0\%);

2. former: intervention: 219 (25.3\%); control: 248 (28.9\%).

BMI (kg/m $\mathbf{m}^{2}$, mean \pm SD):): intervention: $24.3 \pm 3.5$; control: $24.3 \pm 3.6$

Diabetes (N, \%): intervention: 260 (30.1\%); control: 260 (30.3\%)

Hypertension (N, \%): intervention: 599 (69.3\%); control: 576 (67.2\%)

History of MI (N, \%): intervention: 62 (7.2\%); control: 68 (7.9\%)

Statin pretreatment (N, \%): intervention: $143(16.6 \%)$; control: $149(17.4 \%)$

\section{Inclusion criteria:}

1. all participants had been hospitalised for ST-segment elevation myocardial infarction (STEMI) or for non-ST-segment elevation myocardial infarction (NSTEMI) or unstable angina (UA) within 72 hours before randomisation;

2. all participants were at least 20 years of age;

3. LDL-C, measured within 24 hours of hospitalisation for the ACS event, was at least $100 \mathrm{mg} / \mathrm{dL}$ (2.6 $\mathrm{mmol} / \mathrm{L})$;

4. fasting plasma triglyceride level was at least $400 \mathrm{mg} / \mathrm{dL}(4.5 \mathrm{mmol} / \mathrm{L})$ (Friedewald equation)

\section{Exclusion criteria:}


1. major exclusion criteria were the occurrence within 24 hours before enrolment of (i) haemodynamic instabilities such as hypotension, pulmonary oedema, congestive heart failure, acute mitral regurgitation, or ventricular rupture;

2. ischaemic events (stroke, recurrent symptoms of cardiac ischaemia, acute occlusion of target vessel);

3. arrhythmic events (ventricular fibrillation, sustained ventricular tachycardia, advanced heart block).

4. patients in whom CABG was planned for the treatment of an ACS event were excluded;

5. pregnancy;

6. active liver disease or persistent unexplained serum transaminase elevations $(\geq 3 \times$ the upper limit of normal), current treatment with immunosuppressants such as cyclosporine, tacrolimus, azathioprine, or long-term oral glucocorticoids;

7. any other condition that would substantially reduce life expectancy or limit compliance with the protocol;

8. history of alcohol or drug abuse;

9. allergy or sensitivity to any statin, ezetimibe, or their excipients.

Interventions

Intervention: pitavastatin plus ezetimibe $10 \mathrm{mg} /$ day. The starting dose of pitavastatin was $2 \mathrm{mg} /$ day, during the entire study period, the pitavastatin dose ( $1 \mathrm{mg}$ to $4 \mathrm{mg} /$ day) was adjusted to target LDL-C of $1.8 \mathrm{mmol} / \mathrm{L}$.

Comparison: pitavastatin monotherapy. The starting dose of pitavastatin was $2 \mathrm{mg} /$ day, during the entire study period, the pitavastatin dose ( $1 \mathrm{mg}$ to $4 \mathrm{mg} /$ day) was adjusted to target LDL-C of between 2.3 $\mathrm{mmol} / \mathrm{L}$ and $2.6 \mathrm{mmol} / \mathrm{L}$.

Details of any 'run-in' period: none

Concomitant medications: not reported

Excluded medications: not reported

Outcomes

Primary: composite of the first occurrence of a component of the primary endpoint: all-cause death, non-fatal MI, non-fatal stroke, UA, or revascularisation with either PCI or CABG.

\section{Secondary:}

1. cardiovascular event (non-fatal MI non-fatal stroke, UA, ischaemia-driven revascularisation with either $\mathrm{PCl}$ or $\mathrm{CABG}$ ),

2. all-cause death;

3. heart failure;

4. inflammatory markers;

5. adverse events (including new occurrence of malignant tumour).

Notes

Funding: Quote: "This trial was funded by the Japan Research Promotion Society for Cardiovascular Diseases."

UMIN000002742

Emailed trialists to ask for the number of cardiovascular death and data for subgroup analyses of interest. No response.

\section{Risk of bias}

Bias Authors' judgement Support for judgement

$\begin{array}{ll}\begin{array}{l}\text { Random sequence genera- } \\ \text { tion (selection bias) }\end{array} & \text { Low risk }\end{array} \quad \begin{aligned} & \text { Randomisation was by the minimisation method, based on the five factors of } \\ & \text { age, LDL-C level on randomisation, history of statin treatment, history of dia- } \\ & \text { betes mellitus, and clinical site. }\end{aligned}$

Allocation concealment Unclear risk not reported.

(selection bias) 


\section{HIJ-PROPER 2017 (Continued)}
Blinding of participants
High risk
Quote: "Treatment was not masked for patients and physicians." and personnel (performance bias)

All outcomes

\begin{tabular}{ll}
\hline $\begin{array}{l}\text { Blinding of outcome as- } \\
\text { sessment (detection bias) }\end{array}$ & Low risk \\
All outcomes & Quote: "All laboratory analyses were performed at SRL Inc." \\
& $\begin{array}{l}\text { Quote: "these events and pertinent patient documents were reviewed by an } \\
\text { Endpoint Committee masked. An independent statistical data centre analysed } \\
\text { data." }\end{array}$
\end{tabular}

\begin{tabular}{ll}
\hline $\begin{array}{l}\text { Incomplete outcome data } \\
\text { (attrition bias) }\end{array}$ & Low risk \\
$\begin{array}{l}\text { All outcomes } \\
\text { Missing outcome data balanced in numbers across intervention groups (< } \\
\end{array}$ & $\begin{array}{l}\text { andyses, and all randomized patients were included in all analyses, regardless } \\
\text { of protocol violations." }\end{array}$ \\
\hline
\end{tabular}

\begin{tabular}{|c|c|c|}
\hline $\begin{array}{l}\text { Selective reporting (re- } \\
\text { porting bias) }\end{array}$ & Low risk & $\begin{array}{l}\text { The study protocol is available and all of the study's prespecified outcomes } \\
\text { have been reported. }\end{array}$ \\
\hline
\end{tabular}

\begin{tabular}{ll}
\hline Other bias & Low risk \\
& Cardiovascular Diseases, which had no role in conducting the study." \\
UMIN000002742
\end{tabular}

\section{IMPROVE-IT 2015}

Design: multi-centre, double-blind, randomised study
Number of study centres: multi-centres, 1158 enrolling centres in 39 participating countries
Setting: inpatient and outpatient follow-up
Patient recruitment: 26 Octobe, 2005 to 8 July, 2010
Duration of study: 6 years
Clinical setting: acute coronary syndromes (ACS)

\section{Participants}

\section{Enrolment (N): 18144}

Randomised (N): intervention: 9067, control: 9077

Died during follow-up (N): T: 964, control: 968

Withdraw consent (N): intervention: 795 (vital status alive 376, vital status dead 134,vital status unknown 285), control: 808 (vital status alive 374 , vital status dead 159,vital status unknown 275)

Lost to follow-up (N): intervention: 44 , control: 49

Site closure (N): intervention: 39 , control: 36

Vital status only (N): intervention: 357 (vital status alive 240, vital status dead 117), control: 356 (vital status alive 252, vital status dead 104)

Completed final visit (N): intervention: 6868, control: 6860

Analysed (N): intervention: 9067; control: 9077

Mean age (years) (mean \pm SD): intervention: $63.6 \pm 9.7$, control: $63.6 \pm 9.8$ 
Gender (male, N, \%): male: 13728 (76\%) ; intervention: male: 6842 (75.5\%); control: male: 6886 (75.9 $\%)$

Smoking history (N, \%): intervention: 2943/9067 (32.5\% ), control: 3035/9072 (33.5\% )

BMI ( $\left.\mathbf{k g} / \mathbf{m}^{\mathbf{2}}\right)$ : intervention: $28.3 \pm 5.2$, control: $28.3 \pm 5.2$

Diabetes (N, \%): intervention: 2459/9067 (27.1\%), control: 2474/9077 (27.3\%)

Hypertension (N, \%): intervention: 5580/9063 (61.6\%), control: 5557/9072 (61.3\%)

History of MI (N, \%): intervention: 1925/9054 (21.3\%), control: 1881/9077 (20.7\%)

Statin pretreatment (N, \%): intervention: 3135 (34.6\%), control: 3111 (34.3\%)

Lipid-lowering agent pretreatment (N, \%): intervention: 3227( 35.6\%) , control: 3207 (35.4\%)

Inclusion criteria: "Men and women who were at least 50 years of age were eligible for inclusion if they had been hospitalized within the preceding 10 days for an acute coronary syndrome (an acute myocardial infarction, with or without ST-segment elevation on electrocardiography, or high-risk unstable angina). Patients were required to have an LDL cholesterol level of $50 \mathrm{mg} / \mathrm{L}(1.3 \mathrm{mmol} / \mathrm{L})$ or higher. For participants who were not receiving long-term lipid-lowering therapy, the maximum LDL cholesterol level for enrollment was $125 \mathrm{mg} / \mathrm{L}(3.2 \mathrm{mmol} / \mathrm{L})$; for participants who were receiving lipid-lowering therapy, the maximum level was $100 \mathrm{mg} / \mathrm{L}(2.6 \mathrm{mmol} / \mathrm{L})$. The LDL cholesterol level for eligibility was measured locally within the first 24 hours after onset of the acute coronary syndrome."

Exclusion criteria: "Major exclusion criteria include the presence within 24 hours before enrollment of (1) hemodynamic events (hypotension, pulmonary edema/congestive heart failure, acute mitral regurgitation, acute ventricular septal defect); (2) ischemic events (stroke, recurrent symptoms of cardiac ischemia); and (3) arrhythmic events (ventricular fibrillation, sustained ventricular tachycardia, complete heart block, high-grade second-degree heart block). Patients in whom CABG is planned as treatment of their ACS event are excluded. Patients receiving ongoing treatment with cyclosporine, diltiazem, danazol, amiodarone, verapamil, niacin, fibrates as concomitant medications, or any of the potent CYP3A4 inhibitors (itraconazole, ketoconazole, erythromycin, clarithromycin and telithromycin, HIV protease inhibitors, and nefazodone) are excluded from the study. Short-term therapy with antifungal medications or macrolide antibiotics is acceptable, provided that study medication is interrupted during the administration and resumed after the completion of short-term therapy. Other exclusion criteria include pregnancy or the intention to become pregnant; active liver disease or persistent unexplained serum transaminase elevations ( $\geq 2 \times$ upper limit of normal [ULN]); history of alcohol or drug abuse; allergy/sensitivity to any statin, ezetimibe, or their excipients; and use of statin therapy with LDL-C lowering potency greater than simvastatin $40 \mathrm{mg}$. Patients are also excluded if the discontinuation of an existing lipid-lowering regimen poses a health risk."

Interventions

Intervention: simvastatin $40 \mathrm{mg}$ + ezetimibe $10 \mathrm{mg}$

Comparison: simvastatin $40 \mathrm{mg}+$ placebo

Details of any 'run-in' period: not specified

Concomitant medications: aspirin, thienopyridine, angiotensin-converting enzyme inhibitors (ACEI)/ angiotensin receptor antagonist (ARB)

Excluded medications: patients receiving ongoing treatment with cyclosporine, diltiazem, danazol, amiodarone, verapamil, niacin, fibrates as concomitant medications, or any of the potent CYP3A4 inhibitors (itraconazole, ketoconazole, erythromycin, clarithromycin and telithromycin, HIV protease inhibitors, and nefazodone) are excluded from the study.

Outcomes

Primary: composite of death from cardiovascular disease, a major coronary event (nonfatal MI, documented unstable angina requiring hospital admission, or coronary revascularization occurring at least 30 days after randomisation), or nonfatal stroke, assessed from the time of randomisation until the first occurrence of one of the events.

\section{Secondary:}


1. composite of death from any cause, major coronary event, or nonfatal stroke;

2. composite of death from coronary heart disease, nonfatal MI, or urgent coronary revascularisation 30 days or more after randomisation;

3. composite of death from cardiovascular causes, nonfatal MI, hospitalisation for unstable angina, all revascularisation 30 days or more after randomisation, or nonfatal stroke.

Others: liver enzyme levels and creatine kinase levels, episodes of myopathy or rhabdomyolysis, gall bladder-related adverse events, and cancer.

Notes $\quad$ Funding: Supported by Merck.

NCT00202878

\section{Risk of bias}

\begin{tabular}{lll}
\hline Bias & Authors' judgement & Support for judgement \\
\hline $\begin{array}{l}\text { Random sequence genera- } \\
\text { tion (selection bias) }\end{array}$ & Low risk & Quote: "Central Randomization" \\
\hline $\begin{array}{l}\text { Allocation concealment } \\
\text { (selection bias) }\end{array}$ & Low risk & $\begin{array}{l}\text { Quote: "The Central Randomization Center will assign the subject randomiza- } \\
\text { tion number according to the subject's sequential entry into the study. The } \\
\text { subject will be identified by this subject randomization number for the dura- } \\
\text { tion of the study and in the reporting of results of the study. " }\end{array}$
\end{tabular}

\begin{tabular}{ll}
\hline $\begin{array}{l}\text { Blinding of participants } \\
\text { and personnel (perfor- }\end{array}$ & Low risk \\
Quote: "This is a double-blind study; neither the investigator, sponsor, nor the \\
subject will know the content of the bottles"
\end{tabular}
and personnel (perforsubject will know the content of the bottles"

mance bias)

All outcomes

\begin{tabular}{|c|c|c|}
\hline $\begin{array}{l}\text { Blinding of outcome as- } \\
\text { sessment (detection bias) }\end{array}$ & Low risk & $\begin{array}{l}\text { Independent committees to review achieved lipid levels (the Lipid Monitoring } \\
\text { Committee) and trial safety (the Data and Safety Monitoring Board). }\end{array}$ \\
\hline
\end{tabular}

All outcomes

\section{Incomplete outcome data Low risk} (attrition bias)

All outcomes

Number of participants that did not completed final visit were reported and reasons were stated.

Quote: "All efficacy and safety analyses were performed in the intention-totreat population".

Quote: "At study conclusion, there were 93 participants who were lost to follow-up and 75 participants from closed sites without known vital status".

Quote: "Vital status was identified for 713 participants who were lost prior to the close out period".

Quote: "The number of subjects categorized as site closure, lost to follow-up and withdrawn of consent was similar between randomized treatment groups."

Quote: "All subjects, including those who discontinued from treatment, were monitored for suspected clinical endpoint events until the termination of the trial"

\begin{tabular}{|c|c|c|}
\hline $\begin{array}{l}\text { Selective reporting (re- } \\
\text { porting bias) }\end{array}$ & Low risk & $\begin{array}{l}\text { The study protocol is available and all of the study's prespecified outcomes } \\
\text { have been reported. }\end{array}$ \\
\hline
\end{tabular}

\begin{tabular}{ll}
\hline Other bias & Unclear risk \\
& Disclosure forms provided by the authors.
\end{tabular}




\begin{tabular}{ll}
\hline Methods & Design: RCT \\
Number of study centres: not reported \\
Setting: not reported \\
Patient recruitment: not reported \\
Duration of study (Follow-up): 3 years \\
Clinical setting: stable angina pectoris
\end{tabular}

Participants

Enrolment (N): 33

Randomised (N): intervention:16 ; control:17

Withdrawn (N): not reported

Lost to follow-up (N): not reported

Completed the study (N): not reported

Analysed (N): not reported

Age (years) (mean \pm SD): not reported

Sex (male, $\mathbf{N}, \%$ ): not reported

Smoking history (N, \%): not reported

BMI $\left(\mathbf{k g} / \mathbf{m}^{2}\right.$, mean \pm SD):): not reported

Diabetes (N, \%): not reported

Hypertension (N, \%): not reported

History of MI (N, \%): not reported

Statin pretreatment (N, \%): intervention: $16(100 \%)$; control:17(100\%)

Inclusion criteria: "SAP patients receiving PCI method previously treated with statins were Enrolled into the study"

Exclusion criteria: not reported

Comparison: Quote: "treated with incremental dose of statin only"

Details of any 'run-in' period: not reported

Concomitant medications: not reported

Excluded medications: not reported 
Katoh 2017 (Continued)

Outcomes

Primary: coronary artery plaque volume; LDL-C, triglyceride, remnant-like lipoprotein, Apo B48

lipoprotein, campesterol, and sitosterol levels; cardiovascular events

\begin{tabular}{ll}
\hline Notes & Conference abstract only. \\
& Emailed trialists for details. No response \\
& Source of funding: not reported.
\end{tabular}

\section{Risk of bias}

\begin{tabular}{|c|c|c|}
\hline Bias & Authors' judgement & Support for judgement \\
\hline $\begin{array}{l}\text { Random sequence genera- } \\
\text { tion (selection bias) }\end{array}$ & Unclear risk & Not reported \\
\hline $\begin{array}{l}\text { Allocation concealment } \\
\text { (selection bias) }\end{array}$ & Unclear risk & Not reported \\
\hline $\begin{array}{l}\text { Blinding of participants } \\
\text { and personnel (perfor- } \\
\text { mance bias) } \\
\text { All outcomes }\end{array}$ & Unclear risk & Not reported \\
\hline $\begin{array}{l}\text { Blinding of outcome as- } \\
\text { sessment (detection bias) } \\
\text { All outcomes }\end{array}$ & Unclear risk & Not reported \\
\hline $\begin{array}{l}\text { Incomplete outcome data } \\
\text { (attrition bias) } \\
\text { All outcomes }\end{array}$ & Unclear risk & Not reported \\
\hline $\begin{array}{l}\text { Selective reporting (re- } \\
\text { porting bias) }\end{array}$ & Unclear risk & Insufficient information to permit judgement \\
\hline Other bias & High risk & Published conference abstract only \\
\hline
\end{tabular}

Kinouchi 2013

\begin{tabular}{l} 
Design: open-labelled, randomised, balanced-parallel group trial \\
Number of study centres: single centre in Japan \\
Setting: outpatient \\
Patient recruitment: not reported \\
Duration of study (Follow-up): 12 months \\
Clinical setting: hypercholesterolaemia \\
\hline
\end{tabular}

Participants

Enrolment (N): 63

Randomised (N): 54, intervention:28 ; control:26

Withdrawn (N): intervention: 0; control:0

Lost to follow-up (N): intervention: 0; control:0 
Completed the study (N): intervention: 28 ; control:26

Analysed (N): intervention: 28; control:26

Age (years) (mean \pm SD): intervention: $55.2 \pm 12.0$; control: $53.4 \pm 11.4$

Sex (male, N, \%): intervention:20(71.4\%); control:16 (61.5\%)

Smoking history (N, \%): intervention:2(7.1\%) ; control:2 (7.7\%)

BMI (kg/m² mean \pm SD):): intervention: $24.7 \pm 2.5$; control: $24.9 \pm 7.2$

Diabetes (N, \%): intervention: 1(3.6\%); control:2 (7.7\%)

Hypertension (N, \%): intervention: 18 (64.3); control:22 (84.6)

History of CHD (N, \%): not reported

Statin pretreatment (N, \%): not reported

Inclusion criteria: patients with age between 20 and 70 years, plasma LDL cholesterol concentration $>100 \mathrm{mg} / \mathrm{dL}$ according to NCEP ATP II guidelines, and triglyceride concentrations below $500 \mathrm{mg} / \mathrm{dL}$.

Exclusion criteria: Patients with kidney dysfunction, defined as serum creatinine $>2 \mathrm{mg} / \mathrm{dL}$; liver dysfunction, defined as serum transaminase $>2$ times higher than normal; secondary or drug-induced dyslipidaemia; unstable angina; pregnancy; probable pregnancy; or breast feeding; history of allergy to the medication in this study; or those considered inappropriate.

Comparison: fluvastatin $20 \mathrm{mg}$ daily

Details of any 'run-in' period: Quote: "Dietary interventions with instructions to follow a low-fat diet throughout the trial were provided for a 2-12 week run-in period"

Concomitant medications: Antihypertensive and hypoglycaemic agents were appropriately titrated to control blood pressure (BP) and plasma glucose levels, respectively.

Excluded medications: previous medications and therapies other than cholesterol lowering drugs were continued.

Outcomes Primary: the per cent change from baseline in an estimated glomerular filtration rate (eGFR)

Secondary: the per cent changes in surrogate markers for arterial stiffness, as assessed by the cardio-ankle vascular index, augmentation index, ankle-brachial index, and maximum carotid intima-media thickness.

Other: lipid values, adverse events

\begin{tabular}{ll}
\hline Notes & Funding: not reported \\
& Emailed investigators for whether clinical endpoints such as cardiovascular events occurred during the \\
study. No response.
\end{tabular}

\section{Risk of bias}

\begin{tabular}{lll}
\hline Bias & Authors' judgement & Support for judgement \\
\hline $\begin{array}{l}\text { Random sequence genera- } \\
\text { tion (selection bias) }\end{array}$ & Unclear risk & Quote: "simple randomization", no further details \\
\hline $\begin{array}{l}\text { Allocation concealment } \\
\text { (selection bias) }\end{array}$ & High risk & Quote:"There was no allocation concealment" \\
\hline
\end{tabular}


Kinouchi 2013 (Continued)
Blinding of participants
High risk
Open-label. Quote: "No placebo was used and there was no blinding" and personnel (performance bias)

All outcomes

\begin{tabular}{lll}
\hline $\begin{array}{l}\text { Blinding of outcome as- } \\
\text { sessment (detection bias) } \\
\text { All outcomes }\end{array}$ & High risk & Open-label. Quote: "No placebo was used and there was no blinding" \\
\hline $\begin{array}{l}\text { Incomplete outcome data } \\
\text { (attrition bias) }\end{array}$ & Low risk & All patients completed the study. Intention-to-treat (ITT) analysis used \\
\begin{tabular}{l} 
All outcomes \\
\hline
\end{tabular} &
\end{tabular}

\begin{tabular}{lll}
\hline $\begin{array}{l}\text { Selective reporting (re- } \\
\text { porting bias) }\end{array}$ & Unclear risk & No protocol published, or trials registry record found. \\
\hline Other bias & Unclear risk & Insufficient information to assess whether an important risk of bias exists \\
& Disclosure: Quote: "no conflicts of interest" \\
& Funding: not reported \\
\hline
\end{tabular}

Kodali 2011

\begin{tabular}{|c|c|}
\hline \multirow[t]{6}{*}{ Methods } & Design: RCT \\
\hline & Number of study centres: not reported, USA \\
\hline & Setting: not reported \\
\hline & Patient recruitment: not reported \\
\hline & Duration of study (Follow-up): 12 months \\
\hline & Clinical setting: 'statin naive' patients with maximum carotid stenosis $>50 \%$ \\
\hline \multirow[t]{13}{*}{ Participants } & Enrolment (N): 18 \\
\hline & Randomised (N): not reported \\
\hline & Withdrawn (N): not reported \\
\hline & Lost to follow-up (N): not reported \\
\hline & Completed the study $(\mathrm{N})$ : not reported \\
\hline & Analysed (N): not reported \\
\hline & Age (years) (mean \pm SD): not reported \\
\hline & Sex (male, $\mathbf{N}, \%)$ : not reported \\
\hline & Smoking history (N, \%): not reported \\
\hline & BMI $\left(\mathbf{k g} / \mathbf{m}^{2}\right.$, mean $\left.\left.\pm \mathrm{SD}\right):\right):$ not reported \\
\hline & Diabetes (N, \%): not reported \\
\hline & Hypertension (N, \%): not reported \\
\hline & History of CHD ( $\mathrm{N}, \%)$ : not reported \\
\hline
\end{tabular}


Kodali 2011 (Continued)

Statin pretreatment (N, \%): intervention:0\%; control:0\%

Inclusion criteria: 'statin naive' patients with maximum carotid stenosis $>50 \%$

Exclusion criteria: not reported

\begin{tabular}{|c|c|c|}
\hline Interventions & \multicolumn{2}{|c|}{$\begin{array}{l}\text { Intervention: ezetimibe } 10 \mathrm{mg} \text { / simvastatin } 40 \mathrm{mg} \\
\text { Comparison: simvastatin } 40 \mathrm{mg} \\
\text { Details of any 'run-in' period: not reported } \\
\text { Concomitant medications: not reported } \\
\text { Excluded medications: not reported }\end{array}$} \\
\hline Outcomes & \multicolumn{2}{|c|}{$\begin{array}{l}\text { Primary: changes in carotid outer wall area (OWA), lumen area (LA), vessel wall area (VWA), lipid area } \\
(\mathrm{LpA}) \text { and lipid percentage (Lp\%), measured by high-resolution CMR }\end{array}$} \\
\hline Notes & \multicolumn{2}{|c|}{$\begin{array}{l}\text { Two conference abstracts only. } \\
\text { No outcome data relevant to this review. } \\
\text { Emailed trialists for details. No response } \\
\text { Source of funding: not reported. }\end{array}$} \\
\hline \multicolumn{3}{|l|}{ Risk of bias } \\
\hline Bias & Authors' judgement & Support for judgement \\
\hline $\begin{array}{l}\text { Random sequence genera- } \\
\text { tion (selection bias) }\end{array}$ & Unclear risk & Quote: "randomized", but no further details. \\
\hline $\begin{array}{l}\text { Allocation concealment } \\
\text { (selection bias) }\end{array}$ & Unclear risk & Not reported \\
\hline $\begin{array}{l}\text { Blinding of participants } \\
\text { and personnel (perfor- } \\
\text { mance bias) } \\
\text { All outcomes }\end{array}$ & Unclear risk & Not reported \\
\hline $\begin{array}{l}\text { Blinding of outcome as- } \\
\text { sessment (detection bias) } \\
\text { All outcomes }\end{array}$ & Unclear risk & Not reported \\
\hline $\begin{array}{l}\text { Incomplete outcome data } \\
\text { (attrition bias) } \\
\text { All outcomes }\end{array}$ & Unclear risk & Not reported \\
\hline $\begin{array}{l}\text { Selective reporting (re- } \\
\text { porting bias) }\end{array}$ & Unclear risk & Insufficient information to permit judgement \\
\hline Other bias & High risk & Published conference abstract only \\
\hline
\end{tabular}

Kouvelos 2013

Methods Design: prospective randomised, open-label study

Number of study centres: single centre in Greece 
Setting: inpatient and outpatient follow-up

Patient recruitment: patients who underwent elective vascular surgery from January 2007 to June 2009

Duration of study: 12 months

Clinical setting: patients Undergoing elective vascular surgery

Participants

Enrolment (N): 262

Randomised (N): intervention: 126; control: 136

Withdrawn (N): intervention: 4; control: 2

Lost to follow-up (N): Eight patients did not attend their follow-up visit but were reached via telephone

Completed the study (N): not reported

Analysed (N): intervention: 126; control: 136

Age (years) (range): intervention: 70 (41-89); control: 72 (46-88)

Sex (male, N, \%): intervention: 113 (89.7\%); control: 122 (89.7\%)

Smoking history (N, \%): intervention: 68 (54\%); control: 78 (57.4\%)

BMI $\left(\mathbf{k g} / \mathbf{m}^{2}\right.$, mean \pm SD):): not reported

Diabetes (N, \%): intervention: 40 (31.7\%); control: 39 (28.7\%)

Hypertension (N, \%): intervention: 103 (81.7\%); control: 110 (80.9\%)

Existing CHD: (N, \%): intervention: 62 (49.2\%); control: 67 (49.3\%)

Statin pretreatment $(\mathbf{N}, \%)$ : intervention: $0 \%$; control: $0 \%$

Inclusion criteria:

Patients who underwent elective vascular surgery.

Exclusion criteria: any contraindication to the use of statins; emergency surgery; a re-operation within 30 days after a previous procedure; liver disease; a history of a cardiovascular event within the previous 6 months prior to randomisation (Ml or stroke).

Comparison: rosuvastatin alone $(10 \mathrm{mg} /$ day)

Details of any 'run-in' period: 8-week washout period for the patients already on a statin

Concomitant medications: not reported

Excluded medications: not reported

Outcomes

Primary: composite of death from cardiac causes, nonfatal acute MI, ischaemic stroke, and unstable angina.

Secondary: lipids and high-sensitivity C-reactive protein (hs-CRP)

Others: serum creatine kinase (CK) and AST levels as well as clinical evaluation of any adverse event. 
Kouvelos 2013 (Continued)

Risk of bias

\begin{tabular}{|c|c|c|}
\hline Bias & Authors' judgement & Support for judgement \\
\hline $\begin{array}{l}\text { Random sequence genera- } \\
\text { tion (selection bias) }\end{array}$ & Low risk & A computer algorithm was used in the randomisation \\
\hline $\begin{array}{l}\text { Allocation concealment } \\
\text { (selection bias) }\end{array}$ & Unclear risk & Not reported \\
\hline $\begin{array}{l}\text { Blinding of participants } \\
\text { and personnel (perfor- } \\
\text { mance bias) } \\
\text { All outcomes }\end{array}$ & High risk & Open-label study \\
\hline
\end{tabular}

\begin{tabular}{lll}
$\begin{array}{l}\text { Blinding of outcome as- } \\
\text { sessment (detection bias) } \\
\text { All outcomes }\end{array}$ & Unclear risk & Open-label study, insufficient information to make a judgement \\
\hline $\begin{array}{l}\text { Incomplete outcome data } \\
\text { (attrition bias) }\end{array}$ & Low risk & $\begin{array}{l}\text { Quote: "Eight patients did not attend their follow-up visit but were reached via } \\
\text { telephone." }\end{array}$ \\
\hline
\end{tabular}

\begin{tabular}{lll}
\hline $\begin{array}{l}\text { Selective reporting (re- } \\
\text { porting bias) }\end{array}$ & Unclear risk & No protocol published, or trials registry record found. \\
\hline Other bias & Low risk & $\begin{array}{l}\text { Funding:Quote: "The author(s) received no financial support for the research, } \\
\text { authorship, and/or publication of this article" }\end{array}$ \\
& $\begin{array}{l}\text { Declaration of Conflicting Interests: Quote: "no potential conflicts of interest } \\
\text { with respect to the research, authorship, and/or publication of this article." }\end{array}$ \\
\hline
\end{tabular}

Liu 2017

\begin{tabular}{ll}
\hline Design: randomised controlled trial \\
Number of study centres: single centre in China \\
Setting: inpatient and outpatient follow up \\
Patient recruitment: June 2012 to December 2014 \\
Duration of study (Follow-up): 12 months \\
Clinical setting: acute coronary syndrome (ACS) \\
\hline
\end{tabular}

Randomised (N): 230, intervention: 114; control:116

Withdrawn (N): intervention:0 ; control:0

Lost to follow-up (N): intervention:6 ; control:5

Completed the study (N): intervention: 108; control: 111

Analysed (N): intervention: 108; control:111

Age (years) (SD, mean \pm SD): intervention: $84.2 \pm 2.9$; control: $84.0 \pm 1.8$ 
Liu 2017 (Continued)

Sex (male, N, \%): intervention: 60 (52.6); control: 59 (50.9)

Smoking history (N, \%): intervention: 13 (11.4); control: 16 (13.8)

BMI (kg/m² $\mathbf{2}$ mean \pm SD):): intervention: $25.6 \pm 3.5$; control: $25.4 \pm 3.9$

Diabetes (N, \%): intervention: 46 (40.4); control: 42 (36.2)

Hypertension (N, \%): intervention: 81 (71.1); control: 80 (69.0)

History of MI (N, \%): intervention: 22 (19.3); control: 17 (14.7)

Statin pretreatment (N, \%): intervention: control

Inclusion criteria: 1) ACS patients confirmed by coronary angiography; 2) age between 80 and 90 years old.

Exclusion criteria: chronic high-dose statins therapy (atorvastatin $>10 \mathrm{mg} / \mathrm{day}$ ), referral to CABG, abnormal liver enzymes (ALT or AST $>40 \mathrm{U} / \mathrm{L}$ ); renal failure with serum creatinine $>2 \mathrm{mg} / \mathrm{dL}$, muscle disease or refused the trial.

Comparison: double-dose atorvastatin group (atorvastatin $20 \mathrm{mg} /$ day)

Details of any 'run-in' period: not reported

Concomitant medications: not reported

Excluded medications: not reported

\section{Outcomes}

Primary: major adverse coronary events (including cardiac death, spontaneous myocardial infarction, unplanned revascularisation), stroke.

Secondary: creatine kinase myocardial band (CK-MB), troponin-I (TNI), creatine (CK), ALT, AST, creatinine, LDL-C, high sensitive C-reactive protein (hSCRP) levels.

Notes

Funding: The study was not supported by any external source of funding. There are no relationships with industry.

\section{Risk of bias}

\begin{tabular}{|c|c|c|}
\hline Bias & Authors' judgement & Support for judgement \\
\hline $\begin{array}{l}\text { Random sequence genera- } \\
\text { tion (selection bias) }\end{array}$ & Low risk & $\begin{array}{l}\text { Quote: "a randomization list was provided by the sponsor before the begin- } \\
\text { ning of the study using SPSS Statistics version } 20.0 .0 \text { computer software. Block } \\
\text { randomization was used with a block size equal to } 2 \text { " }\end{array}$ \\
\hline $\begin{array}{l}\text { Allocation concealment } \\
\text { (selection bias) }\end{array}$ & Unclear risk & Not reported \\
\hline $\begin{array}{l}\text { Blinding of participants } \\
\text { and personnel (perfor- } \\
\text { mance bias) } \\
\text { All outcomes }\end{array}$ & Unclear risk & Not reported \\
\hline
\end{tabular}

\begin{tabular}{ll}
\hline Blinding of outcome as- & Unclear risk
\end{tabular}

Incomplete outcome data Low risk (attrition bias)
Quote: "There were 6 patients in combined therapy group and 5 in double-dose atorvastatin group lost to follow-up." 
Liu 2017 (Continued)

All outcomes
Intention-to-treat (ITT) analysis used not used, analysis based on participants that completed study.

Missing outcome data balanced in numbers across intervention groups.

\begin{tabular}{lll}
\hline $\begin{array}{l}\text { Selective reporting (re- } \\
\text { porting bias) }\end{array}$ & Unclear risk & No protocol published, or trials registry record found. \\
\hline Other bias & Low risk & $\begin{array}{l}\text { The study was not supported by any external source of funding. There are no } \\
\text { relationships with industry. }\end{array}$ \\
\hline
\end{tabular}

\section{Luo 2014}

\begin{tabular}{ll}
\hline Methods & Design: $\mathrm{RCT}$ \\
Number of study centres: single centre \\
Setting: inpatient and outpatient \\
Patient recruitment: July 2010 and December 2011 \\
Duration of study (Follow-up): 12 months \\
Clinical setting: hypercholesterolaemia
\end{tabular}

\section{Participants}

Enrolment (N): 84

Randomised (N): intervention: 40; control:44

Withdrawn (N): not reported

Lost to follow-up (N): not reported

Completed the study $(\mathrm{N})$ : not reported

Analysed (N): intervention: 40; control:44

Age (years) (mean \pm SD): intervention: $67.2 \pm 6.4$; control: $66.3 \pm 5.8$

Sex (male, N, \%): intervention: 22 (55\%); control: 22 (50\%)

Smoking history (N, \%): not reported

BMI (kg/m², mean \pm SD):): intervention: $24.4 \pm 4.6$; control: $24.7 \pm 4.4$

Diabetes (N, \%): intervention: 12 ; control: 16

Hypertension (N, \%): not reported

History of CHD (N, \%): intervention: 36; control: 34

Statin pretreatment (N, \%): not reported

Inclusion criteria: elderly hypercholesterolaemic patients who still had abnormal LDL-C levels $(\leq 2.6$ $\mathrm{mM}$ ) after undergoing lipid-lowering therapy for three months.

Exclusion criteria: patients with hypertension, blood diseases, hepatorenal dysfunction, severe infectious disease and heart failure were excluded. 
Luo 2014 (Continued)

Details of any 'run-in' period: not reported

Concomitant medications: not reported

Excluded medications: not reported

\begin{tabular}{ll}
\hline Outcomes & 1. Blood lipid level and high-sensitivity C-reactive protein (hsCRP). \\
2. Carotid intima-media thickness, carotid plaque Crouse integral, Carotid diameter \\
3. Cardiovascular events (myocardial infarction, cardiovascular death) and adverse reactions.
\end{tabular}

Notes Funding: not reported

\section{Risk of bias}

\begin{tabular}{lll}
\hline Bias & Authors' judgement & Support for judgement \\
\hline $\begin{array}{l}\text { Random sequence genera- } \\
\text { tion (selection bias) }\end{array}$ & Unclear risk & Quote: "randomised" but no further details \\
\hline $\begin{array}{l}\text { Allocation concealment } \\
\text { (selection bias) }\end{array}$ & Unclear risk & Not reported \\
\hline
\end{tabular}

Blinding of participants Unclear risk Not reported

and personnel (perfor-

mance bias)

All outcomes

Blinding of outcome as- $\quad$ Unclear risk $\quad$ Not reported
sessment (detection bias)
All outcomes

\begin{tabular}{ll}
\hline Incomplete outcome data & Unclear risk \\
(attrition bias) & \\
All outcomes & \\
\hline
\end{tabular}

Selective reporting (re- Unclear risk No protocol published, or trials registry record found.
porting bias)

Other bias Unclear risk Insufficient information to assess whether an important risk of bias exists

Luo 2016

Methods Design: randomised, prospective, double-blind, and placebo-controlled design

Number of study centres: single-centre in China.

Setting: outpatient

Patient recruitment: June 2012 to September 2013

Duration of study (Follow-up): 12 months

Clinical setting: coronary heart disease

$\begin{array}{ll}\text { Participants } & \text { Enrolment (N): } 148 \\ & \text { Randomised (N): intervention: 74; control: } 74\end{array}$


Luo 2016 (Continued)

Withdrawn (N): intervention: 0; control: 0

Lost to follow-up (N): not reported

Completed the study $(\mathrm{N})$ : not reported

Analysed (N): intervention: 74; control: 74

Age (years) (mean \pm SD): intervention: $60.76 \pm 11.56$; control: $61.55 \pm 9.72$

Sex (male, N, \%): intervention: 40 ( 54\%); control: 44 ( 59\%)

Smoking history (N, \%): intervention: 30 (40.5\%); control: 26 (35.1\%)

BMI (kg/m², mean \pm SD):): intervention: $25.23 \pm 4.67$; control: $24.68 \pm 5.42$

Diabetes (N, \%): intervention: 34 (45.9\%); control: 30 (40.5\%)

Hypertension (N, \%): intervention: 38 (51.4\%); control: 36 (48.6\%)

History of CHD (N, \%): intervention: 74 ( 100\%); control: 74 ( 100\%)

Statin pretreatment (N, \%): not reported (patients received lipid-lowering therapy for 3 months before enrolment)

Inclusion criteria: patients with CHD, which was confirmed by coronary angiography

Exclusion criteria: Patients with blood diseases, hepatonephric dysfunction, severe infectious diseases, and heart failure were excluded from the study.

Interventions

Intervention: atorvastatin $20 \mathrm{mg} /$ day + ezetimibe10 $\mathrm{mg} /$ day

Comparison: atorvastatin $20 \mathrm{mg} /$ day

Details of any 'run-in' period: none

Concomitant medications: aspirin, $\beta$-blockers, angiotensin-converting enzyme inhibitors, angiotensin II receptor antagonists, and hypoglycaemic drugs

Excluded medications: not reported

Blood lipid levels, carotid artery plaque, adverse events, rates of major adverse coronary events, in-
cluding cardiac death, hospitalisation for unstable angina, nonfatal Ml, coronary revascularisation, and
stroke.
stroke.

\begin{tabular}{|c|c|c|}
\hline Notes & Funding: not reported & \\
\hline \multicolumn{3}{|l|}{ Risk of bias } \\
\hline Bias & Authors' judgement & Support for judgement \\
\hline $\begin{array}{l}\text { Random sequence genera- } \\
\text { tion (selection bias) }\end{array}$ & Low risk & $\begin{array}{l}\text { Patients were divided into the control and combination groups by the random } \\
\text { number table method }\end{array}$ \\
\hline $\begin{array}{l}\text { Allocation concealment } \\
\text { (selection bias) }\end{array}$ & Unclear risk & Not reported \\
\hline $\begin{array}{l}\text { Blinding of participants } \\
\text { and personnel (perfor- } \\
\text { mance bias) } \\
\text { All outcomes }\end{array}$ & Unclear risk & $\begin{array}{l}\text { Report Quote: "double-blind study, and placebo-controlled", but according to } \\
\text { the sentence "The control group received oral atorvastatin (Lipitor } 20 \text { mg, Pfiz- } \\
\text { er, USA) every night, while the combination group received ezetimibe (Ezetrol } \\
10 \mathrm{mg} \text {, Schering-Plough, USA) in the morning and atorvastatin in the evening", } \\
\text { we are not sure whether the control group was using matching placebo, and } \\
\text { the blinding to the participants and personnel is unclear. }\end{array}$ \\
\hline
\end{tabular}


Luo 2016 (Continued)

Blinding of outcome as- Unclear risk Not reported sessment (detection bias)

All outcomes

\begin{tabular}{lll}
$\begin{array}{l}\text { Incomplete outcome data } \\
\text { (attrition bias) } \\
\text { All outcomes }\end{array}$ & Low risk & Missing outcome data balanced in numbers across intervention groups (<1\%) \\
\hline $\begin{array}{l}\text { Selective reporting (re- } \\
\text { porting bias) }\end{array}$ & Unclear risk & No protocol published, or trials registry record found. \\
\hline Other bias & Unclear risk & $\begin{array}{l}\text { Insufficient information to assess whether an important risk of bias exists } \\
\text { Quote: "All of the authors declare that they have no conflicts of interest regard- } \\
\text { ing this paper" }\end{array}$
\end{tabular}

\section{OCTIVUS 2017}

Methods

Design: double-blinded randomised placebo-controlled trial

Number of study centres: single-centre in Demark

Setting: inpatient and outpatient

Patient recruitment: June 2011 to June 2013

Duration of study (Follow-up): 12months

Clinical setting: ST-segment elevation MI

\section{Participants}

\section{Enrolment (N): 1062}

Randomised (N): intervention: 43; control:44

Withdrawn (N): one patient withdrew consent, but unclear which group.

Lost to follow-up (N): total 4 , the number of each group was unclear.

Completed the study (N): total 70 , the number of each group was unclear.

Analysed (N): lipids, intervention:39; control:41

Age (years) (mean \pm SD): intervention: $55.3 \pm 11.0$; control: $57.2 \pm 9.1$

Sex (male, N, \%): intervention:39 (90.7); control: 36 (81.8)

Smoking history (N, \%): intervention: 25 (58.1); control:23 (52.3)

BMI (kg/m², mean, IQR):): intervention: 27.3 (25.1, 29.2); control:27.4 (24.6, 29.4)

Diabetes (N, \%): intervention:1 (2.3\%) ; control:1 (2.3\%)

Hypertension (N, \%): intervention: 7 (16.3); control:8 (18.2)

History of MI (N, \%): intervention: 0; control:0

Statin pretreatment (N, \%): intervention:0 ; control:0

Inclusion criteria: (1) first-time ST-segment elevation myocardial infarction (STEMI); (2) no prior treatment with statins or other lipid lowering drugs; and (3) a non-significant lesion in one of the two nonculprit coronary arteries (angiographic diameter stenosis $>20 \%$ and $<50 \%$ ). 
Exclusion criteria: (1) age below 18 or above 81 years; (2) serum creatinine $>176 \mu \mathrm{mol} / \mathrm{L}$; (3) women with child-bearing potential who were not using chemical or mechanical contraception; 4) history of malignancy unless a disease-free period of more than five years was present; (5) participation in another randomised trial; (6) treatment with cyclosporine or fibrates.

$\begin{array}{ll}\text { Interventions } & \text { Intervention: atorvastatin } 80 \mathrm{mg} / \text { day + ezetimibe } 10 \mathrm{mg} / \text { day } \\ \text { Comparison: atorvastatin } 80 \mathrm{mg} / \text { day + placebo } \\ \text { Details of any 'run-in' period: not reported } \\ \text { Concomitant medications: not reported } \\ \text { Excluded medications: not reported } \\ \text { Primary: change in the relative necrotic core (NC) content after } 12 \text { months. } \\ \text { Secondary: change in fibrotic (FT), lipidic (LT) and calcific (CT) together with changes in total atheroma } \\ \text { volume (TAV) and percentage atheroma volume (PAV). } \\ \text { Other: lipids } \\ \text { Funding: The Danish Heart Foundation has supported this study. } \\ \text { NCT01385631 } \\ \text { Emailed trialists to enquire additional information. No response }\end{array}$

\section{Risk of bias}

\begin{tabular}{|c|c|c|}
\hline Bias & Authors' judgement & Support for judgement \\
\hline \multirow{2}{*}{$\begin{array}{l}\text { Random sequence genera- } \\
\text { tion (selection bias) }\end{array}$} & Low risk & Quote: "block randomized (1:1) by envelope method" \\
\hline & & $\begin{array}{l}\text { "The randomization procedure was administered by the hospital pharmacy } \\
\text { who also supplied the blinded study medicine." }\end{array}$ \\
\hline $\begin{array}{l}\text { Allocation concealment } \\
\text { (selection bias) }\end{array}$ & Low risk & Quote: "block randomized (1:1) by envelope method" \\
\hline $\begin{array}{l}\text { Blinding of participants } \\
\text { and personnel (perfor- } \\
\text { mance bias) } \\
\text { All outcomes }\end{array}$ & Low risk & Double-blinded and matching placebo was used \\
\hline
\end{tabular}

\begin{tabular}{lll}
\hline $\begin{array}{l}\text { Blinding of outcome as- } \\
\text { sessment (detection bias) } \\
\text { All outcomes }\end{array}$ & Low risk & $\begin{array}{l}\text { Quote: "All recordings were assigned to randomly generated examination } \\
\text { ID numbers corresponding to a list managed by a person not involved in the } \\
\text { study and archived to DVDs." }\end{array}$ \\
\hline $\begin{array}{l}\text { Incomplete outcome data } \\
\text { (attrition bias) }\end{array}$ & Unclear risk & $\begin{array}{l}\text { Withdrawals reported with reasons, not specified which group. Emailed trial- } \\
\text { ists to enquire additional information. No response }\end{array}$ \\
& $\begin{array}{l}\text { Intention-to-treat (ITT) analysis used, but after exclusion of some randomised } \\
\text { patients. }\end{array}$
\end{tabular}

\begin{tabular}{ll}
\hline $\begin{array}{l}\text { Selective reporting (re- } \\
\begin{array}{l}\text { porting bias) } \\
\end{array}\end{array}$ & $\begin{array}{l}\text { Now protocol published, but a pre-registration in a clinical trial registry was } \\
\text { found (NCTO1385631). }\end{array}$ \\
& All outcomes reported as planned. \\
\hline
\end{tabular}

Other bias Low risk The Danish Heart Foundation has supported this study.


Conflicts of interests: Quote: "LOJ has received research grants fromTerumo, Biotronik, St Jude Medical, and Biosensors to her institution and honoraria from Abbott Vascular,AstraZeneca, St Jude Medical and Biotronik. The other authors had nothing to disclose."

Okada 2012

$\begin{array}{ll}\text { Methods } & \text { Design: RCT } \\ \text { Number of study centres: } 13 \text { centres in Japan } \\ \text { Setting: not reported } \\ \text { Patient recruitment: not reported } \\ \text { Duration of study (Follow-up): } 52 \text { weeks } \\ \text { Clinical setting: coronary artery disease }\end{array}$

Participants

Enrolment (N): 200

Randomised (N): intervention: 100; control:100

Withdrawn (N): intervention:22 ; control:28

Lost to follow-up (N): not reported

Completed the study (N): intervention: 78 ; control:72

Analysed (N): intervention: 78; control:72

Age (years) (mean \pm SD): intervention: $65.7 \pm 10.1$; control: $65.9 \pm 8.7$

Sex (male, N, \%): intervention: 57 (73.1\%); control: 53 (73.6\%)

Smoking history (N, \%): intervention: 26(33.3\%); control: 25 (34.7\%)

BMI (kg/m² , mean \pm SD):): intervention: $25.1 \pm 3.0$; control: $25.3 \pm 3.8$

Diabetes (N, \%): intervention: 41 (52.6\%); control: 36 (50.0\%)

Hypertension (N, \%): intervention: 57 (73.1\%) ; control: 57 (79.2\%)

History of MI (N, \%): intervention: 45 (57.7\%) ; control: 42 (58.3\%)

Statin pretreatment (N, \%): intervention: 100\%; control:100\%

Inclusion criteria: Quote: "Patients with coronary artery disease whose LDL-C levels were $\geq 70 \mathrm{mg} / \mathrm{dL}$ after treatment with atorvastatin $10 \mathrm{mg} /$ day or rosuvastatin $2.5 \mathrm{mg} /$ day".

Exclusion criteria: adverse reactions to the study drugs; triglyceride level $>500 \mathrm{~m} \mathrm{~g} / \mathrm{dL}$; ALT level more than twice the upper limit of normal; secondary dyslipidaemia; drug-induced dyslipidaemia; ACS, a history of $\mathrm{PCl}$, coronary artery bypass grafting, or stroke within 3 months. Women who were pregnant, at risk for becoming pregnant, or who were nursing infants were also excluded.

Interventions

Intervention: ezetimibe +atorvastatin $10 \mathrm{mg} /$ day or rosuvastatin $2.5 \mathrm{mg} /$ day

Comparison: atorvastatin $20 \mathrm{mg} /$ day or rosuvastatin $5 \mathrm{mg} /$ day

Details of any 'run-in' period: not reported

Concomitant medications: not reported 
Okada 2012 (Continued)

Excluded medications: not reported

Outcomes Primary: Lipid levels, campesterol, lathosterol, plasma protein convertase subtilisin/kexin type 9 (PCSK9) concentrations.

Notes $\quad$ Funding: Financially supported by Merck Sharp \& Dohme (MSD), Inc. and Bayer, Inc.

\title{
Risk of bias
}

\begin{tabular}{|c|c|c|}
\hline Bias & Authors' judgement & Support for judgement \\
\hline $\begin{array}{l}\text { Random sequence genera- } \\
\text { tion (selection bias) }\end{array}$ & Unclear risk & Randomly assigned, but no further details. \\
\hline $\begin{array}{l}\text { Allocation concealment } \\
\text { (selection bias) }\end{array}$ & Unclear risk & Not reported \\
\hline $\begin{array}{l}\text { Blinding of participants } \\
\text { and personnel (perfor- } \\
\text { mance bias) } \\
\text { All outcomes }\end{array}$ & Unclear risk & Not reported \\
\hline $\begin{array}{l}\text { Blinding of outcome as- } \\
\text { sessment (detection bias) } \\
\text { All outcomes }\end{array}$ & Unclear risk & Not reported \\
\hline $\begin{array}{l}\text { Incomplete outcome data } \\
\text { (attrition bias) } \\
\text { All outcomes }\end{array}$ & High risk & $50 / 200$ withdrew from the study \\
\hline $\begin{array}{l}\text { Selective reporting (re- } \\
\text { porting bias) }\end{array}$ & Unclear risk & No protocol published, or trials registry record found. \\
\hline Other bias & Unclear risk & $\begin{array}{l}\text { Insufficient information to assess whether an important risk of bias exists } \\
\text { Financially supported by Merck Sharp \& Dohme (MSD), Inc. and Bayer, Inc. }\end{array}$ \\
\hline
\end{tabular}

Number of study centres: 17 centres in Japan

Setting: inpatient and outpatient follow-up

Patient recruitment: January 2010 to September 2014

Duration of study: 12 months

Clinical setting: hypercholesterolemia and coronary artery disease

\section{Participants}

\author{
Enrolment (N): 246 \\ Randomised (N): intervention: 122; control: 124 \\ Withdrawn (N): intervention: 1 ; control: 2 \\ Lost to follow-up (N): not reported
}


Completed the study (N): intervention: 100; control: 102

Analysed (N): intervention: 121; control: 122

Age (years) (mean \pm SD): intervention: $66 \pm 10$; control: $67 \pm 10$

Sex (male, N, \%): intervention: 78 (78\%); control: 80 (78\%)

Smoking history (N, \%): intervention: 20 (20\%); control: 32(32\%)

BMI (kg/m² mean \pm SD):): intervention: $24.8 \pm 3.4$; control: $24.9 \pm 3.1$

Diabetes (N, \%): intervention: 29 ( 29\%); control: 31 (30\%)

Hypertension (N, \%): intervention: 75 (75\%); control: 67 (66\%)

Existing CHD: intervention: 100 ( 100\%); control: 102 (100\%)

History of MI (N, \%): intervention: 15 (15\%); control: 13 (13\%)

Statin pretreatment (N, \%): intervention: 46 (46\%) ; control: $49(48 \%)$

\section{Inclusion criteria:}

1. aged 30-85 years at the time of their consent;

2. patients who have been diagnosed as ACS or stable coronary heart disease;

3. patients who undergo CABG or PCI under IVUS guidance;

4. patients with $L D L-C \geq 100 \mathrm{mg} / \mathrm{dL}$ at the time of their consent.

\section{Exclusion criteria:}

1. familial hypercholesterolaemia;

2. being treated with ezetimibe;

3. being treated with fibrates;

4. renal insufficiency (serum creatinine $>=2.0 \mathrm{mg} / \mathrm{dL}$ );

5. altered hepatic function (serum AST or ALT >=3-fold of standard value in each institute);

6. undergoing haemodialysis or peritoneal dialysis;

7. allergic to Lipitor and/or Zetia;

8. severe underlying disease;

9. lack of decision-making capacity;

10.recognised as inadequate by attending doctor. maximum of $20 \mathrm{mg} /$ day with a treatment goal of lowering LDL-C below $70 \mathrm{mg} / \mathrm{dL}$ )

Comparison: atorvastatin

Details of any 'run-in' period: not reported

Concomitant medications: not reported

Excluded medications: not reported

Outcomes

Primary: absolute change from baseline to follow-up in per cent atheroma volume (PAV) in the target lesion

\section{Secondary:}

1. percentage change from baseline (before randomisation) to follow-up (9-12 months after randomisation) in the atheroma volume;

2. change and percentage change from baseline to follow-up in the minimum lumen diameter (MLD) and per cent diameter stenosis (\%DS; 
PRECISE-IVUS 2015 (Continued)

3. percentage changes from baseline to follow-up in serum lipids;

4. correlation between regression of coronary plaque and serum lipids profiles;

5. changes in high-sensitivity CRP (hs-CRP) from baseline to follow-up;

6. correlation between regression of coronary plaque and inflammatory markers (white blood cell count and hs-CRP);

7. change and percentage change from baseline to follow-up in the plaque volume of the PCI target lesion;

8. change and percentage change from baseline to follow-up in the MLD and \%DS of the PCI target lesion;

9. major adverse cardiac events (cardiac death, non-fatal myocardial infarction, non-fatal stroke, coronary revascularization);

10.all-cause death;

11.safety (adverse events, subjective symptoms/objective findings, physical tests), blood tests (haematology, clinical chemistry, glucose metabolism test), urinalysis).

Notes

Funding: Quote: "This work was supported in part by a Grant-in-Aid for Young Scientists B (22790713, 24790769) and a Grant-in-aid for Scientific Research C (26461075) from the Ministry of Education, Science, and Culture, Japan (to Dr. Tsujita)."

NCT01043380

\section{Risk of bias}

\begin{tabular}{lll}
\hline Bias & Authors' judgement & Support for judgement \\
\hline $\begin{array}{l}\text { Random sequence genera- } \\
\text { tion (selection bias) }\end{array}$ & Low risk & Quote: "randomly assigned by using a web-based randomization software" \\
\hline $\begin{array}{l}\text { Allocation concealment } \\
\text { (selection bias) }\end{array}$ & Low risk & Quote: "randomly assigned by using a web-based randomization software" \\
\hline
\end{tabular}

Blinding of participants High risk Open-label study, no blinding of participants and personnel.

and personnel (perfor-

High risk

Open-label study, no blinding of participants and personnel.

mance bias)

All outcomes

Blinding of outcome as- Low risk sessment (detection bias)

All outcomes

$\begin{array}{ll}\begin{array}{l}\text { Incomplete outcome data } \\ \text { (attrition bias) }\end{array} & \text { Low risk } \\ \text { All outcomes } & \text { Safety outcomes analyses were performed by using 'safety analysis set', } \\ & \begin{array}{l}\text { Number of participants that discontinued were reported and reasons were } \\ \text { stated }\end{array}\end{array}$

\begin{tabular}{|c|c|c|}
\hline $\begin{array}{l}\text { Selective reporting (re- } \\
\text { porting bias) }\end{array}$ & Low risk & $\begin{array}{l}\text { The study protocol was published and all of the study's prespecified outcomes } \\
\text { have been reported. }\end{array}$ \\
\hline
\end{tabular}

Other bias Low risk

Quote: "This work was supported in part by a Grant-in-Aid for Young Scientists
B (22790713, 24790769) and a Grant-in-aid for Scientific Research C (26461075)
from the Ministry of Education, Science, and Culture, Japan (to Dr. Tsujita)."

Quote: "Dr. Ogawa has received remuneration for lectures from Bayer, Boehringer Ingelheim, Daiichi-Sankyo, MSD, Pfizer, and Takeda; has received trust research/joint research funds from Bayer, Daiichi-Sankyo, and Novartis; and has received scholarship funds from AstraZeneca, Astellas, Bristol-Myers Squibb, Chugai, Daiichi-Sankyo, Dainippon Sumitomo Pharma, Kowa, MSD, Otsuka, Pfizer, Sanofi, Shionogi, and Takeda. Dr. Ishihara has received remu- 
Number of study centres: single centre in China

Setting: inpatient and outpatient

Patient recruitment: January 2015 to June 2016

Duration of study (Follow-up):12 months

Clinical setting: acute MI

Randomised (N): intervention:55 ; control:58

Withdrawn (N): intervention: 0; control:0

Lost to follow-up (N): intervention: 0; control:0

Completed the study (N): intervention:55 ; control:58

Analysed (N): intervention: 55; control:58

Age (years) (mean \pm SD): intervention: $57.3 \pm 1.5$; control: $60.7 \pm 1.3$

Sex (male, N, \%): intervention:46(79.3\%); control: 48(87.3\%)

Smoking history (N, \%): intervention:38 (65.5\%) ; control:39 (70.9\%)

BMI $\left(\mathbf{k g} / \mathbf{m}^{2}\right.$, mean $\left.\left.\pm \mathrm{SD}\right):\right)$ : not reported

Diabetes (N, \%): intervention: 10(17.2\%); control:10(18.2\%)

Hypertension (N, \%): intervention: 35 (60.3\%); control:31 (56.4)\%

History of MI (N, \%): intervention: 1(1.7\%); control:2(3.6\%)

Statin pretreatment (N, \%): intervention: 6 (10.5\%); control:5 (9.1\%)

Inclusion criteria: Quote: "patients aged within the range of 18 to 80 years were eligible if hospitalized within the preceding $24 \mathrm{~h}$ for acute myocardial infarction, including ST-segment elevation myocardial infarction (STEMI) with or without ST-segment elevation myocardial infarction (NSTEMI)."

Exclusion criteria: i) Contraindications for the intervention; ii) statin use was contraindicated, for example, due to the patient having active hepatitis or being allergic to statins; iii) severe cardiac dysfunction (Killip class III or IV); iv) severe renal insufficiency; and v) other comorbidities, including infection, systemic immune diseases, pericarditis and malicious tumour.

Details of any 'run-in' period: Quote: "Following 1 week of the intervention, 113 patients continued to meet the inclusion criteria and were randomly divided into two groups"

Concomitant medications: not reported 
Ren 2017 (Continued)

Excluded medications: not reported

Outcomes Primary: lipid level, inflammatory markers (high-sensitivity CRP and lipoprotein associated phospholipase $A 2$ ) at 1,3 and 12 months.

\begin{tabular}{lll}
\hline Notes & Funding: not reported \\
\hline Risk of bias & & \\
\hline Bias & Authors' judgement & Support for judgement \\
\hline $\begin{array}{l}\text { Random sequence genera- } \\
\text { tion (selection bias) }\end{array}$ & Low risk & $\begin{array}{l}\text { Randomisation was performed by means of a computer-generated sequence } \\
\text { of random numbers. }\end{array}$ \\
\hline $\begin{array}{l}\text { Allocation concealment } \\
\text { (selection bias) }\end{array}$ & Unclear risk & Double-blind (participant,ilnvestigator, outcomes' assessor) \\
\hline $\begin{array}{l}\text { Blinding of participants } \\
\text { and personnel (perfor- } \\
\text { mance bias) }\end{array}$ & Unclear risk & Not reported \\
$\begin{array}{l}\text { All outcomes } \\
\end{array}$ & & \\
\hline
\end{tabular}

Blinding of outcome as- Unclear risk Not reported

sessment (detection bias)

All outcomes

Incomplete outcome data Low risk All the patients completed the study.

(attrition bias)

All outcomes

Selective reporting (re- Unclear risk No protocol published, or trials registry record found.

porting bias)

Other bias Unclear risk Insufficient information to assess whether an important risk of bias exists.

Methods Design: randomised, open-label, prospective study

Number of study centres: multi-centres (10) in Japan

Setting: outpatient

Patient recruitment: not reported

Duration of study (Follow-up): 52 weeks

Clinical setting: T2DM patients with hypercholesterolaemia

Randomised (N): intervention:53 ; control:56

Withdrawn (N): not reported

Lost to follow-up (N): not reported

Completed the study (N): intervention: 51; control:53 
Analysed (N): intervention: 53; control:56

Age (years) (mean \pm SD): intervention: $61.7 \pm 11.1$; control: $62.6 \pm 9.5$

Sex (male, N, \%): intervention:31 (58.5\%); control: 32 (57.1\%)

Smoking history (N, \%): intervention: 13 (24.5\%); control:13 (23.6\%)

BMI $\left(\mathbf{k g} / \mathbf{m}^{2}\right.$, mean \pm SD):): not reported

Diabetes (N, \%): intervention:51 (100\%) ; control:53 (100\%)

Hypertension (N, \%): not reported

History of CHD (N, \%): intervention: 8 (15.1\%); control:6 (10.7\%)

Statin pretreatment (N, \%): intervention:53 (100\%) ; control:56 (100\%)

Inclusion criteria: the type 2 diabetic outpatients were over 20 years of age and had failed to reach the target LDL-C values recommended by the guideline (LDL-C $<120 \mathrm{mg} / \mathrm{dL}$ for patients with no history of CAD; LDL-C $<100 \mathrm{mg} / \mathrm{dL}$ for patients with a history of CAD) after receiving high-potency statins (10 mg of atorvastatin or $1 \mathrm{mg}$ of pitavastatin) for more than 1 month.

Exclusion criteria: (1) history of hypersensitivity to atorvastatin, pitavastatin or ezetimibe; (2) serum triglyceride level more than $400 \mathrm{mg} / \mathrm{dL}$; (3) hepatic dysfunction (an ALT level that is more than twice the upper limit of the normal range); (4) uncontrolled diabetes (HbA1c more than 9.0\%); (5) renal dysfunction (a creatinine level that is higher than $2.0 \mathrm{mg}$ per $\mathrm{dL}$ ); (6) secondary or drug-induced hypercholesterolaemia; (7) homozygous familial hypercholesterolaemia; (8) pregnant or nursing women or women suspect of pregnancy; (9) judged as inappropriate for study by doctor.

Interventions

Intervention: ezetimibe $10 \mathrm{mg} /$ day + (atorvastatin $10 \mathrm{mg} /$ day or pitavastatin $1 \mathrm{mg} /$ day).

Comparison: atorvastatin $20 \mathrm{mg} /$ day or pitavastatin $2 \mathrm{mg} /$ day

Details of any 'run-in' period: not reported

Concomitant medications: not reported

Excluded medications: statins other than atorvastatin or pitavastatin, anion-exchanging resin agents, fibrates, nicotinic acids, eicosapentaenoic acid, probucol, or other lipid-lowering agents.

Outcomes

Primary: the per cent change in LDL-C from baseline.

Secondary: the rates at which the target LDL-C values recommended by the guidelines were achieved and the values and per cent changes in total cholesterol (TC), triglyceride (TG), HDL-C, high-sensitivity CRP (Hs-CRP), sd-LDL, and remnant-like particle cholesterol (RLP-C).

Other: general parameters such as AST, ALT, creatinine, and creatine phosphokinase (CPK), along with plasma glucose, HbA1c values and serum insulin level. Adverse events.

Notes

Funding: This study was supported by research grants from Japan Vascular Disease Research Foundation.

UMIN000002593

\section{Risk of bias}

\begin{tabular}{lll}
\hline Bias & Authors' judgement & Support for judgement \\
\hline $\begin{array}{l}\text { Random sequence genera- } \\
\text { tion (selection bias) }\end{array}$ & Low risk & $\begin{array}{l}\text { Quote: "Randomization was performed with stratification according to age } \\
\text { and gender. When a patient was enrolled, a doctor placed an order for random } \\
\text { assignment by entering the data (including age and year) into the randomiza- } \\
\text { tion software installed at the monitoring office of Nouvelle Plus." }\end{array}$ \\
\hline
\end{tabular}




\title{
RESEARCH 2017 (Continued)
}

\begin{tabular}{lll}
$\begin{array}{l}\text { Allocation concealment } \\
\text { (selection bias) }\end{array}$ & Unclear risk & Not reported \\
\hline $\begin{array}{l}\text { Blinding of participants } \\
\text { and personnel (perfor- } \\
\text { mance bias) }\end{array}$ & Unclear risk & Not reported \\
All outcomes & &
\end{tabular}

Blinding of outcome as- Unclear risk Not reported

sessment (detection bias)

Not reported

All outcomes

Incomplete outcome data Low risk $\quad$ An intention-to-treat analysis and per protocol analysis were performed.
(attrition bias)

All outcomes

Selective reporting (re- Low risk
porting bias)

No protocol published, but a pre-registration in a clinical trial registry was

porting bias) found (UMIN000002593).

All prespecified outcomes were reported.

Other bias Low risk

\begin{abstract}
Quote: "Funding: This study was supported by research grants from Japan Vascular Disease Research Foundation."

Quote: "Teruo Shiba has received honoraria from Shionogi \& Co., Ltd., Pfizer Japan Inc., Merck Sharp \& Dohme (MSD), Kowa Company, Ltd., and Daiichi Sankyo Company Limited. Tsutomu Yamazaki has received research support and honoraria from Merck Sharp \& Dohme (MSD), Pfizer Japan Inc., Kowa Company, Ltd., Shionogi \& Co., Ltd., and AstraZeneca K.K., and honoraria from Bayer Holding Ltd. and Daiichi Sankyo Company Limited. Akira Tanaka has received research support from Daiichi Sankyo Company Limited and honoraria from Merck Sharp \& Dohme (MSD), and Kewpie Corporation. Takahide Kohro has received research support from AstraZeneca K.K. and honoraria from Merck Sharp \& Dohme (MSD). The other authors have no conflicts of interest to declare."
\end{abstract}

Sawayama 2011

\begin{tabular}{ll}
\hline Methods & Design: RCT \\
Number of study centres: not reported \\
Setting: not reported \\
Patient recruitment: not reported \\
Duration of study (Follow-up): mean follow-up time of 1.2 years \\
Clinical setting: hypercholesterolemic patients \\
Enrolment (N): 60 \\
Randomised $(\mathbf{N}):$ not reported \\
Withdrawn (N): not reported \\
Lost to follow-up (N): not reported \\
Completed the study (N): intervention: ; control:
\end{tabular}


Analysed (N): intervention: 27 ; control:22

Age (years) (mean \pm SD): not reported

Sex (male, $\mathbf{N}, \%$ ): not reported

Smoking history (N, \%): not reported

BMI (kg/m $\mathbf{m}^{2}$, mean \pm SD):): not reported

Diabetes (N, \%): not reported

Hypertension (N, \%): not reported

History of CHD (N, \%): not reported

Statin pretreatment (N, \%): intervention: $100 \%$; control:100\%

Inclusion criteria: hypercholesterolemic patients with LDL-C levels $>120 \mathrm{mg}$ under treatment with lowdose pravastatin ( $5 \mathrm{mg}$ )

\section{Exclusion criteria: not reported}

Comparison: standard-dose pravastatin $(10 \mathrm{mg})$.

Details of any 'run-in' period: not reported

Concomitant medications: not reported

Excluded medications: not reported

\begin{tabular}{ll}
\hline Outcomes & Primary: carotid intima-media thickness (IMT), LDL-C and non-HDL-C \\
\hline Notes & Conference abstracts only. \\
& Lipids outcome data relevant to this review. \\
& Emailed trialists for details. No response \\
& Source of funding: not reported.
\end{tabular}

\section{Risk of bias}

\begin{tabular}{lll}
\hline Bias & Authors' judgement & Support for judgement \\
\hline $\begin{array}{l}\text { Random sequence genera- } \\
\text { tion (selection bias) }\end{array}$ & Unclear risk & No report \\
\hline $\begin{array}{l}\text { Allocation concealment } \\
\text { (selection bias) }\end{array}$ & Unclear risk & No report \\
\hline $\begin{array}{l}\text { Blinding of participants } \\
\text { and personnel (perfor- } \\
\text { mance bias) } \\
\text { All outcomes }\end{array}$ & Unclear risk & No report \\
\hline
\end{tabular}

Blinding of outcome as-
sessment (detection bias) $\quad$ Unclear risk No report

Incomplete outcome data Unclear risk lintention-to-treat analysis
(attrition bias)


Sawayama 2011 (Continued)

All outcomes

Selective reporting (re- Unclear risk $\quad$ Unable to assess
porting bias)

Other bias High risk Published conference abstract only

Suzuki 2013

Design: randomised, open-label, multi-centre trial
Number of study centres: multi-centres in Japan
Setting: not reported
Patient recruitment: not reported
Duration of study (Follow-up): 1 year
Clinical setting: chronic kidney disease

Participants

Enrolment (N): 356

Randomised (N): 296, intervention: 148; control: 148

Withdrawn (N): intervention: 3; control: 7

Lost to follow-up (N): intervention: ; control:

Completed the study (N): intervention: ; control:

Analysed (N): intervention: 145; control: 141

Age (years) (SD, mean \pm SD): intervention: $64 \pm 1$ 2; control: $64 \pm 12$

Sex (male, N, \%): intervention: 96 (66\%); control: 94 (66\%)

Smoking history (N, \%): intervention: 55 (37.9\%); control:60 (42.5\%)

BMI (kg/m² $\mathbf{m}$ mean \pm SD):): intervention: $25.2 \pm 1.6$; control: $25.8 \pm 1.9$

Diabetes (N, \%): intervention: 50 (34\%); control:50 (34\%)

Hypertension (N, \%): intervention: $122(84 \%)$; control:121 (85\%)

History of cardiovascular disease (N, \%): intervention: 4 (2.7\%); control: 4 (2.8\%)

Statin pretreatment (N, \%): intervention: 148(100\%;) control:148(100\%)

Inclusion criteria: (1) age from > 35 to < 75 years; (2) undergoing treatment with low-dose statins; (3) $\mathrm{LDL}-\mathrm{C}>120 \mathrm{mg} / \mathrm{dL}$; and (4) positive proteinuria or estimated glomerular filtration rate (eGFR) $<60 \mathrm{ml} /$ $\mathrm{min} / \mathrm{L} .73 \mathrm{~m}^{2}$ for more than 3 months before enrolment.

Exclusion criteria: (1) undergoing dialysis therapy; (2) uncontrolled hypertension; (3) uncontrolled diabetes; (4) severe liver disease with ALT levels > 2 times the upper limit of normal (ULN); (5) triglycerides (TG) $>400 \mathrm{mg} / \mathrm{dL}$; (6) secondary hyperlipidaemia or hyperlipidaemia associated with the administration of a drug; (7) homozygous familial hypercholesterolaemia; (8) unstable angina,MI, surgical coronary intervention or stroke within 3 months of study entry; (9) pregnancy, possible pregnancy, desire to become pregnant during the study period, or lactation; (10) history of hypersensitivity to any ingredient in ezetimibe tablets; and (11) deemed inappropriate for study entry by the investigator. 
Suzuki 2013 (Continued)

Comparator: doubling of the dose of statin (statin uptitration group).

Details of any 'run-in' period: not reported

Concomitant medications: not reported

Excluded medications: not reported

Primary: the incidence of adverse effects, which included muscle complaints, myalgia, muscle weak-
ness, and muscle cramps with and without elevated creatinine kinase (CK) levels. Increases in ALT and
AST levels $>2$ times the ULN were considered to indicate liver toxicity.
Secondary: $(1)$ changes in serum LDL-C and HDL-C levels, $(2)$ changes in albumin/creatinine of urinary
excretion $(\mathrm{mg} / \mathrm{gCr}),(3)$ the rate of decline in renal function.

Notes $\quad$ Funding: Quote: "This research received no specific grant from any funding agency in the public, commercial, or not-for-profit sectors."

UMIN000002935

\section{Risk of bias}

\begin{tabular}{|c|c|c|}
\hline Bias & Authors' judgement & Support for judgement \\
\hline $\begin{array}{l}\text { Random sequence genera- } \\
\text { tion (selection bias) }\end{array}$ & Low risk & No report, using the dynamic allocation method after stratification \\
\hline $\begin{array}{l}\text { Allocation concealment } \\
\text { (selection bias) }\end{array}$ & Unclear risk & Not reported \\
\hline $\begin{array}{l}\text { Blinding of participants } \\
\text { and personnel (perfor- } \\
\text { mance bias) } \\
\text { All outcomes }\end{array}$ & High risk & Open-label \\
\hline $\begin{array}{l}\text { Blinding of outcome as- } \\
\text { sessment (detection bias) } \\
\text { All outcomes }\end{array}$ & High risk & Open-label \\
\hline $\begin{array}{l}\text { Incomplete outcome data } \\
\text { (attrition bias) } \\
\text { All outcomes }\end{array}$ & Unclear risk & $\begin{array}{l}\text { Proportion of missing data: } 3 / 148 \text { in intervention group, } 7 / 148 \text { in control } \\
\text { group. The intervention group and the control group were excluded from } 3 \\
\text { cases and } 7 \text { cases, respectively, but the reasons were not explained and the } \\
\text { safety analysis was not included. Contact the author but did not respond. }\end{array}$ \\
\hline $\begin{array}{l}\text { Selective reporting (re- } \\
\text { porting bias) }\end{array}$ & Low risk & $\begin{array}{l}\text { No protocol published, but a pre-registration in a clinical trial registry was } \\
\text { found (UMIN000002935). } \\
\text { All prespecified outcomes were reported. }\end{array}$ \\
\hline Other bias & Low risk & $\begin{array}{l}\text { Quote: "This research received no specific grant from any funding agency in } \\
\text { the public, commercial, or not-for-profit sectors" } \\
\text { Quote: "The authors have no conflicts of interest to declare" }\end{array}$ \\
\hline
\end{tabular}

\section{VYCTOR 2009}

Methods

Design: RCT, open-label, 3-arm parallel group design 
Number of study centres: single-centre in Mexico

Setting: not reported

Patient recruitment: not reported

Duration of study (Follow-up): 12 months

Clinical setting: high-risk coronary artery patients

Participants

Interventions
Enrolment (N): 90 in total, of interest are: ezetimibe combined with simvastatin group $(\mathrm{N}=30)$ and simvastatin $\operatorname{group}(\mathrm{N}=30)$.

Randomised (N): intervention: 30; control:30

Withdrawn (N): intervention: 7; control:10

Lost to follow-up (N): not reported.

Completed the study (N): intervention: 23; control:20

Analysed (N): not reported

Age (years) (mean \pm SD): intervention: $58 \pm 9$; control: $57 \pm 8$

Sex (male, N, \%): intervention:19 (63.3\%); control:12 (40\%)

Smoking history (N, \%): not reported

BMI (kg/m², mean \pm SD):): intervention: $29 \pm 6$; control: $29 \pm 4$

Diabetes (N, \%): intervention: 14 (46.7\%); control:15 (50\%)

Hypertension (N, \%): not reported

History of CHD (N, \%): not reported

Statin pretreatment (N, \%): not reported

Inclusion criteria: patients of any gender, aged 40 to 72 years, with a 10-year absolute risk for coronary death or $\mathrm{MI} \geq 20$ according to the ATP III recommendations were recruited.

Exclusion criteria: patients with severe systemic diseases, including liver diseases, chronic renal failure, heart failure, malignancies, autoimmune diseases, acquired immune deficiency syndrome (AIDS), or a history of alcohol or other drug abuse, were excluded. Pregnant or fertile women without a totally reliable contraception method or breastfeeding mothers were also excluded.

Intervention: simvastatin $20 \mathrm{mg}$ + ezetimibe $10 \mathrm{mg}$ (in month 2, doses were scaled to $40 \mathrm{mg} / 10 \mathrm{mg}$, if goal was not attained)

Comparison: simvastatin $40 \mathrm{mg}$ (in month 2, doses were scaled to $80 \mathrm{mg}$, if goal was not attained)

We included the comparison above. The third group was not included (pravastatin $40 \mathrm{mg}$, in month 2, ezetimibe $10 \mathrm{mg}$ was added if goal was not attained).

Details of any 'run-in' period: not reported

Concomitant medications: not reported

Excluded medications: not reported

Outcomes

Primary: carotid Intima-Media Thickness (IMT), the values of vascular stiffness

Secondary: changes in LDL-C and high-sensitivity CRP 
VYCTOR 2009 (Continued)

other: other lipids level, causes of discontinuation.
Funding: Merck Sharp \& Dohme, Mexico; the Mexican Association for the Prevention of Atherosclerosis and its Complications (AMPAC); and the National Association of Cardiologists serving the State Employees (ANCISSSTE).

\title{
Risk of bias
}

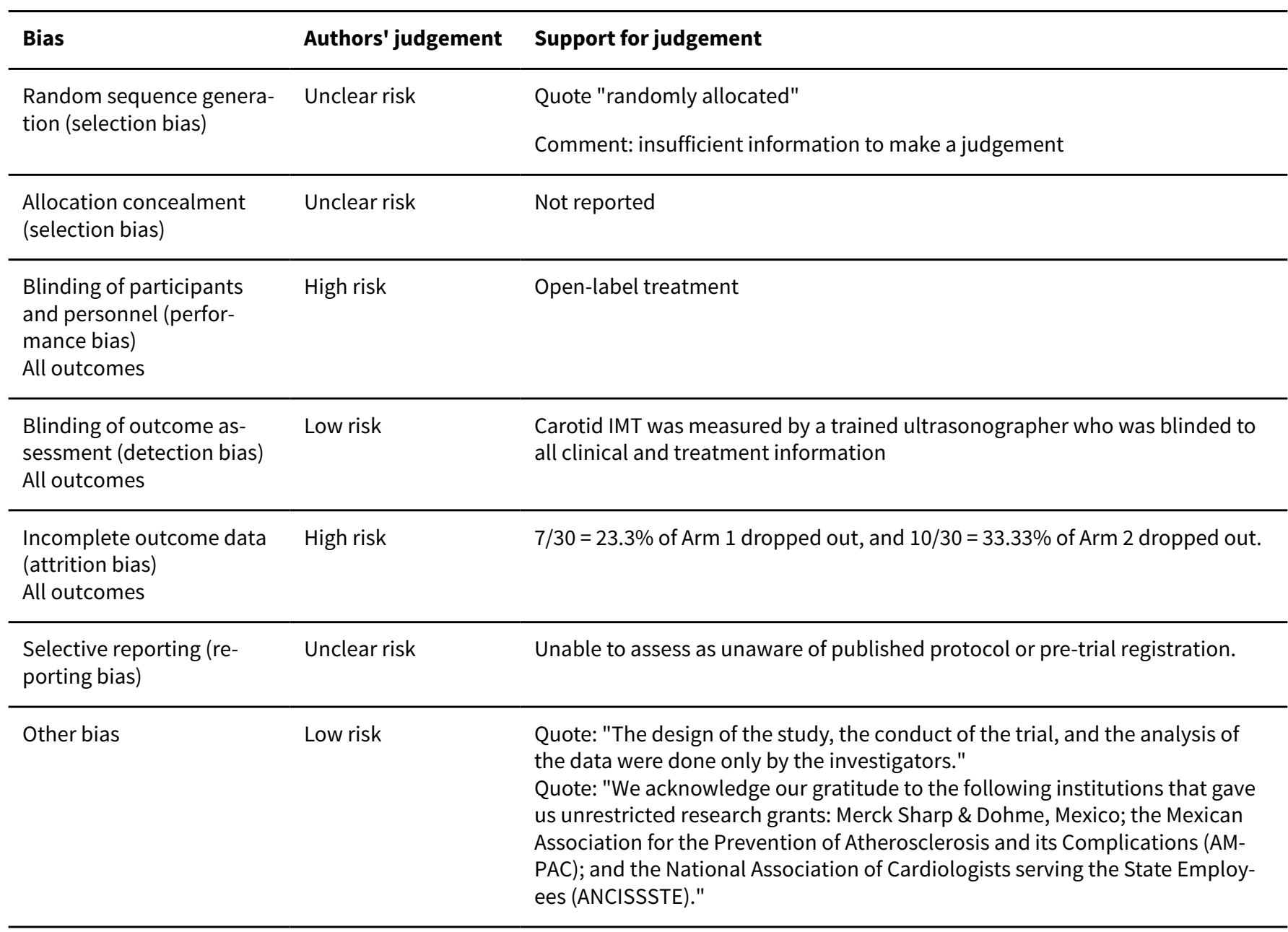

Wang 2016

Methods Design: randomised controlled trial

Number of study centres: single centre in China.

Setting: inpatients

Patient recruitment: January 2011 to January 2014

Duration of study: 12 months

Clinical setting: coronary atherosclerotic heart disease and hyperlipidaemia

\author{
Participants \\ Enrolment (N): 106 \\ Randomised (N): intervention: 55; control: 51
}


Withdrawn (N): intervention: 3; control: 2

Lost to follow-up (N): intervention: 2; control: 1

Completed the study (N): intervention: 50; control: 48

Analysed (N): intervention: 50; control: 48

Age (years) (mean \pm SD): intervention: $63 \pm 10$; control: $65 \pm 12$

Sex (male, N, \%): intervention: 36 (72\%); control: 35 (73\%)

Smoking history (N, \%): intervention: 31 (62\%); control: 29 (60\%)

BMI $\left(\mathbf{k g} / \mathrm{m}^{2}\right.$, mean \pm SD):): not reported

Diabetes (N, \%): intervention: 18 (36\%); control: $17(35 \%)$

Hypertension (N, \%): intervention: 25 ( $50 \%$ ); control: 23 (48\%)

Existing CHD: intervention: 50 (100\%), control: 48 (100\%)

Existing Acute coronary syndrome (N, \%): intervention: 28 ( $56 \%$ ); control: 27 (57\%)

Statin pretreatment (N, \%): not reported

Inclusion criteria: coronary angiography had revealed one or more atherosclerotic lesions near the middle of the coronary arteries; total cholesterol level was $\geq 5.2 \mathrm{mmol} / \mathrm{L}$; and (or) low-density lipoprotein (LDL)-cholesterol level was $\geq 3.6 \mathrm{mmol} / \mathrm{L}$. The atherosclerotic lesions were borderline lesions and (or) severe coronary atherosclerotic lesions. Borderline lesion was $40 \%$ to $70 \%$ stenosis demonstrated by quantitative coronary angiography. Severe lesion was more than $75 \%$ stenosis demonstrated by quantitative coronary angiography.

Exclusion criteria: (1) contraindications for the intervention; (2) statin use is contraindicated, such as the patient has active hepatitis; (3) high (> two-fold normal) transaminase levels.

Comparison: rosuvastatin alone $(10 \mathrm{mg} /$ day $)$

Details of any 'run-in' period: not reported

Concomitant medications: not reported

Excluded medications: not reported

Outcomes

Primary: new or recurrence MI, unstable angina pectoris, cardiac death, stroke.

other:

1. blood lipid levels, high-sensitivity CRP (hSCRP), interleukin-6 (IL-6), and matrix metalloproteinase-9 (MMP-9);

2. coronary plaque size and compositional changes were determined using intravascular ultrasonography;

3. major adverse events. 
Wang 2016 (Continued)

Random sequence genera- Unclear risk Insufficient information about the sequence generation process available tion (selection bias)

\begin{tabular}{ll}
\hline $\begin{array}{l}\text { Allocation concealment } \\
\text { (selection bias) }\end{array}$ & Unclear risk
\end{tabular}

Blinding of participants $\quad$ Unclear risk
and personnel (perfor-
mance bias)
All outcomes

\begin{tabular}{ll}
\hline Blinding of outcome as- & Unclear risk
\end{tabular} Not reported if blinded.

All outcomes

\begin{tabular}{|c|c|c|}
\hline $\begin{array}{l}\text { Incomplete outcome data } \\
\text { (attrition bias) } \\
\text { All outcomes }\end{array}$ & Low risk & $\begin{array}{l}\text { Missing outcome data balanced in numbers across intervention groups, with } \\
\text { similar reasons for missing data across groups. }\end{array}$ \\
\hline
\end{tabular}

\begin{tabular}{|c|c|c|}
\hline $\begin{array}{l}\text { Selective reporting (re- } \\
\text { porting bias) }\end{array}$ & Unclear risk & $\begin{array}{l}\text { No protocol published, or trials registry record found. } \\
\text { This study did not report number of adverse events. }\end{array}$ \\
\hline \multirow[t]{2}{*}{ Other bias } & Low risk & $\begin{array}{l}\text { Quote: "This study was supported by the Medical Science and Technology Re- } \\
\text { search Projects of Henan Province" }\end{array}$ \\
\hline & & Conflict of interest: none \\
\hline
\end{tabular}

Wang 2017

\begin{tabular}{ll}
\hline Methods & Design: $\mathrm{RCT}$ \\
& Number of study centres: single centre in China
\end{tabular}

Setting: inpatient and outpatient

Patient recruitment: June 2015 to June 2016

Duration of study (Follow-up): 12 months

Clinical setting: type 2 diabetes mellitus complicated with coronary heart disease

Participants

\author{
Enrolment (N): 100 \\ Randomised (N): intervention: 51; control:49 \\ Withdrawn (N): intervention:0 ; control:0
}

Lost to follow-up (N): intervention: 0; control:0

Completed the study (N): intervention: 51 ; control:49

Analysed (N): intervention: 51; control:49

Age (years) (mean \pm SD): intervention: $58 \pm 10$; control: $58 \pm 9$

Sex (male, N, \%): intervention: 31 (60.8\%); control: 30 (61.2\%)

Smoking history (N, \%): intervention:27 (52.9\%) ; control:25 (51.0\%) 
Diabetes (N, \%): intervention: 51 (100\%); control:49 (100\%)

Hypertension (N, \%): intervention:34 (66.7\%); control: 32 (65.3\%)

History of CHD (N, \%): intervention:51(100\%) ; control:49 (100\%)

Statin pretreatment (N, \%): intervention:51 (100\%) ; control:49 (100\%)

Inclusion criteria: patients with CAS(carotid atherosclerosis) with type 2 diabetes mellitus and CHD.

Exclusion criteria: type 1 diabetes; malignant tumours; secondary hypertension; diabetic ketoacidosis; hyperglycaemic hyperosmolar status; heart failure; liver and kidney disease and other serious organic disease; suffering from infectious diseases within 2 weeks; trauma, surgery, mental stimulation within 6 months.

Comparison: atorvastatin $20 \mathrm{mg} /$ day

Details of any 'run-in' period: not reported

Concomitant medications: Other drugs for hypertension and arterial sclerosis such as aspirin, $\beta$ blockers, angiotensin converting enzyme inhibitors, angiotensin II receptor antagonist and hypoglycaemic drugs in both groups of patients were routinely applicated.

Excluded medications: not reported
Outcomes
1. The levels of serum lipid, ALT , AST, CK, high-sensitivity CRP (hs-CRP), fasting blood glucose (FBG) and HbAlc.
2. The intima-media thickness (IMT) and plaque area of carotid artery.
3. Side effects.

Notes Funding: none

\section{Risk of bias}

\begin{tabular}{lll}
\hline Bias & Authors' judgement & Support for judgement \\
\hline $\begin{array}{l}\text { Random sequence genera- } \\
\text { tion (selection bias) }\end{array}$ & Unclear risk & Quote: "randomly assigned" but no further details \\
\hline $\begin{array}{l}\text { Allocation concealment } \\
\text { (selection bias) }\end{array}$ & Unclear risk & Not reported \\
\hline $\begin{array}{l}\text { Blinding of participants } \\
\begin{array}{l}\text { and personnel (perfor- } \\
\text { mance bias) }\end{array}\end{array}$ & Unclear risk & Not reported \\
All outcomes & \\
\hline
\end{tabular}

Blinding of outcome as- Unclear risk Not reported
sessment (detection bias)

All outcomes

Incomplete outcome data Low risk All patients completed the study.
(attrition bias)

All outcomes 
Wang 2017 (Continued)
Selective reporting (re-
Unclear risk
No protocol published, or trials registry record found. porting bias)

Other bias

Low risk

Quote: "The authors certify that there is no conflict of interest with any finan-

cial organization regarding the material discussed in the manuscript."

West 2011

Methods

Design: single-centre, prospective, double-blind, randomised trial

Number of study centres: single-centre in the USA

Setting: not reported

Patient recruitment: $2 / 1 / 2006$ to $9 / 20 / 2007$

Duration of study: 2 years

Clinical setting: peripheral arterial disease

Participants

Enrolment (N): 87

Randomised (N): intervention: 22; control: 22

Withdrawn (N): not reported

Lost to follow-up (N): intervention: 1; control: 3

Completed the study (N): intervention: 18; control: 16

Analysed (N): intervention: 18; control: 16

Age (years) (mean \pm SD): intervention: $62 \pm 8$; control: $59 \pm 10$

Sex (male, N, \%): intervention: 10 (56\%); control: 11 (69\%)

Smoking history (N, \%): intervention: 13 (72\%); control: 8 (50\%)

BMI (kg/m² $\mathbf{2}$ mean \pm SD):): intervention: $28 \pm 6$; control: $30 \pm 7$

Diabetes (N, \%): intervention: 5 (28\%); control: 5 (31\%)

Hypertension (N, \%): intervention: 14 (78\%); control: 13(81\%)

History of MI (N, \%): intervention: 10 (56\%); control: 8 (50\%)

Statin pretreatment (N, \%): intervention: $6(33 \%)$; control:2 (13\%)

Inclusion criteria: Statin-naive patients (no statin therapy for at least the prior 6 months) between the ages of 30 and 85 years with symptoms of intermittent claudication and an ankle-brachial index (ABI) between 0.4 and 0.9 , based on vascular lab testing done during the screening period

Exclusion criteria: rest pain, critical limb ischaemia, contraindication to MRI, and pregnancy.

Comparison: simvastatin $40 \mathrm{mg}$ (group S).

Tthe parallel direct treatment study, patients were enrolled already on statin therapy but with LDL-C > $80 \mathrm{mg} / \mathrm{dL}$ and had open-label ezetimibe $10 \mathrm{mg}$ daily added (group E).

Details of any 'run-in' period: none 
West 2011 (Continued)

Outcomes

\section{Primary:}

1. changes in superficial femoral artery vessel wall volume measured by magnetic resonance imaging (MRI);

2. total cholesterol, HDL-C, LDL-C, triglycerides;

3. adverse events; major adverse cardiovascular events, including death, MI, stroke, and transient ischemics attack.
Funding: This work was supported by the National Heart Lung and Blood Institute at the National Institutes of Health, grant number: R01HL075792 (CMK) and the National Center for Research Resources, grant number: M01RR000847 and the National Institute of Biomedical Imaging and Bioengineering, grant number: T32 EB003841 (JDA, AMW). Study drugs were supplied by Merck Schering Plough.

\section{Risk of bias}

\begin{tabular}{|c|c|c|}
\hline Bias & Authors' judgement & Support for judgement \\
\hline $\begin{array}{l}\text { Random sequence genera- } \\
\text { tion (selection bias) }\end{array}$ & Low risk & Used a block randomisation scheme. \\
\hline $\begin{array}{l}\text { Allocation concealment } \\
\text { (selection bias) }\end{array}$ & Low risk & Used a block randomisation scheme. \\
\hline $\begin{array}{l}\text { Blinding of participants } \\
\text { and personnel (perfor- } \\
\text { mance bias) }\end{array}$ & Unclear risk & $\begin{array}{l}\text { The investigators were blinded to therapy until follow-up studies and data } \\
\text { analysis were complete. }\end{array}$ \\
\hline All outcomes & & $\begin{array}{l}\text { The study stated Quote: "double-blind, randomized trial", but did not use the } \\
\text { matching placebo for ezetimibe. }\end{array}$ \\
\hline \multirow{2}{*}{$\begin{array}{l}\text { Blinding of outcome as- } \\
\text { sessment (detection bias) } \\
\text { All outcomes }\end{array}$} & Low risk & $\begin{array}{l}\text { Quote: "The plaque volume analysis was done primarily by two experienced } \\
\text { investigators blinded to study drug and time point with VesselMASS software." }\end{array}$ \\
\hline & & $\begin{array}{l}\text { Quote: "The blinded studies were all overseen and validated by one investiga- } \\
\text { tor." }\end{array}$ \\
\hline $\begin{array}{l}\text { Incomplete outcome data } \\
\text { (attrition bias) } \\
\text { All outcomes }\end{array}$ & High risk & $\begin{array}{l}\text { Proportion of missing data: } 18 \%(4 / 22) \text { in intervention group, } 27 \%(6 / 22) \text { in } \\
\text { control group }\end{array}$ \\
\hline \multirow[t]{2}{*}{$\begin{array}{l}\text { Selective reporting (re- } \\
\text { porting bias) }\end{array}$} & Low risk & $\begin{array}{l}\text { No protocol published, but a pre-registration in a clinical trial registry was } \\
\text { found (NCT00861731). }\end{array}$ \\
\hline & & The published reports include all prespecified outcomes. \\
\hline \multirow[t]{3}{*}{ Other bias } & Low risk & $\begin{array}{l}\text { Quote:"This work was supported by the National Heart Lung and Blood Insti- } \\
\text { tute at the National Institutes of Health." }\end{array}$ \\
\hline & & Quote:"Study drugs were supplied by Merck Schering Plough." \\
\hline & & $\begin{array}{l}\text { "Drs. Epstein, Meyer, Hagspiel, and Kramer receive research support from } \\
\text { Siemens Medical Solutions. All other authors have no declared conflicts of in- } \\
\text { terest." }\end{array}$ \\
\hline
\end{tabular}


Number of study centres: single centre

Setting: not reported

Patient recruitment: not reported

Duration of study (Follow-up): 12 months

Clinical setting: chronic kidney disease (CKD)

\section{Participants}

\section{Enrolment (N): 30}

Randomised (N): intervention: 10; control:10; the third group ( $N=10$; ezetimibe plus simvastatin20 $\mathrm{mg} /$ day) was not included.

Withdrawn (N): not reported

Lost to follow-up (N): not reported

Completed the study (N): not reported

Analysed (N): intervention: 10; control:10

Age (years) (mean \pm SD): intervention: $63 \pm 11$; control: $59 \pm 9$

Sex (male, N, \%): intervention: 5 (5\%); control: 2 (20\%)

Smoking history ( $\mathrm{N}, \%)$ : not reported

BMI $\left(\mathrm{kg} / \mathrm{m}^{2}\right.$, mean $\left.\left.\pm \mathrm{SD}\right):\right)$ : not reported

Diabetes (N, \%): not reported

Hypertension (N, \%): not reported

History of CHD (N, \%): not reported

Statin pretreatment (N, \%): not reported

Inclusion criteria: age >18; LDL-C >100 mg/dL (without concomitant hypolipidaemic drugs); presence of proteinuric chronic nephropathy defined as creatinine clearance $>20 \mathrm{~mL} / \mathrm{min} / 1.73 \mathrm{~m}^{2}$ combined to a urinary protein excretion rate $>0.3 \mathrm{~g} / 24$ hours, without evidence of urinary tract infection or overt heart failure (New York Heart Association class III or more). Patients were classified as CKD on stage 3 and 4 not receiving dialysis.

Exclusion criteria: previous or concomitant treatment with steroids, anti-inflammatory and immunosuppressive agents, vitamin B6, B12, folate or statin; evidence or suspicion of renovascular disease, obstructive uropathy, type I diabetes mellitus, vasculitis.

Comparison: simvastatin $40 \mathrm{mg} / \mathrm{day}$

We included the comparison above. The third group (ezetimibe plus simvastatin $20 \mathrm{mg} /$ day) was not included.

Details of any 'run-in' period: not reported

Concomitant medications: not reported

Excluded medications: not reported

Outcomes Primary:

1. to assess whether ezetimibe-statin combined therapy is more effective than statin alone to achieve the optimum lipid control (LDL-cholesterol $<70 \mathrm{mg} / \mathrm{dL}$ ) in chronic proteinuric nephropathy.; 
Zinellu 2012 (Continued)

2. renal parameters, inflammatory status, markers of endothelial dysfunction.

Notes $\quad$ Funding: This study was supported by the quote: "Fondazione Banco di Sardegna, Sassari, Italy" and by the "Ministero dell'Università e della Ricerca" Italy.

NCT00861731

Intended to contact trialists to enquire whether outcomes of interest to this review were measured.

This was not possible as the email was returned.

No relevant outcome data for this review.

\section{Risk of bias}

\begin{tabular}{lll}
\hline Bias & Authors' judgement & Support for judgement \\
\hline $\begin{array}{l}\text { Random sequence genera- } \\
\text { tion (selection bias) }\end{array}$ & Unclear risk & $\begin{array}{l}\text { Quote "randomly allocated" } \\
\text { Comment: insufficient information to make a judgement }\end{array}$ \\
\hline $\begin{array}{l}\text { Allocation concealment } \\
\text { (selection bias) }\end{array}$ & Unclear risk & Not reported \\
\hline $\begin{array}{l}\text { Blinding of participants } \\
\text { and personnel (perfor- } \\
\text { mance bias) } \\
\text { All outcomes }\end{array}$ & Unclear risk & Not reported \\
\hline
\end{tabular}

Blinding of outcome as- Unclear risk Not reported

sessment (detection bias)

All outcomes

Incomplete outcome data Unclear risk Unable to assess
(attrition bias)
All outcomes

\begin{tabular}{|c|c|c|}
\hline $\begin{array}{l}\text { Selective reporting (re- } \\
\text { porting bias) }\end{array}$ & Low risk & $\begin{array}{l}\text { No protocol published, but a pre-registration in a clinical trial registry was } \\
\text { found (NCT00861731). } \\
\text { Trial registration March 2009, trial start date November 2009, so partially retro- } \\
\text { spective. However, entry appears to reflect reported outcomes }\end{array}$ \\
\hline Other bias & Low risk & $\begin{array}{l}\text { Quote: "This study was supported by the "Fondazione Banco di Sardegna, Sas- } \\
\text { sari, Italy" } \\
\text { Quote: "The authors declare that there is no conflict of interest regarding the } \\
\text { publication of this paper." }\end{array}$ \\
\hline
\end{tabular}

\begin{tabular}{ll}
\hline Methods & Design: RCT \\
& Number of study centres: single centre
\end{tabular}

Setting: not reported

Patient recruitment: not reported

Duration of study (Follow-up): 12 months 
Zou 2016 (Continued)

$$
\text { Clinical setting: } \mathrm{CHD}
$$

Participants

Enrolment (N): 80

Randomised (N): intervention:40 ; control:40

Withdrawn (N): not reported

Lost to follow-up (N): not reported

Completed the study (N): not reported

Analysed (N): intervention: 40; control:40

Age (years) (mean \pm SD): intervention: $69.3 \pm 5.8$; control: $70.3 \pm 7.2$

Sex (male, $\mathbf{N}, \%)$ : not reported

Smoking history (N, \%): not reported

BMI $\left(\mathbf{k g} / \mathbf{m}^{2}\right.$, mean $\left.\pm \mathrm{SD}\right):$ ): not reported

Diabetes (N, \%): not reported

Hypertension (N, \%): not reported

History of CHD (N, \%): not reported

Statin pretreatment (N, \%): not reported

Inclusion criteria: patients with carotid atherosclerosis including the treatment of the secondary prevention of $\mathrm{CHD}$

Exclusion criteria: not reported

\begin{tabular}{|c|c|c|}
\hline Interventions & \multicolumn{2}{|c|}{$\begin{array}{l}\text { Intervention: } 10 \mathrm{mg} \text { ezetimibe with } 10 \mathrm{mg} \text { atorvastatin } \\
\text { Comparison: } 10 \mathrm{mg} \text { atorvastatin alone } \\
\text { Details of any 'run-in' period: not reported } \\
\text { Concomitant medications: not reported } \\
\text { Excluded medications: not reported }\end{array}$} \\
\hline Outcomes & \multicolumn{2}{|c|}{$\begin{array}{l}\text { Carotid atherosclerosis related indicators (carotid intima-media thickness, plaques total integral and } \\
\text { the number of average soft carotid plaques), blood lipid and high-sensitivity CRP (hs-CRP); adverse re- } \\
\text { sponse }\end{array}$} \\
\hline Notes & \multicolumn{2}{|l|}{$\begin{array}{l}\text { Funding: not reported } \\
\text { Conference Abstract }\end{array}$} \\
\hline \multicolumn{3}{|l|}{ Risk of bias } \\
\hline Bias & Authors' judgement & Support for judgement \\
\hline $\begin{array}{l}\text { Random sequence genera- } \\
\text { tion (selection bias) }\end{array}$ & Unclear risk & Quote: "randomly divided', but no further details \\
\hline $\begin{array}{l}\text { Allocation concealment } \\
\text { (selection bias) }\end{array}$ & Unclear risk & Not reported \\
\hline
\end{tabular}


Zou 2016 (Continued)

\begin{tabular}{lll}
$\begin{array}{l}\text { Blinding of participants } \\
\text { and personnel (perfor- } \\
\text { mance bias) } \\
\text { All outcomes }\end{array}$ & Unclear risk & \\
\hline $\begin{array}{l}\text { Blinding of outcome as- } \\
\text { sessment (detection bias) } \\
\text { All outcomes }\end{array}$ & Unclear risk & Not reported \\
\hline $\begin{array}{l}\text { Incomplete outcome data } \\
\text { (attrition bias) } \\
\text { All outcomes }\end{array}$ & Unclear risk & Not reported \\
\hline $\begin{array}{l}\text { Selective reporting (re- } \\
\text { porting bias) }\end{array}$ & Unclear risk & No protocol published, or trials registry record found. \\
\hline $\begin{array}{l}\text { Other bias } \\
\text { Unclear risk }\end{array}$ & $\begin{array}{l}\text { Insufficient information to assess whether an important risk of bias exists } \\
\text { Quote: "The authors declare that there is no conflict of interest regarding the } \\
\text { publication of this paper." }\end{array}$
\end{tabular}

ACS: acute coronary syndrome; ALT: alanine aminotransferase; ARB: angiotensin receptor antagonist; AST: aspartate aminotransferase; BMI: body mass index; CAD: coronary artery disease; CHD: coronary heart disease; CABG: coronary artery bypass grafting; CK: creatinine kinase; CPK: creatine phosphokinase; CRP: C-reactive protein; eGFR: estimated glomerular filtration rate; HbA1c: glycated haemoglobin; HDL-C: high-density lipoprotein cholesterol; IVUS: intravascular ultrasound; LDL-C: low-density lipoprotein cholesterol; MI: myocardial infarction; MLD: minimum lumen diameter; $\mathrm{PCl}$ : MRI: magnetic resonance imaging; percutaneous coronary intervention; RCT: randomised controlled trial; RLP-C : remnant-like particle cholesterol ; SD: standard deviation; T2DM: type 2 diabetes mellitus; TC: total cholesterol; TG: triglyceride; ULN: upper limit of normal.

\section{Characteristics of excluded studies [ordered by study ID]}

\begin{tabular}{|c|c|}
\hline Study & Reason for exclusion \\
\hline ARBITER 6-HALTS & Ineligible comparison, ezetimibe versus niacin \\
\hline Arimura 2012 & Follow-up less than 12 months (6-9 months) \\
\hline Auscher 2015 & Ineligible comparison, ezetimibe was not randomly assigned \\
\hline Bays 2008 & Inappropriate study design; follow-up less than 12 months \\
\hline Crespo-Leiro 2008 & Study was not an RCT \\
\hline Dagli 2007 & Follow-up less than 12 months (6 months) \\
\hline DESCARTES 2014 & Irrelevant intervention, evolocumab versus placebo \\
\hline Dujovne 2008 & Study was not an RCT \\
\hline EASEGO 2008 & Follow-up less than 12 months (12 weeks) \\
\hline ELIMIT 2013 & Ineligible comparison, triple-therapy with simvastatin, niacin and ezetimibe versus simvastatin \\
\hline Enajat 2009 & Ineligible comparison, atorvastatin plus ezetimibe versus placebo \\
\hline Ferrieres 2016 & Study was not an RCT \\
\hline
\end{tabular}




\begin{tabular}{|c|c|}
\hline Study & Reason for exclusion \\
\hline Foody 2013 & Study was not an RCT \\
\hline Habara 2014 & Follow-up less than 12 months (9 months) \\
\hline Hayek 2013 & Study was not an RCT \\
\hline HEAVEN 2012 & Ineligible comparison \\
\hline Hiro 2014 & Follow-up less than 12 months ( 6 months) \\
\hline Jackowska 2016 & Follow-up less than 12 months ( 6 months) \\
\hline Japaridze 2017 & Follow-up less than 12 months ( 16 weeks) \\
\hline Koren 2014 & Follow-up less than 12 months ( 12 weeks) \\
\hline Kral 2011 & Ineligible comparison \\
\hline Le 2015 & Follow-up less than 12 months (12 weeks) \\
\hline Lopez 2008 & Study was not an RCT \\
\hline Masana 2005 & Follow-up less than 12 months ( 48 weeks) \\
\hline Masia 2009 & $\begin{array}{l}\text { Ineligible comparison (intensive versus standard intervention), ezetimibe was not randomly as- } \\
\text { signed }\end{array}$ \\
\hline Masuda 2015 & Follow-up less than 12 months ( 6 months) \\
\hline McKenney 2006 & $\begin{array}{l}\text { Follow-up less than } 12 \text { months ( } 48 \text { weeks); Ineligible comparison, ezetimibe was not randomly as- } \\
\text { signed. }\end{array}$ \\
\hline Nicholls 2016 & Follow-up less than 12 months (90 days) \\
\hline ODYSSEY COMBO II & Ineligible comparison, ezetimibe versus alirocumab \\
\hline Okada 2010 & Follow-up less than 12 months ( 12 weeks) \\
\hline Okuyama 2012 & Ineligible comparison, pitavastatin vs ezetimibe \\
\hline Palacio 2016 & Study was not an RCT \\
\hline Pandey 2008 & Follow-up less than 12 months ( 6 weeks) \\
\hline Patel 2013 & Study was not an RCT \\
\hline Pauriah 2014 & Study was not an RCT \\
\hline Pesaro 2010 & Follow-up less than 12 months ( 6 weeks) \\
\hline Pop-Purceleanu 2009 & Ineligible comparison \\
\hline Pytel 2017 & Follow-up less than 12 months ( 6 months) \\
\hline Ran 2017 & Follow-up less than 12 months ( 12 weeks) \\
\hline
\end{tabular}




\begin{tabular}{|c|c|}
\hline Study & Reason for exclusion \\
\hline REMEDY 2016 & Inappropriate study design; ineligible comparison \\
\hline SANDS 2008 & Inappropriate study design; ineligible comparison, ezetimibe was not randomly assigned. \\
\hline Santos 2014 & Study was not an RCT \\
\hline SEAS 2008 & Ineligible comparison, simvastatin plus ezetimibe vs placebo \\
\hline Sertbas 2010 & Study was not an RCT \\
\hline SHARP 2011 & Ineligible comparison, simvastatin plus ezetimibe vs placebo \\
\hline Steg 2008 & Inappropriate study design, cluster-RCT \\
\hline Stein 2008 & Follow-up less than 12 months ( 12 weeks) \\
\hline Strony 2008 & Inappropriate study design \\
\hline Strony $2008 a$ & Study was not an RCT \\
\hline Suzuki 2010 & Study was not an RCT \\
\hline Takase 2017 & Follow-up less than 12 months (6-8 months) \\
\hline Tendolkar 2012 & Ineligible comparison, atorvastatin plus ezetimibe vs placebo \\
\hline Teramoto 2013 & Study was not an RCT \\
\hline Thongtang 2012 & Follow-up less than 12 months ( 6 weeks) \\
\hline Troxel 2016 & Inappropriate study design; ineligible intervention and control \\
\hline Turk 2008 & Study was not an RCT \\
\hline UK-HARP-ᄑ 2006 & Follow-up less than 12 months ( 6 months) \\
\hline van der Graaf 2008 & Inappropriate study design and population \\
\hline van Kuilenburg 2011 & Ineligible comparison, atorvastatin plus ezetimibe vs placebo \\
\hline Vera-Lastra 2016 & Study was not an RCT \\
\hline Wierzbicki 2005 & Follow-up less than 12 months ( 3 months) \\
\hline Zhao 2014 & Study was not an RCT \\
\hline ZIPANGU 2017 & Follow-up less than 12 months ( 9 months) \\
\hline
\end{tabular}

$\mathrm{RCT}$ : randomised controlled trial

Characteristics of studies awaiting assessment [ordered by study ID] 


\begin{tabular}{ll}
\hline Methods & Parallel randomised study \\
\hline Participants & Inclusion criteria: \\
1. dyslipidaemic patients under treatment with fibrates, whose LDL-C levels do not meet those rec- & ommended by Japan Atherosclerosis Society Guidelines for prevention of Atherosclerotic Cardio- \\
vascular Disease; & 2. patients who have aortic atherosclerotic plaques detected by MRI; \\
3. outpatients; & 4. participants who gave written informed consent; \\
5. age: $20-80$ years-old. \\
Exclusion criteria: \\
1. allergy against ezetimibe; \\
2. under treatment with statins; \\
3. poorly-controlled hypertension (DBP $>110 \mathrm{mmHg}$ ); \\
4. poorly-controlled diabetes (HbAlc $>10.0 \%$ ); \\
5. history of stroke, acute coronary syndrome or any cardiovascular diseases needed for inpa- \\
tient-treatments within 6 months; \\
6. either level of AST or ALT exceeds three-fold of the normal limits; \\
7. chronic renal failure (serum creatinine $>2.0 \mathrm{mg} / \mathrm{dl}) ;$ \\
8. malignancies or other diseases with poor prognosis; \\
9. pregnant; \\
10.participants whose doctor in charge did not agree to join the trial.
\end{tabular}

Fibrate monotherapy versus fibrate-ezetimibe combination

1. Area of atherosclerotic plaques in aorta detected by MRI, $12 / 24$ months after randomisation
2. Serum lipids (total/LDL/HDL-cholesterol, triglycerides), $6 / 12 / 24$ months after randomisation
3. Flow-mediated vasodilation in forearm, 6 months after randomisation
4. Heparin-releasable extracellular superoxide dismutase (EC-SOD) levels, 6 months after randomi-
sation
$\begin{aligned} & \text { 5. Markers indicating obesity (e.g. adiponectin), inflammation (high-sensitive C-reactive protein), } \\ & \text { oxidative stress, early-staged kidney diseases (microalbuminuria), } 6 / 12 / 24 \text { months after randomi- } \\ & \text { sation }\end{aligned}$

Recruitment status: Terminated

Location: Japan

Contact information: Katsunori lkewaki; katsunorike@ndmc.ac.jp

Expected completion date: unknown

Contacted trialists to ask about status and anticipated completion date, but no response.

Methods Parallel Randomized, open label study


1. dyslipidaemic patients whose LDL-C levels did not reach those recommended by Japan Atherosclerosis Society Guidelines for Prevention of Atherosclerotic Cardiovascular Diseases;

2. patients who have aortic atherosclerotic plaques detected by MRI;

3. outpatients.

\section{Exclusion criteria:}

1. allergy against rosuvastatin or ezetimibe;

2. poorly-controlled diabetes ( $\mathrm{HbA} 1 \mathrm{c}>10.0 \%)$;

3. history of stroke, acute coronary syndrome or any cardiovascular diseases needed for inpatient-treatments within 6 months;

4. either level of aspartate aminotransaminase or alanine aminotransferase exceeds three-fold of the normal limits.;

5. end-stage renal disease;

6. symptomatic (New York Heart Association class III or IV) congestive heart failure;

7. malignancies or other diseases with poor prognosis;

8. pregnant;

9. participants whose doctor in charge did not agree to join the trial.

Rosuvastatin/ezetimibe combination therapy versus rosuvastatin monotherapy

\section{Outcomes}

\section{Primary outcomes:}

1. carotid atherosclerosis evaluated by ultrasound (Intima-media thickness; IMT (meanIMT/maxIMT) and plaque score), 12/24 months after randomisation;

2. area and thickness of atherosclerotic plaques in aorta detected by MRI, 12/24 months after randomisation;

3. flow-mediated vasodilation in forearm, 6 months after randomisation.

\section{Secondary outcomes:}

1. ankle/brachial index and cardio ankle vascular index;

2. markers for diabetes (haemoglobin Alc, glycoalbumin, blood glucose);

3. serum lipids;

4. markers indicating obesity (e.g. adiponectin);

5. markers indicating inflammation (e.g. high-sensitive C-reactive protein);

6. markers indicating oxidative stress;

7. markers indicating chronic renal diseases (urine albumin / liver fatty acid-binding protein);

8. blood/urine urate levels;

9. Body weight/waist circumference;

10.blood pressures.

Recruitment status: Completed

Location: Japan

Contact information: Katsunori lkewaki (katsunorike@ndmc.ac.jp)

Expected completion date: unknown

Contacted trialists to ask about status and anticipated completion date, but no response. 
NCT01086020

\begin{tabular}{|c|c|}
\hline Methods & Randomised open-label parallel group study, 2 years follow-up \\
\hline Participants & $\begin{array}{l}\text { Inclusion Criteria: } \\
\text { 1. age } 18 \text { to } 75 \text { years; } \\
\text { 2. willing to receive the coronary angiography and potential } \mathrm{PCl} \text { therapy } \\
\text { Exclusion Criteria: } \\
\text { 1. patients was treated by statins before randomisation; } \\
\text { 2. patient with } \leq 20 \% \text { and } \geq 70 \% \text { coronary narrowing and target lesion; } \\
\text { 3. ST elevation myocardial infarction less than } 7 \text { days; } \\
\text { 4. without informed consent; } \\
\text { 5. abnormal liver function before randomisation, (AST, ALT } \geq U L N) \text {; } \\
\text { 6. active hepatitis or muscular disease; } \\
\text { 7. impaired renal function with serum creatinine level }>3 \text { mg/dL; } \\
\text { 8. impaired left ventricular function with LVEF > } 30 \% \text {; } \\
\text { 9. participate in other studies. }\end{array}$ \\
\hline Interventions & Atorvastatin $10 \mathrm{mg} /$ day versus atorvastatin $5 \mathrm{mg} /$ day plus ezetimibe $5 \mathrm{mg} /$ day \\
\hline Outcomes & $\begin{array}{l}\text { Primary endpoint: the change of coronary artery plaque volume measured by intravascular ultra- } \\
\text { sound (IVUS) at one year after randomisation. } \\
\text { Secondary endpoint: the composite of adverse cardiac events (MACE), including cardiac death, } \\
\text { non-fatal infarction and target vessel revascularisation at two years after randomisation. }\end{array}$ \\
\hline Notes & $\begin{array}{l}\text { Study Start Date: January } 2010 \\
\text { Recruitment Status: unknown } \\
\text { Last Update Posted: April 4, } 2011 \\
\text { Location: China } \\
\text { Contact information: Ruiyan Zhang, MD; zhangruiyan@263.net } \\
\text { Contacted trialists to ask about status and anticipated completion date, but no response. }\end{array}$ \\
\hline
\end{tabular}

\section{NCT02588235}

Methods Randomised, controlled, open-label, single-centre study, 12 months follow-up

\section{Participants}

\section{Inclusion Criteria:}

1. stable angina or acute coronary syndrome;

2. $18-80$ years old;

3. hypercholesterolaemia :total cholesterol level $>220 \mathrm{mg} / \mathrm{dL}(5.7 \mathrm{mmol} / \mathrm{L})$ and/or LDL-C level $>140$ $\mathrm{mg} / \mathrm{dL}(3.6 \mathrm{mmol} / \mathrm{L})$, or previously receiving statins therapy;

4. the target vessel for optical coherence tomography (OCT) interrogation has not undergone angioplasty and has angiographic diameter stenosis from $25 \%$ to $75 \%$;

5. there are thin-cap fibroatheroma (TCFA) in non-culprit, mild-to-moderate stenotic lesions above.

\section{Exclusion Criteria:}

1. administration of lipid-lowering drugs other than statins before enrolment;

2. significant stenotic lesions in all coronary vessels; 
3. severe congestive heart failure (New York Heart Association class IV) ,or left ventricular ejection fraction<35\%;

4. more than 3 times of the upper limit of normal (ULN) in the creatine kinase (CK) and the transaminase level before enrolment and no relation with Ml;

5. renal failure (serum creatinine $>2.0 \mathrm{mg} / \mathrm{dL}$ );

6. hypersensitivity to $\mathrm{x}$-ray contrast media, statin, clopidogrel or ezetimibe;

7. others: terminal stage cancer,a positive pregnancy test.

Interventions Atorvastatin $(20 \mathrm{mg} /$ day $)$ plus ezetimibe $(10 \mathrm{mg} /$ day $)$ versus atorvastatin (20 $\mathrm{mg} /$ day)

\begin{tabular}{ll}
\hline Outcomes & $\begin{array}{l}\text { The primary efficacy endpoint is the change in minimum fibrous cap thickness measured by optical } \\
\text { coherence tomography from baseline to follow-up. }\end{array}$
\end{tabular}
coherence tomography from baseline to follow-up.

\begin{tabular}{ll}
\hline Notes & Study Start Date: October 2015 \\
& Recruitment Status: unknown \\
& Last Update Posted: October 27, 2015 \\
& Location: China \\
& Contact information: Dongdong Sun (51483696@qq.com) \\
& Contacted trialists to ask about status and anticipated completion date, but no response. \\
\hline
\end{tabular}

ALT: alanine aminotransferase; AST: aspartate aminotransferase; DBP: diastolic blood pressure; HbA1c: glycated haemoglobin; HDL-C: highdensity lipoprotein cholesterol; LDL-C: low-density lipoprotein cholesterol; LVEF: left ventricular ejection fraction; MRI: magnetic resonance imaging; $\mathrm{PCl}$ : percutaneous coronary intervention.

Characteristics of ongoing studies [ordered by study ID]

\section{NCT03044665}

Trial name or title

Methods

RAndomized Comparison of efficacy and safety of lipid-lowerING with statin monotherapy versus statin/ezetimibe combination for high-risk cardiovascular diseases (RACING trial)

\section{Inclusion Criteria:}

1. age $19-75$ years;

2. documented cardiovascular disease, previous myocardial infarction, acute coronary syndrome, coronary revascularisation and other arterial revascularisation procedures, ischaemic stroke, or peripheral artery disease (PAD)

\section{Exclusion Criteria:}

1. active liver disease or persistent unexplained serum AST or ALT elevation more than 2 times the upper limit of normal range;

2. allergy or hypersensitivity to any statin or ezetimibe;

3. solid organ transplantation recipient;

4. history of any adverse drug reaction requiring discontinuation of statin;

5. pregnant women, women with potential childbearing, or lactating women;

6. life expectancy less than 3 years;

7. inability to follow the patient over the period of 1 year after enrolment, as assessed by the investigator;

8. inability to understand or read the informed content. 
NCT03044665 (Continued)

Interventions Rosuvastatin $20 \mathrm{mg} /$ day versus rosuvastatin $10 \mathrm{mg} / \mathrm{d}$ plus ezetimibe $10 \mathrm{mg} / \mathrm{day}$

Outcomes Primary: composite of cardiovascular death, major cardiovascular event, nonfatal stroke. Proportion of patients with LDL-cholesterol less than $70 \mathrm{mg} / \mathrm{dL}$.

Secondary: statin discontinuation or dose-reduction caused by intolerance.

\begin{tabular}{ll}
\hline Starting date & February 1, 2017 \\
\hline Contact information & Yang-Soo Jang; jangys1212@yuhs.ac \\
\hline Notes & Location: Korea \\
& Expected completion date: February 2022. \\
\hline
\end{tabular}

\section{NCT03169985}

Trial name or title

Usual dose Rosuvastatin plus EZetimibe versus high-dose rosuvastatin on coronary atherosclerotic plaque (Rosuzet-IVUS)

\begin{tabular}{ll}
\hline Methods & Prospective, open-label, two-arm, randomised controlled trial \\
\hline Participants & Estimated Enrollment: 280 \\
Inclusion Criteria: & \\
1. among patients who undergo coronary angiography (CAG) for suspected ischaemic heart disease \\
and meet all of the followings: moderate stenosis (30\% to $70 \%)$ in coronary artery, deferred to \\
medical treatment based on physiologic or radiologic evaluation; \\
2. agreement obtained by participant.
\end{tabular}

\section{Exclusion Criteria:}

1. severe renal failure (glomerular filtration rate $<30 \mathrm{~mL} / \mathrm{min} / 1.73 \mathrm{~m}^{2}$, haemodialysis or peritoneal dialysis);

2. active liver disease;

3. patient taking Niacin or fibrate (if possible, patient can be enrolled to the study after stopping those medication);

4. medical or family history of myositis, unexplained creatine kinase (CK) elevation $>3$ times ULN at first visit;

5. life expectancy $<2$ years (judged by investigator);

6. co-administration of cyclosporine;

7. untreated hypothyroidism;

8. patient with poor compliance including alcohol abuse;

9. history of hypersensitivity including myotoxicity for either statin or ezetimibe;

10.pregnant or breast-feeding woman;

11.other conditions inappropriate for enrolment by investigator: eligible patients will be randomly assigned to treatment arms, stratified by diagnosis on admission(acute coronary syndrome or stable ischaemic heart disease) and presence of chronic statin use (more than one month).

\begin{tabular}{ll}
\hline Interventions & Rosuvastatin $10 \mathrm{mg} /$ day plus ezetimibe $10 \mathrm{mg} /$ day versus rosuvastatin $20 \mathrm{mg} / \mathrm{day}$ \\
\hline Outcomes & Primary: \\
& $\begin{array}{l}\text { 1. change in per cent atheroma volume (PAV) in non-culprit lesions (Time Frame: } 12 \text { months after } \\
\text { index CAG). }\end{array}$
\end{tabular}




\section{Secondary:}

1. change in normalised total atheroma volume (TAV) in non-culprit lesions (Time Frame: 12 months after index CAG);

2. change in indexed TAV (Time Frame: 12 months after index CAG);

3. change in fibrous cap thickness by OCT(optical coherence tomography) (Time Frame: 12 months after index CAG);

4. change in fractional flow reserve (FFR) (Time Frame: 12 months after index CAG;)

5. change in coronary flow reserve (CFR) (Time Frame: 12 months after index CAG);

6. change in index of microcirculatory resistance (IMR) (Time Frame: 12 months after index CAG);

7. change in TAV in coronary computed tomography(CT) angiography (Time Frame: 24 months after index CAG);

8. major adverse cardiovascular events (MACE) (Time Frame: 12, 24 and 36 months after index CAG, MACE is defined as a composite of death, $\mathrm{Ml}$, stroke and revascularisation;

9. change in homeostatic model assessment (HOMA) index (Time Frame: 6 months after index CAG);

10.change in fasting glucose (Time Frame: 6 and 12 months after index CAG);

11.change in HbA1c (Time Frame: 6 and 12 months after index CAG)

12.change in lipid profile (Time Frame: 1,6 and 12 months after index CAG);

13.change in high-sensitivity C-reactive protein(hs-CRP) (Time Frame: 1 and 12 months after index CAG);

14.safety endpoint: number of participants with abnormal laboratory values and adverse events (Time Frame: 1 and 12 months after index CAG).

\begin{tabular}{ll}
\hline Starting date & July 12, 2017 \\
\hline Contact information & Joo-Yong Hahn, MD, PhD; 82-2-3410-6653; ichjy1@gmail.com \\
\hline Notes & Location: Korea \\
& Recruitment Status: Recruiting \\
& Expected completion date: December 31, 2023 \\
\hline
\end{tabular}

\section{NCT03543774}

Trial name or title

Lipid-lowering therapies in Vietnamese Chronic Kidney Disease population (VietCKD)

Methods Randomised, parallel assignment, open-label study

\section{Participants}

\section{Estimated Enrollment: 30}

\section{Inclusion Criteria:}

1. ages eligible for study: $\geq 50$ years old but not treated with chronic dialysis or kidney transplantation In adults aged 18-49 years with CKD but not treated with chronic dialysis or kidney transplantation, statin treatment in people with one or more of the following: known coronary disease (MI or coronary revascularisation); diabetes mellitus; prior ischaemic stroke; estimated 10-year incidence of coronary death or non-fatal $\mathrm{MI}>10 \%$;

2. CKD in the 3,4 stage: (e-GFR: $15-60 \mathrm{~mL} /$ minute $/ 1.73 \mathrm{~m}^{2}$ );

3. CKD proteinuria (defined as creatinine clearance $>20 \mathrm{~mL} / \mathrm{min} / 1.73 \mathrm{~m}^{2}$ combines with urinary protein excretion rate $>300 \mathrm{mg} / 24$ hours);

4. $\mathrm{LDL}$ cholesterol concentration $>100 \mathrm{mg} / \mathrm{dL}(2.59 \mathrm{mmol} / \mathrm{L})$.

\section{Exclusion Criteria:}

(in adults with dialysis-dependent CKD) 
NCT03543774 (Continued)

1. heart failure (New York Heart Association class III or more);

2. previous or concomitant treatment with corticoids, statin, immunosuppressive agents, vitamin B6, B12, folate;

3. pregnancy;

4. patients who do not agree to participate the research;

5. patients are unable to understand the purposes and the risks of the study.

Interventions

Arm1: simvastatin $40 \mathrm{mg} / \mathrm{day}$

Arm2: ezetimibe/simvastatin $10 \mathrm{mg} / 20 \mathrm{mg} /$ day

Arm3: ezetimibe/simvastatin $10 \mathrm{mg} / 40 \mathrm{mg} /$ day

\section{Outcomes}

\section{Primary:}

1. to measure the serum level of TC, LDL-C, HDL-C, TG, creatinine, uric acid, and allantoin in Vietnamese CKD population and in healthy persons at the base time;

2. to measure the serum level of taurine, Tryp, and Kyn in Vietnamese CKD population and in healthy persons at the base time;

3. to measure the number of red blood cells, white blood cells and platelets in Vietnamese CKD population and in healthy persons at the base time;

4. to measure the serum level of malondialdehyde (MDA) in Vietnamese CKD population and in healthy persons at the base time;

5. to measure the level of albuminuria and urine creatinine in Vietnamese CKD population and in healthy persons at the base time;

6. to measure the serum level of ALT, AST, and CK in Vietnamese CKD population and in healthy persons at the base time.

\section{Secondary:}

1. to measure the serum level of TC, LDL-C, HDL-C, TG, creatinine, uric acid, and allantoin in Vietnamese CKD population at 4th, 8th, 12th month;

2. to measure the serum level of taurine, Tryp, and Kyn in Vietnamese CKD population at 4th, 8th, 12th month;

3. to measure the number of red blood cells, white blood cells and platelets in Vietnamese CKD population at 4th, 8th, 12th month;

4. to measure the serum level of MDA in Vietnamese CKD population at 4th, 8th, 12th month.

5. to measure the serum levels of ALT, AST and Creatinine Kinase in Vietnamese CKD population at 4th month, 8th month and the 12th month;

6. to measure the level of albuminuria and urine creatinine in Vietnamese CKD population at 4th, 8th, 12th month.

\begin{tabular}{ll}
\hline Starting date & June 15, 2018 \\
\hline Contact information & Duong Thi Ngoc Lan, Master; 084-903572535; duongngoclan80@yahoo.com.vn \\
& Ciriaco Carru, Professor; 0039-3204299322; carru@uniss.it \\
\hline Notes & Location: Vietnam \\
& Expected completion date: September 15, 2019 \\
\hline & \\
ALT: alanine aminotransferase; AST: aspartate aminotransferase; CK: creatine kinase; CKD: chronic kidney disease; e-GFR: estimated \\
glomerular filtration rate; HbA1c: glycated haemoglobin; HDL-C: high-density lipoprotein cholesterol; IVUS: intravascular ultrasound; LDL- \\
C: low-density lipoprotein cholesterol; MI: myocardial infarction; TC: total cholesterol; TG: triglycerides; RCT: randomised controlled trial; \\
ULN: upper limit of normal; Tryp, and Kyn: tryptophan and kynurenine.
\end{tabular}




\section{DATA AND ANALYSES}

\section{Comparison 1. Ezetimibe plus other lipid-modifying drugs vs other lipid-modifying drugs alone or plus placebo}

\begin{tabular}{|c|c|c|c|c|}
\hline Outcome or subgroup title & No. of studies & $\begin{array}{l}\text { No. of partici- } \\
\text { pants }\end{array}$ & Statistical method & Effect size \\
\hline $\begin{array}{l}1 \text { MACE (subgroup analysis: duration of follow } \\
\text { up) }\end{array}$ & 10 & 21727 & $\begin{array}{l}\text { Risk Ratio (M-H, Fixed, } \\
95 \% \mathrm{Cl})\end{array}$ & $0.94[0.90,0.98]$ \\
\hline 1.1 follow up $>2$ years & 2 & 19865 & $\begin{array}{l}\text { Risk Ratio (M-H, Fixed, } \\
95 \% \mathrm{Cl})\end{array}$ & $0.94[0.90,0.98]$ \\
\hline 1.2 follow up $\leq 2$ years & 8 & 1862 & $\begin{array}{l}\text { Risk Ratio (M-H, Fixed, } \\
95 \% \mathrm{Cl})\end{array}$ & $1.03[0.79,1.35]$ \\
\hline $\begin{array}{l}2 \text { MACE (subgroup analysis: participates with/ } \\
\text { without ASCVD) }\end{array}$ & 9 & 21465 & $\begin{array}{l}\text { Risk Ratio }(\mathrm{M}-\mathrm{H} \text {, Fixed, } \\
95 \% \mathrm{Cl})\end{array}$ & $0.94[0.90,0.98]$ \\
\hline 2.1 with ASCVD & 8 & 20745 & $\begin{array}{l}\text { Risk Ratio (M-H, Fixed, } \\
95 \% \mathrm{Cl})\end{array}$ & $0.94[0.90,0.98]$ \\
\hline 2.2 without ASCVD & 1 & 720 & $\begin{array}{l}\text { Risk Ratio (M-H, Fixed, } \\
95 \% \mathrm{Cl})\end{array}$ & $1.45[0.56,3.77]$ \\
\hline $\begin{array}{l}3 \text { MACE (sensitivity analysis: only including } \\
\text { low risk of bias studies) }\end{array}$ & 2 & 18864 & $\begin{array}{l}\text { Risk Ratio (M-H, Fixed, } \\
95 \% \mathrm{Cl})\end{array}$ & $0.94[0.90,0.98]$ \\
\hline $\begin{array}{l}4 \text { MACE (sensitivity analysis: random-effects } \\
\text { models) }\end{array}$ & 10 & 21727 & $\begin{array}{l}\text { Risk Ratio (M-H, Ran- } \\
\text { dom, } 95 \% \mathrm{Cl} \text { ) }\end{array}$ & $0.94[0.90,0.98]$ \\
\hline $\begin{array}{l}5 \text { MACE (sensitivity analysis: excluding the } \\
\text { studies compared ezetimibe plus statins ver- } \\
\text { sus double-dose statins alone) }\end{array}$ & 9 & 21508 & $\begin{array}{l}\text { Risk Ratio (M-H, Fixed, } \\
95 \% \mathrm{Cl})\end{array}$ & $0.94[0.90,0.98]$ \\
\hline $\begin{array}{l}6 \text { All-cause mortality (subgroup analysis: du- } \\
\text { ration of follow up) }\end{array}$ & 8 & 21222 & $\begin{array}{l}\text { Risk Ratio (M-H, Fixed, } \\
95 \% \mathrm{Cl})\end{array}$ & $0.98[0.91,1.05]$ \\
\hline 6.1 follow up $>2$ year & 2 & 19865 & $\begin{array}{l}\text { Risk Ratio (M-H, Fixed, } \\
95 \% \mathrm{Cl})\end{array}$ & $0.97[0.91,1.05]$ \\
\hline 6.2 follow up $\leq 2$ year & 6 & 1357 & $\begin{array}{l}\text { Risk Ratio }(\mathrm{M}-\mathrm{H}, \text { Fixed, } \\
95 \% \mathrm{Cl})\end{array}$ & $1.35[0.61,3.00]$ \\
\hline $\begin{array}{l}7 \text { All-cause mortality (subgroup analysis: par- } \\
\text { ticipates with/without ASCVD) }\end{array}$ & 8 & 21222 & $\begin{array}{l}\text { Risk Ratio }(\mathrm{M}-\mathrm{H}, \text { Fixed, } \\
95 \% \mathrm{Cl})\end{array}$ & $0.98[0.91,1.05]$ \\
\hline 7.1 with ASCVD & 6 & 20343 & $\begin{array}{l}\text { Risk Ratio }(\mathrm{M}-\mathrm{H} \text {, Fixed, } \\
95 \% \mathrm{Cl})\end{array}$ & $0.98[0.91,1.05]$ \\
\hline 7.2 without ASCVD & 2 & 879 & $\begin{array}{l}\text { Risk Ratio (M-H, Fixed, } \\
95 \% \mathrm{Cl})\end{array}$ & $0.78[0.16,3.89]$ \\
\hline $\begin{array}{l}8 \text { All-cause mortality (sensitivity analysis: only } \\
\text { including low risk of bias studies) }\end{array}$ & 2 & 18864 & $\begin{array}{l}\text { Risk Ratio (M-H, Fixed, } \\
95 \% \mathrm{Cl})\end{array}$ & $0.99[0.92,1.06]$ \\
\hline
\end{tabular}




\begin{tabular}{|c|c|c|c|c|}
\hline Outcome or subgroup title & No. of studies & $\begin{array}{l}\text { No. of partici- } \\
\text { pants }\end{array}$ & Statistical method & Effect size \\
\hline $\begin{array}{l}9 \text { All-cause mortality (sensitivity analysis: ran- } \\
\text { dom-effects models) }\end{array}$ & 8 & 21222 & $\begin{array}{l}\text { Risk Ratio (M-H, Ran- } \\
\text { dom, } 95 \% \mathrm{Cl} \text { ) }\end{array}$ & $0.98[0.91,1.05]$ \\
\hline $\begin{array}{l}10 \text { All-cause mortality (sensitivity analysis: ex- } \\
\text { cluding the studies compared ezetimibe plus } \\
\text { statins versus double-dose statins alone) }\end{array}$ & 7 & 21003 & $\begin{array}{l}\text { Risk Ratio (M-H, Fixed, } \\
95 \% \mathrm{Cl})\end{array}$ & $0.98[0.91,1.05]$ \\
\hline 11 Myocardial infarction (non-fatal) & 6 & 21145 & $\begin{array}{l}\text { Risk Ratio (M-H, Fixed, } \\
95 \% \mathrm{Cl})\end{array}$ & $0.88[0.81,0.95]$ \\
\hline $\begin{array}{l}12 \text { Myocardial infarction (sensitivity analysis: } \\
\text { only including low risk of bias studies) }\end{array}$ & 2 & 18864 & $\begin{array}{l}\text { Risk Ratio (M-H, Fixed, } \\
95 \% \mathrm{Cl})\end{array}$ & $0.88[0.81,0.95]$ \\
\hline $\begin{array}{l}13 \text { Myocardial infarction (sensitivity analysis: } \\
\text { excluding the studies compared ezetimibe } \\
\text { plus statins versus double-dose statins alone) }\end{array}$ & 5 & 20926 & $\begin{array}{l}\text { Risk Ratio (M-H, Fixed, } \\
95 \% \mathrm{Cl})\end{array}$ & $0.88[0.81,0.95]$ \\
\hline 14 Ischaemic stroke (non-fatal) & 6 & 21205 & $\begin{array}{l}\text { Risk Ratio (M-H, Fixed, } \\
95 \% \mathrm{Cl})\end{array}$ & $0.83[0.71,0.97]$ \\
\hline $\begin{array}{l}15 \text { Ischaemic stroke (sensitivity analysis: only } \\
\text { including low risk of bias studies) }\end{array}$ & 2 & 18864 & $\begin{array}{l}\text { Risk Ratio (M-H, Fixed, } \\
95 \% \mathrm{Cl})\end{array}$ & $0.80[0.67,0.94]$ \\
\hline $\begin{array}{l}16 \text { Ischaemic stroke (sensitivity analysis: ex- } \\
\text { cluding the studies compared ezetimibe plus } \\
\text { statins versus double-dose statins alone) }\end{array}$ & 5 & 20986 & $\begin{array}{l}\text { Risk Ratio (M-H, Fixed, } \\
95 \% \mathrm{Cl})\end{array}$ & $0.81[0.69,0.96]$ \\
\hline 17 Cardiovascular mortality & 6 & 19457 & $\begin{array}{l}\text { Risk Ratio (M-H, Fixed, } \\
95 \% \mathrm{Cl})\end{array}$ & $1.00[0.89,1.12]$ \\
\hline $\begin{array}{l}18 \text { Cardiovascular mortality (sensitivity analy- } \\
\text { sis: only including low risk of bias studies) }\end{array}$ & 2 & 18864 & $\begin{array}{l}\text { Risk Ratio (M-H, Fixed, } \\
95 \% \mathrm{Cl})\end{array}$ & $1.00[0.89,1.12]$ \\
\hline $\begin{array}{l}19 \text { Cardiovascular mortality (sensitivity analy- } \\
\text { sis: excluding the studies compared ezetim- } \\
\text { ibe plus statins versus double-dose statins } \\
\text { alone) }\end{array}$ & 5 & 19238 & $\begin{array}{l}\text { Risk Ratio (M-H, Fixed, } \\
95 \% \mathrm{Cl})\end{array}$ & $1.00[0.89,1.12]$ \\
\hline 20 Coronary revascularization & 7 & 21323 & $\begin{array}{l}\text { Risk Ratio (M-H, Fixed, } \\
95 \% \mathrm{Cl})\end{array}$ & $0.94[0.89,0.99]$ \\
\hline $\begin{array}{l}21 \text { Coronary revascularization (sensitivity } \\
\text { analysis: only including low risk of bias stud- } \\
\text { ies) }\end{array}$ & 2 & 18864 & $\begin{array}{l}\text { Risk Ratio (M-H, Fixed, } \\
95 \% \mathrm{Cl})\end{array}$ & $0.94[0.89,1.00]$ \\
\hline $\begin{array}{l}22 \text { Coronary revascularization (sensitivity } \\
\text { analysis: excluding the studies compared eze- } \\
\text { timibe plus statins versus double-dose statins } \\
\text { alone) }\end{array}$ & 6 & 21104 & $\begin{array}{l}\text { Risk Ratio (M-H, Fixed, } \\
95 \% \mathrm{Cl})\end{array}$ & $0.94[0.89,0.99]$ \\
\hline 23 Adverse events - hepatopathy & 4 & 20687 & $\begin{array}{l}\text { Risk Ratio (M-H, Fixed, } \\
95 \% \mathrm{Cl})\end{array}$ & $1.14[0.96,1.35]$ \\
\hline
\end{tabular}




\begin{tabular}{|c|c|c|c|c|}
\hline Outcome or subgroup title & No. of studies & $\begin{array}{l}\text { No. of partici- } \\
\text { pants }\end{array}$ & Statistical method & Effect size \\
\hline $\begin{array}{l}24 \text { Adverse events - hepatopathy (sensitivity } \\
\text { analysis: only including low risk of bias stud- } \\
\text { ies) }\end{array}$ & 2 & 18860 & $\begin{array}{l}\text { Risk Ratio }(\mathrm{M}-\mathrm{H}, \text { Fixed, } \\
95 \% \mathrm{Cl})\end{array}$ & $1.08[0.90,1.30]$ \\
\hline 25 Adverse events - myopathy & 3 & 20581 & $\begin{array}{l}\text { Risk Ratio (M-H, Fixed, } \\
95 \% \mathrm{Cl})\end{array}$ & $1.31[0.72,2.38]$ \\
\hline $\begin{array}{l}26 \text { Adverse events - myopathy (sensitivity } \\
\text { analysis: only including low risk of bias stud- } \\
\text { ies) }\end{array}$ & 2 & 18860 & $\begin{array}{l}\text { Risk Ratio (M-H, Fixed, } \\
95 \% \mathrm{Cl})\end{array}$ & $1.55[0.73,3.30]$ \\
\hline 27 Adverse events - rhabdomyolysis & 2 & 19865 & $\begin{array}{l}\text { Risk Ratio (M-H, Fixed, } \\
95 \% \mathrm{Cl})\end{array}$ & $0.79[0.40,1.55]$ \\
\hline $\begin{array}{l}28 \text { Adverse events - rhabdomyolysis (sensi- } \\
\text { tivity analysis: only including low risk of bias } \\
\text { studies) }\end{array}$ & 1 & & $\begin{array}{l}\text { Risk Ratio (M-H, Fixed, } \\
95 \% \mathrm{Cl})\end{array}$ & $\begin{array}{l}\text { Totals not select- } \\
\text { ed }\end{array}$ \\
\hline 29 Adverse events - cancer & 5 & 20455 & $\begin{array}{l}\text { Risk Ratio (M-H, Fixed, } \\
95 \% \mathrm{Cl})\end{array}$ & $1.01[0.92,1.11]$ \\
\hline $\begin{array}{l}30 \text { Adverse events - cancer (sensitivity analy- } \\
\text { sis: only including low risk of bias studies) }\end{array}$ & 1 & & $\begin{array}{l}\text { Risk Ratio (M-H, Fixed, } \\
95 \% \mathrm{Cl})\end{array}$ & $\begin{array}{l}\text { Totals not select- } \\
\text { ed }\end{array}$ \\
\hline $\begin{array}{l}31 \text { Adverse events - cancer (sensitivity analy- } \\
\text { sis: excluding the studies compared ezetim- } \\
\text { ibe plus statins versus double-dose statins } \\
\text { alone) }\end{array}$ & 3 & 20127 & $\begin{array}{l}\text { Risk Ratio (M-H, Fixed, } \\
95 \% \mathrm{Cl})\end{array}$ & $1.01[0.92,1.11]$ \\
\hline 32 Adverse events - gallbladder-related AE & 3 & 20024 & $\begin{array}{l}\text { Risk Ratio (M-H, Fixed, } \\
95 \% \mathrm{Cl})\end{array}$ & $0.88[0.75,1.03]$ \\
\hline $\begin{array}{l}33 \text { Adverse events - gallbladder-related AE } \\
\text { (sensitivity analysis: only including low risk of } \\
\text { bias studies) }\end{array}$ & 1 & & $\begin{array}{l}\text { Risk Ratio (M-H, Fixed, } \\
95 \% \mathrm{Cl})\end{array}$ & $\begin{array}{l}\text { Totals not select- } \\
\text { ed }\end{array}$ \\
\hline 34 Discontinuation due to adverse event & 10 & 21746 & $\begin{array}{l}\text { Risk Ratio (M-H, Fixed, } \\
95 \% \mathrm{Cl})\end{array}$ & $0.91[0.75,1.09]$ \\
\hline $\begin{array}{l}35 \text { Discontinuation due to adverse event (sen- } \\
\text { sitivity analysis: only including low risk of bias } \\
\text { studies) }\end{array}$ & 2 & 18864 & $\begin{array}{l}\text { Risk Ratio (M-H, Fixed, } \\
95 \% \mathrm{Cl})\end{array}$ & $1.00[0.78,1.27]$ \\
\hline $\begin{array}{l}36 \text { Discontinuation due to adverse event (sen- } \\
\text { sitivity analysis: excluding the studies com- } \\
\text { pared ezetimibe plus statins versus dou- } \\
\text { ble-dose statins alone) }\end{array}$ & 8 & 21486 & $\begin{array}{l}\text { Risk Ratio (M-H, Fixed, } \\
95 \% \mathrm{Cl})\end{array}$ & $0.92[0.76,1.11]$ \\
\hline 37 LDL-C (end of follow up) & 21 & 17854 & $\begin{array}{l}\text { Mean Difference (IV, } \\
\text { Fixed, } 95 \% \mathrm{CI} \text { ) }\end{array}$ & $\begin{array}{l}-16.79[-17.36 \\
-16.23]\end{array}$ \\
\hline $\begin{array}{l}38 \text { LDL-C (end of follow up) (sensitivity analy- } \\
\text { sis: excluding the studies compared ezetim- } \\
\text { ibe plus statins versus double-dose statins } \\
\text { alone) }\end{array}$ & 16 & 17283 & $\begin{array}{l}\text { Mean Difference (IV, } \\
\text { Fixed, } 95 \% \mathrm{CI} \text { ) }\end{array}$ & $\begin{array}{l}-16.88[-17.45 \\
-16.31]\end{array}$ \\
\hline
\end{tabular}




\begin{tabular}{|c|c|c|c|c|}
\hline Outcome or subgroup title & No. of studies & $\begin{array}{l}\text { No. of partici- } \\
\text { pants }\end{array}$ & Statistical method & Effect size \\
\hline $\begin{array}{l}39 \text { LDL-C (end of follow up) (sensitivity analy- } \\
\text { sis: excluding studies with serious missing da- } \\
\text { ta) }\end{array}$ & 16 & 16218 & $\begin{array}{l}\text { Mean Difference (IV, } \\
\text { Fixed, } 95 \% \mathrm{CI} \text { ) }\end{array}$ & $\begin{array}{l}-16.80[-17.38 \\
-16.22]\end{array}$ \\
\hline 40 TC (end of follow up) & 18 & 16330 & $\begin{array}{l}\text { Mean Difference (IV, } \\
\text { Fixed, } 95 \% \mathrm{CI} \text { ) }\end{array}$ & $\begin{array}{l}-19.70[-20.48 \\
-18.92]\end{array}$ \\
\hline $\begin{array}{l}41 \text { TC (end of follow up) (sensitivity analysis: } \\
\text { excluding the studies compared ezetimibe } \\
\text { plus statins versus double-dose statins alone) }\end{array}$ & 15 & 16011 & $\begin{array}{l}\text { Mean Difference (IV, } \\
\text { Fixed, } 95 \% \mathrm{CI} \text { ) }\end{array}$ & $\begin{array}{l}-19.77[-20.55, \\
-18.98]\end{array}$ \\
\hline $\begin{array}{l}42 \text { TC (end of follow up) (sensitivity analysis: } \\
\text { excluding studies with serious missing data) }\end{array}$ & 14 & 15981 & $\begin{array}{l}\text { Mean Difference (IV, } \\
\text { Fixed, } 95 \% \mathrm{CI} \text { ) }\end{array}$ & $\begin{array}{l}-19.76[-20.55 \\
-18.98]\end{array}$ \\
\hline $43 \mathrm{HDL}-\mathrm{C}$ (end of follow up) & 18 & 16434 & $\begin{array}{l}\text { Mean Difference (IV, } \\
\text { Fixed, } 95 \% \mathrm{CI} \text { ) }\end{array}$ & $0.66[0.30,1.03]$ \\
\hline $\begin{array}{l}44 \mathrm{HDL}-\mathrm{C} \text { (end of follow up) (sensitivity analy- } \\
\text { sis: excluding the studies compared ezetim- } \\
\text { ibe plus statins versus double-dose statins } \\
\text { alone) }\end{array}$ & 13 & 15798 & $\begin{array}{l}\text { Mean Difference (IV, } \\
\text { Fixed, } 95 \% \mathrm{CI} \text { ) }\end{array}$ & $0.68[0.30,1.05]$ \\
\hline $\begin{array}{l}45 \mathrm{HDL}-\mathrm{C} \text { (end of follow up) (sensitivity analy- } \\
\text { sis: excluding studies with serious missing da- } \\
\text { ta) }\end{array}$ & 14 & 16085 & $\begin{array}{l}\text { Mean Difference (IV, } \\
\text { Fixed, } 95 \% \mathrm{CI} \text { ) }\end{array}$ & $0.66[0.29,1.03]$ \\
\hline 46 TG (end of follow up) & 12 & 1253 & $\begin{array}{l}\text { Mean Difference (IV, } \\
\text { Fixed, } 95 \% \mathrm{CI} \text { ) }\end{array}$ & $\begin{array}{l}-27.58[-33.67, \\
-21.49]\end{array}$ \\
\hline $\begin{array}{l}47 \text { TG (end of follow up) (sensitivity analysis: } \\
\text { excluding the studies compared ezetimibe } \\
\text { plus statins versus double-dose statins alone) }\end{array}$ & 9 & 865 & $\begin{array}{l}\text { Mean Difference (IV, } \\
\text { Fixed, } 95 \% \mathrm{CI} \text { ) }\end{array}$ & $\begin{array}{l}-32.88[-39.50, \\
-26.27]\end{array}$ \\
\hline $\begin{array}{l}48 \text { TG (end of follow up) (sensitivity analysis: } \\
\text { excluding studies with serious missing data) }\end{array}$ & 9 & 1054 & $\begin{array}{l}\text { Mean Difference (IV, } \\
\text { Fixed, } 95 \% \mathrm{CI} \text { ) }\end{array}$ & $\begin{array}{l}-27.68[-33.96 \\
-21.41]\end{array}$ \\
\hline
\end{tabular}

\section{Analysis 1.1. Comparison 1 Ezetimibe plus other lipid-modifying drugs vs other lipid-modifying drugs alone or plus placebo, Outcome 1 MACE (subgroup analysis: duration of follow up).}

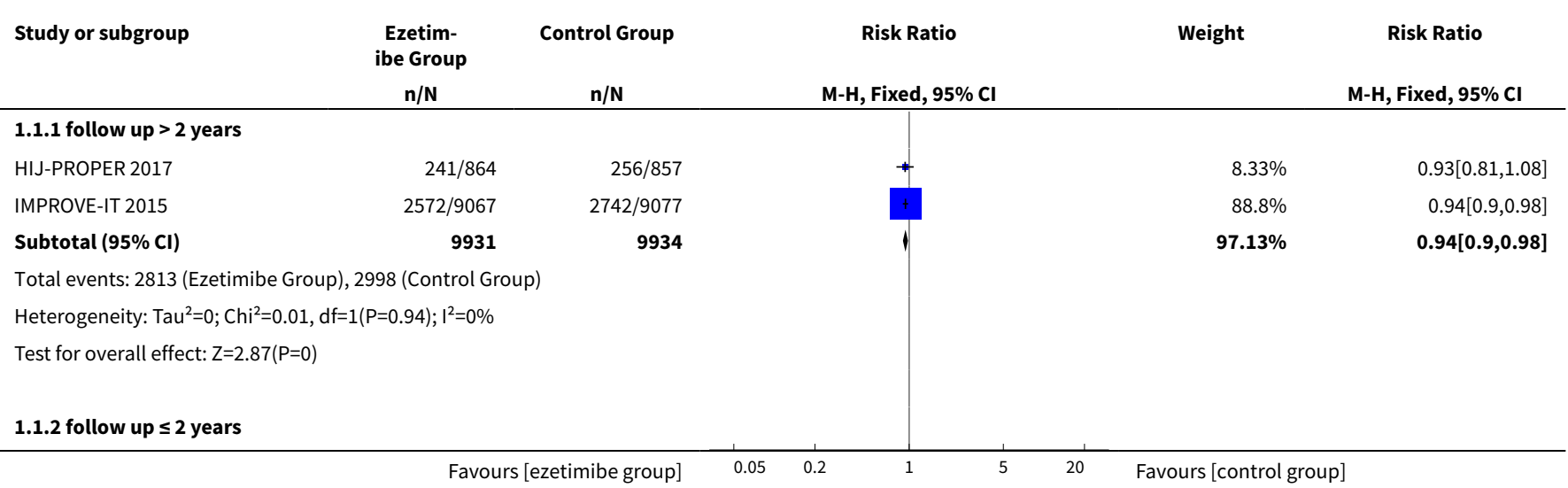




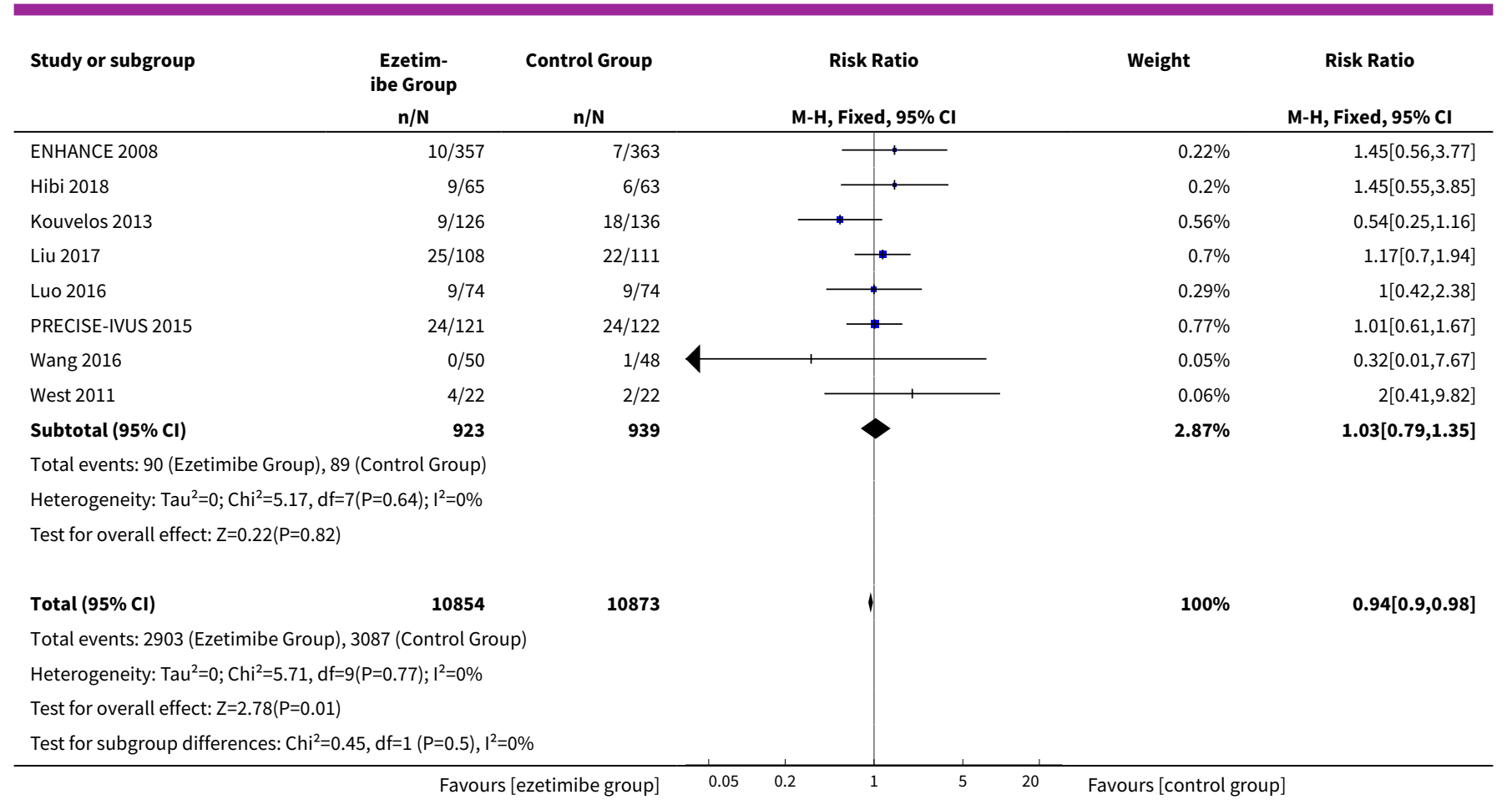

Analysis 1.2. Comparison 1 Ezetimibe plus other lipid-modifying drugs vs other lipid-modifying drugs alone or plus placebo, Outcome 2 MACE (subgroup analysis: participates with/without ASCVD).

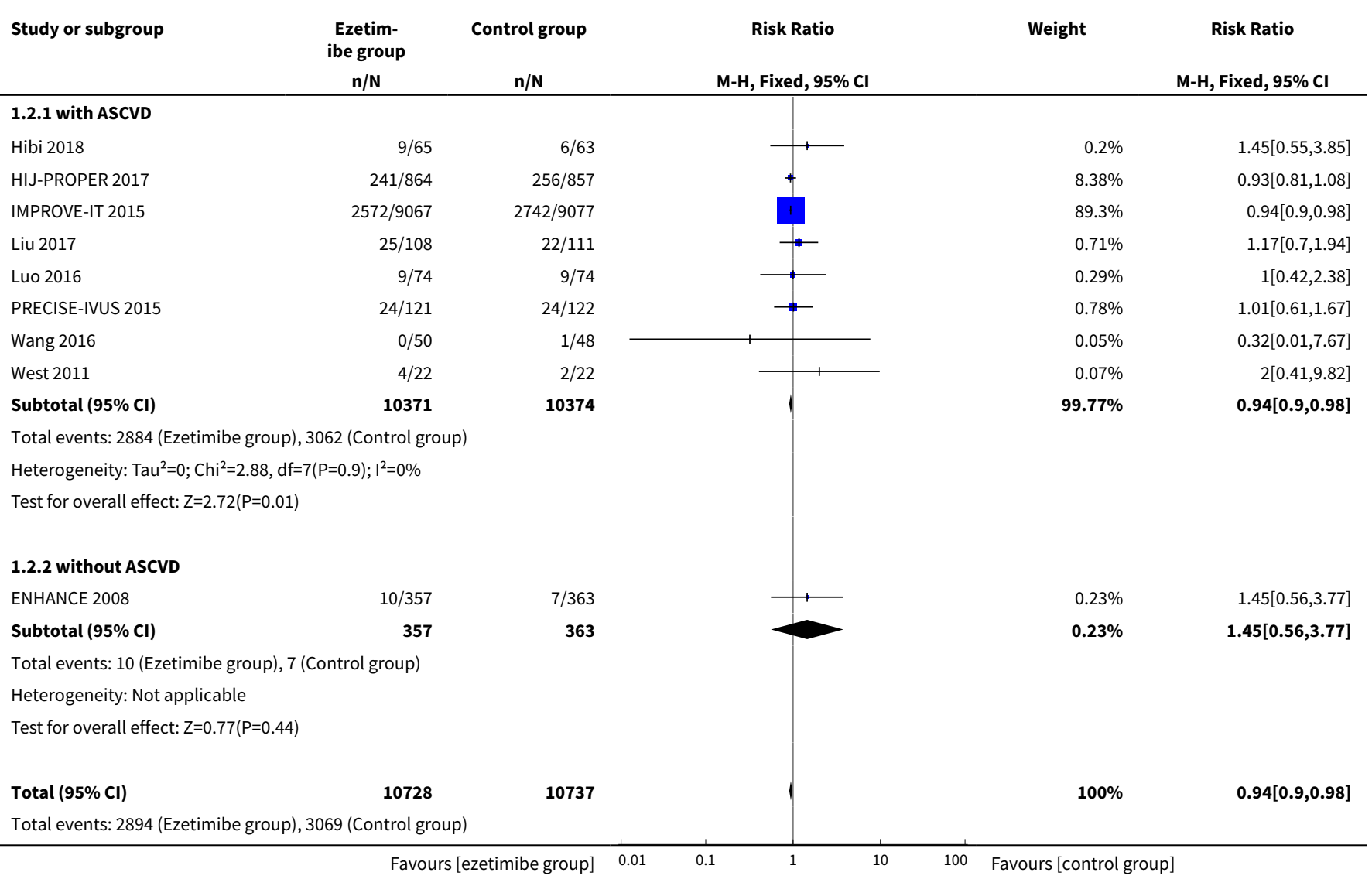




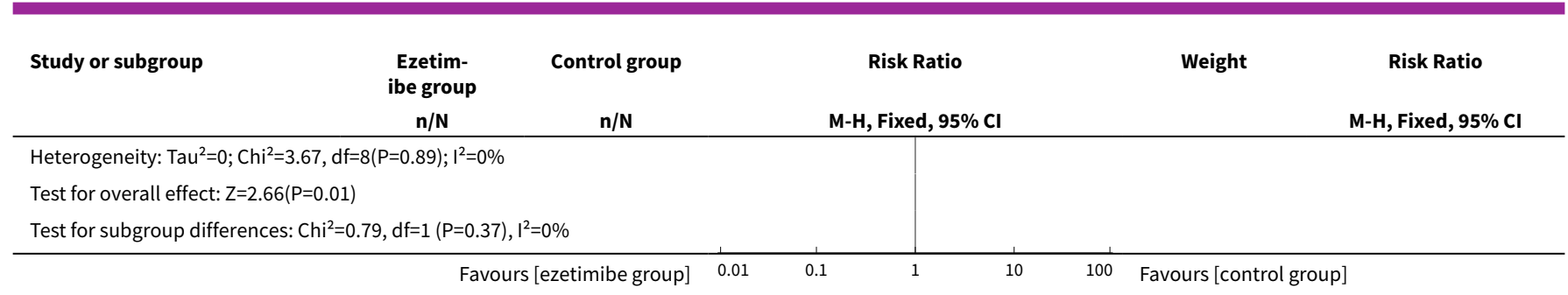

Analysis 1.3. Comparison 1 Ezetimibe plus other lipid-modifying drugs vs other lipid-modifying drugs alone or plus placebo, Outcome 3 MACE (sensitivity analysis: only including low risk of bias studies).

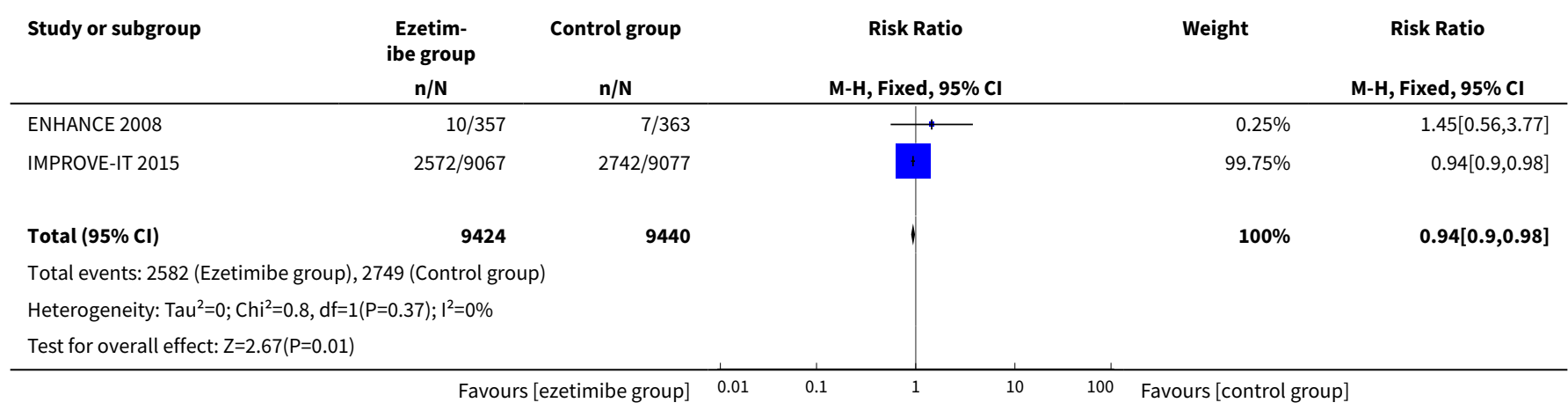

\section{Analysis 1.4. Comparison 1 Ezetimibe plus other lipid-modifying drugs vs other lipid-modifying drugs alone or plus placebo, Outcome 4 MACE (sensitivity analysis: random-effects models).}

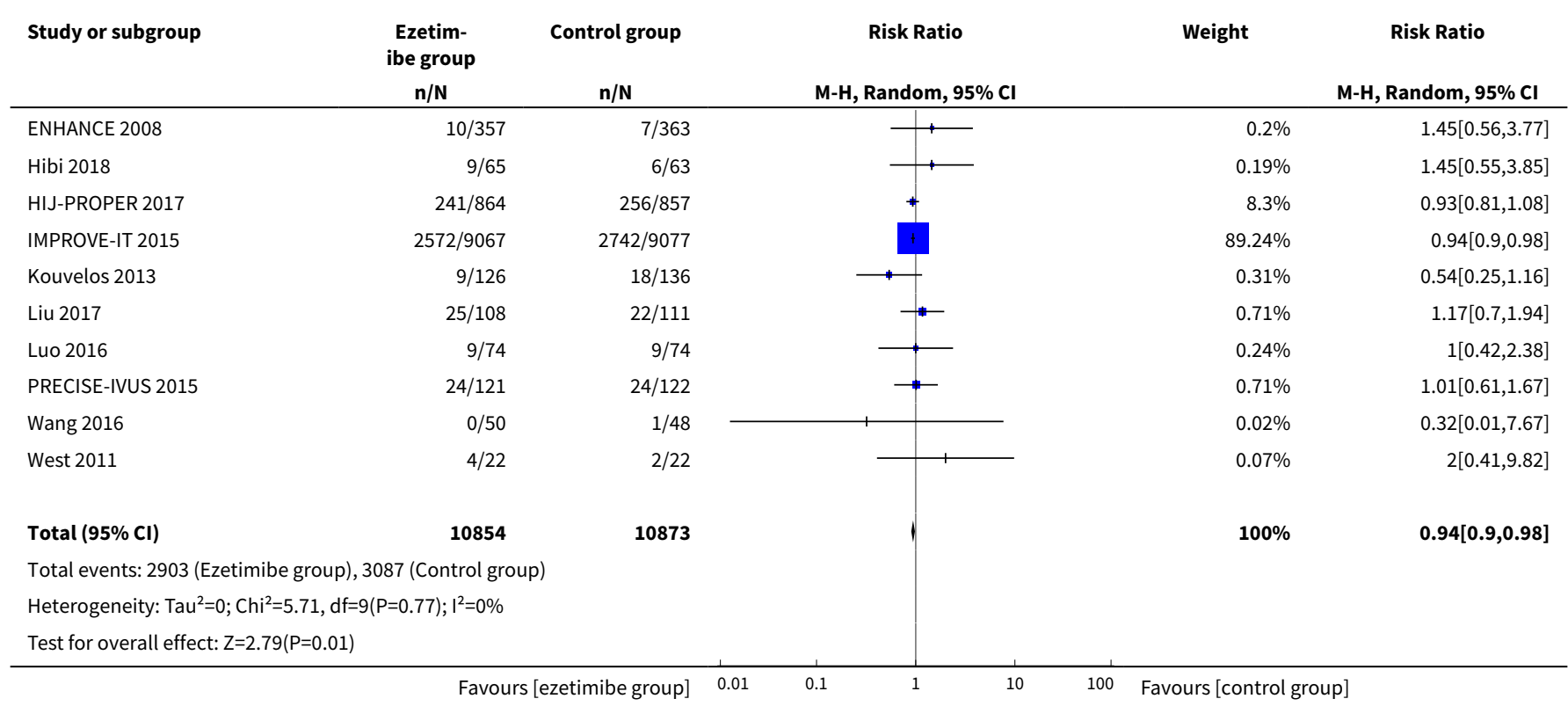


Analysis 1.5. Comparison 1 Ezetimibe plus other lipid-modifying drugs vs other lipidmodifying drugs alone or plus placebo, Outcome 5 MACE (sensitivity analysis: excluding the studies compared ezetimibe plus statins versus double-dose statins alone).

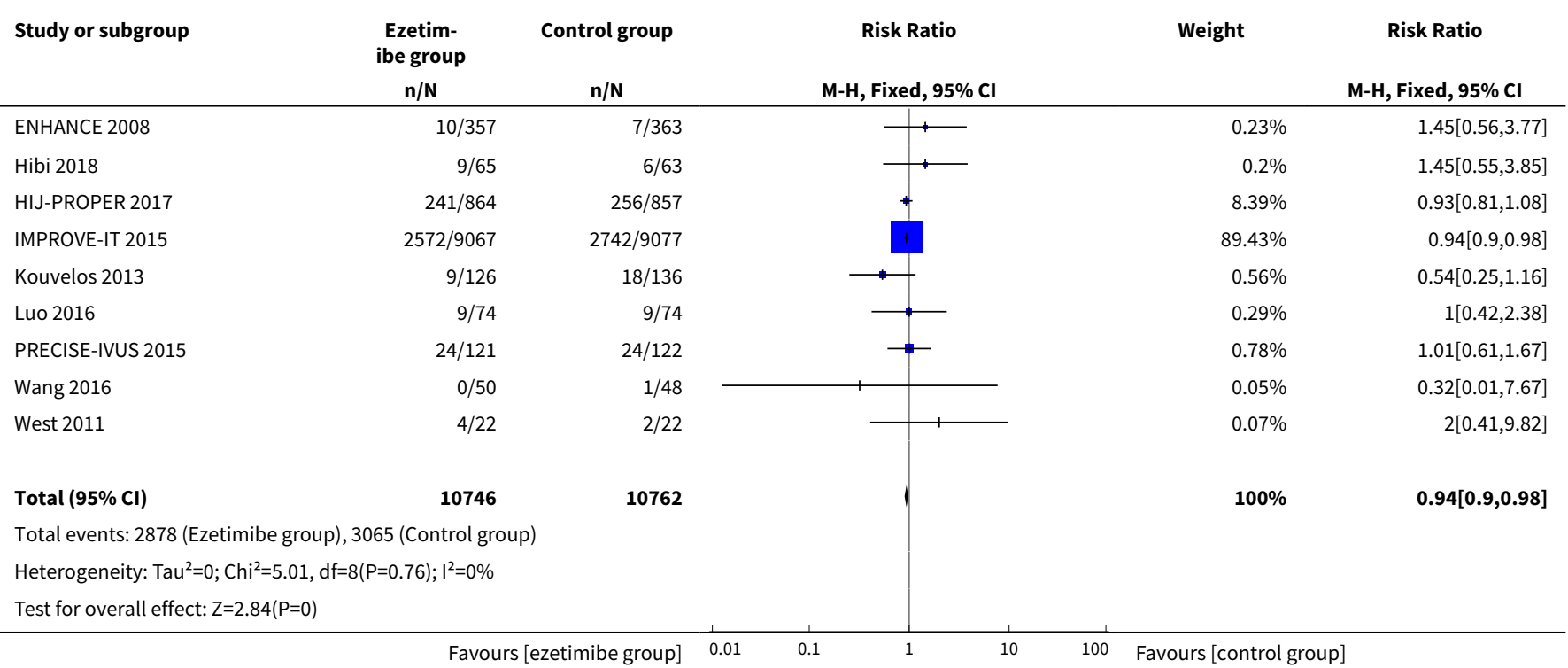

\section{Analysis 1.6. Comparison 1 Ezetimibe plus other lipid-modifying drugs vs other lipid-modifying drugs} alone or plus placebo, Outcome 6 All-cause mortality (subgroup analysis: duration of follow up).

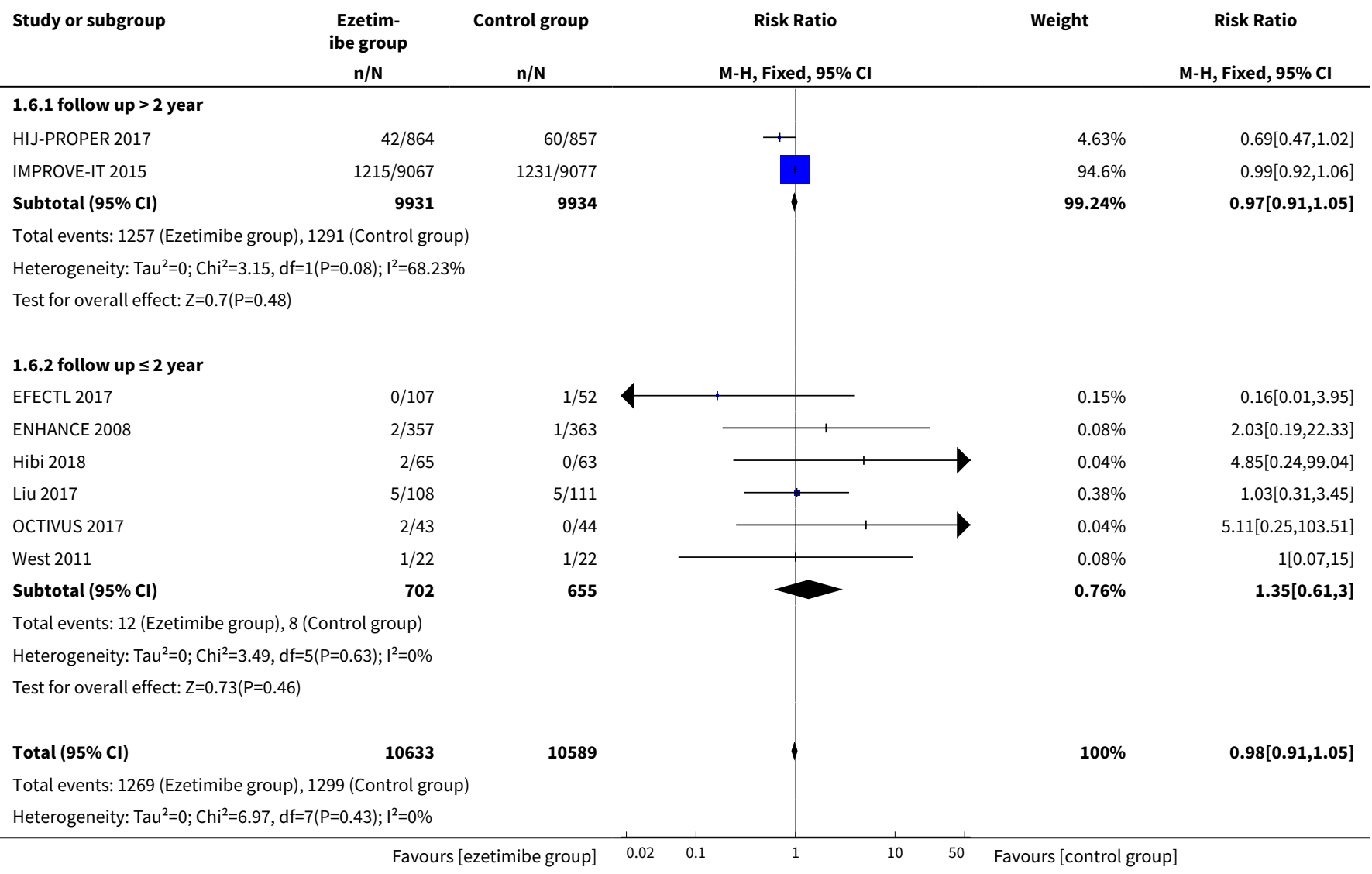




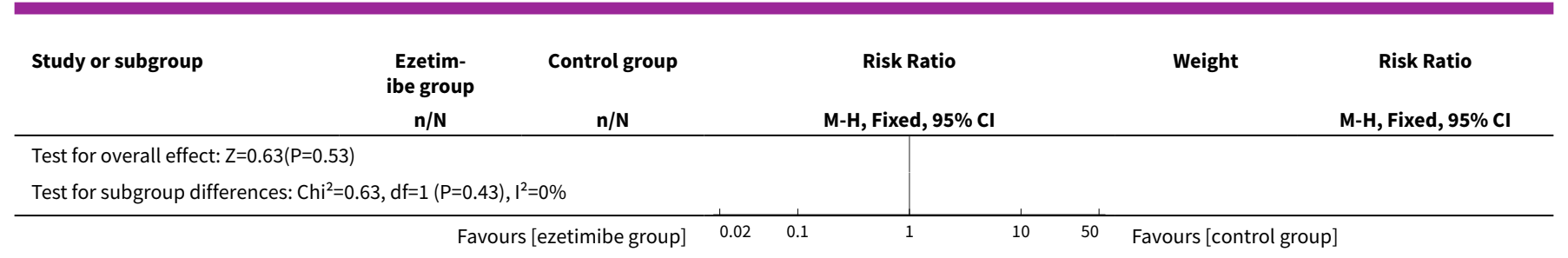

Analysis 1.7. Comparison 1 Ezetimibe plus other lipid-modifying drugs vs other lipid-modifying drugs alone or plus placebo, Outcome 7 All-cause mortality (subgroup analysis: participates with/without ASCVD).

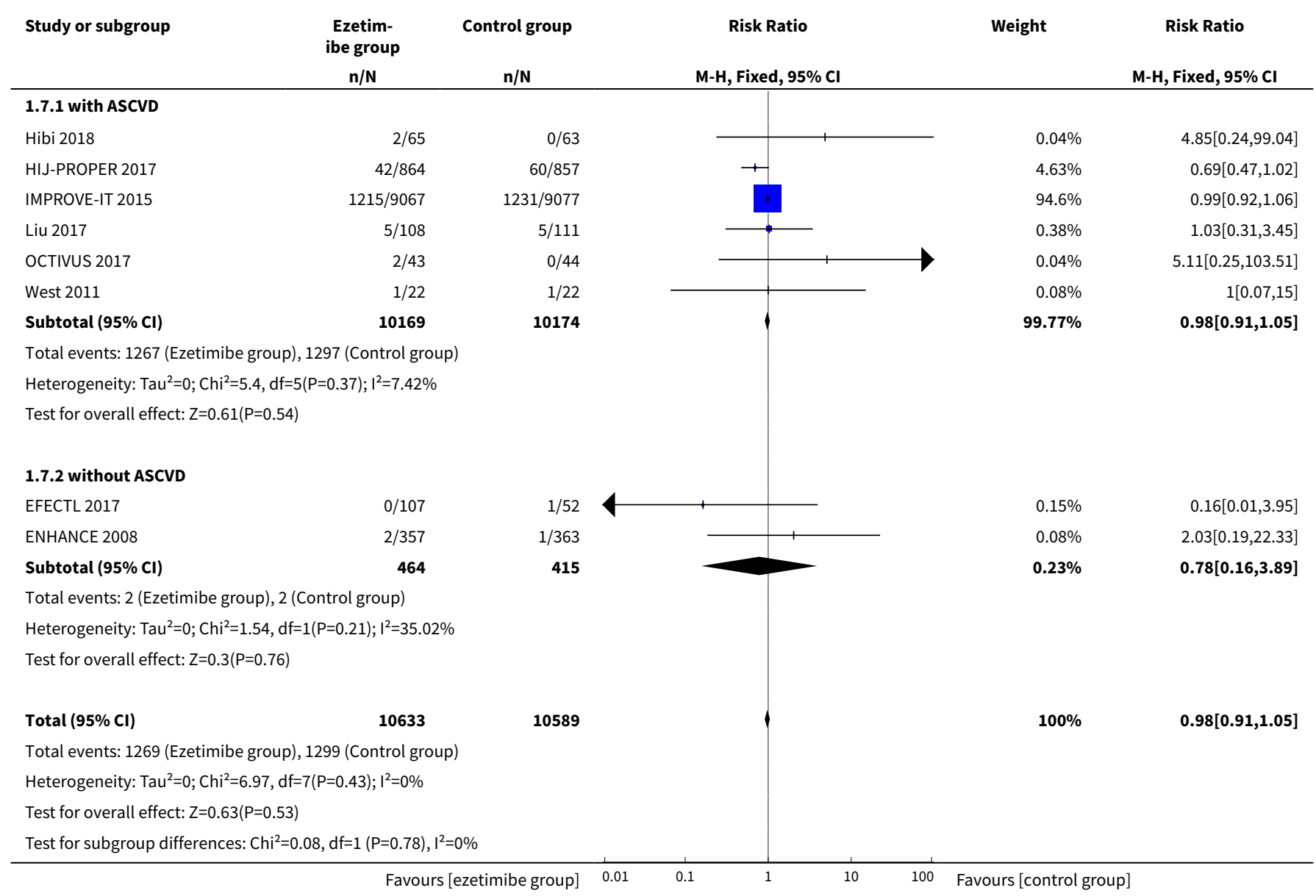

Analysis 1.8. Comparison 1 Ezetimibe plus other lipid-modifying drugs vs other lipid-modifying drugs alone or plus placebo, Outcome 8 All-cause mortality (sensitivity analysis: only including low risk of bias studies).

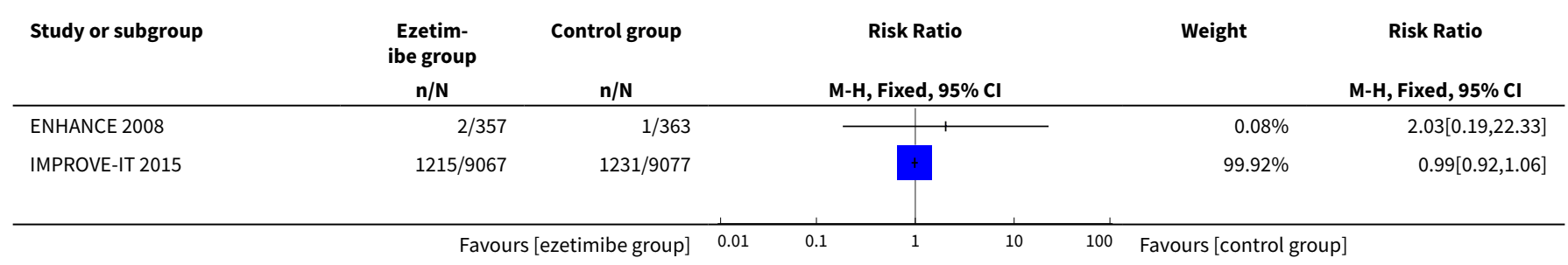




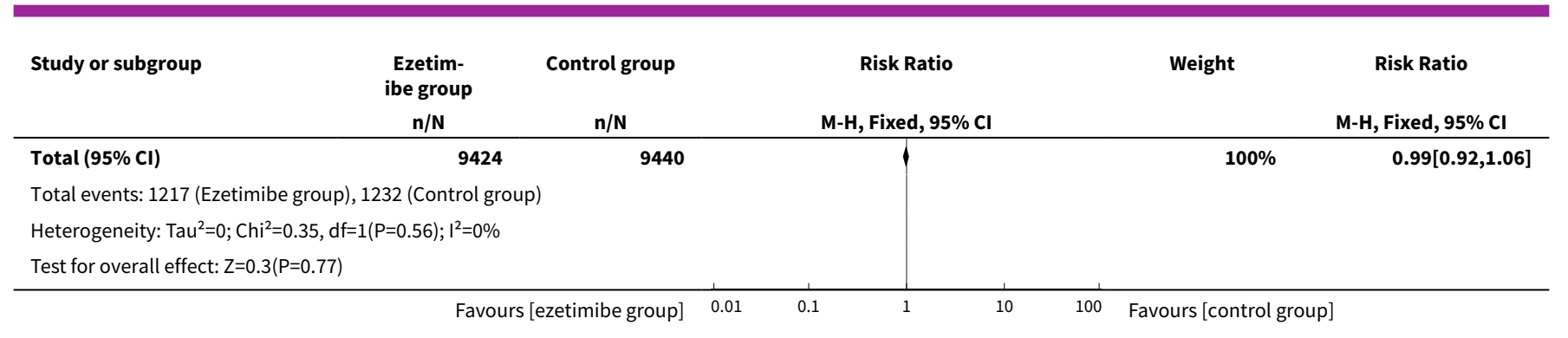

\section{Analysis 1.9. Comparison 1 Ezetimibe plus other lipid-modifying drugs vs other lipid-modifying drugs alone or plus placebo, Outcome 9 All-cause mortality (sensitivity analysis: random-effects models).}

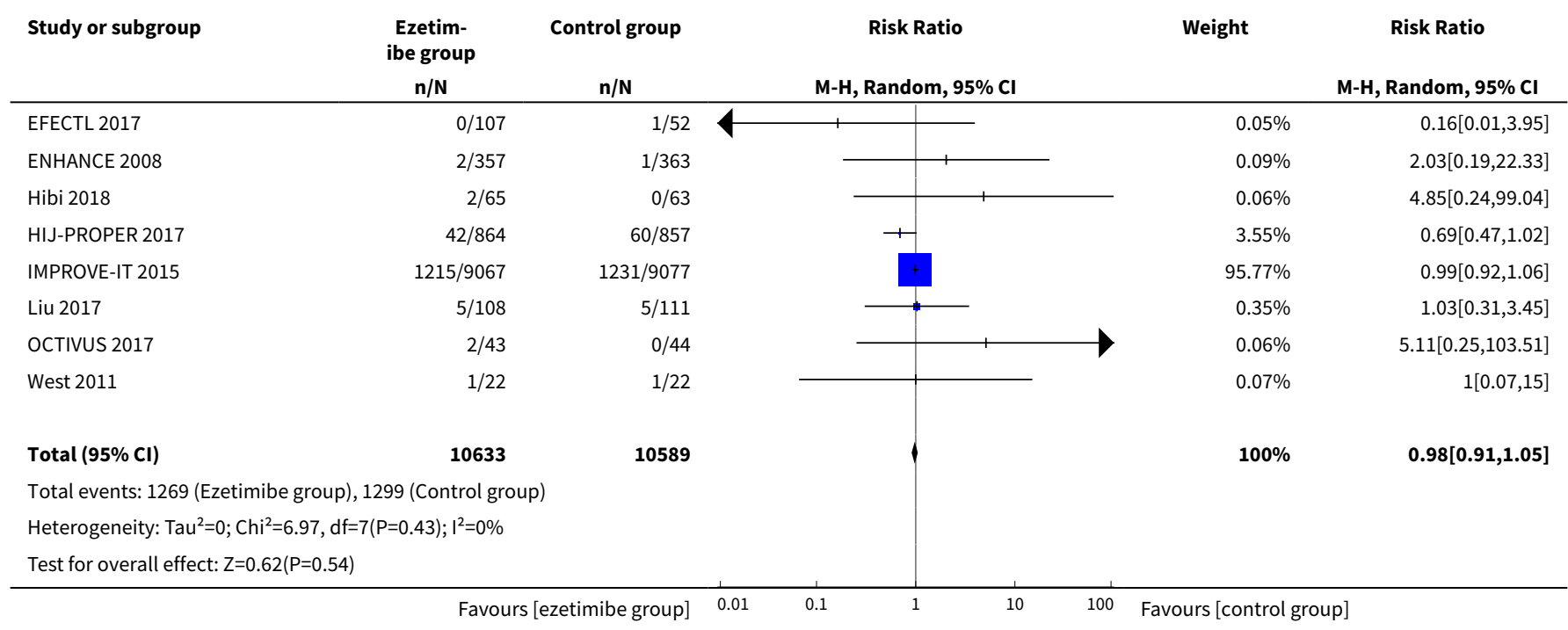

Analysis 1.10. Comparison 1 Ezetimibe plus other lipid-modifying drugs vs other lipidmodifying drugs alone or plus placebo, Outcome 10 All-cause mortality (sensitivity analysis: excluding the studies compared ezetimibe plus statins versus double-dose statins alone).

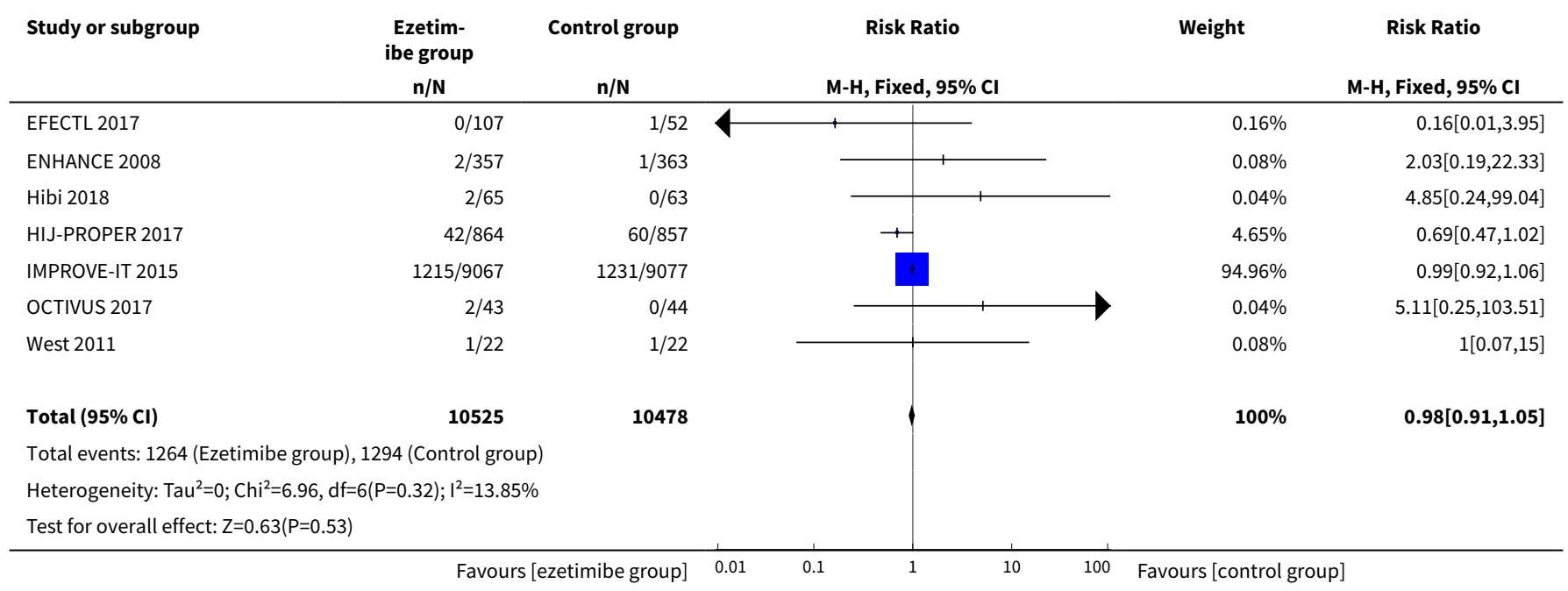


Analysis 1.11. Comparison 1 Ezetimibe plus other lipid-modifying drugs vs other lipidmodifying drugs alone or plus placebo, Outcome 11 Myocardial infarction (non-fatal).

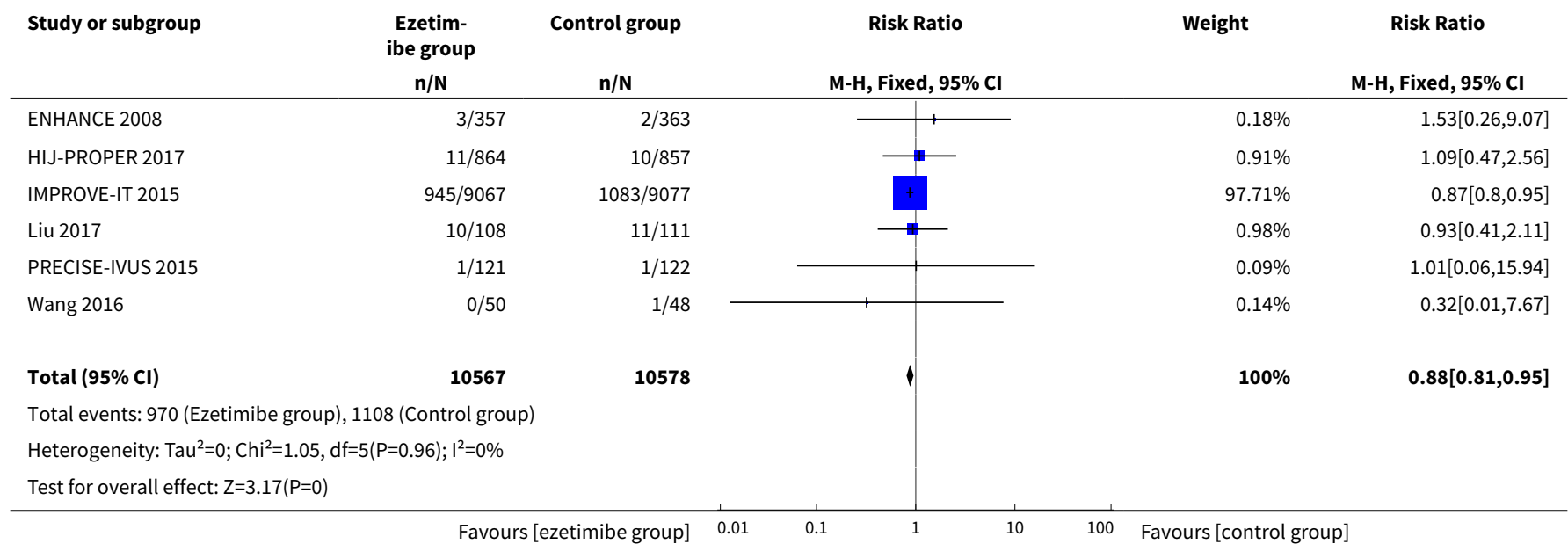

Analysis 1.12. Comparison 1 Ezetimibe plus other lipid-modifying drugs vs other lipid-modifying drugs alone or plus placebo, Outcome 12 Myocardial infarction (sensitivity analysis: only including low risk of bias studies).

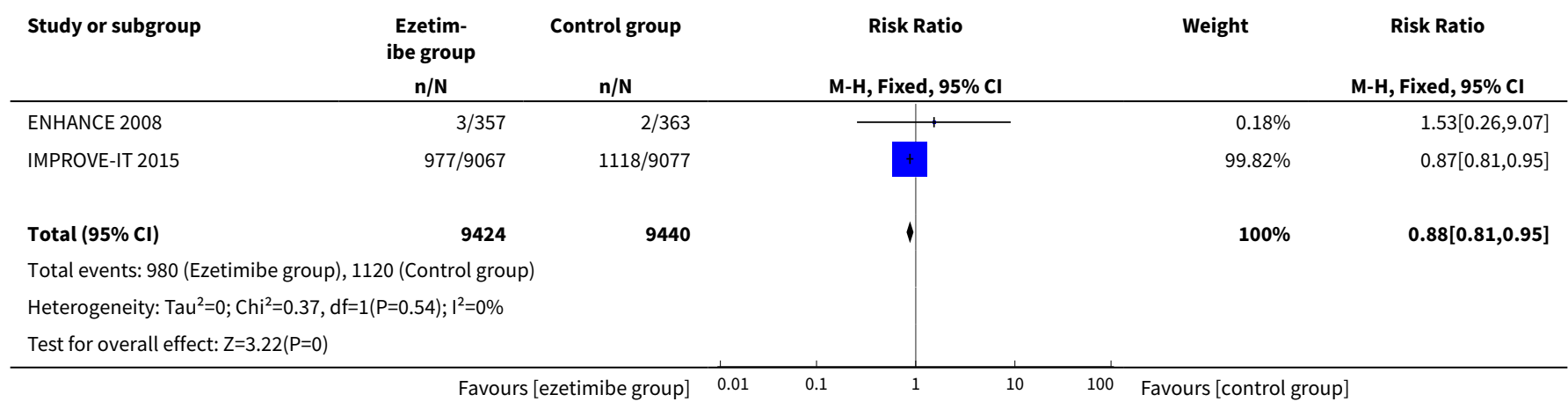

Analysis 1.13. Comparison 1 Ezetimibe plus other lipid-modifying drugs vs other lipidmodifying drugs alone or plus placebo, Outcome 13 Myocardial infarction (sensitivity analysis: excluding the studies compared ezetimibe plus statins versus double-dose statins alone).

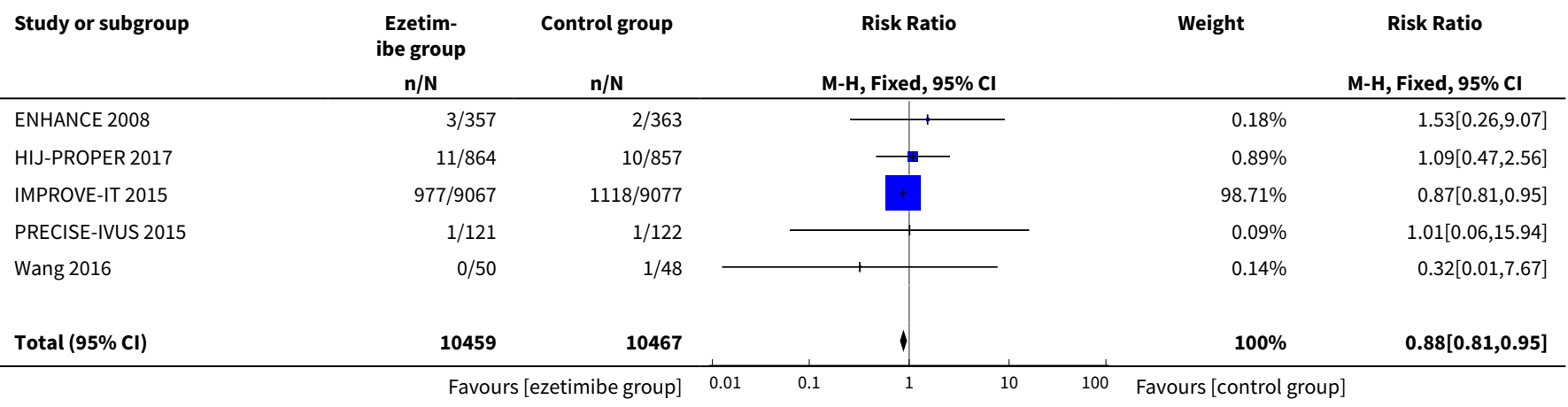




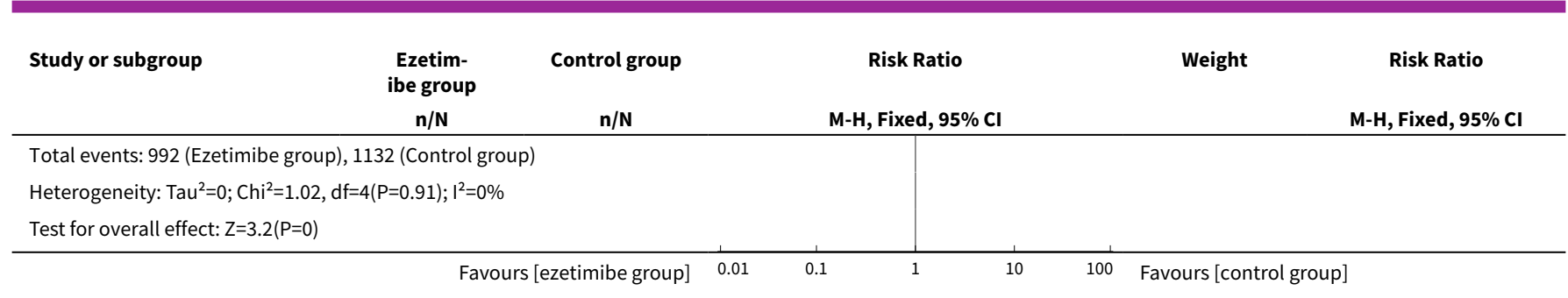

Analysis 1.14. Comparison 1 Ezetimibe plus other lipid-modifying drugs vs other lipidmodifying drugs alone or plus placebo, Outcome 14 Ischaemic stroke (non-fatal).

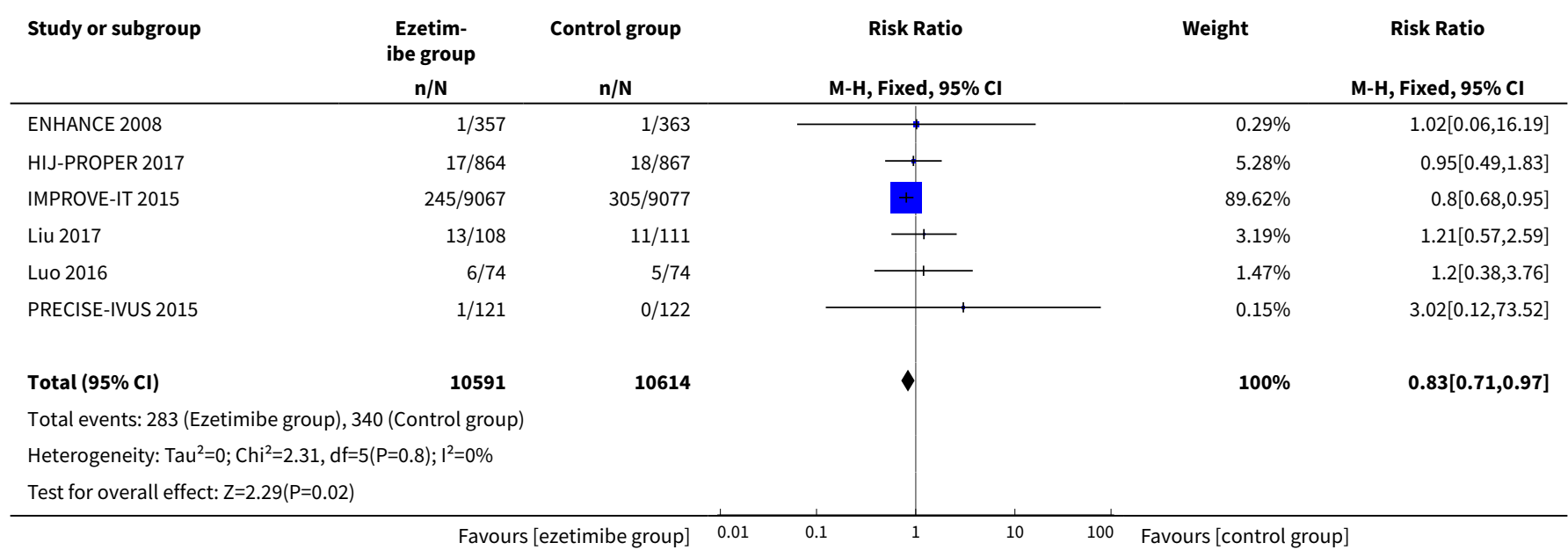

Analysis 1.15. Comparison 1 Ezetimibe plus other lipid-modifying drugs vs other lipid-modifying drugs alone or plus placebo, Outcome 15 Ischaemic stroke (sensitivity analysis: only including low risk of bias studies).

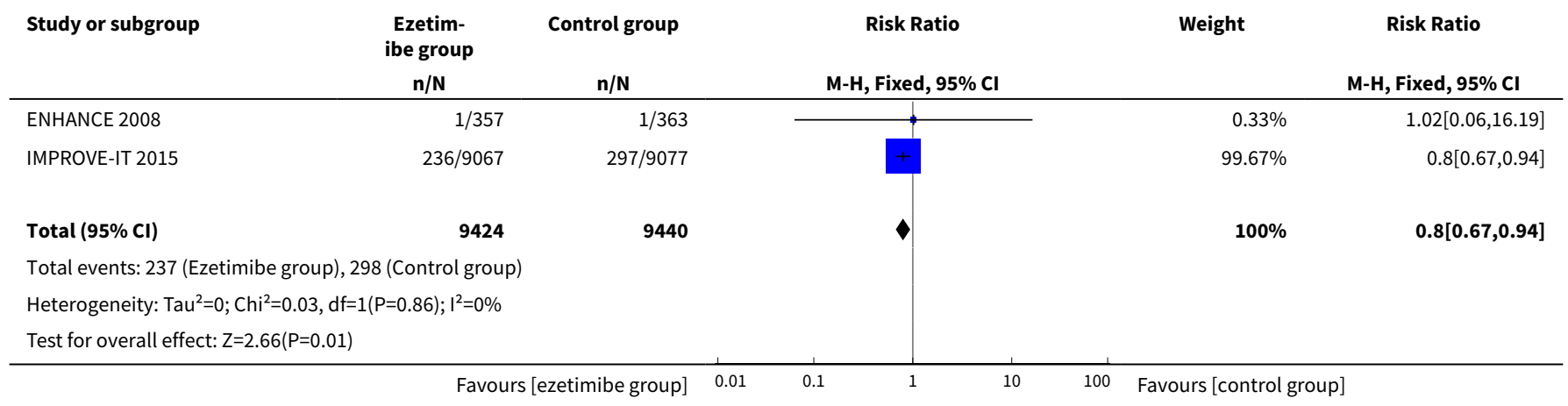


Analysis 1.16. Comparison 1 Ezetimibe plus other lipid-modifying drugs vs other lipidmodifying drugs alone or plus placebo, Outcome 16 Ischaemic stroke (sensitivity analysis: excluding the studies compared ezetimibe plus statins versus double-dose statins alone).

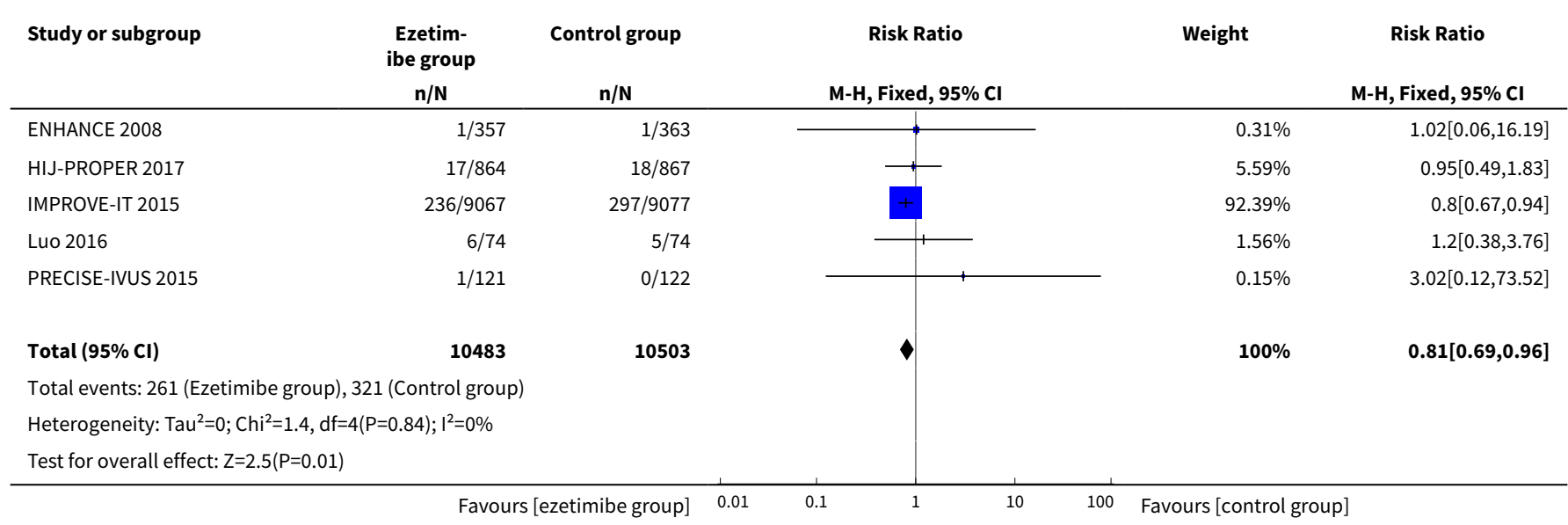

Analysis 1.17. Comparison 1 Ezetimibe plus other lipid-modifying drugs vs other lipid-modifying drugs alone or plus placebo, Outcome 17 Cardiovascular mortality.

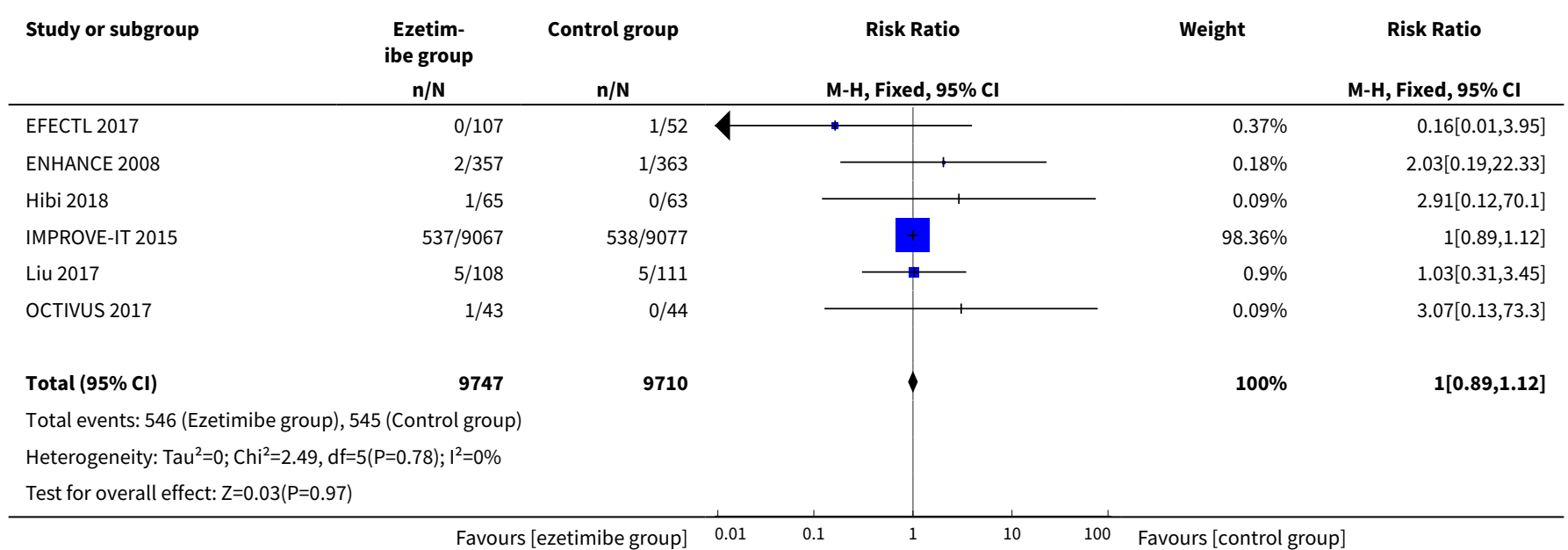

Analysis 1.18. Comparison 1 Ezetimibe plus other lipid-modifying drugs vs other lipid-modifying drugs alone or plus placebo, Outcome 18 Cardiovascular mortality (sensitivity analysis: only including low risk of bias studies).

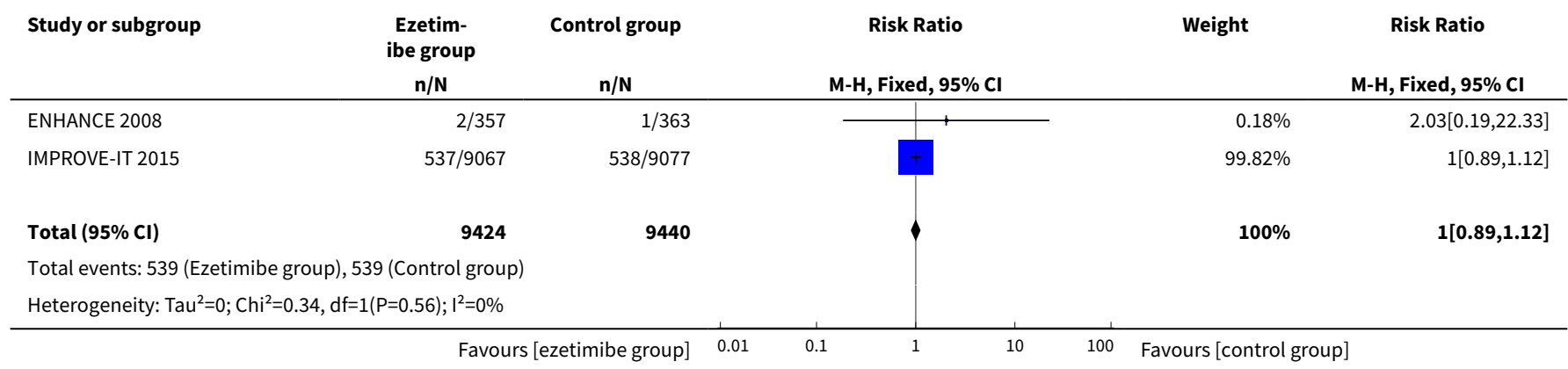




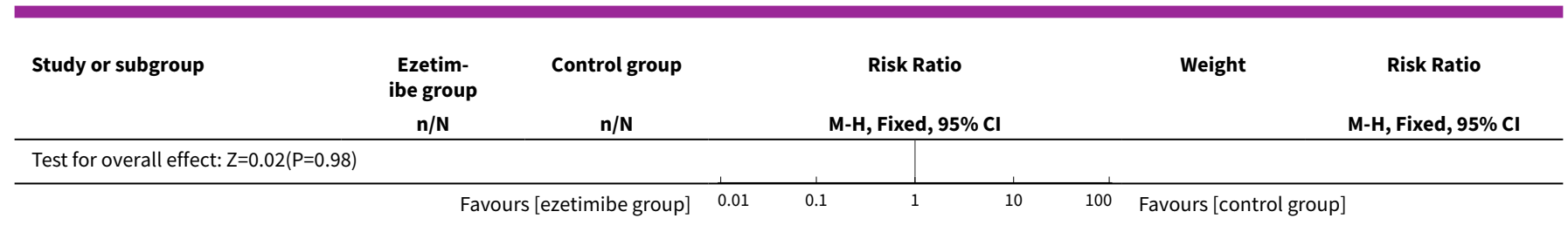

Analysis 1.19. Comparison 1 Ezetimibe plus other lipid-modifying drugs vs other lipidmodifying drugs alone or plus placebo, Outcome 19 Cardiovascular mortality (sensitivity analysis: excluding the studies compared ezetimibe plus statins versus double-dose statins alone).

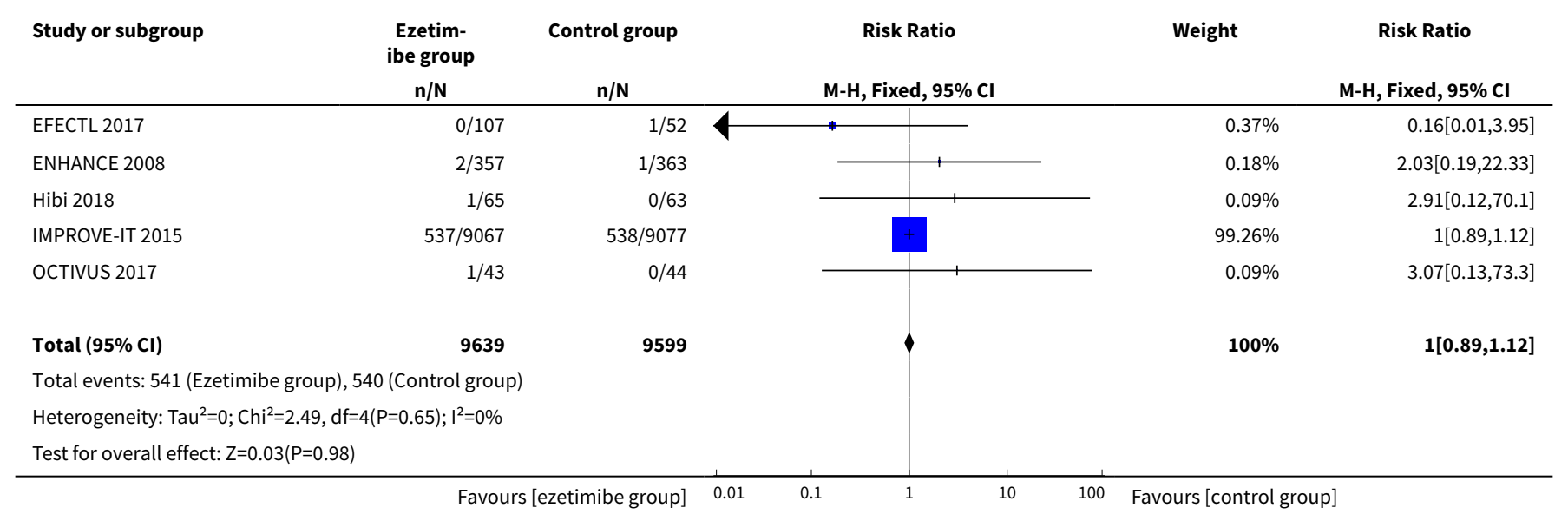

Analysis 1.20. Comparison 1 Ezetimibe plus other lipid-modifying drugs vs other lipid-modifying drugs alone or plus placebo, Outcome $\mathbf{2 0}$ Coronary revascularization.

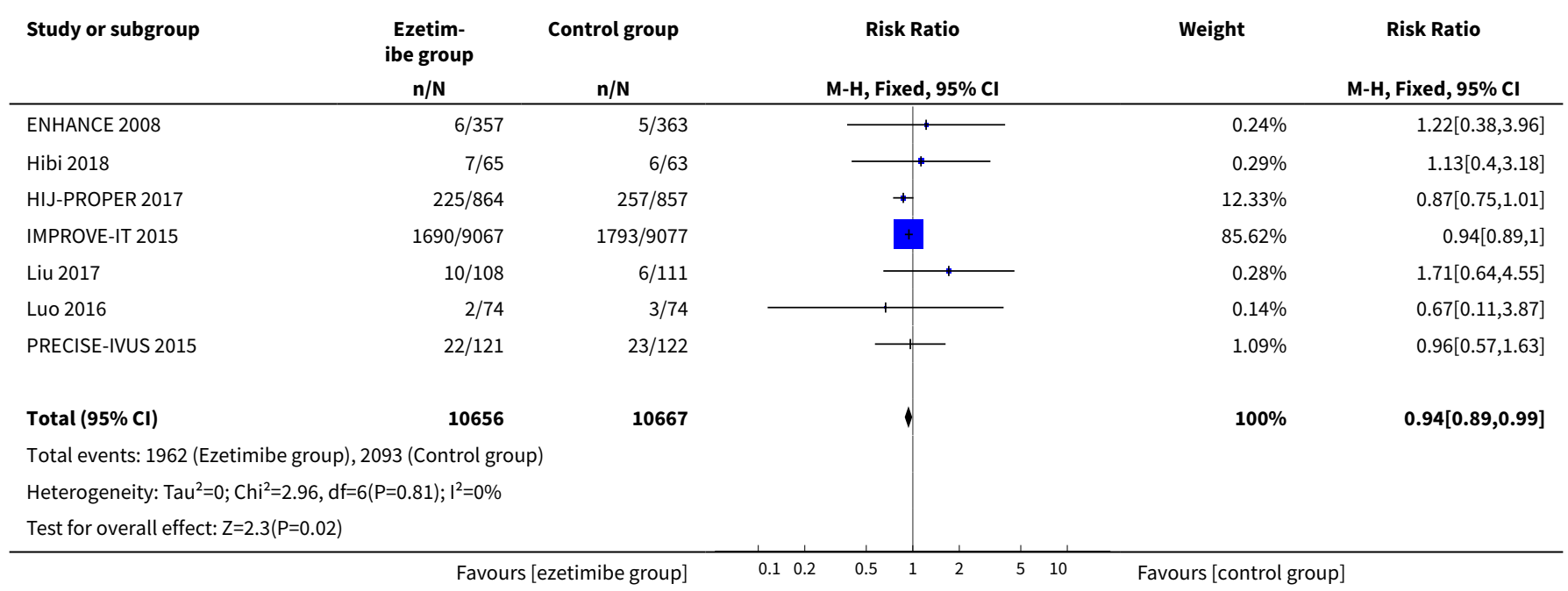


Analysis 1.21. Comparison 1 Ezetimibe plus other lipid-modifying drugs vs other lipid-modifying drugs alone or plus placebo, Outcome $\mathbf{2 1}$ Coronary revascularization (sensitivity analysis: only including low risk of bias studies).

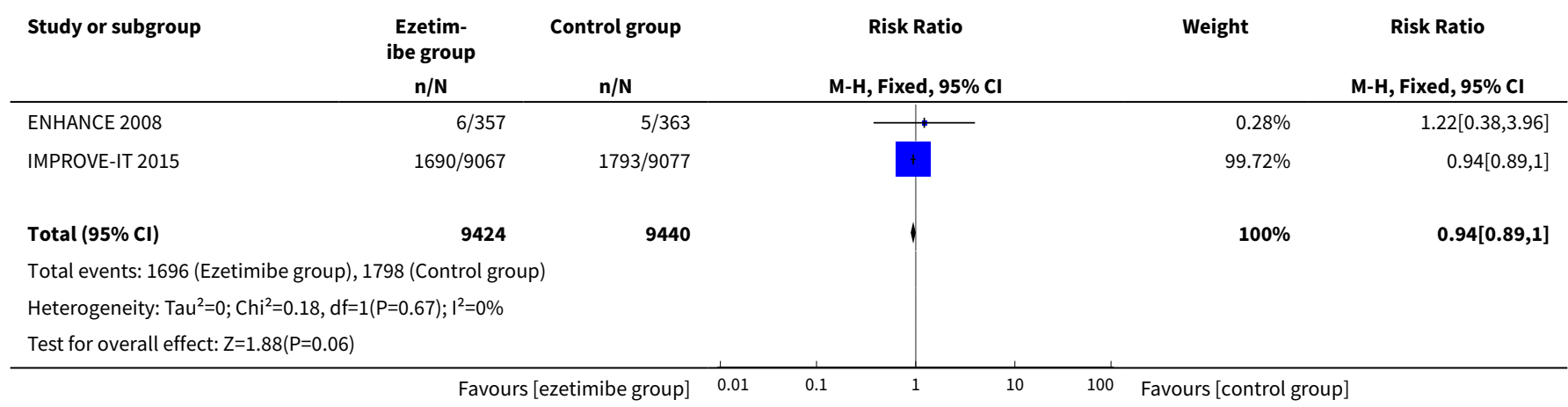

Analysis 1.22. Comparison 1 Ezetimibe plus other lipid-modifying drugs vs other lipid-modifying drugs alone or plus placebo, Outcome $\mathbf{2 2}$ Coronary revascularization (sensitivity analysis: excluding the studies compared ezetimibe plus statins versus double-dose statins alone).

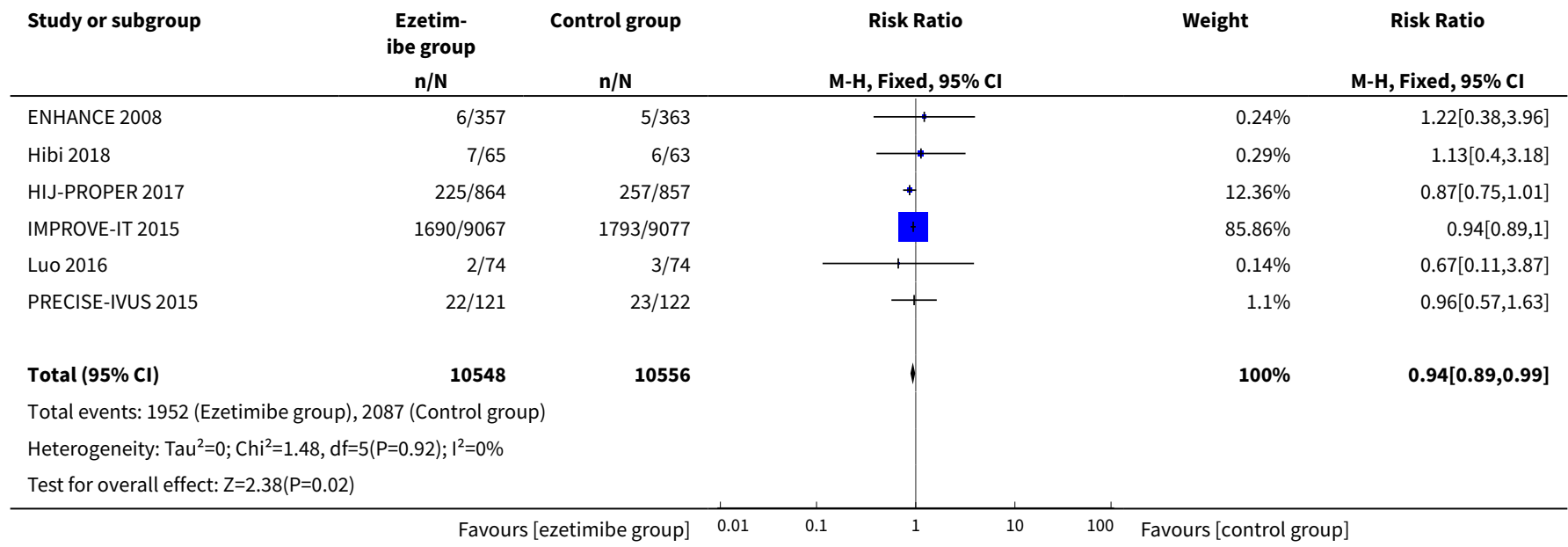

Analysis 1.23. Comparison 1 Ezetimibe plus other lipid-modifying drugs vs other lipidmodifying drugs alone or plus placebo, Outcome 23 Adverse events - hepatopathy.

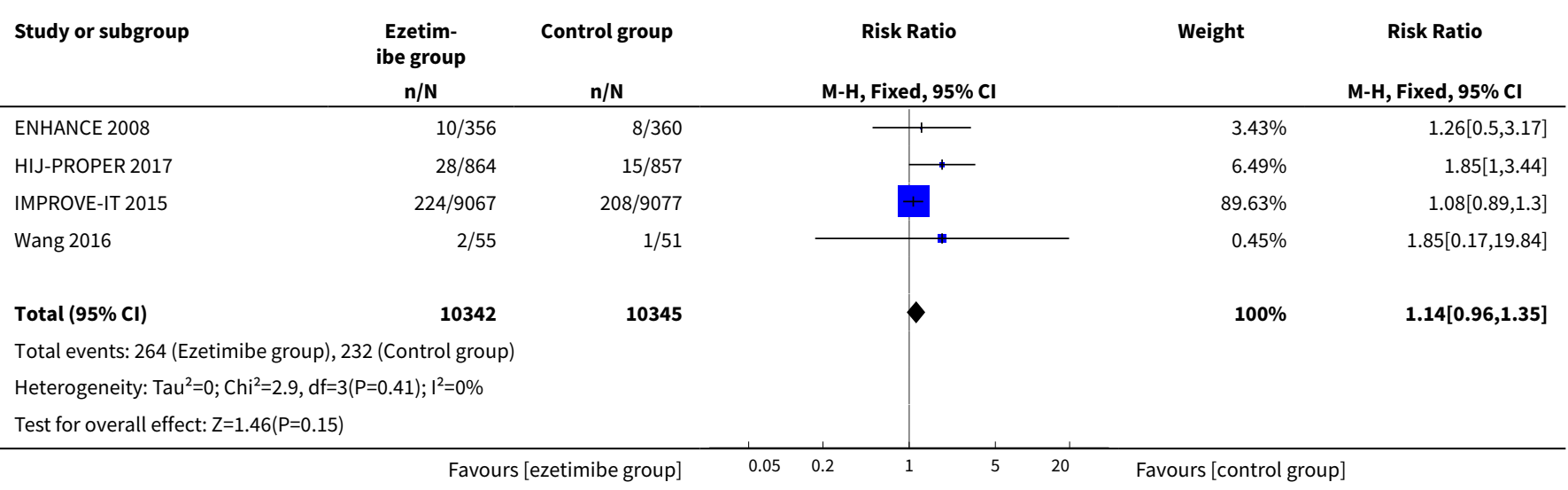


Analysis 1.24. Comparison 1 Ezetimibe plus other lipid-modifying drugs vs other lipid-modifying drugs alone or plus placebo, Outcome 24 Adverse events

- hepatopathy (sensitivity analysis: only including low risk of bias studies).

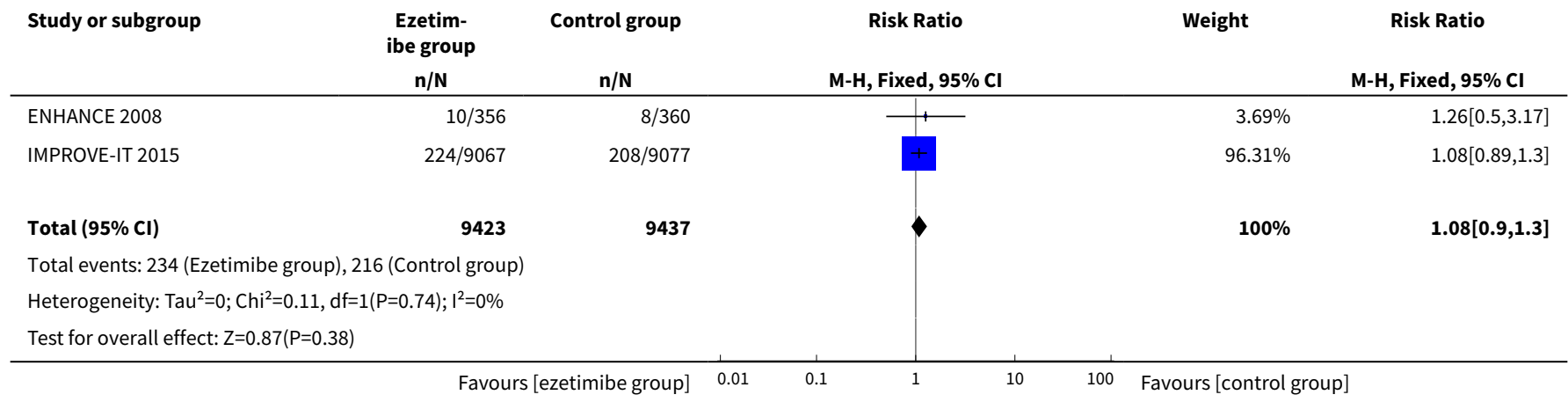

Analysis 1.25. Comparison 1 Ezetimibe plus other lipid-modifying drugs vs other lipid-modifying drugs alone or plus placebo, Outcome 25 Adverse events - myopathy.

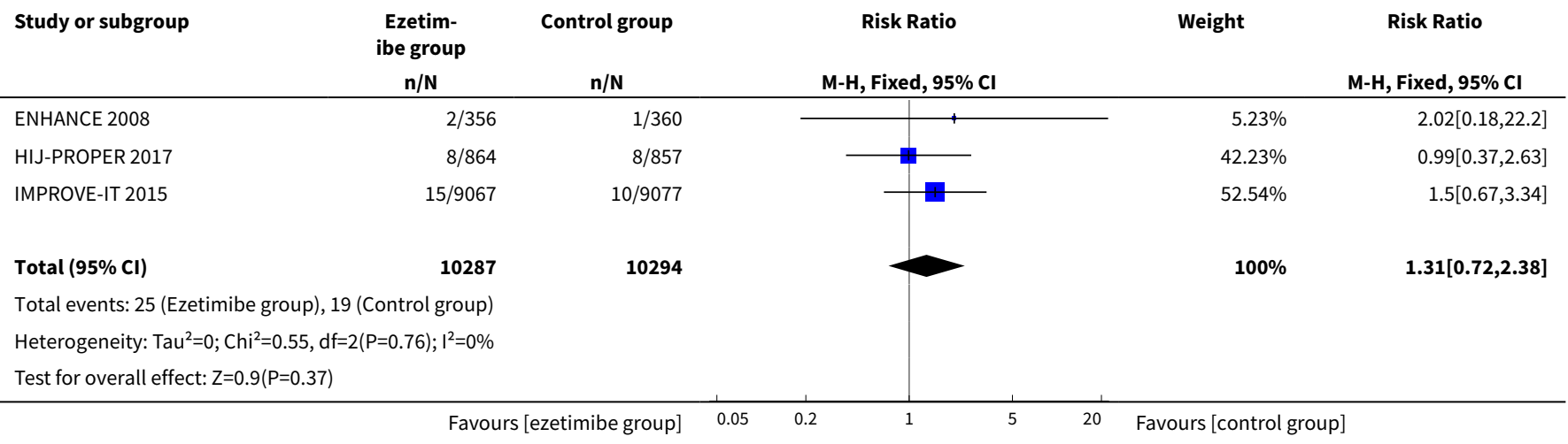

Analysis 1.26. Comparison 1 Ezetimibe plus other lipid-modifying drugs vs other lipid-modifying drugs alone or plus placebo, Outcome 26 Adverse events - myopathy (sensitivity analysis: only including low risk of bias studies).

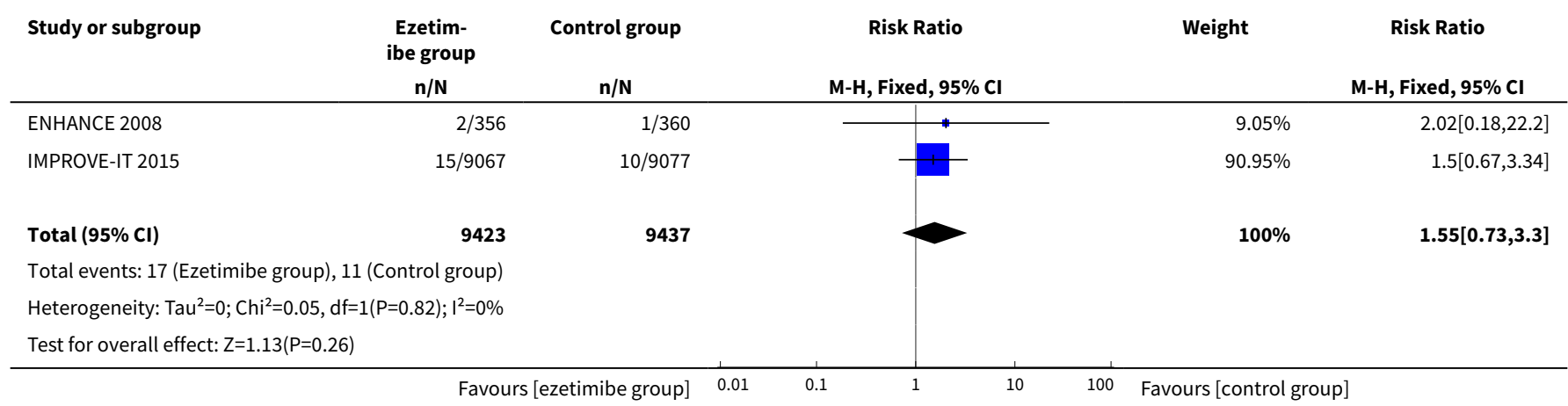


Analysis 1.27. Comparison 1 Ezetimibe plus other lipid-modifying drugs vs other lipidmodifying drugs alone or plus placebo, Outcome 27 Adverse events - rhabdomyolysis.

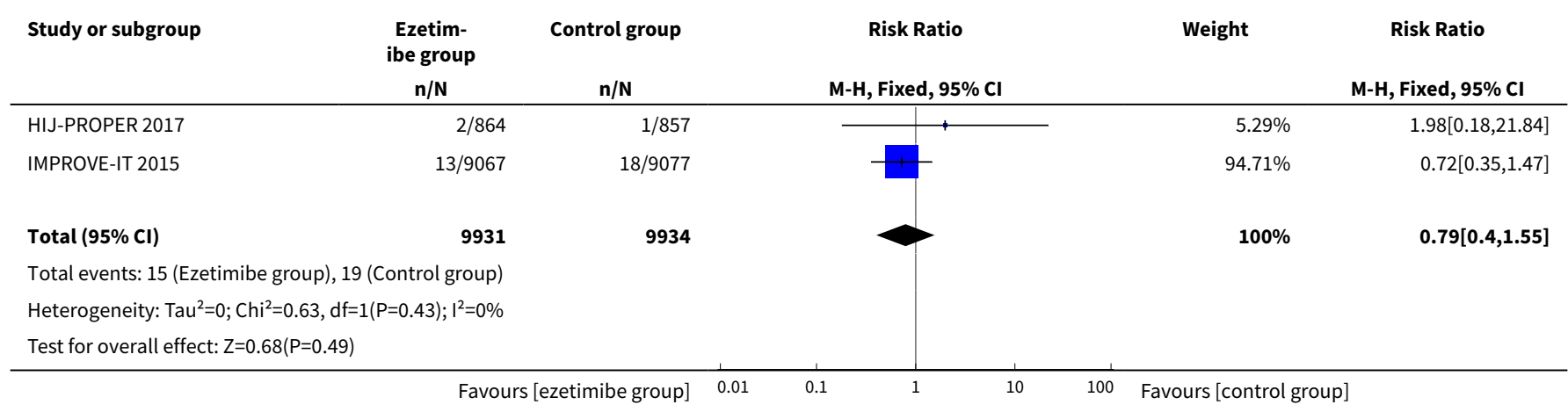

Analysis 1.28. Comparison 1 Ezetimibe plus other lipid-modifying drugs vs other lipid-modifying drugs alone or plus placebo, Outcome 28 Adverse events - rhabdomyolysis (sensitivity analysis: only including low risk of bias studies).

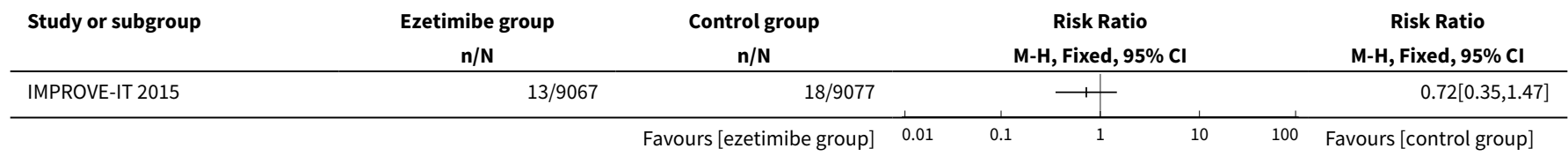

Analysis 1.29. Comparison 1 Ezetimibe plus other lipid-modifying drugs vs other lipid-modifying drugs alone or plus placebo, Outcome 29 Adverse events - cancer.

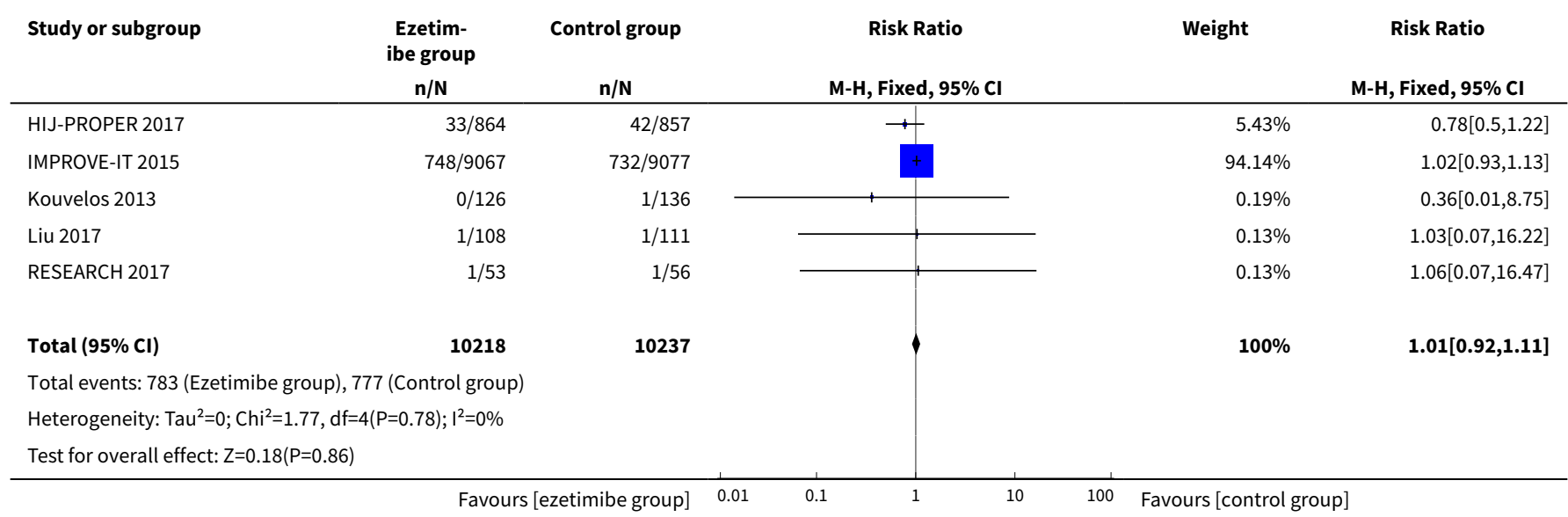


Analysis 1.30. Comparison 1 Ezetimibe plus other lipid-modifying drugs vs other lipid-modifying drugs alone or plus placebo, Outcome 30 Adverse events - cancer (sensitivity analysis: only including low risk of bias studies).

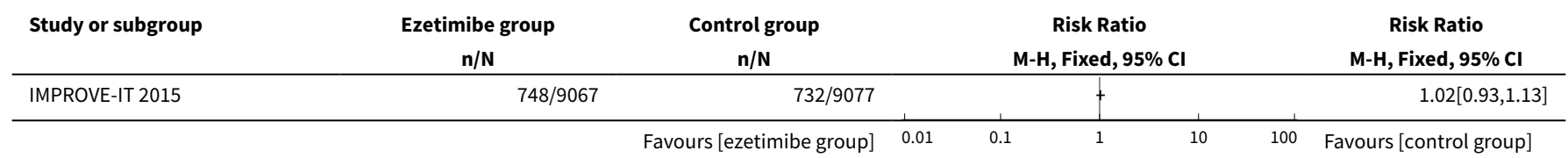

Analysis 1.31. Comparison 1 Ezetimibe plus other lipid-modifying drugs vs other lipidmodifying drugs alone or plus placebo, Outcome 31 Adverse events - cancer (sensitivity analysis: excluding the studies compared ezetimibe plus statins versus double-dose statins alone).

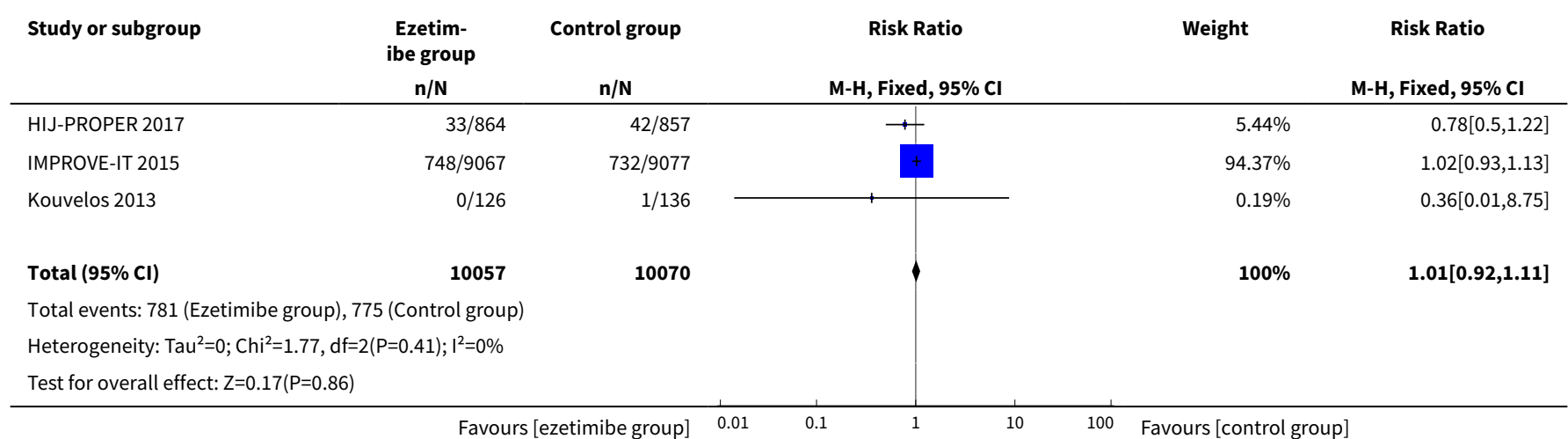

Analysis 1.32. Comparison 1 Ezetimibe plus other lipid-modifying drugs vs other lipidmodifying drugs alone or plus placebo, Outcome 32 Adverse events - gallbladder-related AE.

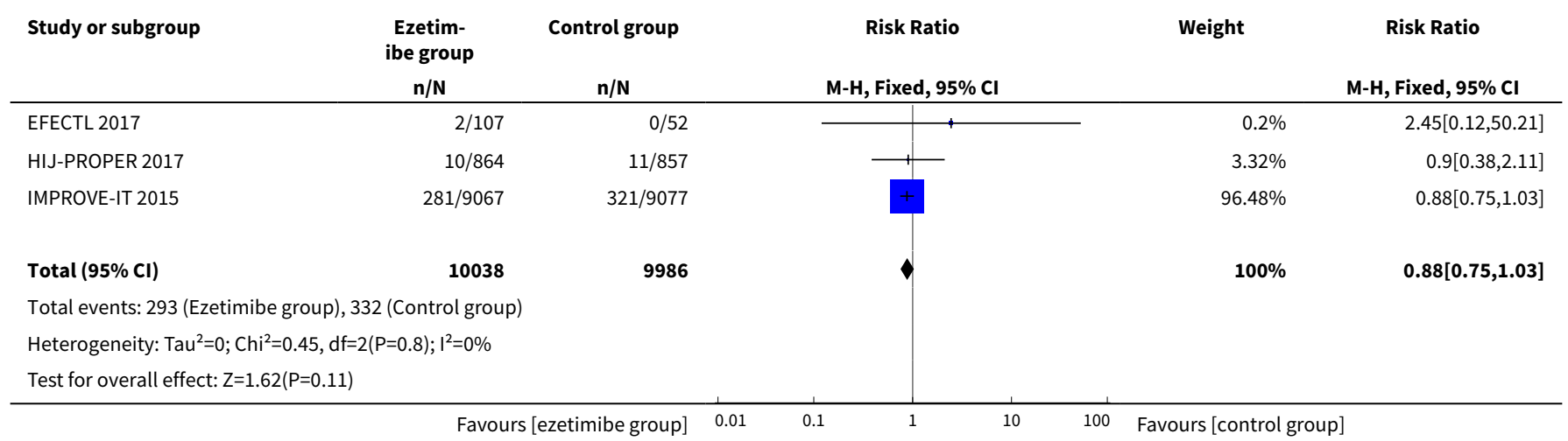


Analysis 1.33. Comparison 1 Ezetimibe plus other lipid-modifying drugs vs other lipid-modifying drugs alone or plus placebo, Outcome 33 Adverse events gallbladder-related AE (sensitivity analysis: only including low risk of bias studies).

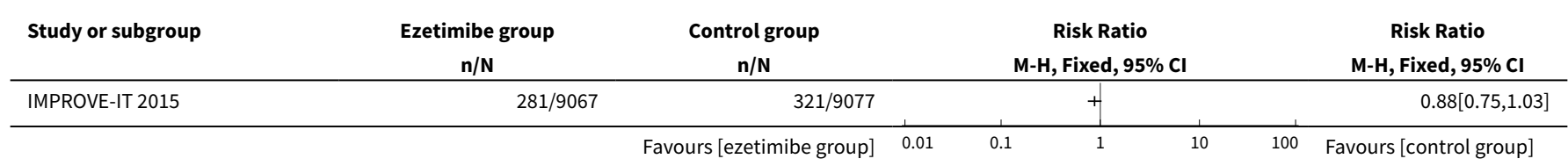

Analysis 1.34. Comparison 1 Ezetimibe plus other lipid-modifying drugs vs other lipidmodifying drugs alone or plus placebo, Outcome 34 Discontinuation due to adverse event.

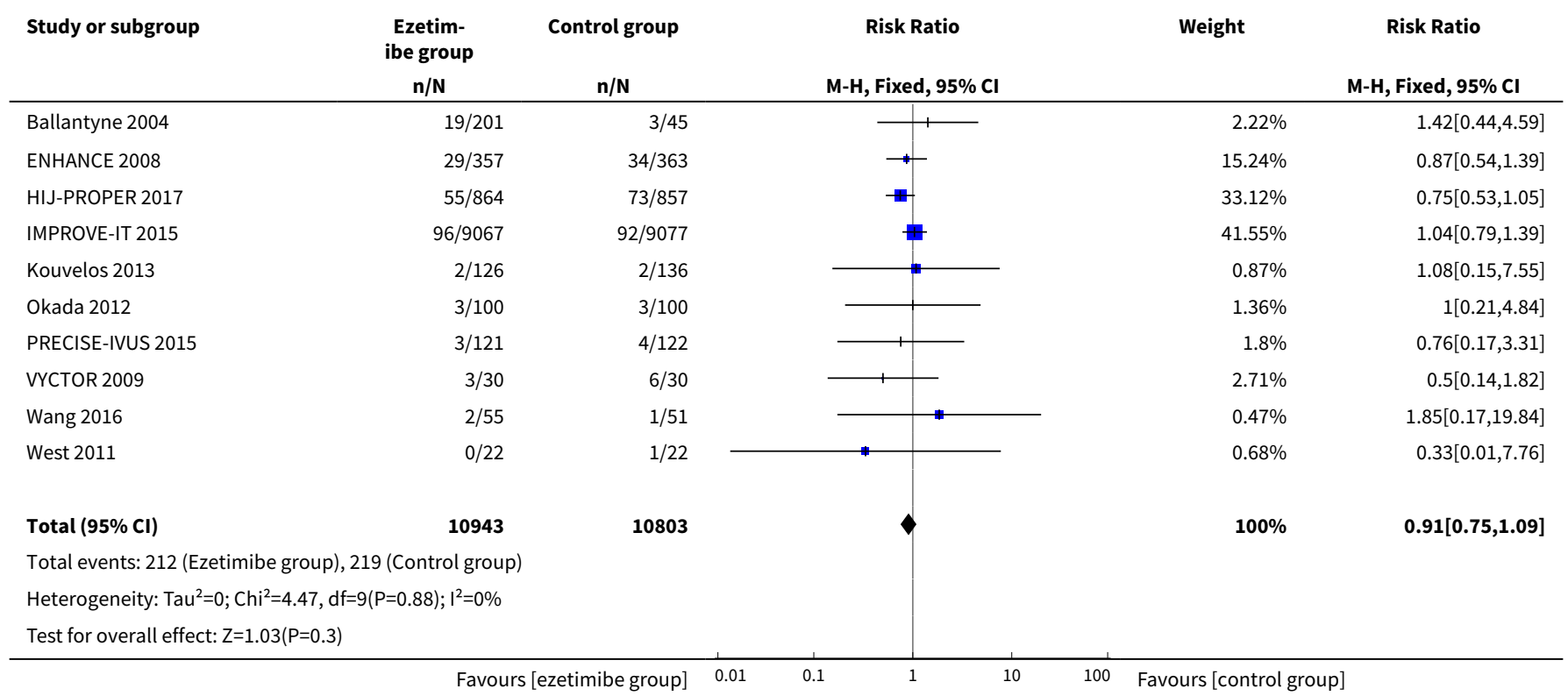

Analysis 1.35. Comparison 1 Ezetimibe plus other lipid-modifying drugs vs other lipid-modifying drugs alone or plus placebo, Outcome 35 Discontinuation due to adverse event (sensitivity analysis: only including low risk of bias studies).

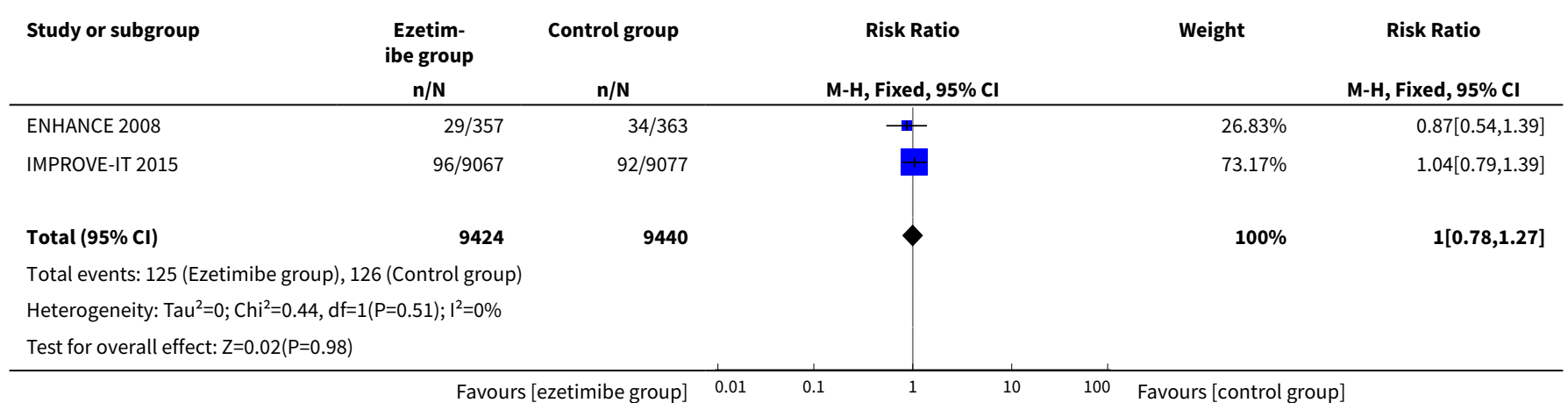


Analysis 1.36. Comparison 1 Ezetimibe plus other lipid-modifying drugs vs other lipid-modifying drugs alone or plus placebo, Outcome 36 Discontinuation due to adverse event (sensitivity analysis: excluding the studies compared ezetimibe plus statins versus double-dose statins alone).

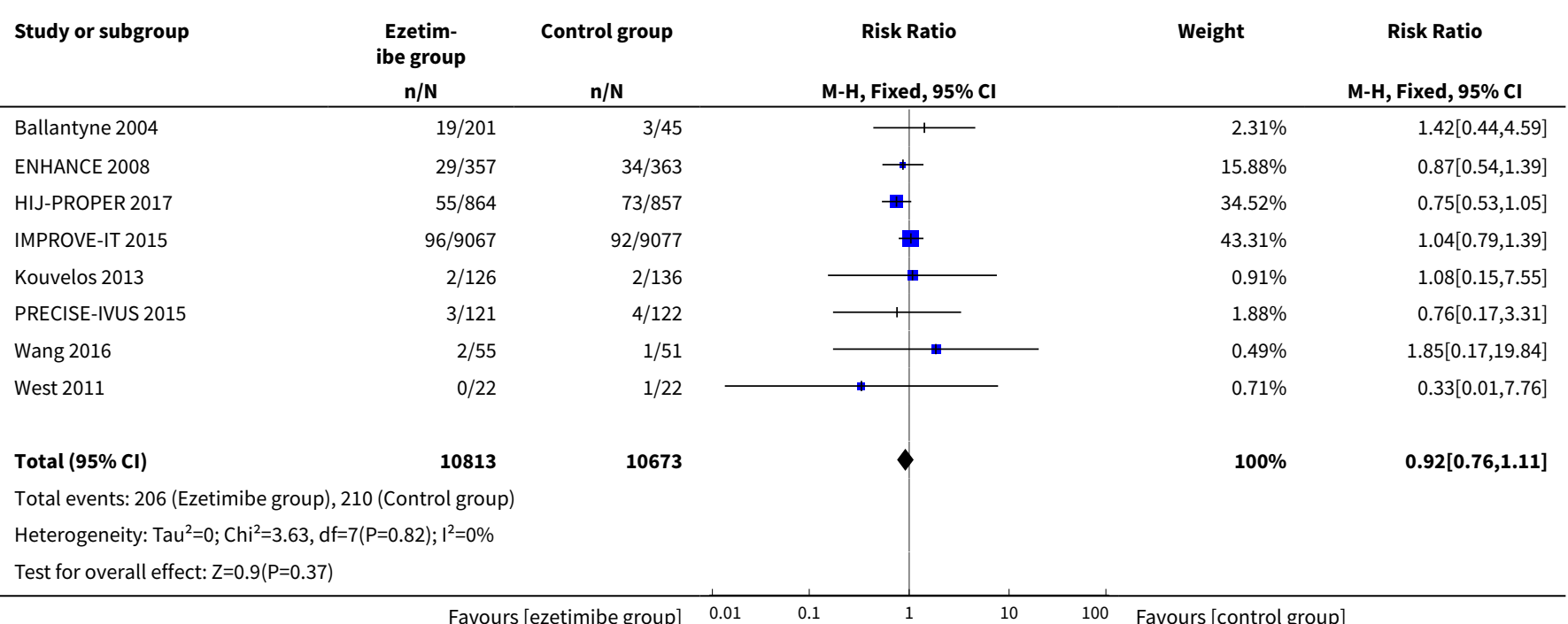

Analysis 1.37. Comparison 1 Ezetimibe plus other lipid-modifying drugs vs other lipid-modifying drugs alone or plus placebo, Outcome 37 LDL-C (end of follow up).

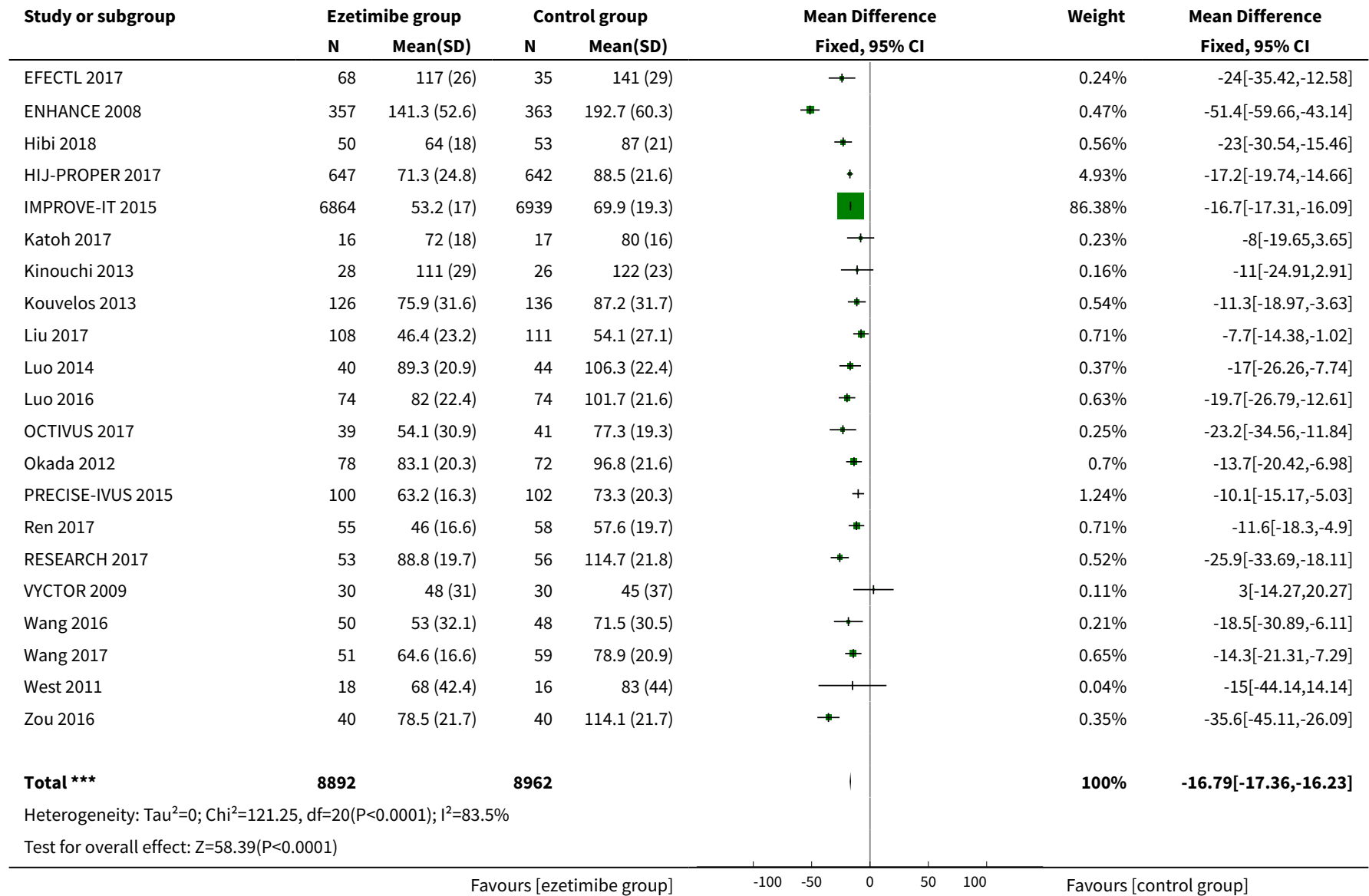


Analysis 1.38. Comparison 1 Ezetimibe plus other lipid-modifying drugs vs other lipidmodifying drugs alone or plus placebo, Outcome 38 LDL-C (end of follow up) (sensitivity analysis: excluding the studies compared ezetimibe plus statins versus double-dose statins alone).

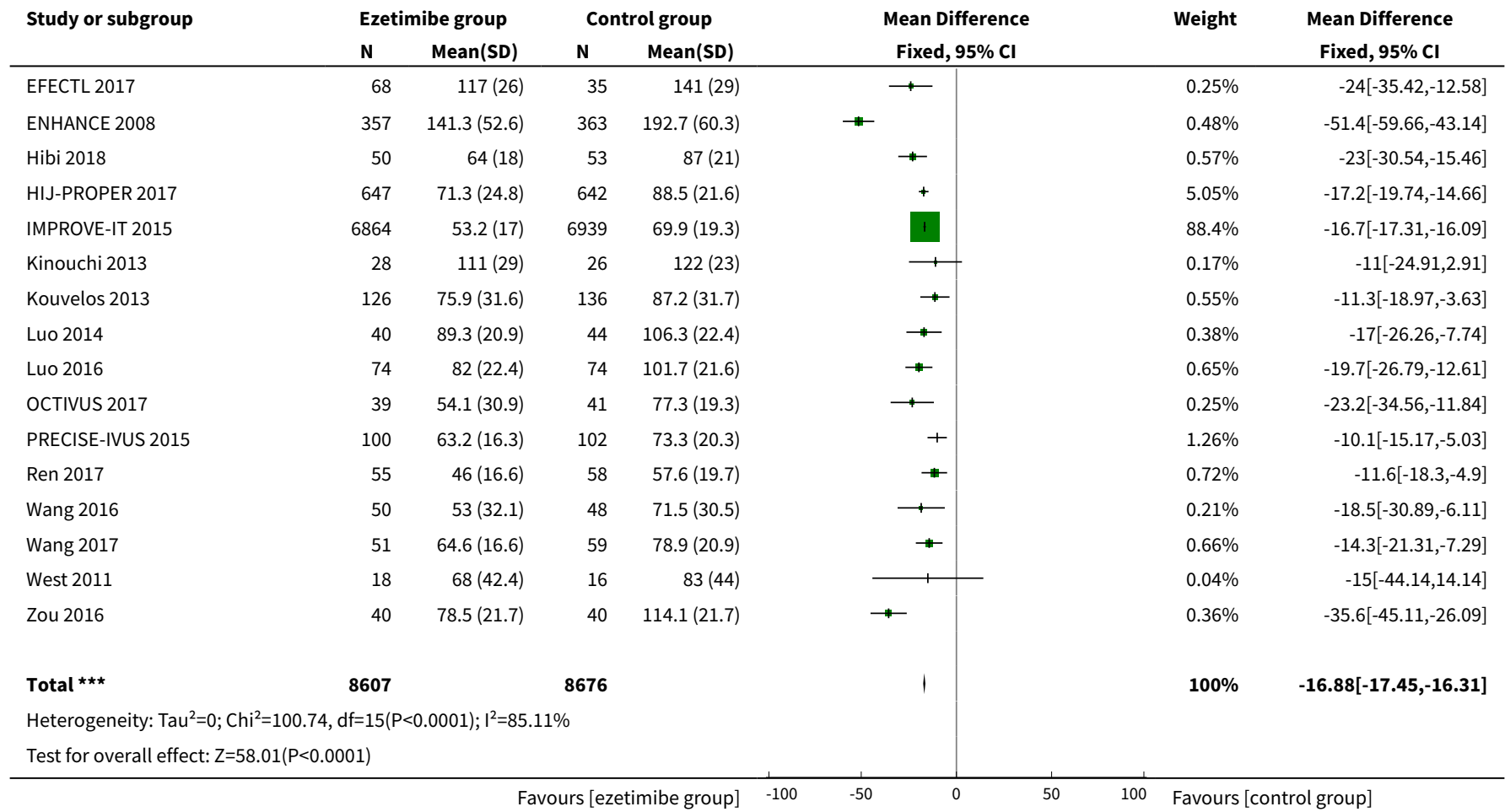

Analysis 1.39. Comparison 1 Ezetimibe plus other lipid-modifying drugs vs other lipid-modifying drugs alone or plus placebo, Outcome 39 LDL-C (end of follow up) (sensitivity analysis: excluding studies with serious missing data).

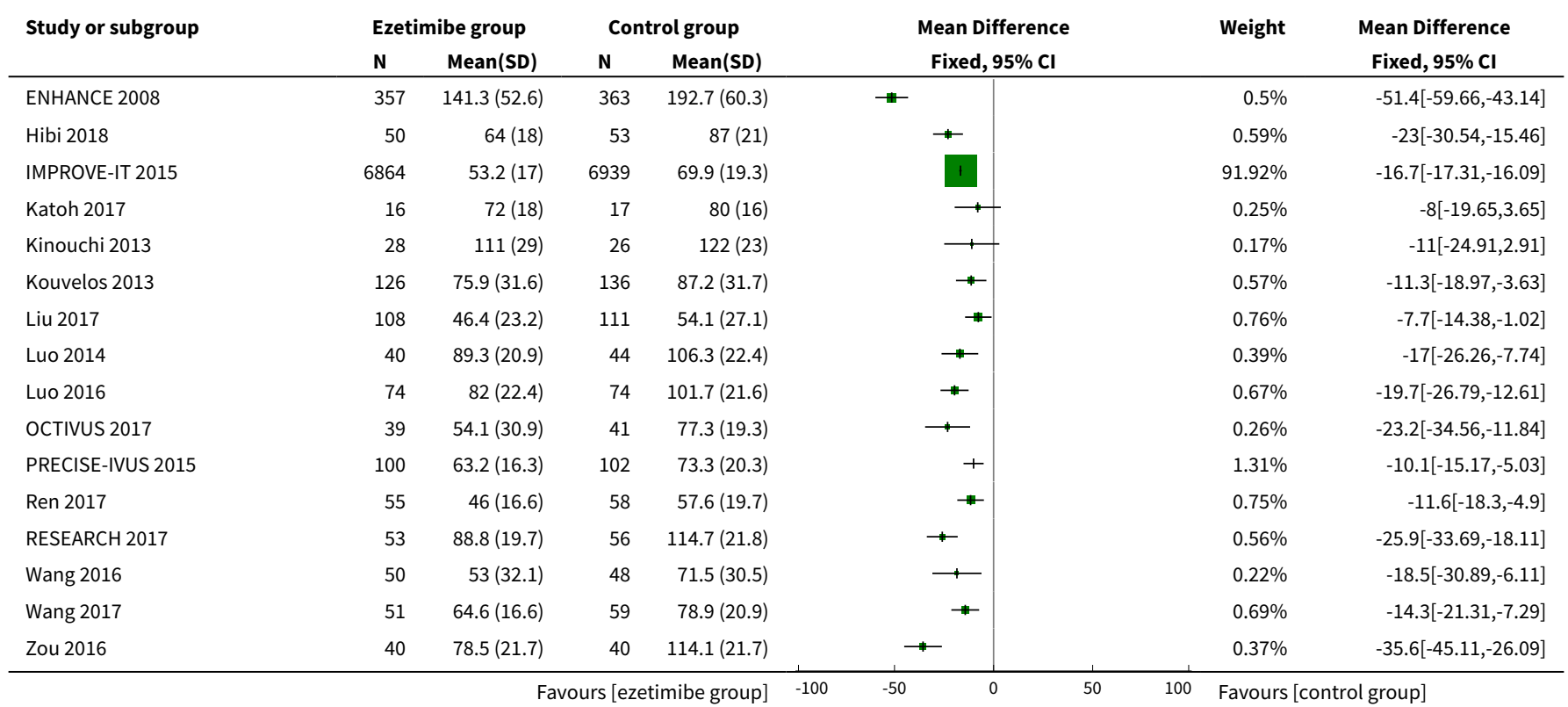




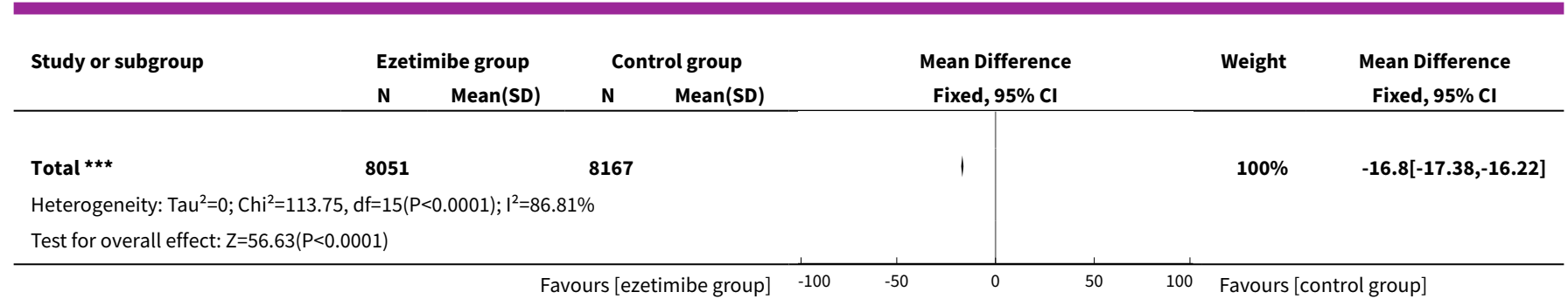

Analysis 1.40. Comparison 1 Ezetimibe plus other lipid-modifying drugs vs other lipid-modifying drugs alone or plus placebo, Outcome 40 TC (end of follow up).

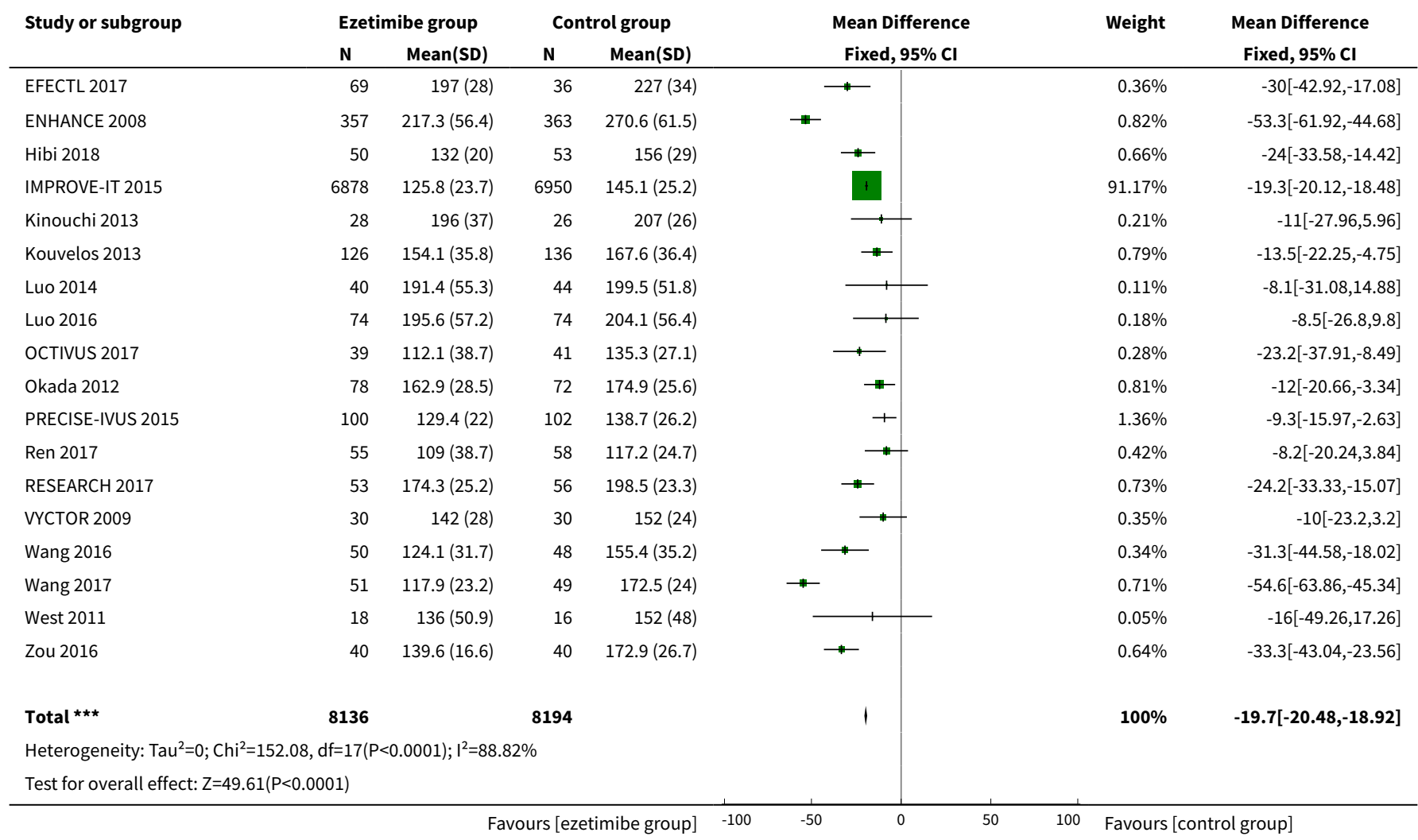

Analysis 1.41. Comparison 1 Ezetimibe plus other lipid-modifying drugs vs other lipidmodifying drugs alone or plus placebo, Outcome 41 TC (end of follow up) (sensitivity analysis: excluding the studies compared ezetimibe plus statins versus double-dose statins alone).

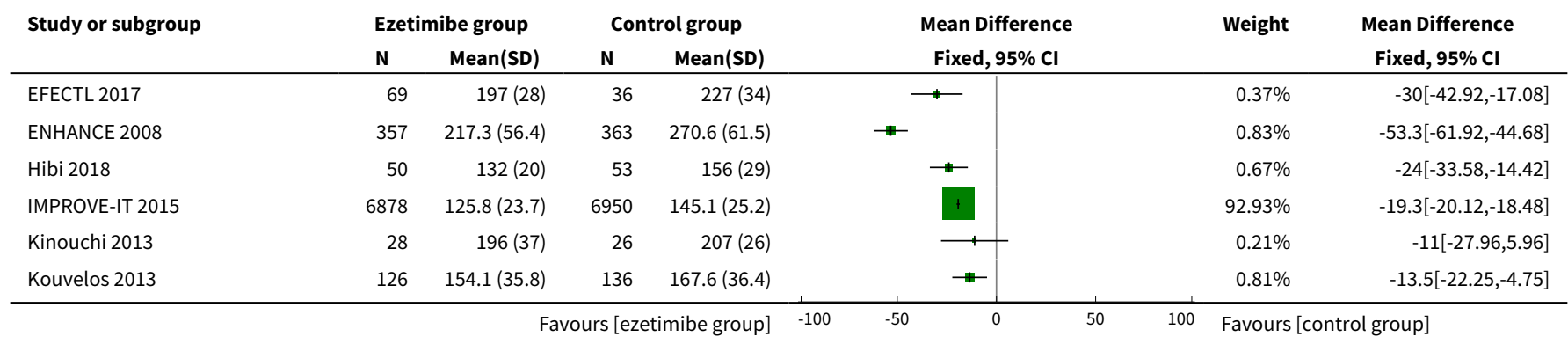




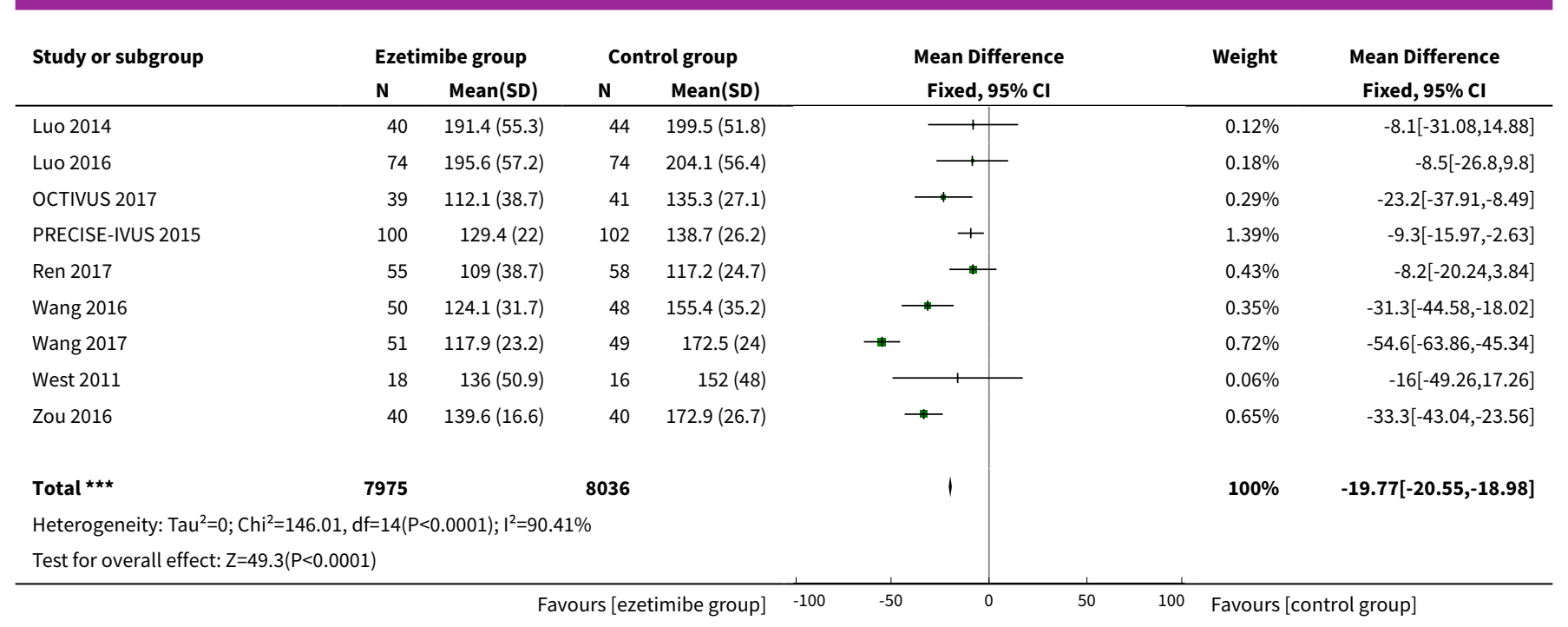

Analysis 1.42. Comparison 1 Ezetimibe plus other lipid-modifying drugs vs other lipid-modifying drugs alone or plus placebo, Outcome $42 \mathrm{TC}$ (end of follow up) (sensitivity analysis: excluding studies with serious missing data).

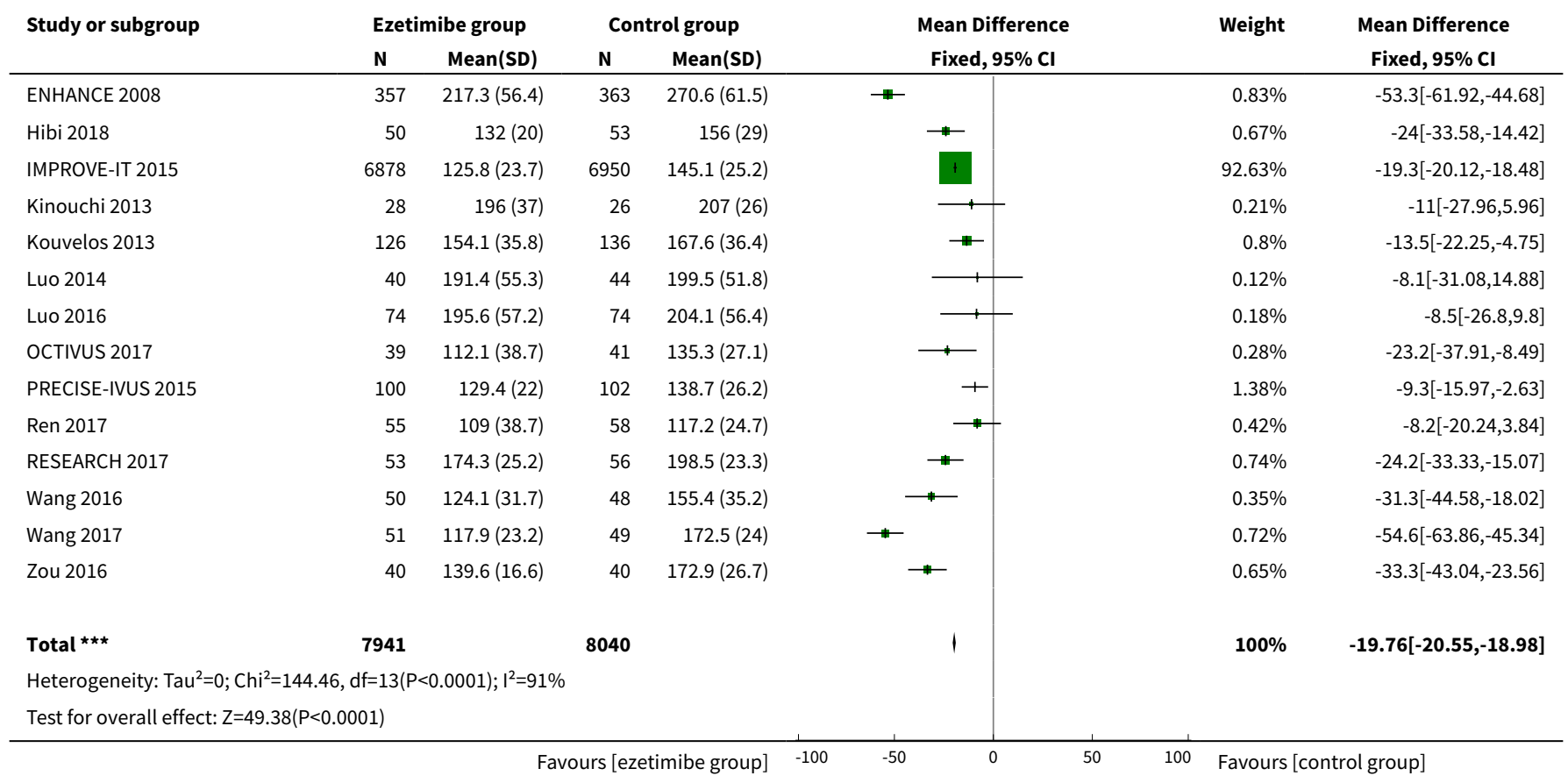

Analysis 1.43. Comparison 1 Ezetimibe plus other lipid-modifying drugs vs other lipid-modifying drugs alone or plus placebo, Outcome 43 HDL-C (end of follow up).

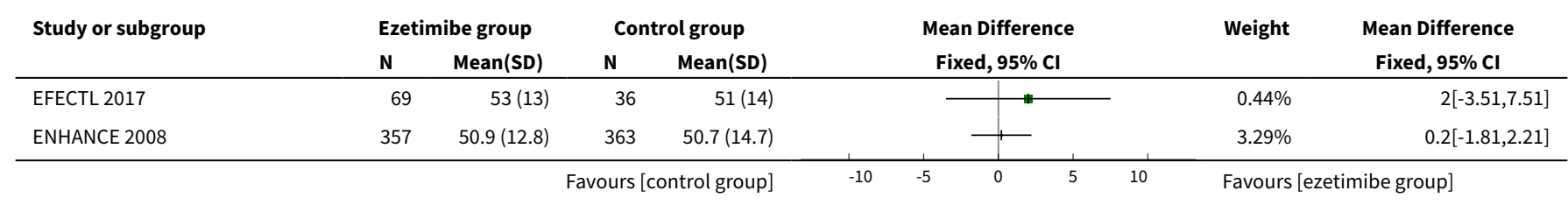




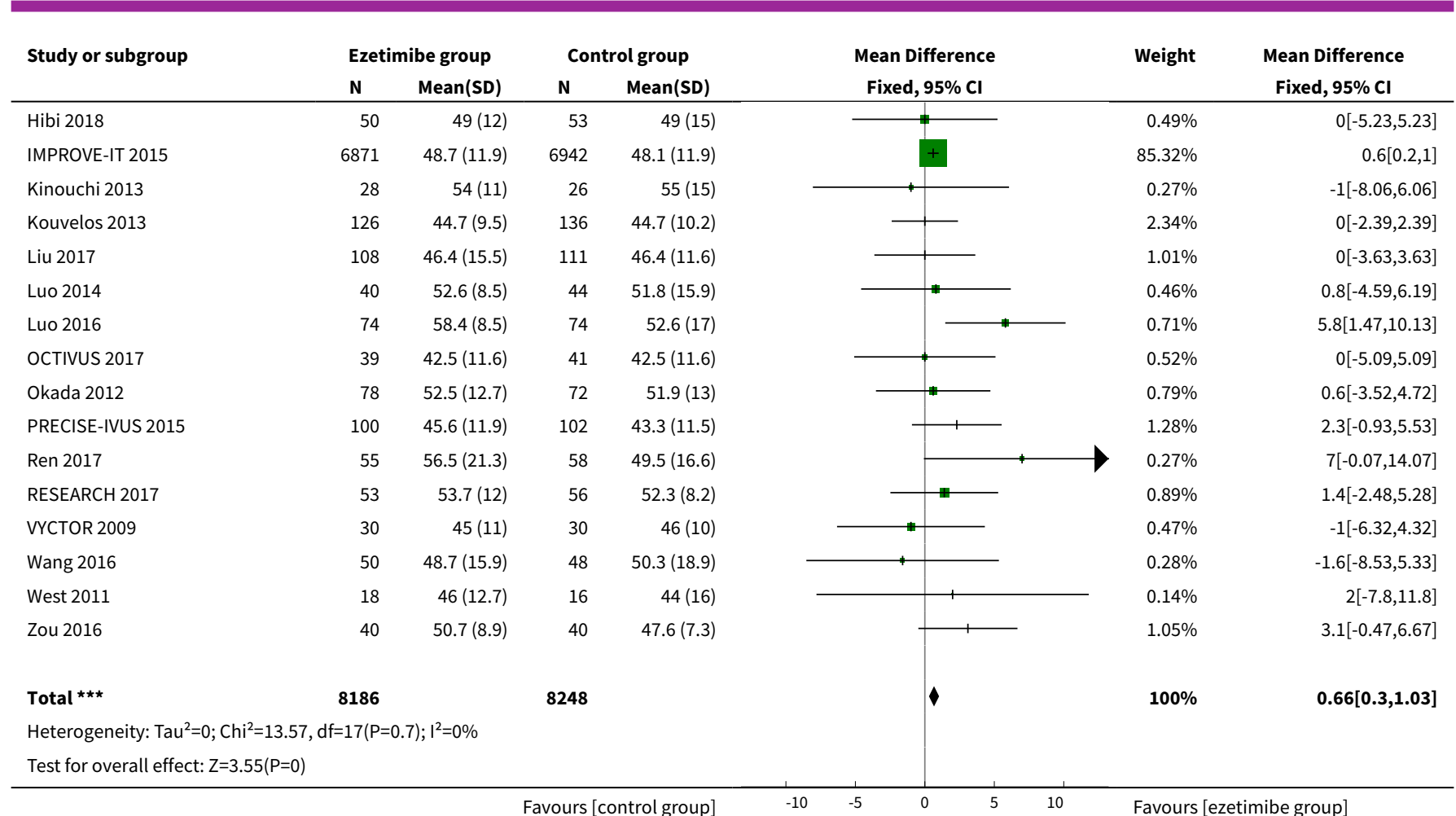

Favours [ezetimibe group]

Analysis 1.44. Comparison 1 Ezetimibe plus other lipid-modifying drugs vs other lipidmodifying drugs alone or plus placebo, Outcome $44 \mathrm{HDL}-\mathrm{C}$ (end of follow up) (sensitivity analysis: excluding the studies compared ezetimibe plus statins versus double-dose statins alone).

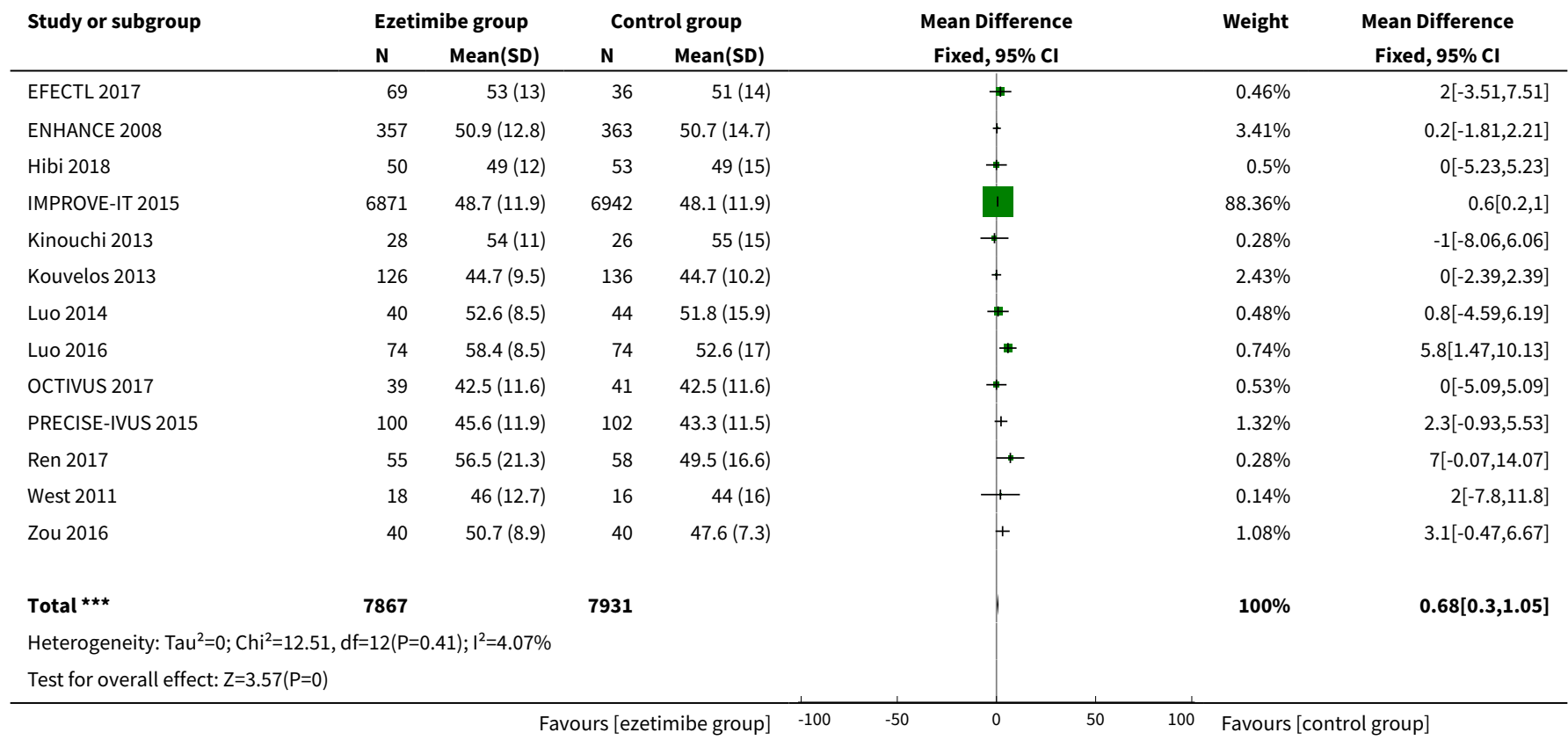


Analysis 1.45. Comparison 1 Ezetimibe plus other lipid-modifying drugs vs other lipid-modifying drugs alone or plus placebo, Outcome $45 \mathrm{HDL}-\mathrm{C}$ (end of follow up) (sensitivity analysis: excluding studies with serious missing data).

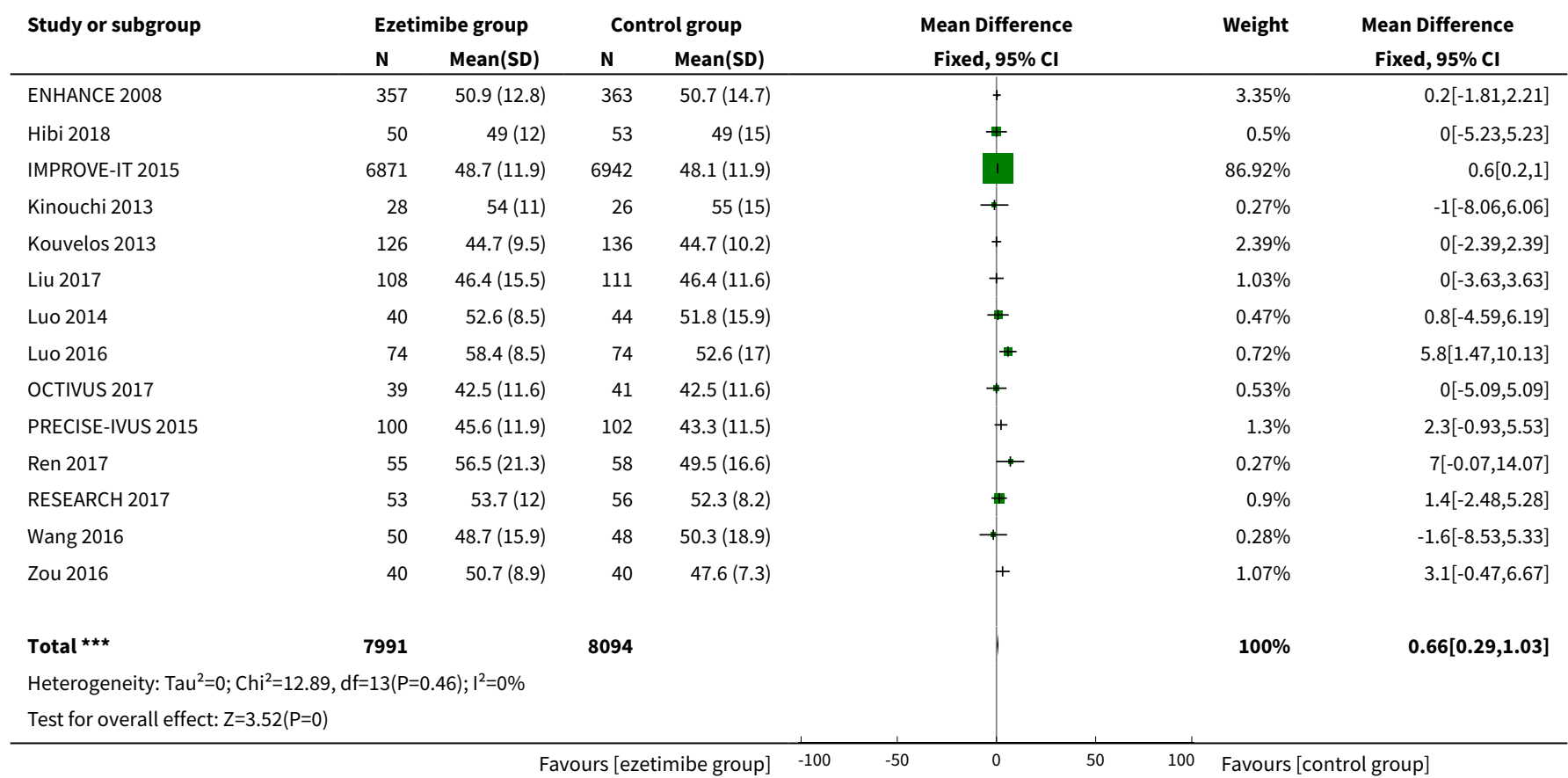

Analysis 1.46. Comparison 1 Ezetimibe plus other lipid-modifying drugs vs other lipid-modifying drugs alone or plus placebo, Outcome 46 TG (end of follow up).

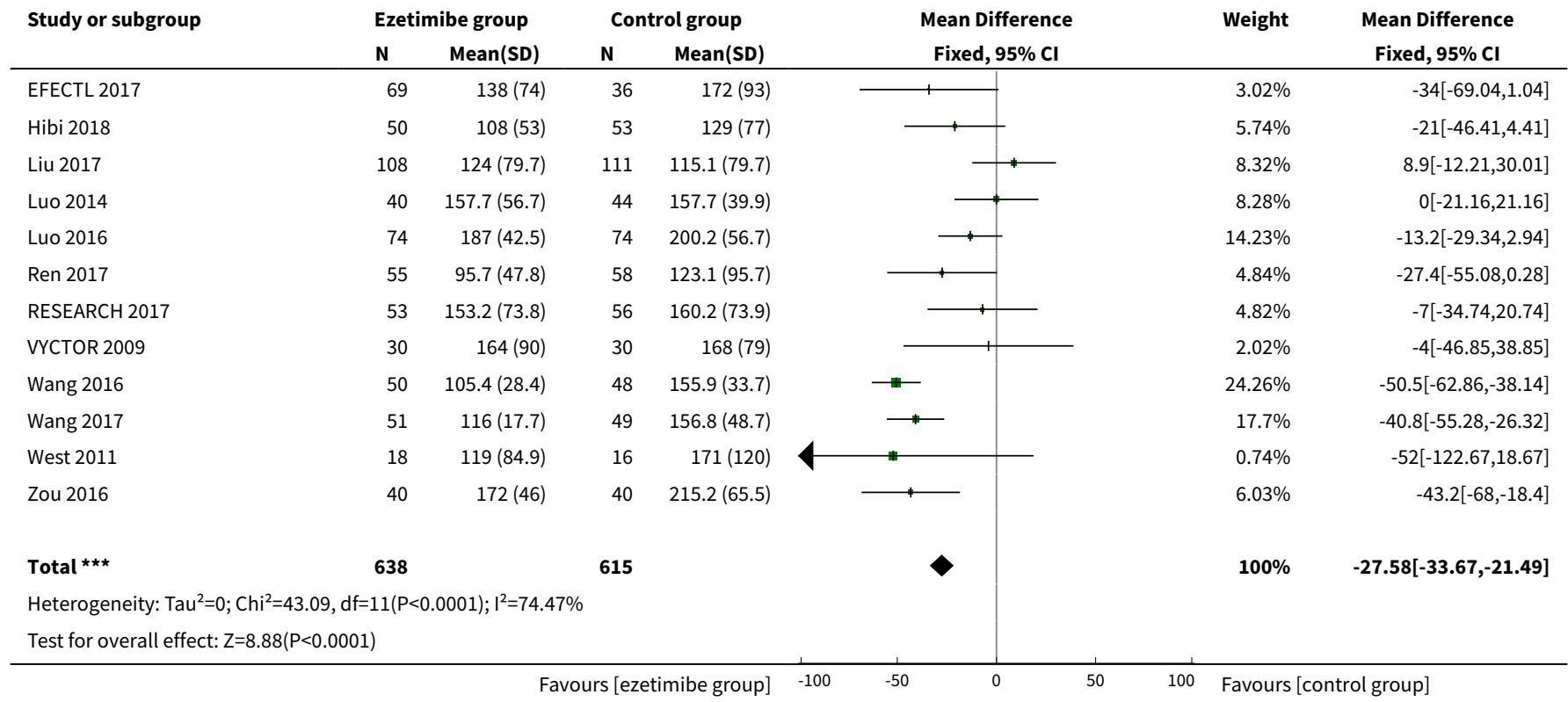


Analysis 1.47. Comparison 1 Ezetimibe plus other lipid-modifying drugs vs other lipidmodifying drugs alone or plus placebo, Outcome 47 TG (end of follow up) (sensitivity analysis: excluding the studies compared ezetimibe plus statins versus double-dose statins alone).

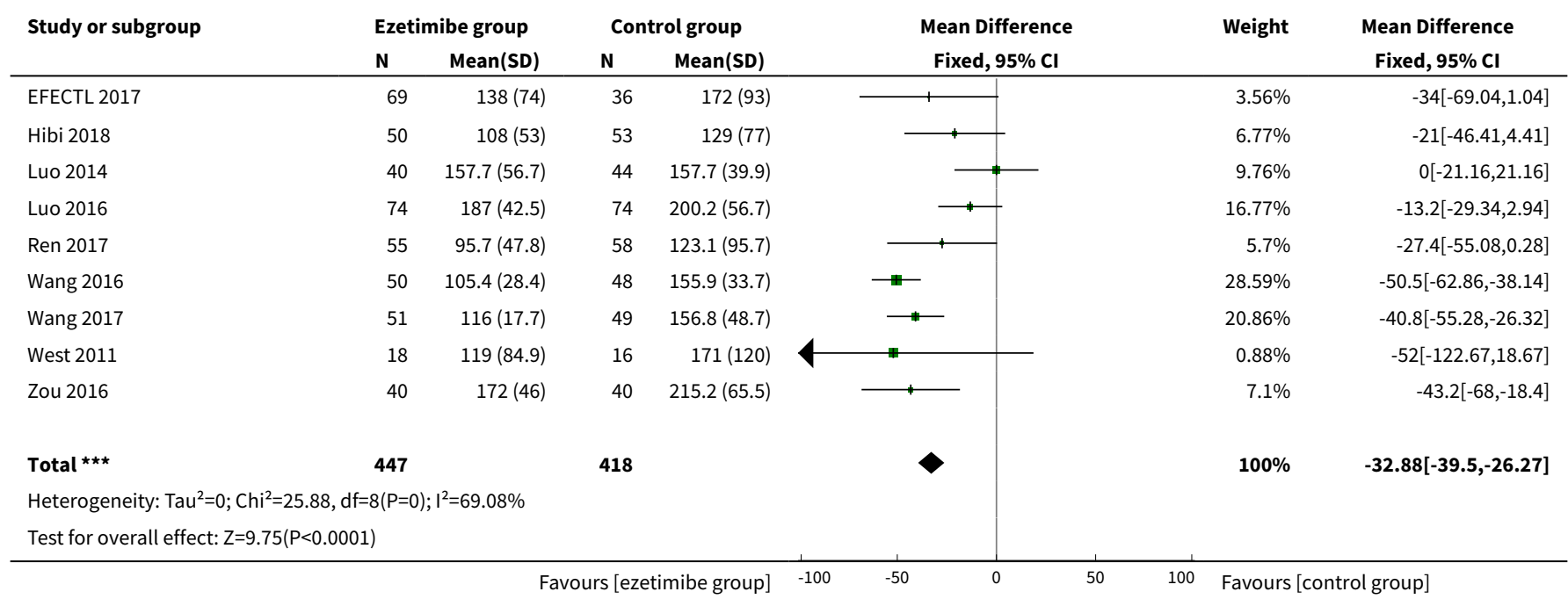

Analysis 1.48. Comparison 1 Ezetimibe plus other lipid-modifying drugs vs other lipid-modifying drugs alone or plus placebo, Outcome 48 TG (end of follow up) (sensitivity analysis: excluding studies with serious missing data).

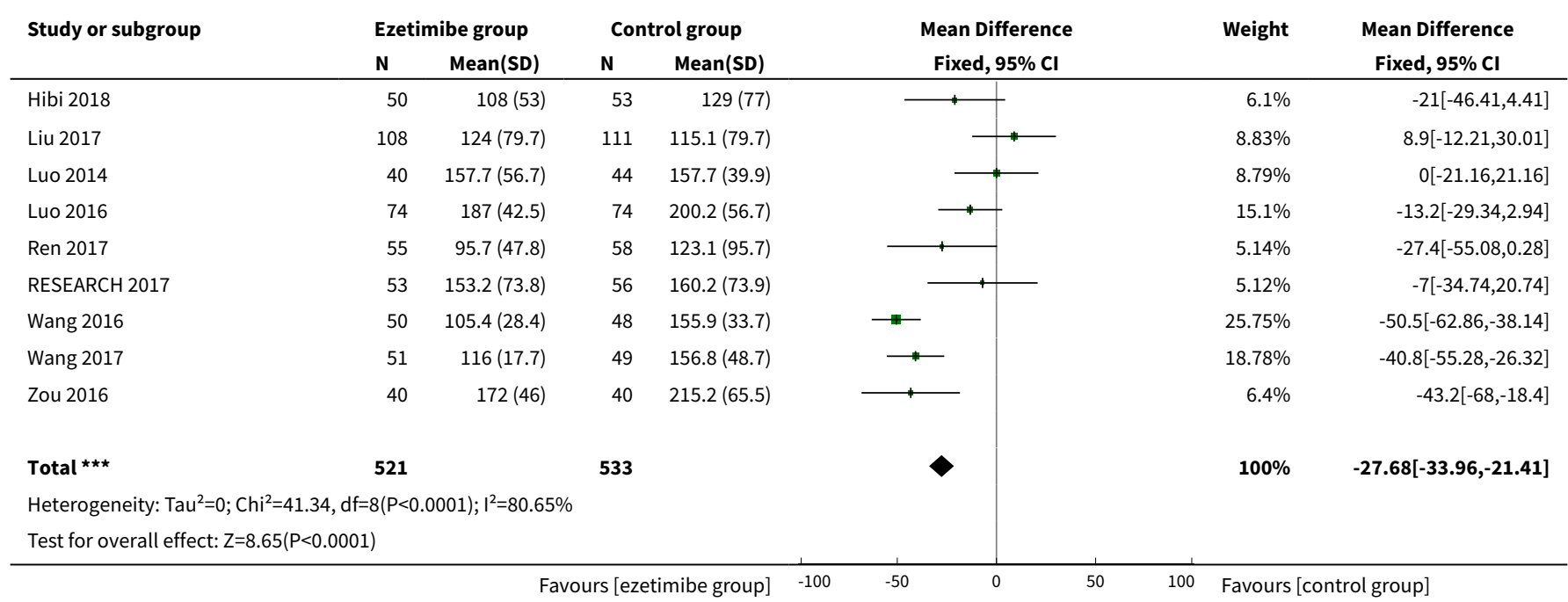




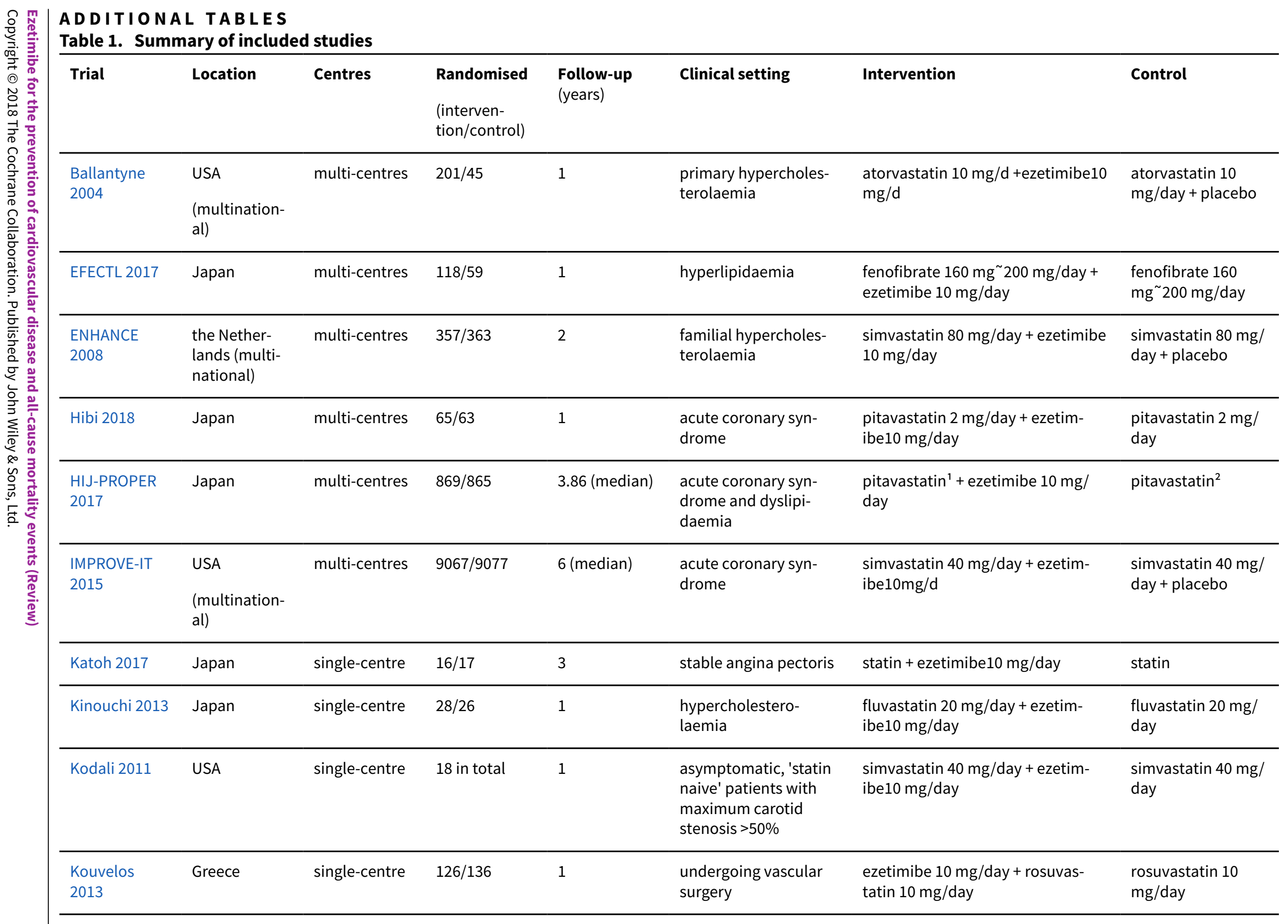




\begin{tabular}{|c|c|c|c|c|c|c|c|}
\hline Liu 2017 & China & single-centre & $114 / 116$ & 1 & $\begin{array}{l}\text { acute coronary syn- } \\
\text { drome }\end{array}$ & $\begin{array}{l}\text { atorvastatin } 10 \mathrm{mg} / \text { day + ezetim- } \\
\text { ibe10 } \mathrm{mg} / \text { day }\end{array}$ & $\begin{array}{l}\text { atorvastatin } 20 \\
\mathrm{mg} / \text { day }\end{array}$ \\
\hline Luo 2014 & China & single-centre & $44 / 40$ & 1 & $\begin{array}{l}\text { hypercholestero- } \\
\text { laemia }\end{array}$ & $\begin{array}{l}\text { atorvastatin } 20 \mathrm{mg} / \text { day + ezetim- } \\
\text { ibe } 10 \mathrm{mg} / \text { day }\end{array}$ & $\begin{array}{l}\text { atorvastatin } 20 \\
\mathrm{mg} / \text { day }\end{array}$ \\
\hline Luo 2016 & China & single-centre & $74 / 74$ & 1 & coronary heart disease & $\begin{array}{l}\text { atorvastatin } 20 \mathrm{mg} / \text { day + ezetim- } \\
\text { ibe10 mg/day }\end{array}$ & $\begin{array}{l}\text { atorvastatin } 20 \\
\mathrm{mg} / \text { day }\end{array}$ \\
\hline OCTIVUS 2017 & Danish & single-centre & $43 / 44$ & 1 & $\begin{array}{l}\text { ST-segment elevation } \\
\text { myocardial infarction }\end{array}$ & $\begin{array}{l}\text { atorvastatin } 80 \mathrm{mg} / \text { day + ezetim- } \\
\text { ibe10 mg/day }\end{array}$ & $\begin{array}{l}\text { atorvastatin } 80 \\
\mathrm{mg} / \text { day }+ \text { placebo }\end{array}$ \\
\hline Okada 2012 & Japan & multi-centres & $100 / 100$ & 1 & coronary heart disease & $\begin{array}{l}\text { statin (atorvastatin } 10 \mathrm{mg} / \text { day or } \\
\text { rosuvastatin } 2.5 \mathrm{mg} / \text { day) + ezetim- } \\
\text { ibe } 10 \mathrm{mg} / \text { day }\end{array}$ & $\begin{array}{l}\text { statin(atorvastatin } \\
20 \mathrm{mg} / \text { day or rosu- } \\
\text { vastatin } 5 \mathrm{mg} / \text { day ) }\end{array}$ \\
\hline Ren 2017 & China & single-centre & $55 / 58$ & 1 & $\begin{array}{l}\text { acute myocardial in- } \\
\text { farction }\end{array}$ & $\begin{array}{l}\text { rosuvastatin } 10 \mathrm{mg} / \text { day + ezetim- } \\
\text { ibe } 10 \mathrm{mg} / \text { day }\end{array}$ & $\begin{array}{l}\text { rosuvastatin } 10 \\
\mathrm{mg} / \text { day }\end{array}$ \\
\hline $\begin{array}{l}\text { RESEARCH } \\
2017\end{array}$ & Japan & multi-centres & $53 / 56$ & 1 & $\begin{array}{l}\text { hypercholestero- } \\
\text { laemia }\end{array}$ & $\begin{array}{l}\text { statin (atorvastatin } 10 \mathrm{mg} / \text { day or } \\
\text { pitavastatin } 1 \mathrm{mg} / \text { day ) + ezetimibe } \\
10 \mathrm{mg} / \text { day }\end{array}$ & $\begin{array}{l}\text { statin(atorvas- } \\
\text { tatin } 20 \mathrm{mg} / \text { day or } \\
\text { pitavastatin } 2 \mathrm{mg} / \\
\text { day ) }\end{array}$ \\
\hline $\begin{array}{l}\text { PRECISE-IVUS } \\
2015\end{array}$ & Japan & multi-centres & $122 / 124$ & 1 & $\begin{array}{l}\text { Hypercholesterolemia } \\
\text { and Coronary Artery } \\
\text { Disease }\end{array}$ & $\begin{array}{l}\text { atorvastatin }{ }^{3}+\text { ezetimibe } 10 \mathrm{mg} / \\
\text { day }\end{array}$ & atorvastatin ${ }^{3}$ \\
\hline $\begin{array}{l}\text { Sawayama } \\
2011\end{array}$ & Japan & single-centre & 60 in total & 1.2 (mean) & $\begin{array}{l}\text { hypercholestero- } \\
\text { laemia }\end{array}$ & $\begin{array}{l}\text { pravastatin } 5 \mathrm{mg} / \text { day + ezetim- } \\
\text { ibe10 } \mathrm{mg} / \text { day }\end{array}$ & pravastatin $10 \mathrm{mg}$ \\
\hline Suzuki 2013 & Japan & multi-centres & $148 / 148$ & 1 & chronic kidney disease & statin $^{4}+$ ezetimibe $10 \mathrm{mg} /$ day & statin $^{4}$ \\
\hline VYCTOR 2009 & Mexico & single-centre & $30 / 30$ & 1 & $\begin{array}{l}\text { high risk patiens of } \\
\text { coronary artery dis- } \\
\text { ease }\end{array}$ & $\begin{array}{l}\text { simvastatin } 20 \mathrm{mg} / \text { day + ezetim- } \\
\text { ibe10 mg/day }\end{array}$ & $\begin{array}{l}\text { simvastatin } 40 \mathrm{mg} / \\
\text { day }\end{array}$ \\
\hline Wang 2016 & China & single-centre & $55 / 51$ & 1 & $\begin{array}{l}\text { coronary atheroscle- } \\
\text { rotic heart disease and } \\
\text { hyperlipidaemia }\end{array}$ & $\begin{array}{l}\text { ezetimibe } 10 \mathrm{mg} / \text { day + rosuvas- } \\
\text { tatin } 10 \mathrm{mg} / \text { day }\end{array}$ & $\begin{array}{l}\text { rosuvastatin } 10 \\
\mathrm{mg} / \text { day }\end{array}$ \\
\hline Wang 2017 & China & single-centre & $51 / 49$ & 1 & coronary heart disease & $\begin{array}{l}\text { atorvastatin } 20 \mathrm{mg} / \text { day + ezetim- } \\
\text { ibe10 } \mathrm{mg} / \text { day }\end{array}$ & $\begin{array}{l}\text { atorvastatin } 20 \\
\mathrm{mg} / \text { day }\end{array}$ \\
\hline
\end{tabular}




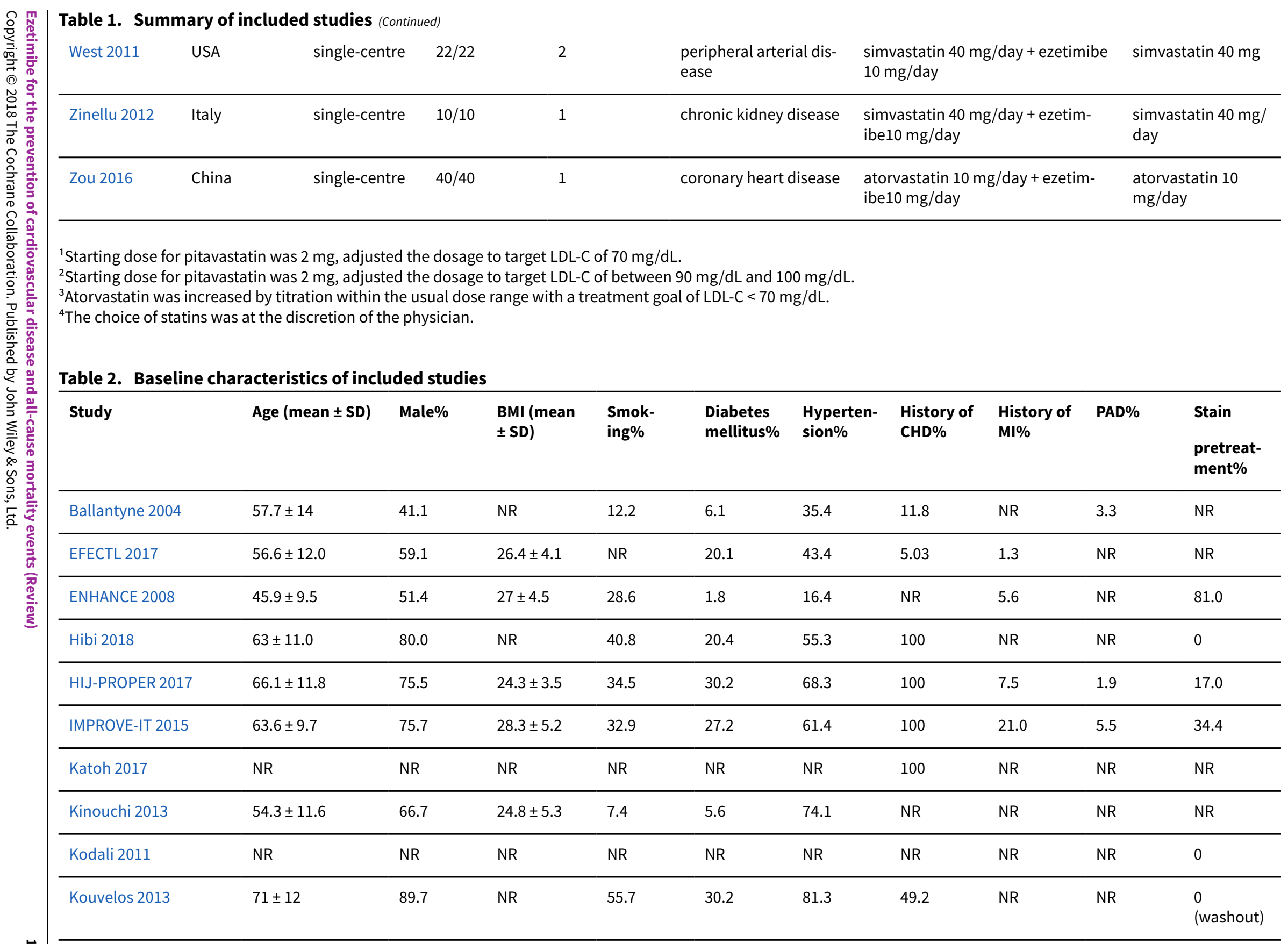

2Starting dose for pitavastatin was $2 \mathrm{mg}$ adjusted the dosage to target LDL-C of between $90 \mathrm{mg} / \mathrm{dL}$ and $100 \mathrm{mg} / \mathrm{dL}$.

${ }^{3}$ Atorvastatin was increased by titration within the usual dose range with a treatment goal of LDL-C $<70 \mathrm{mg} / \mathrm{dL}$.

Table 2. Baseline characteristics of included studies 


\begin{tabular}{|c|c|c|c|c|c|c|c|c|c|c|}
\hline Liu 2017 & $84.1 \pm 2.4$ & 51.7 & $24.5 \pm 3.7$ & 12.6 & 38.3 & 70 & 100 & 17.0 & NR & NR \\
\hline Luo 2014 & $66 . \pm 76.1$ & 52.4 & $24.6 \pm 4.5$ & NR & 33.3 & NR & 83.3 & NR & NR & NR \\
\hline Luo 2016 & $61.2 \pm 12.6$ & 56.8 & $25.0 \pm 5.1$ & 37.8 & 43.2 & 50 & 100 & NR & NR & NR \\
\hline OCTIVUS 2017 & $56.3 \pm 10.1$ & 86.2 & $27.3 / 27.4$ & 55.2 & 2.3 & 17.2 & 100 & 0 & NR & 0 \\
\hline Okada 2012 & $65.8 \pm 9.4$ & 73.3 & $25.2 \pm 3.4$ & $34.0 \%$ & 51.3 & 76.0 & 100 & 58.0 & 3.3 & 100 \\
\hline Ren 2017 & $59.0 \pm 2.2$ & 83.2 & NR & 68.1 & 17.7 & 58.4 & 100 & 2.7 & NR & 9.7 \\
\hline RESEARCH 2017 & $62.2 \pm 10.7$ & 57.8 & NR & 23.9 & 100 & NR & 12.8 & NR & NR & 100 \\
\hline PRECISE-IVUS 2015 & $66.5 \pm 10.0$ & 78.2 & $24.9 \pm 3.2$ & 25.7 & 29.7 & 70.3 & 100 & 13.9 & 3.5 & 47 \\
\hline Sawayama 2011 & NR & NR & NR & NR & NR & NR & NR & NR & NR & 100 \\
\hline Suzuki 2013 & $64 \pm 12$ & 66.4 & $25.5 \pm 1.8$ & 40.2 & 35.0 & 84.9 & 2.8 & 0 & 4.2 & 100 \\
\hline VYCTOR 2009 & $57.5 \pm 8.5$ & 51.7 & $29 \pm 5.1$ & NR & 31.7 & NR & NR & NR & NR & NR \\
\hline Wang 2016 & $64.0 \pm 11.0$ & 72.4 & NR & 61.2 & 35.7 & 50.0 & 56.1 & NR & NR & NR \\
\hline Wang 2017 & $58 \pm 9.5$ & 61.0 & NR & 52.0 & 100 & 66.0 & 100 & NR & NR & 100 \\
\hline West 2011 & $60.6 \pm 9.0$ & 61.8 & $28.9 \pm 6.5$ & 61.8 & 29.4 & 79.4 & 52.9 & NR & 100 & 23.5 \\
\hline Zinellu 2012 & $61 \pm 10.0$ & 40.0 & NR & NR & NR & NR & NR & NR & NR & NR \\
\hline Zou 2016 & $69.8 \pm 6.5$ & NR & NR & NR & NR & NR & 100 & NR & NR & NR \\
\hline
\end{tabular}

BMI: body mass index; CHD: coronary heart disease; MI: myocardial infarction; NR: not reported; PAD: peripheral arterial disease; SD: standard deviation.

Table 3. Summary of changes in lipid parameters

\begin{tabular}{|c|c|c|c|c|c|c|c|c|c|c|c|c|}
\hline \multirow[t]{2}{*}{ Trial } & \multirow{2}{*}{$\begin{array}{l}\text { Inter- } \\
\text { vetion } \\
\text { or con- } \\
\text { trol }\end{array}$} & \multicolumn{2}{|c|}{ LDL-C (mean $\pm \mathrm{SD}, \mathrm{mg} / \mathrm{dL}$} & \multicolumn{2}{|c|}{$\mathrm{TC}($ mean $\pm \mathrm{SD}, \mathrm{mg} / \mathrm{dL})$} & \multicolumn{4}{|c|}{ HDL-C (mean \pm SD, mg/dL } & \multicolumn{3}{|c|}{ TG $($ mean $\pm S D, m g / d L)$} \\
\hline & & baseline & end & $\begin{array}{l}\text { \%change baseline } \\
\text { from }\end{array}$ & end & $\begin{array}{l}\text { \%change } \\
\text { from }\end{array}$ & $\begin{array}{l}\text { base- } \\
\text { line }\end{array}$ & end & $\begin{array}{l}\% \text { cha } \\
\text { from }\end{array}$ & baseline & end & $\begin{array}{l}\text { \%change } \\
\text { from }\end{array}$ \\
\hline
\end{tabular}




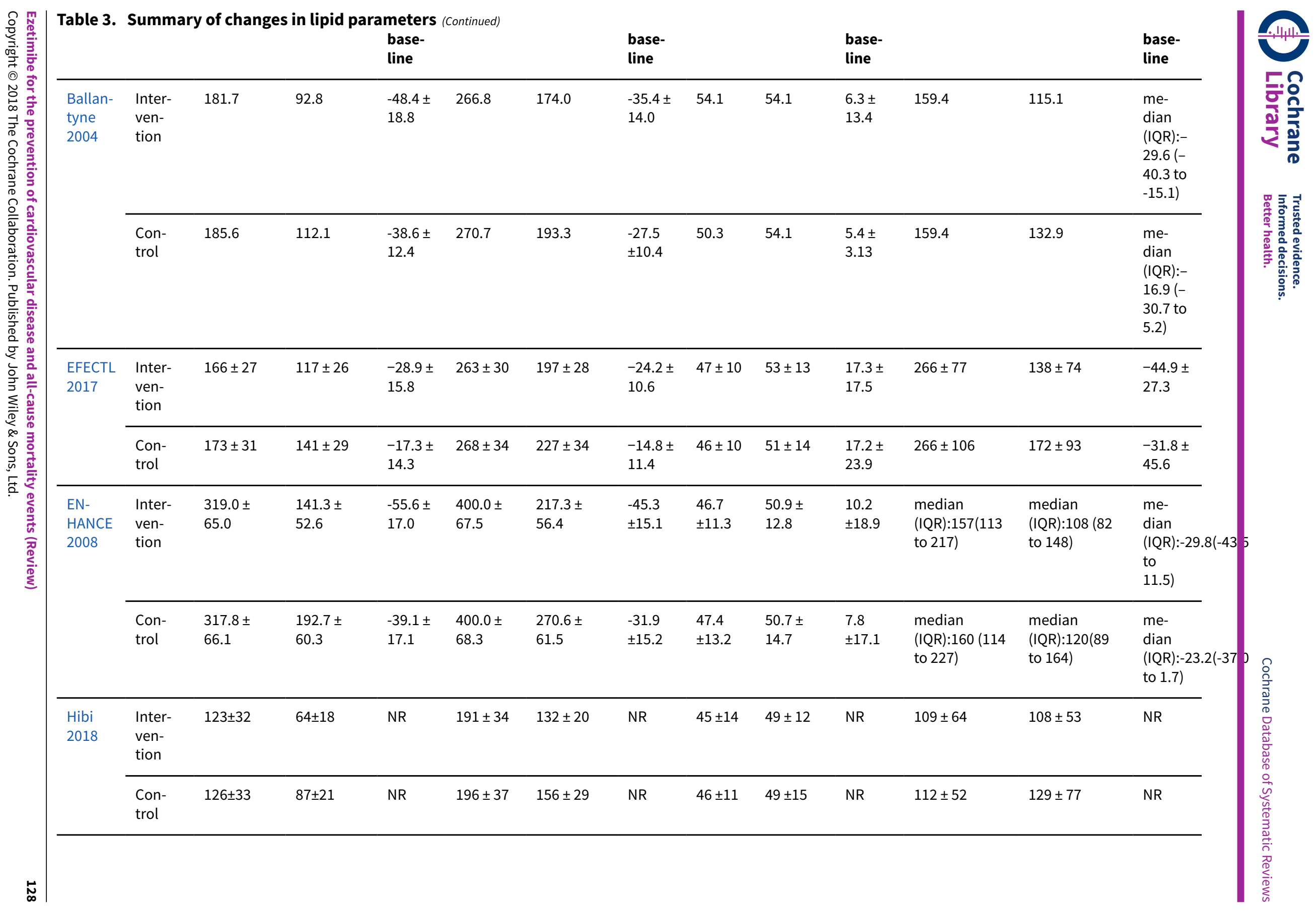




\begin{tabular}{|c|c|c|c|c|c|c|c|c|c|c|c|c|c|}
\hline \multirow[t]{2}{*}{$\begin{array}{l}\text { HIJ- } \\
\text { PROP- } \\
\text { ER } \\
2017\end{array}$} & $\begin{array}{l}\text { Inter- } \\
\text { ven- } \\
\text { tion }\end{array}$ & $\begin{array}{l}134.8 \pm \\
29.3\end{array}$ & $71.3 \pm 24.8$ & NR & NR & NR & NR & NR & NR & NR & NR & NR & NR \\
\hline & $\begin{array}{l}\text { Con- } \\
\text { trol }\end{array}$ & $\begin{array}{l}135.6 \pm \\
30.0\end{array}$ & $88.5 \pm 21.6$ & NR & NR & NR & NR & NR & NR & NR & NR & NR & NR \\
\hline \multirow[t]{2}{*}{$\begin{array}{l}\text { IIM- } \\
\text { PROVE-IT } \\
2015\end{array}$} & $\begin{array}{l}\text { Inter- } \\
\text { ven- } \\
\text { tion }\end{array}$ & $\begin{array}{l}\text { mean:93.8; } \\
\text { medi- } \\
\text { an(25th, } \\
75 \text { th):95.0(79 } \\
110.2)\end{array}$ & $\begin{array}{l}\text { mean:53.2; } \\
\text { medi- } \\
\text { an }(25 \text { th, } \\
.0,5 \text { th }): 50.0 \\
(39.0,62.0)\end{array}$ & NR & $\begin{array}{l}\text { mean:162.7; } \\
\text { medi- } \\
\text { an(25th, } \\
75 \text { th):162.4 } \\
(144.0 \\
181.0)\end{array}$ & $\begin{array}{l}\text { 7;mean:125.8; } \\
\text { medi- } \\
\text { an(25th, } \\
\text { 75th):121.0 } \\
(107.0 \\
139.0)\end{array}$ & NR & $\begin{array}{l}\text { mean:42. } \\
\text { medi- } \\
\text { an(25th, } \\
75 \text { th):40.0 } \\
(33.0, \\
49.0)\end{array}$ & $\begin{array}{l}\text { 1mean:48.7; } \\
\text { medi- } \\
\text { an(25th, } \\
075 \text { th):47.0 } \\
(40.0 \\
56.0)\end{array}$ & NR & $\begin{array}{l}\text { mean:137.6; } \\
\text { median }(25 \text { th, } \\
75 \text { th):120.0 } \\
(85.0,172.0)\end{array}$ & $\begin{array}{l}\text { mean:120.4; } \\
\text { median }(25 \text { th, } \\
75 \text { th):104.0 } \\
(77.0,143.0)\end{array}$ & NR \\
\hline & $\begin{array}{l}\text { Con- } \\
\text { trol }\end{array}$ & $\begin{array}{l}\text { mean:93.8; } \\
\text { medi- } \\
\text { an(25th, } \\
75 \text { th):95.0(79 } \\
110.0)\end{array}$ & $\begin{array}{l}\text { mean:69.9; } \\
\text { medi- } \\
\text { an }(25 \text { th, } \\
.0,5 \text { th }): 67.0 \\
(55.0,81.0)\end{array}$ & NR & $\begin{array}{l}\text { mean:162.6 } \\
\text { medi- } \\
\text { an(25th, } \\
75 \text { th):162.4 } \\
(144.0 \\
181.0)\end{array}$ & $\begin{array}{l}\text { 6;mean:145.1; } \\
\text { medi- } \\
\text { an(25th, } \\
+75 \text { th):142.0 } \\
(126.0 \\
160.0)\end{array}$ & NR & $\begin{array}{l}\text { mean:42.2 } \\
\text { medi- } \\
\text { an(25th, } \\
75 \text { th):40.0 } \\
(33.0 \\
49.0)\end{array}$ & $\begin{array}{l}2 \text { mean:48.1; } \\
\text { medi- } \\
\text { an(25th, } \\
075 \text { th):46.0 } \\
(39.0 \\
55.0)\end{array}$ & NR & $\begin{array}{l}\text { mean:137.5; } \\
\text { median (25th, } \\
\text { 75th):121.0 } \\
(85.0,172.0)\end{array}$ & $\begin{array}{l}\text { mean:137.1; } \\
\text { median (25th, } \\
75 \text { th):116.0 } \\
(84.0,165.0)\end{array}$ & NR \\
\hline \multirow[t]{2}{*}{$\begin{array}{l}\text { Katoh } \\
2017\end{array}$} & $\begin{array}{l}\text { Inter- } \\
\text { ven- } \\
\text { tion }\end{array}$ & $111 \pm 27$ & $72 \pm 18$ & NR & NR & NR & NR & NR & NR & NR & NR & NR & NR \\
\hline & $\begin{array}{l}\text { Con- } \\
\text { trol }\end{array}$ & $101 \pm 27$ & $80 \pm 16$ & NR & NR & NR & NR & NR & NR & NR & NR & NR & NR \\
\hline \multirow[t]{2}{*}{$\begin{array}{l}\text { Ki- } \\
\text { nouchi } \\
2013\end{array}$} & $\begin{array}{l}\text { Inter- } \\
\text { ven- } \\
\text { tion }\end{array}$ & $159 \pm 21$ & $111 \pm 29$ & $\begin{array}{l}-30.0 \pm \\
15.9\end{array}$ & $249 \pm 30$ & $196 \pm 37$ & $-21.6 \pm 11$ & $154 \pm 12$ & $54 \pm 11$ & $\begin{array}{l}2.3 \pm \\
14.3\end{array}$ & $\begin{array}{l}\text { median } \\
(\mathrm{IQR}): 144(78 \\
\text { to } 218)\end{array}$ & $\begin{array}{l}\text { median } \\
(\mathrm{IQR}): 121(88 \\
\text { to } 180)\end{array}$ & $\begin{array}{l}\text { medi- } \\
\text { an }(I Q R):-16.0( \\
\text { to } \\
10.5)\end{array}$ \\
\hline & $\begin{array}{l}\text { Con- } \\
\text { trol }\end{array}$ & $156 \pm 20$ & $122 \pm 23$ & $\begin{array}{l}-20.8 \pm \\
13.8\end{array}$ & $242 \pm 26$ & $207 \pm 26$ & $-14 \pm 8.2$ & $54 \pm 16$ & $55 \pm 15$ & $\begin{array}{l}3.5 \pm \\
13.3\end{array}$ & $\begin{array}{l}\text { median } \\
(\mathrm{IQR}): 149(103 \\
\text { to } 213)\end{array}$ & $\begin{array}{l}\text { median } \\
(\mathrm{IQR}): 152(86 \\
\text { to } 215)\end{array}$ & $\begin{array}{l}\text { me- } \\
\text { dian } \\
(I Q R): 2.7(-29.9 \\
\text { to } \\
43.1)\end{array}$ \\
\hline $\begin{array}{l}\text { Kou- } \\
\text { velos } \\
2013\end{array}$ & $\begin{array}{l}\text { Inter- } \\
\text { ven- } \\
\text { tion }\end{array}$ & $\begin{array}{l}148.2 \pm \\
58.1\end{array}$ & $75.9 \pm 31.6$ & NR & $\begin{array}{l}243.3 \pm \\
63.8\end{array}$ & $\begin{array}{l}154.1 \pm \\
35.8\end{array}$ & NR & $\begin{array}{l}40.9 \\
\pm 12.8\end{array}$ & $44.7 \pm 9.5$ & NR & 159 & 144 & NR \\
\hline
\end{tabular}




\begin{tabular}{|c|c|c|c|c|c|c|c|c|c|c|c|c|c|}
\hline & $\begin{array}{l}\text { Con- } \\
\text { trol }\end{array}$ & $143 \pm 54.1$ & $87.2 \pm 31.7$ & NR & $\begin{array}{l}239.3 \pm \\
63.2\end{array}$ & $\begin{array}{l}167.6 \pm \\
36.4\end{array}$ & NR & $\begin{array}{l}41.3 \\
\pm 11\end{array}$ & $\begin{array}{l}44.7 \\
\pm 10.2\end{array}$ & NR & 160.2 & 155 & $N R$ \\
\hline \multirow[t]{2}{*}{$\begin{array}{l}\text { Liu } \\
2017\end{array}$} & $\begin{array}{l}\text { Inter- } \\
\text { ven- } \\
\text { tion }\end{array}$ & $85.1 \pm 23.2$ & $46.4 \pm 23.2$ & NR & NR & NR & NR & $\begin{array}{l}46.4 \pm \\
11.6\end{array}$ & $\begin{array}{l}46.4 \\
\pm 15.5\end{array}$ & NR & $132.9 \pm 88.6$ & $124.0 \pm 79.7$ & NR \\
\hline & $\begin{array}{l}\text { Con- } \\
\text { trol }\end{array}$ & $88.9 \pm 30.9$ & $54.1 \pm 27.1$ & $N R$ & $N R$ & $N R$ & NR & $50.3 \pm 11.6$ & $\begin{array}{l}46.4 \\
\pm 11.6\end{array}$ & NR & $141.7 \pm 132.9$ & $115.1 \pm 79.7$ & NR \\
\hline \multirow[t]{2}{*}{$\begin{array}{l}\text { Luo } \\
2014\end{array}$} & $\begin{array}{l}\text { Inter- } \\
\text { ven- } \\
\text { tion }\end{array}$ & $\begin{array}{l}126.4 \pm \\
14.1\end{array}$ & $89.3 \pm 20.9$ & NR & $\begin{array}{l}222.4 \pm \\
61.1\end{array}$ & $\begin{array}{l}191.4 \pm \\
55.3\end{array}$ & NR & $\begin{array}{l}45.2 \\
\pm 14.7\end{array}$ & $\begin{array}{l}52.6 \pm \\
8.5\end{array}$ & NR & $201.9 \pm 42.5$ & $157.7 \pm 56.7$ & NR \\
\hline & $\begin{array}{l}\text { Con- } \\
\text { trol }\end{array}$ & $\begin{array}{l}130.0 \pm \\
17.8\end{array}$ & $\begin{array}{l}106.3 \pm \\
22.4\end{array}$ & $N R$ & $\begin{array}{l}227.4 \pm \\
54.9\end{array}$ & $\begin{array}{l}199.5 \pm \\
51.8\end{array}$ & NR & $\begin{array}{l}45.6 \\
\pm 17.8\end{array}$ & $\begin{array}{l}51.8 \pm \\
15.9\end{array}$ & NR & $208.1 \pm 56.7$ & $157.7 \pm 39.9$ & NR \\
\hline \multirow[t]{2}{*}{$\begin{array}{l}\text { Luo } \\
2016\end{array}$} & $\begin{array}{l}\text { Inter- } \\
\text { ven- } \\
\text { tion }\end{array}$ & $\begin{array}{l}138.0 \pm \\
14.7\end{array}$ & $82.0 \pm 22.4$ & $N R$ & $\begin{array}{l}227.3 \pm \\
56.1\end{array}$ & $\begin{array}{l}195.6 \pm \\
57.2\end{array}$ & NR & $\begin{array}{l}45.2 \\
\pm 15.5\end{array}$ & $58.4 \pm 8.5$ & NR & $219.7 \pm 39.0$ & $187.0 \pm 42.5$ & $N R$ \\
\hline & $\begin{array}{l}\text { Con- } \\
\text { trol }\end{array}$ & $\begin{array}{l}136.1 \pm \\
17.8\end{array}$ & $\begin{array}{l}101.7 \pm \\
21.6\end{array}$ & NR & $\begin{array}{l}231.2 \pm \\
56.8\end{array}$ & $\begin{array}{l}204.1 \pm \\
56.4\end{array}$ & NR & $\begin{array}{l}46.0 \\
\pm 17.8\end{array}$ & $\begin{array}{l}52.6 \pm \\
17.0\end{array}$ & NR & $226.8 \pm 56.7$ & $200.2 \pm 56.7$ & NR \\
\hline \multirow[t]{2}{*}{$\begin{array}{l}\text { OC- } \\
\text { TIVUS } \\
2017\end{array}$} & $\begin{array}{l}\text { Inter- } \\
\text { ven- } \\
\text { tion }\end{array}$ & $\begin{array}{l}143.1 \pm \\
27.1\end{array}$ & $54.1 \pm 30.9$ & $\begin{array}{l}-62.0 \pm \\
19.2\end{array}$ & $\begin{array}{l}204.9 \pm \\
34.8\end{array}$ & $\begin{array}{l}112.1 \pm \\
38.7\end{array}$ & $-46.8 \pm 16.4$ & $\begin{array}{l}442.5 \\
\pm 11.6\end{array}$ & $\begin{array}{l}42.5 \\
\pm 11.6\end{array}$ & $\begin{array}{l}-3.6 \pm \\
25.8\end{array}$ & NR & NR & NR \\
\hline & $\begin{array}{l}\text { Con- } \\
\text { trol }\end{array}$ & $\begin{array}{l}158.5 \pm \\
34.8\end{array}$ & $77.3 \pm 19.3$ & $\begin{array}{l}-52.4 \pm \\
10.9\end{array}$ & $\begin{array}{l}220.4 \pm \\
38.7\end{array}$ & $\begin{array}{l}135.3 \pm \\
27.1\end{array}$ & $-38.9 \pm 9.7$ & $\begin{array}{l}42.5 \\
\pm 11.6\end{array}$ & $\begin{array}{l}42.5 \\
\pm 11.6\end{array}$ & $\begin{array}{l}-1.1 \pm \\
18.1\end{array}$ & NR & NR & NR \\
\hline \multirow[t]{2}{*}{$\begin{array}{l}\text { Okada } \\
2012\end{array}$} & $\begin{array}{l}\text { Inter- } \\
\text { ven- } \\
\text { tion }\end{array}$ & $\begin{array}{l}119.9 \pm \\
22.6\end{array}$ & $83.1 \pm 20.3$ & $N R$ & $\begin{array}{l}193.8 \pm \\
26.6\end{array}$ & $\begin{array}{l}162.9 \pm \\
28.5\end{array}$ & NR & $\begin{array}{l}51.4 \pm \\
11.4\end{array}$ & $\begin{array}{l}52.5 \\
\pm 12.7\end{array}$ & NR & $\begin{array}{l}\text { median } \\
\text { (IQR):139.0(92.0 } \\
\text { to } 197.5)\end{array}$ & $\begin{array}{l}\text { median } \\
(\text { IQR):127.5(98.3 } \\
\text { to } 181.0)\end{array}$ & NR \\
\hline & $\begin{array}{l}\text { Con- } \\
\text { trol }\end{array}$ & $\begin{array}{l}109.3 \pm \\
23.2\end{array}$ & $96.8 \pm 21.6$ & NR & $\begin{array}{l}189.8 \pm \\
24.6\end{array}$ & $\begin{array}{l}174.9 \pm \\
25.6\end{array}$ & NR & $\begin{array}{l}51.3 \pm \\
12.2\end{array}$ & $\begin{array}{l}51.9 \pm \\
13.0\end{array}$ & NR & $\begin{array}{l}\text { median } \\
\text { (IQR):131(76.0 } \\
\text { to } 167.3)\end{array}$ & $\begin{array}{l}\text { median } \\
\text { (IQR):124.5(87.3 } \\
\text { to } 155.8)\end{array}$ & NR \\
\hline $\begin{array}{l}\text { Ren } \\
2017\end{array}$ & $\begin{array}{l}\text { Inter- } \\
\text { ven- } \\
\text { tion }\end{array}$ & $\begin{array}{l}116.0 \pm \\
37.1\end{array}$ & $46.0 \pm 16.6$ & NR & $\begin{array}{l}175.9 \pm \\
58.0\end{array}$ & $\begin{array}{l}109.0 \pm \\
38.7\end{array}$ & NR & $\begin{array}{l}40.2 \pm \\
10.1\end{array}$ & $\begin{array}{l}56.5 \pm \\
21.3\end{array}$ & NR & $170.1 \pm 101.0$ & $95.7 \pm 47.8$ & NR \\
\hline
\end{tabular}




\begin{tabular}{|c|c|c|c|c|c|c|c|c|c|c|c|c|c|}
\hline & $\begin{array}{l}\text { Con- } \\
\text { trol }\end{array}$ & $\begin{array}{l}113.3 \pm \\
39.4\end{array}$ & $57.6 \pm 19.7$ & NR & $\begin{array}{l}165.5 \pm \\
49.1\end{array}$ & $\begin{array}{l}117.2 \pm \\
24.7\end{array}$ & NR & $\begin{array}{l}41.0 \pm \\
8.9\end{array}$ & $\begin{array}{l}49.5 \pm \\
16.6\end{array}$ & NR & $156.8 \pm 92.1$ & $123.1 \pm 95.7$ & NR \\
\hline \multirow[t]{2}{*}{$\begin{array}{l}\text { RESEARC } \\
2017\end{array}$} & $\begin{array}{l}\text { Hnter- } \\
\text { ven- } \\
\text { tion }\end{array}$ & $126 \pm 21$ & $88.8 \pm 19.7$ & $\begin{array}{l}-28.3 \pm \\
20.5\end{array}$ & $211 \pm 29$ & $\begin{array}{l}174.3 \pm \\
25.2\end{array}$ & $-16.7 \pm 14$ & $\begin{array}{c}156.7 \pm \\
15.2\end{array}$ & $\begin{array}{l}53.7 \pm \\
12.0\end{array}$ & NR & $147 \pm 95$ & $153.2 \pm 73.8$ & NR \\
\hline & $\begin{array}{l}\text { Con- } \\
\text { trol }\end{array}$ & $132 \pm 24$ & $\begin{array}{l}114.7 \pm \\
21.8\end{array}$ & $\begin{array}{l}-9.19 \pm \\
20.5\end{array}$ & $219 \pm 27$ & $\begin{array}{l}198.5 \pm \\
23.3\end{array}$ & $-7.6 \pm 14.7$ & $\begin{array}{l}54.7 \pm \\
9.6\end{array}$ & $\begin{array}{l}52.3 \pm \\
8.2\end{array}$ & NR & $162 \pm 88$ & $160.2 \pm 73.9$ & NR \\
\hline \multirow[t]{2}{*}{$\begin{array}{l}\text { PRECISE- } \\
\text { IVUS } \\
2015\end{array}$} & $\begin{array}{l}\text { Inter- } \\
\text { ven- } \\
\text { tion }\end{array}$ & $\begin{array}{l}109.8 \pm \\
25.4\end{array}$ & $63.2 \pm 16.3$ & $\begin{array}{l}-40 \pm \\
18\end{array}$ & $\begin{array}{l}177.3 \pm \\
32.4\end{array}$ & $\begin{array}{l}129.4 \pm \\
22.0\end{array}$ & $-25 \pm 17$ & $\begin{array}{l}41.1 \pm \\
9.5\end{array}$ & $\begin{array}{l}45.6 \pm \\
11.9\end{array}$ & $14 \pm 26$ & $\begin{array}{l}\text { median } \\
\text { (IQR):114 me- } \\
\text { dian(IQR):(81 } \\
\text { to } 158)\end{array}$ & $\begin{array}{l}\text { median } \\
\text { (IQR):92 (76 to } \\
120)\end{array}$ & $\begin{array}{l}\text { me- } \\
\text { dian } \\
\text { (IQR):- } \\
14(-33 \\
\text { to } 18)\end{array}$ \\
\hline & $\begin{array}{l}\text { Con- } \\
\text { trol }\end{array}$ & $\begin{array}{l}108.3 \pm \\
26.3\end{array}$ & $73.3 \pm 20.3$ & $\begin{array}{l}-29 \pm \\
24\end{array}$ & $\begin{array}{l}172.7 \pm \\
32.6\end{array}$ & $\begin{array}{l}138.7 \pm \\
26.2\end{array}$ & $-18 \pm 18$ & $\begin{array}{l}40.0 \\
\pm 10.3\end{array}$ & $\begin{array}{l}43.3 \pm \\
11.5\end{array}$ & $11 \pm 25$ & $\begin{array}{l}\text { median } \\
(\mathrm{IQR}): 116 \text { (92 } \\
\text { to } 159)\end{array}$ & $\begin{array}{l}\text { median } \\
(\text { IQR):111 (87 } \\
\text { to } 139)\end{array}$ & $\begin{array}{l}\text { me- } \\
\text { dian } \\
(\text { IQR):- } \\
9(-33 \\
\text { to } 25)\end{array}$ \\
\hline \multirow[t]{2}{*}{$\begin{array}{l}\text { VYC- } \\
\text { TOR } \\
2009\end{array}$} & $\begin{array}{l}\text { Inter- } \\
\text { ven- } \\
\text { tion }\end{array}$ & $131 \pm 39$ & $48 \pm 31$ & NR & $216 \pm 40$ & $142 \pm 28$ & NR & $46 \pm 11$ & $45 \pm 11$ & NR & $195 \pm 82$ & $164 \pm 90$ & NR \\
\hline & $\begin{array}{l}\text { Con- } \\
\text { trol }\end{array}$ & $130 \pm 33$ & $45 \pm 37$ & NR & $215 \pm 38$ & $152 \pm 24$ & NR & $45 \pm 9$ & $46 \pm 10$ & NR & $198 \pm 86$ & $168 \pm 79$ & NR \\
\hline \multirow[t]{2}{*}{$\begin{array}{l}\text { Wang } \\
2016\end{array}$} & $\begin{array}{l}\text { Inter- } \\
\text { ven- } \\
\text { tion }\end{array}$ & $\begin{array}{l}140.0 \pm \\
45.6\end{array}$ & $53.0 \pm 32.1$ & NR & $\begin{array}{l}218.4 \pm \\
95.5\end{array}$ & $\begin{array}{l}124.1 \pm \\
31.7\end{array}$ & NR & $\begin{array}{l}43.7 \pm \\
8.1\end{array}$ & $\begin{array}{l}48.7 \pm \\
15.9\end{array}$ & NR & $174.5 \pm 59.4$ & $105.4 \pm 28.4$ & NR \\
\hline & $\begin{array}{l}\text { Con- } \\
\text { trol }\end{array}$ & $\begin{array}{l}134.5 \pm \\
48.7\end{array}$ & $71.5 \pm 30.5$ & NR & $\begin{array}{l}215.7 \pm \\
99.7\end{array}$ & $\begin{array}{l}155.4 \pm \\
35.2\end{array}$ & NR & $\begin{array}{l}43.7 \pm \\
8.5\end{array}$ & $\begin{array}{l}50.3 \pm \\
18.9\end{array}$ & NR & $174.5 \pm 57.6$ & $155.9 \pm 33.7$ & NR \\
\hline \multirow[t]{2}{*}{$\begin{array}{l}\text { Wang } \\
2017\end{array}$} & $\begin{array}{l}\text { Inter- } \\
\text { ven- } \\
\text { tion }\end{array}$ & $\begin{array}{l}136.5 \pm \\
33.6\end{array}$ & $64.6 \pm 16.6$ & NR & $\begin{array}{l}203.4 \pm \\
25.9\end{array}$ & $\begin{array}{l}117.9 \pm \\
23.2\end{array}$ & NR & NR & NR & NR & $170.1 \pm 16.8$ & $116.0 \pm 17.7$ & NR \\
\hline & $\begin{array}{l}\text { Con- } \\
\text { trol }\end{array}$ & $\begin{array}{l}133.4 \\
\pm 29.0\end{array}$ & $78.9 \pm 24.9$ & NR & $\begin{array}{l}204.2 \pm \\
26.7\end{array}$ & $\begin{array}{l}172.5 \pm \\
24.0\end{array}$ & NR & NR & NR & NR & $169.2 \pm 18.6$ & $156.8 \pm 48.7$ & NR \\
\hline
\end{tabular}




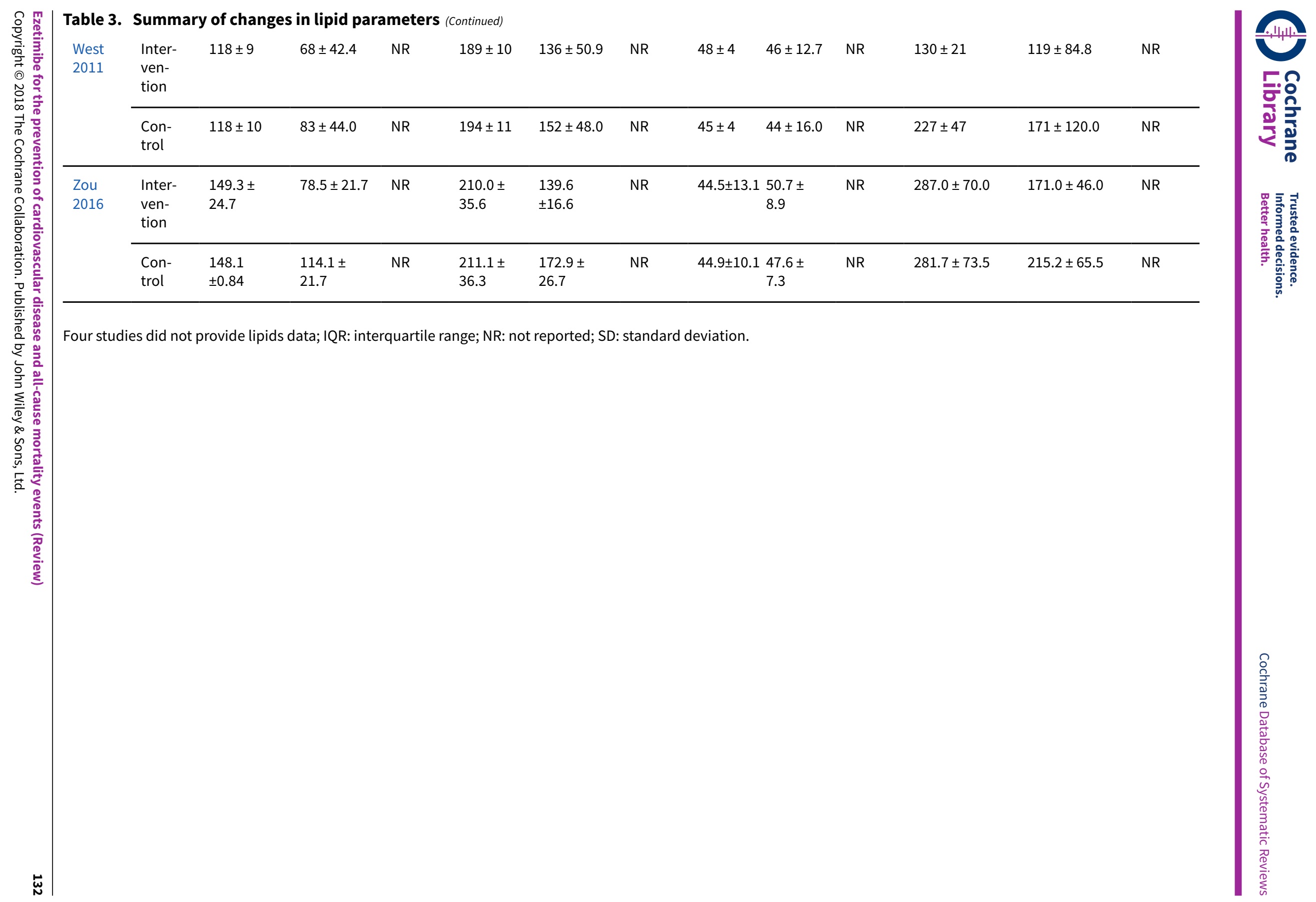




\section{AP PEN DICES}

\section{Appendix 1. Search strategies}

\section{CENTRAL}

\#1 MeSH descriptor: [Ezetimibe] explode all trees

\#2 (ezetimibe or ezetimib)

\#3 ezetrol

\#4 zetia

\#5 vytorin

\#6 inegy

\#7 SCH-58235

\#8 SCH 58235

\#9 SCH58235

$\# 10 \# 1$ or \#2 or \#3 or \#4 or \#5 or \#6 or \#7 or \#8 or \#9

\section{MEDLINE Ovid}

1. exp ezetimibe/

2. (ezetimibe or ezetimib).tw.

3. ezetrol.tw.

4. zetia.tw.

5. vytorin.tw.

6. inegy.tw.

7. SCH-58235.tw.

8. SCH 58235.tw.

9. SCH58235.tw.

10. 1 or 2 or 3 or 4 or 5 or 6 or 7 or 8 or 9

11. randomized controlled trial.pt.

12. controlled clinical trial.pt.

13. randomized.ab.

14. placebo.ab.

15. drug therapy.fs.

16. randomly.ab.

17. trial.ab.

18. groups.ab.

19.11 or 12 or 13 or 14 or 15 or 16 or 17 or 18

20. exp animals/ not humans.sh. 
21. $19 \operatorname{not} 20$

22. 10 and 21

\section{Embase Ovid}

1. exp ezetimibe/

2. (ezetimibe or ezetimib).tw.

3. ezetrol.tw.

4. zetia.tw.

5. vytorin.tw.

6. inegy.tw.

7. SCH-58235.tw.

8. SCH 58235.tw.

9. SCH58235.tw.

10. 1 or 2 or 3 or 4 or 5 or 6 or 7 or 8 or 9

11. random\$.tw.

12. factorial\$.tw.

13. crossover\$.tw.

14. cross over\$.tw.

15. cross-over\$.tw.

16. placebo\$.tw.

17. (doubl\$ adj blind\$).tw.

18. (singl\$ adj blind\$).tw.

19. assign\$.tw.

20. allocat\$.tw.

21. volunteer\$.tw.

22. crossover procedure/

23. double blind procedure/

24. randomized controlled trial/

25. single blind procedure/

26. 11 or 12 or 13 or 14 or 15 or 16 or 17 or 18 or 19 or 20 or 21 or 22 or 23 or 24 or 25

27. (animal/ or nonhuman/) not human/

28. 26 not 27

29. 10 and 28

\section{Web of Science}

\section{\# 12 \#11 AND \#10}

\# 11 TS=(random ${ }^{\star}$ or blind ${ }^{\star}$ or allocat ${ }^{\star}$ or assign ${ }^{\star}$ or trial ${ }^{*}$ or placebo* or crossover $^{\star}$ or cross-over $\left.^{\star}\right)$ 
\# 10 \#9 OR \#8 OR \#7 OR \#6 OR \#5 OR \#4 OR \#3 OR \#2 OR \#1

\# 9 TS=SCH58235

\# $8 \mathrm{TS}=\mathrm{SCH} 58235$

\# 7 TS=SCH-58235

\# 6 TS=inegy

\# 5 TS=vytorin

\# 4 TS=zetia

\# 3 TS=ezetrol

\# 2 TS=(ezetimibe or ezetimib)

\# 1 TS=ezetimibe

\section{ClinicalTrials.gov}

Intervention: ezetimibe

Condition: cardiovascular OR hyperlipidemia OR dyslipidemia

Study type: Intevention studies

\section{WHO ICTRP}

Intervention: ezetimibe

Condition: cardiovascular OR hyperlipidemia OR dyslipidemia

Recruitment status: All

\section{CONTRIBUTIONSOF AUTHORS}

Zhan Shipeng drafted the protocol and review, screened titles and abstracts, retrieved potentially eligible full texts, assessed full texts for eligibility, screened reference lists and trials registries, extracted data, assessed risk of bias, conducted the analyses, assessed the quality of the evidence.

Xia Peiyuan edited and advised on parts of the protocol and review, assessed full texts for eligibility, arbitrated of disagreement, provided guidance on the methodology of the review.

Tang Min edited and advised on parts of the protocol and review, screened titles and abstracts, assessed full texts for eligibility and extracted data.

Liu Fang edited and advised on parts of the protocol and review, assessed risk of bias, assessed the quality of the evidence.

Shu Maoqin advised on parts of the protocol and review, provided comments on the methodology of the review.

Wu Xiaojiao advised on parts of the protocol and review, provided comments on the statistical methodology of the review.

\section{DECLARATIONSOF INTEREST}

Zhan Shipeng: no conflict of interest

Xia Peiyuan: no conflict of interest

Tang Min: no conflict of interest

Liu Fang: no conflict of interest

Shu Maoqin: no conflict of interest

Wu Xiaojiao: no conflict of interest 


\section{SOURCESOF SUPPORT}

\section{Internal sources}

- No sources of support supplied

\section{External sources}

- The Cochrane Heart Group US Satellite is supported by intramural support from the Northwestern University Feinberg School of Medicine and the Northwestern University Clinical and Translational Science (NUCATS) Institute (UL1TR000150)., USA.

- This project was supported by the National Institute for Health Research, via Cochrane Infrastructure funding to the Heart Group. The views and opinions expressed therein are those of the authors and do not necessarily reflect those of the Systematic Reviews Programme, NIHR, NHS or the Department of Health, UK.

\section{DIFFERENCES BETWEEN PROTOCOLANDREVIEW}

In the protocol, we planned to include randomised controlled trials (RCTs) that had a follow-up of at least 12 months and reported at least one clinical outcome. However, because outcomes may have been measured but not reported, we did not make the reporting of an outcome an inclusion criteria for this review.

In the protocol, we stated the comparison of "ezetimibe plus other lipid-modifying drug(s) versus other lipid-modifying drug(s) alone" as one of the interventions. In order to make the statement clearer, we have revised it to "ezetimibe plus other lipid-modifying drug(s) versus other lipid-modifying drug(s) alone or plus placebo".

We conducted a comprehensive search as planned. In addition, we retrieved publicly application materials of the IMPROVE-IT study that were published on the FDA website to obtain unpublished outcome data.

We planned to include quality of life in the 'Summary of findings' table. None of the included studies reported quality of life and, whilst this is an important finding in itself, we decided to include two adverse event outcomes in the 'Summary of findings' table instead (hepatopathy and myopathy). This ensures that both potential harms and benefits are included in the 'Summary of findings' table.

We analysed adverse events including hepatopathy, myopathy and cancer as planned. In order to assess the safety of treatment more comprehensively, we added several analyses for adverse events including rhabdomyolysis, gallbladder-related disease and discontinuation due to adverse events.

We planned to perform six subgroup analyses, however, we were only able to perform subgroup analyses based on duration of follow-up and participants with or without existing atherosclerotic cardiovascular disease (ASCVD) because data for the other prespecified subgroups were unavailable.

We noted that coronary revascularisation contributed to a large proportion of MACE events. This endpoint was investigator-determined and based on many factors which could be biased and unblinded. Thus, we added the coronary revascularisation as a secondary outcome to better analyse the results.

We planned to perform a sensitivity analysis that excluded studies at a high risk of bias. However, the studies that were judged as unclear risk of bias may have a potential bias for the results, so we decided to conduct a sensitivity analysis by only including studies assessed at low risk of bias.

We added a sensitivity analysis that excluded studies comparing ezetimibe plus statins versus double-dose statins alone to explore the impact of these studies in the overall assessment of results.

\section{N DEX TERMS}

\section{Medical Subject Headings (MeSH)}

Anticholesteremic Agents [adverse effects] [ ${ }^{*}$ therapeutic use]; Cardiovascular Diseases [mortality] [* prevention \& control]; Cause of Death; Cholesterol [blood]; Cholesterol, LDL [blood]; Drug Therapy, Combination; Ezetimibe [adverse effects] [*therapeutic use]; Fenofibrate [therapeutic use]; Hydroxymethylglutaryl-CoA Reductase Inhibitors [therapeutic use]; Myocardial Infarction [mortality] [prevention \& control]; Randomized Controlled Trials as Topic; Simvastatin [adverse effects] [therapeutic use]; Stroke [mortality] [prevention \& control]; Triglycerides [blood]

\section{MeSH check words}

Aged; Aged, 80 and over; Humans; Middle Aged 